


$$
\text { - }
$$

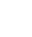





\section{OUTLINES OF POLITICAL ECONOMY}




\section{A SELECT LIST OF BOOKS ON POLITICAL ECONOMY, E'TC.}

POLITICAL ECONOMY. By JOHN STUART MiLl. New Edition, with an Introduction by W. J. AshLEY, M.A., M.Com., Professor of Conmerce in the University of Birmingham, and an Index by Miss M. F. Ellis. Crown 8 vo, $5^{\text {s. }}$

POLITICAL ECONOMY : a Short Text-book of Political Economy. With Problems for Solution, Hints for Supplementary Reading, and a Supplementary Chapter on Socialism. By J. E. Symes, M.A. Crown 8vo, 2s. 6 .

UNEMPLOYMENT: a Problem of Industry. By W. H. BEveridge, Stowell Civil Law Fellow of University College, Oxford. 8 vo, $7 s$. $6 d$. net.

ITHE TRUST MOVEMENT IN BRITISH INDUSTRY: a Study of Business Organisation. By HENRY W. MACROSTY, B.A., Lecturer, London School of Economics. 8vo, 9s. net.

PROBLEMS OF MODERN INDUSTRY. By SIDNEY and BEATRICE WEBB. 8vo, 5s. net.

HISTORY OF MONEY IN THE BRITISH EMPIRE AND THE UNITED STATES. By AGNes F. DODD. Crown 8 vo, 5s. net.

A HISTORY OF COMMERCE. By Clive Day, Ph.D., Assistant Professor of Economic History in Yale University. With 34 Maps. Crown 8vo, 7s. 6d. net.

LONGMANS, GREEN AND CO., LONDON, NEW YORK, BOMBAY AND CALCUTTA. $\because$ 
$E_{c}$

C4664nz

\section{OUTLINES OF}

\section{POLITICAL ECONOMY}

BY

S. J. CHAPMAN, M.A., M.Сом.

PROFESSOR OF POLITICAL ECONOMY AND DEAN OF THE FACULTY OF COMMERCE

IN THE UNIVERSITY OF MANCHESTER; SOMETIME EXAMINEK IN THE

UNIVERSITIES OF CAMBRIDGE, LIVERPOOL, LONDON, WALES

AND IN THE NATIONAL UNIVERSITY OF IRELAND

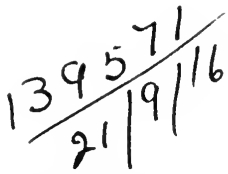

L ONGMANS, GREEN AND CO.

39 PATERNOSTER ROW, LONDON

NEW YORK, BOMBAY AND CALCUTTA 
"And as he had acquired absolutely nothing about political economy or about logic, and was therefore at the mercy of the first agreesble sophistry that might take his fancy by storm, his unfitness to commence the business of being a citizen almost reached perfection."- "Claybanger," by Arnold Bennetr. 


\section{PREFACE.}

THIs book is designed for any who are beginning the study of Political Economy.

On a first perusal, all parts in small print might be omitted and also chapters XII, XIII and XXIX. Moreover, I should recommend only a hasty scanning of Book I, in the first instance, and at the same time the entire omission of Book V, except by those who are specially interested in problems of money and banking. Chapters XXX and XXXI may be read at once or not, according to the reader's taste; they raise questions which are not exclusively economic.

The diagrams are intended only for those who find their understanding aided by diagrams. In every case, these symbolic demonstrations are merely supplementary to the argument in words, which has been made complete without them.

My indebtedness to Dr. Marshall's teaching will be apparent throughout. I have also to thank Mr. C. F. Bickerdike for revising the proofs, Professor Bastable, Professor Cannan and Professor Gonner for making suggestions as regards the list of books with which these outlines conclude, and my wife for helping me with the proofs and in other ways.

UNIVERSITY,

$$
\text { S. J. CHAPMAN. }
$$

Manchester,

September, 1911. 


\section{Digitized by the Internet Archive in 2007 with funding from Microsoft Corporation}




\section{ANALYTICAL TABLE OF CONTENTS.}

Sections marked * (which are in small print), and chapters and divisions indicated similarly, might be omitted on a first reading.

\section{BOOK I.}

\section{Scope AND Method.}

CHAPTER I.

Nature and Scope of Political Economy . . . . 1

Definition . . . . . . . . . . . 1

Positive and normative sciences and arts $\quad$. $\quad$. $\quad$. 2

Political economy embraces a positive science, a normative science, and several arts . . . . . . . . 5

Pcsitive economic science may or may not be evolutionary 7

Classification of economic studies . . . . . . 8

\section{CHAPTER II.}

Assumptions and Methods of Economic Science . . 10

Can the actions of free agents be reduced to law ? . . 10

The permanence of character and social assimilation . . 12

The abstract method . . . . . . . . 15

Historic and realistic methods . . . . . 18

Much of the data of economics is measurable . $\quad$. $\quad 19$

Divisions of political economy and relations between them . 20

\section{BOOK II.}

Consumption, or Demand and its Satisfaction. CHAPTER III.

Wants and Demand

Scope of the economics of consumption . . . . . . 21

Wants, utility, satisfaction, and demand . . . . 22

*Psychological basis of demand . . . . . . 24

Systems of demand . $\quad . \quad$. $\quad . \quad$. $\quad . \quad 26$ 


\section{CHAPTER IV.}

Diminishing Utility and Marginal Use . . . . . 29

Diminishing utility . . . . . . . . . $\quad$. 29

*Diagrammatic representations of diminishing utility . $\quad$. 30

Limitations of diminishing utility . . . . . . 32

Are all wants satiable? . $\quad . \quad$. $\quad . \quad . \quad . \quad . \quad 35$

Utility of complements and substitutes . $\quad$ - . $\quad$ - 36

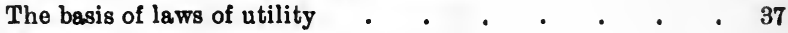

Marginal quality $. \quad . \quad . \quad . \quad . \quad . \quad . \quad . \quad 37$

CHAPTER V.

Demand Prices, Expenditure and Consumers' Surplus . $\quad 39$

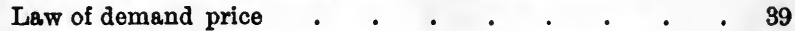

Elasticity of demand . . . . . . . . 40

"Diagrammatic representation of demand . . . . 41

The law of substitution, indifference, or equi-marginal utility

in consumption. $. \quad . \quad . \quad . \quad . \quad . \quad . \quad 443$

Observations on the law of substitution . . . . $\quad$. 45

*Diagrammatic representation of equi-marginal returns . $\quad 48$

Consumer's surplus of satisfaction . • • . . 49

* Diagrammatic representation of consumer's surplus of satis-

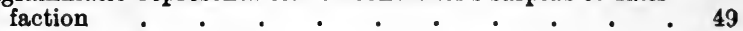

Measurement in money of consumers' surplus . $\quad$ - 51

CHAPTER VI.

Value, Goods and Wealth . . . . . . . 54

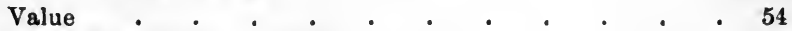

Goods and wealth . $. \quad . \quad . \quad . \quad . \quad . \quad 55$

Necessaries, comforts and luxuries . . . . . $\quad$. 58

BOOK III.

Production on Supply.

CHAPTER VII.

Nature of Production and the Agents of Production . . 62

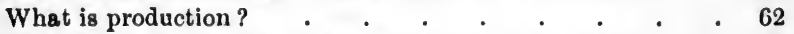

Manufacture specializes the possible uses of materials . $\quad 65$

Joint and alternative supply . . . . . . 67

The agents in production and their efficiency . . . . 67 


\section{CHAPTER VIII.}

PAGE

Capital . . • . . . . . . . . . . 71

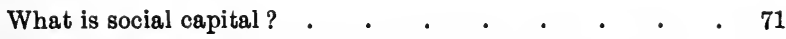

Are free gifts of nature and personal wealth social capital ? $\quad \mathbf{7 4}$

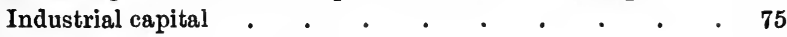

Classification of social capital . . . . . . . 76

Private capital . . . . . . . . . $\quad 77$

Production with capital is a round-about process . . $\quad 78$

\section{CHAPTER IX.}

Machinery and Division of Labour . $\quad$. $\quad$. $\quad . \quad 81$

The economies of substituting machinery for labour . $\quad$. 81

What becomes of the displaced labour? . $\quad$ - $\quad$ - $\quad$ - 82

Economies of specialized labour and machinery ..$\quad$. 84

Effect of specialization and machinery on labour . . $\quad$. 85

\section{CHAPTER X.}

The Growth and Specialization of Businesses . . $\quad 89$

The growth of businesses : . . . . . . . 90

The limit of growth . $\quad . \quad$. $\quad . \quad . \quad . \quad . \quad 592$

*The normal magnitude of the business . . . . $\quad$. 94

The law of substitution, indifference, or equi-marginal returns in production . . . . . . . . . . . $\quad .95$

Expansion and contraction of businesses $\quad . \quad \ldots \quad . \quad . \quad . \quad 96$

Specialization of businesses . . . . . . . . 97

Specialism by product and specialism by process . . 100

Internal and external economies and the localization of in-

dustries . . . . . . . . . . 101

\section{CHAPTER XI.}

The Laws of Increasing and Decreasing Returns . . 103

Meaning of increasing, decreasing, and constant returns $\quad 103$

- Observations on increasing and decreasing returns . . 104

The non-evolutionary laws of increasing and decreasing returns . . . . . . . . . . 105

The evolutionary law of increasing returns . $\quad$. $\quad$. 107 


\section{"CHAPTER XII.}

Markets and Commercial Functions. . . . . . 109

What are markets? . . . . . . . . . 109

Evolution of markets $\quad . \quad$. $\quad . \quad$. $\quad . \quad$. $\quad . \quad .110$

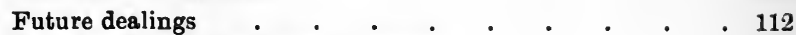

*Technicalities of dealings in futures . . . . . 113

Markets for capital . . . . . . . . . 115

Price steadiness and its effects . . . . . . 116

Does speculation steady prices? . . . . . . . 117

The marketing function . . . . . . . . . 119

The risks of anticipating . . : . . . . . . 120

*Distribution of the risks of anticipating . . . . . 121

${ }^{*}$ Differentiation of productive systems . . . . . 124

* Reactions of commercial organization on industrial organization

\section{* chapter xiII.}

Trpes of Productive Organization . . . . . . . 128 Agricultural systems . . . . . . . . . 128

Private businesses and companies . $\quad . \quad$. $\quad . \quad$. $\quad .131$

Co-operation . . . . . . . . . . 134

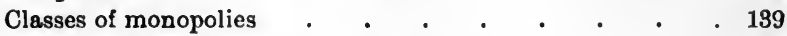

Trusts and kartels . $. \quad . \quad$. $\quad . \quad$. $\quad . \quad 140$

*Generation and stability of trusts and cartels . . . . . 143

BOOK IV.

Exchange, or the Equilibrium between Demand and SUPPLX.

\section{CHAPTER XIV.}

Competition, Barten and the Price of Non-reproducible THINGS .

Competition

The theory of barter $\quad . \quad$. $\quad . \quad . \quad . \quad . \quad 149$

*Diagrammatic treatment of barter . . . . . . 151

The price of fixed stocks . . . . . . . . 152 
CHAPTER XV.

The Long Period and Supply Prices

Normal or long-period effects . . . . . . . 154

Determination of supply prices . . . . . . . 157

Cost of production has many meanings . $\quad$. $\quad$. $\quad$. 161

\section{CHAPTER XVI.}

Normal Price $. \quad . \quad . \quad . \quad . \quad . \quad . \quad . \quad . \quad .163$

Equilibrium of demand and supply . . . . . 163

*Equilibrium of demand and supply diagrammatically treated 165

Joint, composite, and alternative demand and supply . $\quad 167$

*Diagrammatic representation of joint demand and joint

supply . . . . . . . . . . . 168

CHAPTER XVII.

The Short Period and Sub-normal Price . . . . 170

The short period . $. \quad . \quad . \quad . \quad . \quad . \quad . \quad .170$

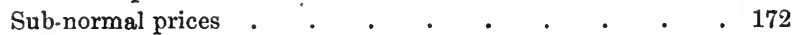

Some features of sub-normal conditions . . . . . 173

CHAPTER XVIII.

Theory of Monopoly Prices . . . . . . . . . 175

Fundamental ideas . . • . . . • • . 175

Determination of monopoly price in the absence of price discriminations . . . . . . . . 176

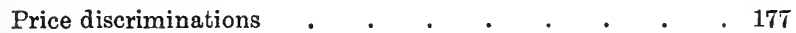

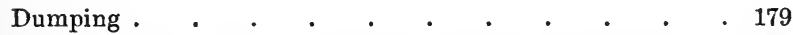

Determination of prices when discriminations are possible . 180

*Monopoly price diagrammatically represented . . . 182

Restrictions experienced by monopolists . . . . 183

CHAPTER XIX.

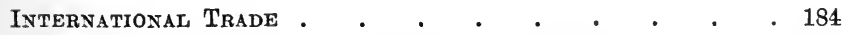

International immobility of labour and capital . . . 184

Permanent international trade starts when there are differences between comparative values (costs) . . . 186

International values . . . . . . . . 188

Summary of conclusions and a corollary . . . . 190 
"Diagrammatic representation . . . . . . . 191

Balance of trade . . . . . . . . . 193

Effects of foreign loans on imports and exports . . . 195

${ }^{*} \mathrm{BOOK} \mathrm{V}$.

Money and the Mechanism of Exchange.

CHAPTER XX.

The Theory of Money $\quad . \quad$. $\quad . \quad$. . . . . 197

Inconveniences of barter and emergence of money $\quad . \quad 197$

Choice of the money commodity . . . . . . 200

Determination of the value of money a . . . . 202

-Symbolic and diagrammatic expression of the theory of the

value of money . . . . . . . . 206

Functions of money summarized . . . . . . 208

Appreciation and depreciation of money . . . . 209

"Index numbers of prices . . . . . . . . 210

CHAPTER XXI.

Theory of Banking and Credit Money . . . . . 213

Banking creates a loan fund . . . . . . . 213

How much may the bank lend? . . . . . . 215

A plausible fallacy . . . . . . . . . 217

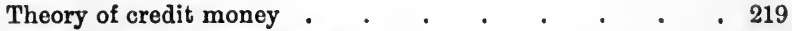

Functions and value of banks . $\quad . \quad$. $\quad . \quad$. $\quad 222$

"Interdependence of banks and bank amalgamation . . 223

CHAPTER XXII.

Forms of MoneY . . . . . . . • . . 225

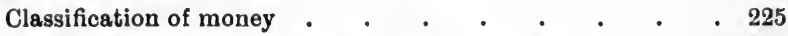

Free and gratuitous coinage and Gresham's law . . . 228

Credit money . . • . . . . . . . 231

*Governmental limitation of note issues . . . . . 232

Inconvertible money . . . . . • . . 234

Currencies may be exclusively paper but convertible . . 236

*Bimetallism . . . . . . . . . . 238

*Why bimetallism has been advocated . . . . . 240

*Are rising, falling, or steady prices best ? . . . . 242

"Trimetallism, symmetallism, the gold exchange system and the limping standard 
CHAPTER XXIII.

PAGE

The Foreign Exchanges and Reserves . . . . . 244

Some definitions . . . . . . . . . . . 244

The foreign exchanges . . . . . . . . 244

Methods of stopping foreign drains of gold . . . . 247

${ }^{*}$ Reserves . . . . . . . . . . . 250

CHAPTER XXIV.

Trade and Credit Cycles and Crises . . . . . 254

Synchronism and periodicity of fluctuations in trade . . 254

The objective explanation . . . . . . . 255

The subjective explanation . . . . . . . 258

Are trade fluctuations increasing ? . . . . . . . 260

Banking in relation to trade cycles . . . . . . 261

BOOK VI.

Distribution, or the Sharing of Wealth.

CHAPTER XXV.

INTRODUCTORY AND INTEREST . . . . . . . 263

Analysis of Distribution . . . . . . . . 263

Gross and net interest . . . . . . . . . . 264

Demand for capital . . . . . . . . . 267

Why capital is saved . . . . . . . . . 268

Saving and the power to save . . . . . . . 270

*Insurance and saving . . . . . . . . . . 271

Interaction of demand and supply . . . . . . 272

* Possibility of a zero rate of interest . . . . . . 274

Effect of progress on the rate of interest and value of capital 276

*The earnings and value of fixed capital . . . . . 277

* Effect of the appreciation and depreciation of money on the

rate of interest . . . . . . . . 279

*Diagrammatic treatment . . . . . . . . 279

CHAPTER XXVI.

Rent ANd QUASI-RENT . . . . . . . . . 281

Meaning of rent . . . . . . . . . . 281

Rent of differential fertility . . . . . . . 282 


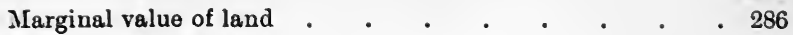

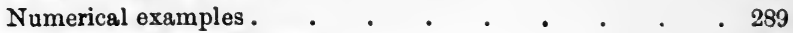

*Diagrammatic representation.

Situational rent of agricultural land . . . . . . 291

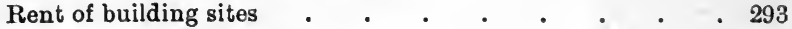

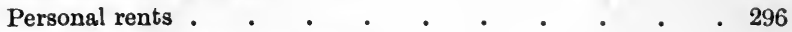

Rent does not determine price $\quad$. $\quad . \quad$. $\quad . \quad 297$

Quasi-rent $. \quad . \quad . \quad . \quad . \quad . \quad . \quad . \quad . \quad .299$

\section{CHAPTER XXVII.}

Wages and Profits $. \quad . \quad . \quad . \quad . \quad . \quad . \quad . \quad .301$

The value of services supplied by labour alone . . . 301

Wages and profits under group production . . . . 304

Allowance for differences in efficiency between employers . 307

Definition of profits . . . . . . . . . 308

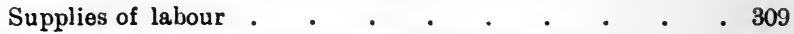

Competition between grades-vertical mobility . . . 311

Conclusions as regards the determination of wages. $\quad . \quad 313$

*The doctrine of the wages fund and the iron law of wages . 315

\section{CHAPTER XXVIII.}

Producers' Surplos and Labour Problems . • • . . 318

Summary of the theory of distribution . . . . . 318

Producers' surplus . . . . . . . . . 320

"Diagrammatic exposition of producer's surplus of utility . 322

The hours of labour . . . . . . . . . . 323

Collective bargaining . . . . . . . . 326

Piece-rates, time-rates, premium systems, sliding scales, and profit-sharing . . . . . . . . . 329

Methods of industrial peace . . . . . . . . 331

- chapter xxix.

UNEMPLOYMENT • • . • • • • • • . 334

Causes of unemployment. $\quad . \quad$. $\quad . \quad$. $\quad . \quad 394$

Remedies . . . . . . . . . . . 338

Yeans of mitigating the distress caused by unemployment . 341 


\section{BOOK VII.}

Public Economics and Public Finance.

* CHAPTER XXX.

The State in Relation to Business . . . . . . 343

Classification of State action which is economic . . . 343

The need for supplementing"private enterprise . . . 344

State industries . . . . . . . . . . 349

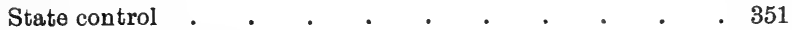

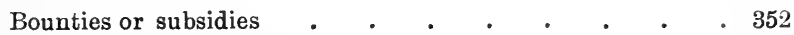

Protection, fair trade, retaliation, and reciprocity . . . 353

Laws to facilitate business . . . . . . . 357

* CHAPTER XXXI.

The State in Relation to Social Conditions . . . . 359

Factory acts and public health acts $\quad$. $\quad$. $\quad$. $\quad$. 359

The State in relation to wages and employment . . . 362

The State in relation to social insurance . $\quad . \quad$. 365

The State in relation to the provision of opportunities . $\quad 367$

Public provision of the higher social goods and housing 369

Public aid . . . . . . . . . . . 369

The doctrine of maximum satisfaction . . . . 372

CHAPTER XXXII.

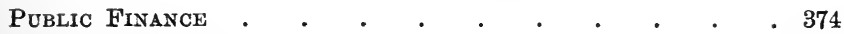

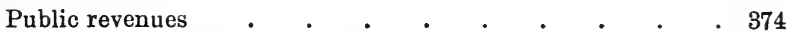

The principle of equity in taxation . . . . . . 376

Progressive taxation . . . . . . . . 378

Other principles of taxation . . . . . . . . 380

Betterment and the unearned increment . . . . 383

Public debts . . . . . . . . . . 384

CHAPTER XXXIII.

The Incidence of Taxes . . . . • • . . . 385

Nature of the problem of incidence. . . . . . 385

Taxes on income, property, and savings . . . . . 387 
Taxes connected with land Taxes on commodities and services . . . . . . 394 -Diagrammatic treatment of taxes on commodities. . . 395 Taxes on monopolies . . . . . . . . . 396 Import and export duties . . . . . . . 396 Incldence of a taxation system as a whole . . . 400

Appendix. Select List of Books . . . . . . . . 403

INDEX • • • • • • • • • • • 407 


\section{BOOK I.}

\section{SCOPE AND METHOD. ${ }^{1}$}

\section{CHAPTER I.}

\section{NATURE AND SCOPE OF POLITICAL ECONOMY.}

Definition.- " Political Economy " is derived from the three Greek words, $\pi$ ódıs, a state or organized community, oíkos, a house or home, and vópos, law. It means, therefore, according to its derivation, the law of household management in its application to communities. Whether the old term "political economy" in its original significance appropriately designates the modern study of which an outline will be given in this book, will become apparent to the reader as he or she proceeds. To-day political economy, or, as it is sometimes called, economics, treats of all the actions of human beings in relation to wealth, including the attitude of people to wealth, the responses of Nature to their attacks on her resources, and the conditions of their productive efficiency, as well as the making, exchanging, sharing and using of wealth. "Wealth" for the present I shall leave undefined. For preliminary purposes all my readers have a sufficiently accurate conception of what wealth is.

${ }^{1}$ N.B. - In the preface I have indicated portions of this bookin addition to those in small print-which might be onitted on : first reading. 
Political economy is in the main, you will observe, a social study. It may be classified as a branch of sociology, and sociology is the study of the natures and activities of individuals, regarded as members of communities, and of the relations between them. A study, or systematized body of knowledge, is defined by (1) its data and (2) its point of view. The data of sociology may be broadly described as all social facts. The data of political economy, as I have said, are all those social facts which have reference to wealth.

The two departments of sociology which have been most systematized are political economy or economics, and politics. Of these two, economics is the most capable of being systematized and is the most highly systematized. Why, I shall explain later (p. 19). The rest of sociology is as yet only imperfectly systematized. Much material has yet to be collected, and much classification has yet to be attempted, before any appreciable number of important unifying generalizations can be looked for.

Economics, we have already remarked, is differentiated from general sociology by the fact that the activities which it recognizes are those only which have reference to wealth. Politics is distinguished similarly by the reference of its data to government. Economics and politics overlap. Much human action within communities has reference at the same time to wealth and to government-public finance and factory legislation, for instance, are subjects which relate to both.

Positive and normative sciences and arts.- So far I have avoided the term "science". I have done so for two reasons. The one reason is that all systematized bodies of knowledge are not sciences. Some are what are ordinarily termed "arts". The other reason is that "science" is an ambiguous term, sometimes used in a narrow sense, but sometimes in a broad sense to cover all the results of thinking about facts from whatever point of view the thinking proceeds. 
There are at least two possible points of view, namely the positive and the normative. When we assume the positive point of view, we take the facts of the universe as they are. When we assume the normative point of view we deal not with facts, as facts are ordinarily understood, but with the ideals of facts, or standards; and, though intangible, these standards, be it understood, are as real as tangible things. "Norm" is derived from the Latin word norma, meaning a rule or standard. Ethics (or the science of what conduct ought to be and why) and resthetics (or the science of what perfectly beautiful things ought to be like and why) are normative sciences. All the so-called natural sciences are positive sciences.

Before considering what a science aims at and how scientific investigation is conducted, it will be desirable to define an art. The constructor of an art assumes that the attainment, if possible, of a given end has been decided upon, and tries to lay down a logical scheme of rules for its attainment. Navigation is an art; and much of the writing grouped under the heading "politics" really treats of the art of Government. The end, of which the attainment is desired, may have reference to some particular need; or it may be the ideal defined as a result of normative inquiries. Arts are sometimes known as practical sciences when attention is focused on their scientific side.

I shall now analyse the character of positive science; and much that I shall say has reference also to normative science. The object of every devotee of positive science is to understand a class of facts. He must first, then, think of his facts as a class, that is see them as similar in certain respects. Thus the world of space is the scope of physics: spatial facts make up the universe for physicists. But the physicist rejects all except certain aspects of these facts; he notices only their aspects as matter (however that may be interpreted) and 
motion. Human beings are part of the data for biologists, but merely as living organisms. As sentient and self-conscious, human beings are also facts for the psychologist; as engaged in governing and being governed, they are facts for the political scientist; as makers and sharers of wealth, they are facts for the economist. You will realize at once that a flash of insight which reveals a unifying aspect of apparently diverse things is the pre-requisite of a science. The reactions of human intelligence on facts, as they are directly presented, create the universes of science.

After forming his provisionally appropriate, unifying idea of the facts, the scientist has to observe, classify, and explain them. The operations of observing, classifying and explaining are by no means mechanical. They do not consist in just looking at the facts, sorting them according to their outstanding similarities and then waiting for the laws to leap out like Jack-in-the-box. The scientist does not first observe, then classify on the results of observation, then gather up laws which have, as it were, projected themselves. On the contrary, every process in observing, classifying and explaining, reacts on every other, and every one necessitates minute investigation under the guidance of ideas. Explanation almost invariably compels a revision of classification, and even of the results first reached by an analysis of the facts. Sometimes, indeed, the nature of the facts is discovered by deduction from the laws connecting them. Thus it is the most advanced inquiries into the laws uniting physical facts which have given rise to the latest theories as regards the substance of the facts themselves. Again, in classifying we must have in mind what are the essential features of the facts from the point of view of the science, as opposed to their external resemblances, and also we must have in mind what are the lines of their explanation. Explanation broadly refers to the enunciation of laws. A law is a generalization which links one change 
with another in the system of facts. Sometimes "law" is used more broadly, but it is convenient here to confine its reference to the relation commonly known as that of cause and effect. To sum up with contrasts, which like all striking contrasts are not exactly true, though they may be illuminating, observation detects uniformity in facts, explanation seeks uniformity in action, while classification aims at the arrangement which brings the two sets of uniformities into the most convenient correspondence with one another.

Political economy embraces a positive science, a normative science and several arts.-It will already, no doubt, have begun to dawn upon the reader that political economy is not one unified body of knowledge, but several bodies of knowledge which may be distinguished by outlook, aim and approach. These several separate but kindred studies I shall define next, and also some of the more obvious relations between them. Later we must return to our prolegomena and ask the question, Is a science of society possible at all? Provisionally we shall assume that this question must be answered in the affirmative.

First we must remind ourselves that economic facts can be regarded from two points of view, namely, the normative and the positive. As on one side economic facts are a part of human conduct, the normative science of political economy is clearly a branch of ethics. We must separately recognize, then, the positive science of economics and economic ethics.

Again, because social facts cover human conduct which may be directed to different social ends, various arts of political economy are possible. Much of the literature of economics is in the form of the art. A writer assumes, for instance, that sweating ought to be suppressed and then demonstrates how he thinks it might be suppressed. Again there is the art of business envisaged by certain writers. 
It is premissed that the business man desires to do the best for himself with his capital, and then it has to be discovered how in general he should act in the various circumstances in which he is likely to be placed. The study is conceived as systematized business strategy and tactics, and strategy and tactics are arts. The numerous works which have been produced on land tenure, in which peasant proprietorship, métayage, different leasehold systems and other arrangements, are contrasted with a practical end in view, must be grouped with the arts, though they have, of course, no relation to the fine arts. A treatise on the fine arts might be in form scientific, of the normative order, and be properly placed under the "science of æsthetics". Further, an economic art may be related to economic ethics. When ideals are formulated by the latter, the procedure needed for their realization must be considered. Its consideration makes up an art.

In connexion with all economic strategy and tactics, or arts of political economy, we must emphasize the importance of economic science. Action is entailed if ends are to be reached, and the prudent choice of action implies knowledge of its effects. Positive economic science which is non-evolutionary is concerned with these relations of cause and effect. Also, for the study of economic ethics, a knowledge of economic science is equally a pre-requisite. The framing of social ideals is not a mere exercise of the imagination. On the contrary it proceeds largely by deduction from known facts and generalizations relating to society economically conceived. An ideal that can be recommended must be one which is not inconsistent with human nature. It must be workable. The function of a locomotive is to travel; and nobody ignorant of the principles of mechanics would try to think out the ideal locomotive. But we must never forget that human nature is adaptable and that its modifications can be intentionally directed. 


\section{Positive economic science may or may not be eyolu-} tionary.-The recognition of social change brings to our notice economic writings which depict social change in what might be termed the evolutionary order. Some of these writings aim, moreover, at establishing laws or uniformities of social development. It would be as well, perhaps, to classify these writings as evolutionary economic science. This science is not yet an accomplished fact, but it is in the making. We must not confound economic history, which aims at restoring and explaining the past for us in its temporal order, and the evolutionary science, which seeks to represent and explain economic development, or devolution-for the question of progress must not be begged,-in its logical order, though most of the best works on economic history contain masses of evolutionary social science.

Sometimes-generally perhaps - the evolutionary science of economics, which is a positive science, is known as economic dynamics. The positive economic science which is not evolutionary is then known by contrast as economic statics. I feel some hesitation about adopting in this connexion the terms "statics" and "dynamics" because in this connexion they are given meanings different from those which they bear in mathematics. In mathematics, statics refers to problems of rest and dynamics to problems of motion. But non-evolutionary economics refers to problems of motion, though it assumes that no change takes place in the fundamental nature of its data. An evolutionary science takes cognizance of the laws of change in the units with which it deals as well as of their grouping. If we choose to give the name "economic dynamics" to evolutionary economics and the name "economic statics" to non-evolutionary economics, we must remember that we are using "statics" and "dynamics" with meanings different from their mathematical ones. I need not add that whenever facts change in 
nature-as for instance biological facts-an evolutionary science results from the study of them. As the elemental facts of physios do not change in nature, so far as we are aware, there is no evolutionary science of physics.

Classification of economic studies.-To sum up we may say that the following are the studies included under economics :-

$$
\text { Positive economic science }\left\{\begin{array}{l}
(1) \text { non-evolutionary or } \\
\text { static } ; \\
(2) \text { evolutionary or } \\
\text { dynamic. }
\end{array}\right.
$$

Economic history.

Economic ethics.

Practical economics or economic arts.

It goes without saying that an examination of one society, from the positive and non-evolutionary point of view, will not necessarily yield the same results as a similar examination of another society, or of the same society in another period, especially when the results are intended to be in a high degree realistic and detailed. But, as we shall learn in the next chapter, the construction of a very general economics of a non-evolutionary kind is feasible, though the finished product might prove disappointing in its proportions; and such a science, which holds broadly of every advanced Western nation under present conditions, is already an accomplished fact. Nevertheless we must be on our guard against committing what are known as the errors of universalism and perpetualism, that is to say against assuming that generalizations which apply only locally and temporarily have a wider reference.

It follows from these reflections that the features of a given economic art may vary from time to time and place to place. The proximate economic ideal of Germany may differ in detail from that of Italy, and likewise the best 
method of bringing about a given end in the one country may be at variance with the best method of bringing it about in the other.

The present work treats mainly of the elements of that positive economic science which is concerned with non-evolutionary uniformities, so far as they are common to advanced Western communities at the present time, but I shall occasionally slip designedly into discussions which properly belong to other divisions of political economy-designedly, because by a too exclusive adherence to one range of considerations we are apt to lose grasp of and interest in social life as a whole. 


\section{CHAPTER II.}

ASSUMPTIONS AND METHODS OF ECONOMIC SCIENCE.

Can the actions of free agents be reduced to law ?This work treats in the main of that part of political economy which is a positive science relating to advanced Western communities. But when we think of political economy as a science akin to the natural sciences, we may begin to doubt whether a positive science of things exercising volitional initiative-of things aspiring, striving, failing and succeeding-is possible. There is nothing self-contradictory in the conception of things as acting according to law when they have no volition. They cannot help themselves. They do not exercise choice. They are not in a position to refuse to act according to law. Subserviency to law is not inconsistent with the nature of these things. The apple cannot confute science by declining to fall to the earth. But is there not something self-contradictory in the conception of things as acting according to law when they have volition? Cannot any individual, perhaps out of sheer perversity, determine to act so as to break the uniformity of an alleged social law?

Now in this short treatise we cannot pretend to enter into the controversy between those who believe in Free Will of various degrees and those who believe in Determinism of its several kinds. It is sufficient for our purpose to recognize that a something, which we shall call "volition," distinguishes human being, if not from animals, at least from all other forms of life, and to consider whether the action of volitional 
creatures can be subject to scientific law. One of the purposes of the present discussion is to show that economics does not imply any particular view on the question of Free Will.

In dealing with the difficulty just described, we may notice in the first place that all the experiences of a volitional creature do not come within the sphere of his choice. If they did, our lives would be very different from what they are. We do not decide to feel pleased or sorry : we cannot help ourselves. I cannot prevent my appetite from getting satisfied if I go on eating. Nor can I prevent myself from getting tired if I go on working without cessation. Nor can I prevent myself from getting more and more inefficient as I get more and more exhausted. Examples need not be multiplied. Much of this uncontrollable experience has a direct bearing on economic uniformities, and much of it affects economic uniformities indirectly through the bearing which it has on the preferences to which economic uniformities relate.

In the second place we may observe that just as some of our economic experiences are governed by laws of the human organism beyond our control, so some of our economic experiences are governed by laws of external nature beyond our control. We get much of our income out of the responses of nature (which is external to us) to our efforts, and these responses are governed by the laws of external nature. To give one example, the law of decreasing returns, so far as it relates to such responses of external nature, derives its uniformity from the uniformity of nature.

In the third place and finally, we may point out that the economist has confidence in generalizations, the truth of which seems to be at the mercy of caprice (in view of the volition with which the things generalized about are endowed), because man is rational in some degree and struggles to be so in a higher degree. People will not as a rule deliberately do what they think to be foolish. A man may buy a pair of boots for 
21s. 6 d. when he could procure them elsewhere with no more inconvenience for $18 \mathrm{~s} .6 \mathrm{~d}$., if he is not aware of the existence of the cheaper shop; but he will not of set purpose under modern conditions go to the dearer shop, providing there is no reason for his preferring to deal at the dearer shop rather than the cheaper one. That is to say, other things being equal, he will not elect to buy dear rather than cheap. He might elect to buy dear to achieve social distinction, or in order to discourage sweating. But in these events other things are not equal. Motives extraneous to expense are at work, for which the economist can and does allow. Apart from such additional motives, it is conceivable, of course, that some persons might deliberately determine to buy dear to prove that economic laws were not laws in the sense that they were universally true. But persons do not act in this way in any appreciable numbers, if at all." If some few did, their actions would have the effect of a drop in a bucket. Insane persons, again, are sometimes possessed by a passion of misrule; but economics assumes that the great majority of people at large are sane. Hence we may conclude that the uniformity in reason implies some uniformity in human affairs, i.e. law in human affairs. When we lay down a law of social action where volition has play, we do not allege that every man must behave in a certain way, but that in the aggregate men will actually behave in a certain way. Uniformity in the aggregate only is affirmed. It is not an avowal damaging to the conception of economics as a science to concede that certain social laws partake of universality in a less degree than most natural laws. The degree of the universality of a social law is naturally less when an abundant measure of knowledge, resource and enterprise in the persons generalized about must be supposed.

The permanence of character and social assimilation.-I have now to draw the reader's attention to three 
very important features of the data with which the economist is primarily occupied. These features simplify his task, and permit of his fitting the material into generalizations which would otherwise be inapplicable.

The one feature may be defined by saying that a person's character commonly presents in its fundamentals comparatively permanent traits. Character is slowly acquired and as a rule only slowly modified. And our acts express our characters-" We know ourselves by action only, never by contemplation". I shall be pretty much the same in a year or so, as I am now, and I shall therefore act then much in the same way as I do to-day. The cases in which Nature makes a leap are rare-so rare, that in the consideration of aggregates they need not be allowed for. That sudden conversions take place the most sceptical must allow; nevertheless, what is true in general to-day, say, of the manners and customs of colliers in South Wales will still be approximately true in a year, or two years, or ten.

Another feature of our data is that all people are in their natures wonderfully alike, apart from the fact that all have the gift of reason.

A third feature is that under certain conditions people become alike in disposition. A process whereby people are made alike is known as a process of assimilation. Physiological and psychological processes of assimilation are constantly at work.

Physiological assimilation is especially important to nations which are recruited from many races, like the American nation. Through intermarriage of the several races with one another, a common racial strain tends to be generated. Racial assimilation may, of course, be deliberately resisted. Americans resist racial assimilation with negroes and Asiatics.

In addition to this physiological process, there is the important psychological process which has a subconscious, or 
unvolitional, and a volitional side. We are far more imitative of one another than we are aware, when we share in a common life. We imitate one another deliberately, perhaps in order to enjoy social approbation, which is only won when we conform to some extent to the ideas of others in the little worlds to which we belong; and we also imitate one another because we cannot help it. This imitation, deliberate and unintentional, expresses the instinct of gregariousness in the world of consciousness. Hence we can speak of the standard of life of a class. The standard of life of a class comprises the common habits of its members with reference to spending and working. Most of them tend to spend and work in pretty much the same way. Any two families of the same size with the same wage, if they work at the same trade in the same locality, will usually live pretty much the same lives. They will dress similarly, spend roughly equal amounts on rent and holidays, visit the same entertainments, despise the same people and reject the same food. It may be true that there are as many personalities as persons; but it is equally true that, despite the numbers of persons in a class, the class personality, so to speak, - the idea of the tribe-will tend to be one. When the class idea affects dress, we call it "fashion "; when manners, we call it "form" ; when conduct, " respectability"; when the desire for beautiful things, "taste"; when intellectual pursuits, "culture". Its voice is called "public opinion". In politics it makes parties. In all classes the class idea works and rubs down personal angularities. Its despotism is beneficent in so far as it insures a minimum of decency, culture and sociability, but maleficent if it suppresses all individuality and retards change for the better.

The remarks in this section, taken in conjunction with the propositions laid down at the end of Chapter I, should enable us to decide on formal grounds in what sense it is true to say that each country must work out for itself its own political economy. 
The abstract method.-Economics is occasionally to-day - but less frequently than it was a quarter of a century agocondemned as abstract. But to say that a study is a science is to say that it is abstract. Even the so-called classification sciences are abstract. To classify is to generalize and to generalize is to let slip certain facts. But to discard certain facts, if we discard appropriately, is to discover certain truths. The biologist, qua biologist, is blind to all the engaging ways of dogs which make them companions and regards each of them merely as genus dog, species whatever it is, and as a certain link in the evolutionary chain exhibiting certain peculiarities, all of which peculiarities are general ideas and not facts. Even myself, the biologist takes as something quite other than that which really makes me myself. History, too, in so far as it is selective or philosophizes, is abstract. I reassert, then, that to object to economics because it is abstract is to complain that its method is scientific. The vital question to settle is whether the abstractions of political economy are appropriate. Solvitur ambulando-achievements will justify. If it explains satisfactorily, its abstractions cannot be altogether faulty. It is, however, necessary to investigate its abstractions.

Man is a bundle of motives and therefore highly complex. For the purposes of science, the conception of this complex thing may be simplified. Certain leading motives might be disengaged and personified to form the unit of the science. When they were, the product was known as the "economic man". He was not a lovable creation and he won not a little well-merited, and much undeserved, unpopularity. His vices are nowhere more thoroughly, though melodramatically, exposed than in Dickens's "Hard Times". But when he was criticized from the scientific point of view, it was sometimes overlooked that the motives isolated happened to bo the dominant ones in business relations, with which much 
of political economy deals. It was frequently overlooked, too, that in many departments of the science the abstract procedure, which was denounced, led to remarkably correct forecasts. It was even overlooked time and again that a sermon was not necessarily being preached to the end that people should stifle all motives other than the ones separated for examination. At the same time, nevertheless, criticism was effective in warning economists to be cautious about their practical deductions. The popularizers of political economy undesignedly aided the critics. They proved by their appalling practical deductions how dangerous the early abstract method could be in inexpert hands, and how liable people were to think that the real world was the abstract universe of the economists, who on their part did not by any means keep entirely clear of the same unfortunate mistakes.

Ultimately a strong methodological reaction was excited. The German and English historical schools distrusted abstractions. By others a claim was advanced that social studies should follow more closely the lines of biological studies, which had at the time been stimulated enormously by the doctrine of evolution. And some demanded a science of men as they ought to be in their business relations. The trend of the period-and not only in social science-was to bring together again things which had been driven apart for a time by scientific requirements.

But the thinking of things together is barren without the thinking of them apart. It was, therefore, inevitable that a section of political economy should again secede from an environment less amenable than itself to exact formulation. It was not necessary, however, that Political Economy should simply revert to the old a priori lines, and it did not. It discovered a new way and along this new way it is advancing - but not to the desertion of other ways-with a caution unpractised before the last quarter of the nineteenth century. 
The new method consists, not in abstracting a motive, but in abstracting normal or average men and women in normal relationships, and abstracting from the activities of such typical people those which have reference to making a living. The normal man is the product of the family in which he was brought up, and he may have a family of his own, of which he is again a product. He is taken as possessed of a character which has been moulded by family influences, family responsibilities, and all the features of his social life. The economist who admits competition, even if he provisionally supposes it to rule unchecked, need not disregard the family and the potency of crystallized public opinion, and make his science unnaturally individualistic. He may admit, and ought to admit, competition only in the degree in which it works within the complex of social impulses-compare, for instance, what has been said above about standards of life. A society is not atomistic but an organism hierarchically constituted of smaller group organisms of which families are the chief. We shall see later how important is the function of the family in the preparation and disposal of the labour of the rising generation and in other ways. The new analytical procedure is methodologically superior to the old. From the old, only rough approximations could be derived in most departments of economics; but it achieved notable results, and it is still resorted to to-day and must be to some extent.

I must reiterate, in order that there may be no mistake, that modern analytical economics neither assumes nor advises selfishness. But without relegating sentiment to Saturn, we may hold that the affections do not directly enter into most business transactions. "Oh 'tis love, 'tis love, that makes the world go round," asseverated the duchess in "Alice in Wonderland". " "Somebody whispered," said Alice, "that it's done by everybody minding his own business." However, among the impulses which are the motive power 
of business activities, the affections may play a large part indirectly. A man may work his best to make as much as possible in the interests of his family or friends, or even for philanthropic purposes. Finally, it must not be imagined that, in the absence of altruistic motives, a man who works his hardest for success must be sordid. The passion of great business leaders is commonly quite other than that of the miser. Because money provides the counters which measure commercial triumphs, we are apt to go astray in our analysis. Those who play cards for cowries are not mastered by a passion for cowries. Until we understand the motives now at work in the economic field, we are not likely to make the best practical use of economic knowledge.

Historic and realistic methods.-The bare deductive method, which argues from general principles to particular cases, is so dangerous in certain branches of economics that it is incumbent upon the economist to return constantly to reality to test his theory. He will find it profitable, also, to watch patiently the heaving sea of facts as a whole and the interplay of its details. When facts are kept continuously under observation, it is not unlikely that the receptive mind will take the impress of their uniformities. As directly impressed, a uniformity, or law, may be vague. But by abstraction, inference, and special inquiry guided by hypotheses, it can be made definite. As first impressed, it must be a puzzle. Induction, that is generalization from a number of particular observed cases, may establish that the law is, but not why it is. To find out why it is, we must again fall back on abstraction, selective scrutiny and ratiocination.

History, too, the imaged sweep of events in the past, by presenting us with data somewhat different from those of the present and differently collocated, and by taking sequences out of time so that they may be perceived at once without our waiting for time to make them, is of incalculable value 
even to the economist who merely wants to explain social facts as they are in his day. And it goes without saying that, severed from historical studies, the evolutionary science of political economy would be an impossibility.

Much of the data of economics is measurable.-We may now try to account for the relatively high state of development of positive non-evolutionary economic science in comparison with other social sciences. The chief explanation. is that the former is concerned largely with measurable things. The chief of these measurable things are the choices or preferences underlying all actions which have reference to wealth. Other measurable things are the effects of consuming, or using things, on productivity. Most social action is directed by choice or preference, but many preferences are only measurable against each other in the roughest fashion. It is not so, however, with the bulk of those preferences which become effective when wealth is being produced and exchanged. Most communities possess some kind of money, and money measures the preferences which interact in the making and sharing of income. Money, as a measure of value, despite imperfections which will be noted in due course, does in general for economics what standards of space and weight do for physics. As soon as the facts of a body of knowledge become capable of some kind of measurement, that body of knowledge advances to a higher rank in the hierarchy of systematized studies. Its facts may be represented as quantitatively interrelated. However, many economic data which are measurable do not lend themselves readily to exact, or even approximate, measurement. It is not generally feasible, therefore, to calculate the quantity of the effect which will follow the causes actually operating at any moment. Let me add by way of recapitulation that the measurable facts with which the economist deals when he argues deductively are those found among typical persons. 


\section{Dixisions of political economy and relations between} them.-There is no agreement among authorities as to the best way of dividing up political economy regarded as a positive non-evolutionary science, but I prefer the division into the economics of (1) consumption, or demand, (2) production or supply, (3) exchange, or the equilibrium of demand and supply, and (4) distribution, or the sharing of wealth. Think of the members of a community as working together to produce wealth. Their actions constitute the data of the economics of production. What is produced annually is sometimes called "the national dividend". The study of the initial impulses under which production begins is a part of the economics of consumption. The examination of the effects on efficiency of the consumption of things, in different degrees and proportions, is another part. The economics of exchange explains why some things, in the pile of wealth produced, have more value than other things. "Distribution," when used to indicate a department of economics, is applied in a special technical sense. It does not mean transportation or the delivering of goods to consumers. It refers simply to the sharing of the product, and denotes that section of political economy which explains why wages, profits, rent and so forth, are of the amounts that they are.

In order to bring our imagery into closer relation with facts, we must suppose that all the economic processes described above go on at once and continuously. Wealth is distributed, for instance, as it is produced. The product is a flow and never a fund.

As the reader works his way into this treatise he will realize that it is impossible to tear each section of political economy quite apart from other sections. He will, therefore, understand why a strictly logical division of subjects is not observed in the arrangement of the sections of this book. 


\title{
BOOK II.
}

\section{CONSUMPTION, OR DEMAND AND ITS SATIS- FACTION.}

\section{CHAPTER III.}

\author{
WANTS AND DEMAND.
}

Scope of the economics of consumption.-The economics of consumption comprehends, as we have already learnt, human wants and their direct satisfaction. It includes inquiries into the following subjects:-

I. Wants in their relation to the means of satisfying them and to each other.

II. The expenditure of income.

III. The reactions of the satisfying of wants on production.

In satisfying our wants we are said to consume wealth, when wealth is needed for their satisfaction. I say "when wealth is needed for their satisfaction " because wealth, as ordinarily conceived, is not always needed for the satisfaction of a want. We sometimes want to do things-to sing, or go for a walk, or sleep-and just doing a thing is not ordinarily regarded as consuming wealth, though the possession of some wealth may sometimes be required to do it. In using the term "wealth" I must still rely upon general conceptions. Its definition must be deferred until we have studied wants, 
because wealth is the correlative of many wants. Without wants there would be no wealth.

The reactions of consuming on efficiency belong equally to the economics of consumption and the economics of production. In, this treatise we shall only notice these reactions cursorily. The study of wants and demand is assigned to the economics of consumption because they initiate consuming. I do not drink cocoa ordinarily unless I want to.

Wants, utility, satisfaction and demand.-"Want," which sometimes passes current as synonymous with "desire," is an ambiguous term which may refer (1) to a craving or longing, or (2) to a decision to make sacrifices, if need be, to possess some particular thing, or perform some particular action. There is no contradiction in saying that a man with a passion for alcohol, who is a total abstainer, wants an alcoholic beverage when he wants a glass of water. What is meant is that he has a longing for beer though he is trying to get not beer but water. One of the earliest and sorest experiences of most of us has been learning that we must not always choose what we long for.

It is with want in the second sense that the economist qua economist is directly concerned, according to my views. The relations between wants of this kind we may call "preferences". Merely for convenience, I shall speak of things as having or yielding utility or satisfaction in the degrees in which they are preferred-but merely for convenience.

It must be clearly understood, let me repeat again and emphasize, that "utility" and "satisfaction" are used in this book merely as conventional objective representations of degrees of preference. By preferences I understand the relations between wants as I have defined them for our purposes above.

Let me explain exactly what I mean. Bentham suggested that in courts of justice witnesses should be invited to state 
degrees of belief by reference to an objective standard, say to a yard measure. If this suggestion were carried out, and a witness indicated his belief that he met a certain person on a certain day by two feet and his belief that he met him some other day by six inches, he would not mean necessarily that corresponding to these beliefs there were within him two subjective states of two feet and six inches in length respectively, or even two such states the one of which was four times greater than the other. He would simply mean, were he a plain man concerned to give evidence and not to provoke a discussion on psychology, that his degrees of belief were related to one another in the ratio of four to one, and to certainty as twenty-four and six are respectively related to thirty-six. The twenty-four inches and six inches would be to him just conventional objective representations of degrees of belief, and nothing more.

So, if I should say that a man gets ten units of satisfaction or utility from his newspaper at breakfast, and two units of satisfaction or utility from his coffee, I should simply mean that he prefers the newspaper to the coffee in the ratio of ten to two. The ten and the two units of satisfaction or utility are, as I shall use them, just conventional objective representations of degrees of preference or choice and nothing more. You will recall my decision to imply merely that a thing possesses the qualities which render it an object of choice when I attribute utility to it.

The word "demand" has so far been employed provisionally. I must now explain definitely how it is to be interpreted hereafter in this work.

Demand is frequently said to be the expression of a want on the part of a person who is in a position to offer something to get what he wants. This view of demand is not wholly satisfactory, as everybody who is not quite destitute is in a position to offer something even for the Koh-i-noor diamond. 
If we try to evade this objection by saying that demanding consists in making a reasonable offer for what we want, we do not entirely escape it, since we are logically compelled to define what constitutes in each case a reasonable offer. Sometimes demand is simply regarded as the tangible expression of preferences in terms of exchange. So I shall regard it in the following pages. Demands, we may say, are the quantitative objective definitions of preferences.

The psychological basis of demand. - Some economic writers have assumed that any apparent conflict between the two sorts of wanting described above is illusory. Let us provisionally call want in the second sense, in its reference to economic conditions, "demand," and want in the first sense, "longing". Let us also call the conative correlative or consequent of longing, whereby it produces action, "impulse". It is supposed by these writers that demands measure longings or impulses : that, when we seem to act against our impulses, the explanation is that deliberating has brought out other and stronger impulses which, by virtue of their greater strength, triumph over the earlier impulses. Now I should contend that these writers are treating as settled a psychological question (i.e. a question belonging to the science of the mind) which is still controversial, or might at least become so, and a question upon which psychologists alone are capable of expressing an opinion. The economist's intrusion into psychology is both venturesome and unnecessary. If choice does not always fall on the course to which the strongest impulse points, the economist is wrong when he represents demand as measuring impulses. And if choice does al ways fall on the course to which the strongest impulse points, to say that demand measures impulses has no more significance for economic purposes than to say that demand measures preferences. Of course if it can be maintained psychologically that preference alone indicates the strongest impulse, preference and not impulse is the bedrock of fact upon which our oconomics must be founded. Choices and the relations between thein, or preferences, are the only ultimate facts about which we as economists can feel quite sure. And they are sufficient. 'To go beyond them is not our business as economists but the business of psychologists. 
I may add here that those writers who state that demand, as above interpreted, measures motives or inducements to action, are making either the assertion which has just been criticized, or the assertion which I shall examine next, if they do not mean merely that demand measures preferences.

There are other economists who derive their explanation of demand from the consequences in the form of utility to which they suppose its satisfaction leads. They may accept the view that impulse is the direct cause of action, but, if so, they believe that the inpulse measures the expectation of utility. Choice, they assume, must fall on the action which is followed by the greatest utility or satisfaction, so far as anticipation is not mistaken. They therefore suppose that demand measures utility or satisfaction. Seeming instances to the contrary they imagine to be explained by the new expectations of utility and disutility aroused after reflection.

Before we can examine this doctrine a few words must be said of the meanings assigned to "utility" and "satisfaction". These terms are usually employed as interchangeable, but "satisfaction" is at present the more popular term, because "utility" was a standard term current in the Utilitarian philosophy, and it is almost impossible now to sever its technical usage from the implications of that philosophy, which we need not discuss. "Satisfaction" on the contrary has the negative merit of vagueness. Many who employ "satisfaction" in place of "utility" would be content to say merely that it denotes a measurable psychical state of the feeling kind, which is induced when wants are satisfied.

Against taking the doctrine that demand measures satisfaction as one of the fundamentals of economics, I should bring objections identical with those already advanced against taking the doctrine that demand measures cravings or impulses as a fundamental economic thesis. It is at least likely that we do not choose things in the order of the degrees in which we expect to derive satisfaction from them, if satisfaction is measurable apart from the facts of choice. And if satisfaction is not measurable apart from the facts of choice, and we only know that one of two things has the greater utility because it is chosen in a cool hour by a wise man who is not mistaken in his forecasts, then to say that demand measures utility or satisfaction is merely to commit ourselves unnecessarily to an 
inference from the undoubted fact that demand measures choice or preference.

Systems of demand.-Some of the most elemental experiences of life have to be pointed out to most of us before we become alive to their existence. The first thing to observe about demand is one of these elemental experiences. It is that all people demand things in groups. Quite strictly speaking, there is no such thing as a detached demand for any article. My demands, for instance, for books, ink, pens, paper, a quiet study, leisure, a tennis racket and tennis balls to furnish me with exercise, a bicycle (to reach the tennis courts with and for other purposes) are all constituents of one massive group demand. After meditating over this example and others, you will allow that individual things are demanded as parts of a systematic whole.

The system of demand, or group demand, of each of us, is moulded by a variety of influences. In the first place, it is shaped by individual tastes. In the second place, it is shaped by standards of life or standards of comfort (see p. 14) that is by the conventional ideas prevalent at the time as to the amount and kind of expenditure expected of the members of each particular social class or grade.

A person's system of demand is only gradually built up ; and it is only gradually modified. In its initial form it is handed down to him by his parents, and this inheritance is supplemented, subtracted from and remodelled, as an outcome of his education and experience and the social influences brought to bear upon him. So far as a person is consciously active in the construction of his standard of living, he has to devise that particular compromise, between his individual tastes and the expectations of his friends and his class, which yields him most satisfaction ("satisfaction" as defined on p. 22). This compromise is not reached at once, but is approached step by step. Even if no compromise were needed, it would 
not be easy to spend an income straight away to the best purpose. Our first divinations of the relative amounts of utility obtainable in different ways are bound to be falsified.

Systems of demand crystallize into habits. Hence it becomes difficult for us to alter them fundamentally. It is advantageous that habit should be allowed to settle the small recurrent problems of life for us, because habit economizes time and effort. The housekeeper would never have a moment for anything else if she had to think out her weekly expenditure $a b$ initio every week. But we all run the risk of getting so thickly encrusted with habits that we are rendered incapable of developing. The supreme importance of fostering adaptability, of keeping our habits open, so to speak, as well as our minds, while our habits are left at the same time with a strength which suffices to save us the worry of thinking out anew each small outlay, on the repetition of the need for it, is abundantly manifest.

Owing to the fact that our systems of demand are only slowly built up, it will frequently be found that a sudden rise of our incomes is accompanied either by a degree of saving which is afterwards curtailed, or for a time by ill-judged extravagance. And, inasmuch asithe deprivation of something included in our systems of demand means, not only the loss of the satisfaction derived from consuming it, but also the added discomfort of breaking a habit, it will frequently be found that a reduction of income is accompanied by a running into debt or by the exertion of special efforts to restore the old income. We may gauge the force of habit from the effect upon price of a permanent shrinkage in the supply of something of which the consumption has become habitual. Suppose the wheat supply were permanently cut down. Immediately there would follow an immense elevation of price, because most people would not know how to dispense with any of the wheaten bread to which they had grown ac- 
customed. Ultimately the very high price would subside somewhat, because rye-bread and other forms of food would gradually be substituted for wheaten bread in systems of demand and standards of living.

The demands of each person, I have said, must, strictly speaking, be conceived as a whole. But some of the constituent demands of a group demand are so little dependent upon other demands that they may be conceived as practically independent. Between the others-the closely dependent demands-a number of different relations hold. The chief of these are complementary and substitutional relations.

The demands for two or more things may be complementary. When united by complementary demand, things are said to be in joint demand. We have an example in the demand for knives, which is a joint demand for knife-blades and knifehandles. Two or more things may be demanded jointly in a fixed ratio or fixed ratios, or in a variable ratio or variable ratios. Again, one or more of the constituents of the joint demand may also be demanded independently, or in a different joint relation. Golf-clubs and golf-balls are jointly demanded in a variable ratio. When golf-balls rise in price, golfers demand fewer, because they take greater care of them, search longer for lost balls, and are less fastidious; but the demand for golf-clubs is not much affected. The ratio is more rigidly fixed in the case of table-knives and forks. Mustard is demanded in more than one joint relation and also separately. It is demanded jointly with bacon and jointly with beef, but independently for mustard plasters.

Two or more things may be substitutes and may, therefore, be demanded to the partial or almost complete exclusion of each other for the time being. Examples are found in beef and mutton, and tea and coffee. 


\section{CHAPTER IV.}

\section{DIMINISHING UTILITY AND MARGINAL USE.}

Diminishing utility.-We may now consider the demand for individual things. At first I shall notice only its broad aspects and not aim at rigid exactitude of statement. Finally I shall try to state the facts more precisely.

Of all the laws of demand far the most important is the law of diminishing utility or of satiable wants. It declares broadly that the more we have of a thing the less we want additional increments of it, or the more we want not to have additional increments of it. We become gradually indifferent to chocolate, for example, as we consume it less abstemiously, and then inimical to it. Put in terms of utility the law proclaims generally that, as the amount of a thing consumed within a given time increases, the utility derived from it increases at a diminishing rate (so long as utility increases at all). The increases of utility are called "marginal utilities". Consider your monthly consumption of coffee. Let the facts be as follows :-

\begin{tabular}{|c|c|c|}
\hline $\begin{array}{c}\text { Pounds of Coffee } \\
\text { Consumed per } \\
\text { Month. }\end{array}$ & $\begin{array}{c}\text { Utility Derived } \\
\text { from Consumption. }\end{array}$ & Marginal Utility. \\
\hline 1 & 100 & 100 \\
2 & 180 & 80 \\
3 & 230 & 50 \\
4 & 270 & 40 \\
5 & 290 & 20 \\
\hline
\end{tabular}


Each figure in the third column is obtained by deducting from the figure in the second column in the same line the previous figure in the second column. Remember what I have said on page 22 about the meaning of utility.

I'may now define marginal utility more accurately and with it total utility. Marginal utility means the reduction of total utility caused by a minute curtailment of our consumption of a commodity. Total utility means the whole of the utility we extract from the commodity. According to the above table the total utility (monthly) of $4 \mathrm{lb}$. of coffee to you is 270 while the marginal utility is 40 . In this example the increments, i.e. pounds, have been taken too large, but they will serve for the purpose of illustration. You must not say, observe particularly, that the utility or satisfaction got from the fourth pound of coffee is 40 . If you analyse your experiences, you will clearly perceive that all you are entitled to say is that the total satisfaction derived from coffee is increased by 40 when consumption is raised from $3 \mathrm{lb}$. to $4 \mathrm{lb}$.

Notice that it is not always possible, even in theory, to give a utility for the initial increments of a thing because it is indefinite. Consider for instance the utility of water.

The marginal utility of most things to us drops to zero after a time. And if, after zero utility is reached, our supplies of a thing are still unexhausted and we are forced to consume them, or at least keep them, we begin to experience dissatisfaction in place of satisfaction. That this dissatisfaction or disutility (which is the negative of satisfaction or utility, as pain is the negative of pleasure) will increase at an increasing rate as our supplies increase, needs no proof.

Diagrammatic representation of diminishing utility. - Consider fig. 1, ignoring at first the dotted lines. Let $a b, b c, c d, \ldots . .$, stand for successive increments of a commodity, say pounds of tea consumed by me per month. We may represent the satisfaction drawn from $1 \mathrm{lb}$. by the rectangle on $a b$, and the satisfaction got from $2 \mathrm{lb}$. 
by the rectangles on $a b$ and $b c$, and so forth. The rectangles on $b c$, $c d, \ldots$, therefore, represent the additions made to the satisfaction derived by me from consumption by raising the consumption of tea from $1 \mathrm{lb}$. to $2 \mathrm{lb}$., from $2 \mathrm{lb}$. to $3 \mathrm{lb}$, and so forth respectively. The law of diminishing utility asserts that the rectangles will get less and less in height successively as we pass from left to right. As we increase our consumption of tea, the total utility enjoyed by us increases, at any rate up to a point, but it increases at a diminishing rate. The diminishing rate in my imaginary case is shown by the decrease in size of the rectangles in fig. 1. I must not say that the satisfaction got by me from the second pound of tea is the rectangle on $b c$, and the satisfaction got from the third pound the

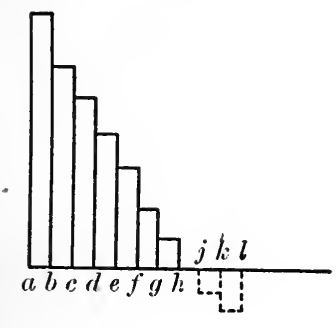

Fig. 1.

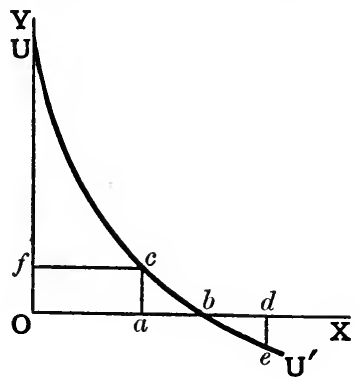

Fig. 2.

rectangle on $c d$, and so forth. When my consumption is raised from $1 \mathrm{lb}$. to $2 \mathrm{lb}$., all that the facts warrant me in saying is that the total satisfaction derived by me from tea is increased by the rectangle on $b c$. The rectangle on $b c$ stands for the difference made to my total satisfaction by the second pound of tea. Similar statements, of course, may be made of all the other rectangles in the figure. If $3 \mathrm{lb}$. $(a d)$ of tea are consumed monthly, the total utility is the sum of the rectangles on $a b, b c$ and $c d$, while the marginal utility is the rectangle on $c d$. If $4 \mathrm{lb}$. (ae) of tea are consumed, total utility is the sum of the rectangles on $a b$, $b c, c d$ and $d e$, while marginal utility is the rectangle on $d e$.

When consumption reaches $a j$ in our imaginary case, the utility of the last increment, $h j$, is zero. When consumption is $a k$ we 
find marginal dissatisfaction instead of marginal satisfaction. The maryinal dissatisfaction is the rectangle below $j k$. And the rectangle below $k l$ is greater than that below $j k$. Dissatisfaction is indicated by rectangles below the vertical line al. If al of the commodity is consumed, the net utility derived is equal to the rectangles above al, less the rectangles (marked with dotted lines) below al.

I may next draw the reader's attention to a method of representing the variation of the utility derived from a commodity with the quantity of it consumed which is more convenient than that followed in constructing fig. 1 . If as the basis of fig. 1 we took ounces of tea instead of pounds, each of the divisions along al would be divided into sixteen parts and the rectangles standing on these sub-sections would be very narrow. Consequently the difference between the aggregate area of the rectangles and the area enclosed between a line joining the top right-hand corners of the rectangles, $a j$ and the top and left boundaries of the rectangle on $a b$, would be very small. And this difference could be made as small as we pleased by taking the units along $a j$ as small as we pleased. Hence fig. 1 may be reduced to fig. 2 . We may call $U U^{\prime}$ in fig. 2 a "utility curve". When $\mathrm{O} a$ of the commodity to which the curve relates is consumed, the total utility obtained from it is $\mathrm{OacU}$ and the marginal utility is a rectangle whose height is ac. If the supply were reckoned in very small increments this rectangle would be very thin. For short we may simply say that the marginal utility is ac. If $\mathbf{O} b$ is consumed total utility is $\mathbf{O} b \mathbf{U}$ and marginal utility is zero. If $\mathrm{O} d$ is consumed total utility is $\mathrm{O} b \mathrm{U}$ - bed and the marginal disutility is de.

When things are represented as varying with one another as in fig. 2 the lines meeting at a right angle at $O$ are called co-ordinates and are usually lettered $O X$ and $O Y$. Distances along $O X$ are called abscissae and distances along $O Y$ are called ordinates.

It is not always possible, theoretically even, to start the curve $U^{\prime}$ at a point on OY because the utility of initial increments of a commodity might be indefinite, as $I$ have pointed out above.

\section{Limitations of diminishing utility.-The law of} diminishing utility is ordinarily taken to relate to the effects in the long run of making a thing more plentiful, that is to 
effects after time has been given to the consumer to adapt himself and modify, if need be, his consumption of other things. In most cases, however, it will be found that the law holds also of immediate effects. These points having been registered, we may review certain qualifications and apparent qualifications of the law of diminishing utility.

In the long run the marginal utility of certain commodities may begin by rising though it is bound to fall ultimately. We must have a moderate amount of some commodities before we can appreciate them. If we took the increments of a commodity small enough, marginal utility would generally mount at first. Consider the value of ounces of coal per day. An ounce of coal is no good to anybody. Coal would not yield any value to speak of till we had very many ounces.

Other commodities really change in character, or in their appeal to certain consumers, as the quantity of them possessed by those consumers increases. To a collector of eggs the value of great auk's eggs, of which there are very few, might ascend with his success in getting great auk's eggs because they would add at a growing rate to the uniqueness of his collection. To have two great auk's eggs is to be envied, but to have six is to be a prince among egg collectors.

Moreover the marginal utilities of some things to individuals are sensibly governed, not only by the quantities of those things which they possess, but also by the quantities of them possessed by other people, and even, in certain cases, by the classes of people who are possessed of the things in question. The value of a telephone to any one user is enhanced when more people get linked on to the service with which it is connected. The value of rare things to a collector appreciates when some of the supply not held by him is destroyed. The value of a thing of fashion may expand as some classes acquire it and contract as other classes acquire it. In order to bring these instances under the law of diminishing utility, we have 
to limit the law by assuming that the quantity or distribution of the supply of the commodity which is not in the hands of the person whose demand we are studying remains constant.

We must also remind ourselves (pp. 26, 28) that the value of a thing is almost sure to depend in some degree, though it may be in a very slight degree, upon the abundance of other things which its owner possesses. If a man's income suddenly doubled, the level of the utility yielded him by certain quantities of certain things might be raised. The reason would be that his greater wealth in other things brought out the value of these particular things. The utility of furniture is a case in point. The value of a fourth bedstead to anybody who lived in a cottage might be paltry, but it would become high if he inherited a fortune and a mansion. On the other hand the enlargement of a person's income lowers the estimation in which he holds some classes of goods. The value of a bicycle to a man who bicycles because he cannot afford a motor-car may drop to zero when he gets a motor-car.

Further the marginal utility of a person's income as a whole might actually rise as his income rose. His wants might be stimulated by power to satisfy them. In more affluent circumstances he might become a different individual. $\mathrm{He}$ might have been debarred by the meagreness of his income from embarking upon a career which attracted him. If fortune brought him just sufficient wealth to enable him to follow his bent, his life might be transformed, and the marginal utility of his income in his good fortune might easily exceed what the marginal utility of his income had been previously. Suppose a man with $£ 1000$ a year has a passion for politics but would not feel justified in entering Parliament unless he could depend upon an income of $£ 1500$ a year. It is quite likely that the marginal utility yielded him by $£ 1500$ would exceed the marginal utility yielded him by $£ 1000$ a year. 
Are all wants satiable? - From the fact that the marginal utility of a commodity may subside to zero, and even sink to a negative quantity, it does not follow that human wants in their entirety are within measurable distance of being satiated or are indeed satiable. Man may be conceived as a bundle of wants. He wants two sorts of things. He wants things that cannot be directly bought, such as health, culture, a model society. These wants, we may affirm, can never be completely appeased, if we may generalize from so much of the future as our mental vision can penetrate into. Man also wants things that can be directly, bought. These wants are largely derived from the wants for things that cannot be directly bought. A man may demand dumb-bells because he aspires to be muscular. He may never, perhaps, become as muscular as he would like to be, but he will soon have as many dumb-bells as he has any use for if he goes on buying more and more of them.

Wants of the second class may all be regarded as theoretically satiable, from a common-sense point of view. Anybody with an income of $£ 10,000,000$ could buy all the purchasable things which he had time to covet. But for practical purposes the aggregate wants of the second class of almost the whole world's population may be regarded as insatiable, because very few people are enormously wealthy. Of almost all peop'e it is true that they could spend without difficulty very much larger incomes and that they would enjoy having very much larger incomes to spend.

One reason why wants in general are practically insatiable is that new particular wants appear as the old are met. It has been asserted that the satisfaction of old wants actually creates now wants, and there is some ground for the assertion. When my demand for an elementary text-book of political economy is satisfied, in the sense that I have procured it and read it, a want for more advanced books on 
political economy is generated which could not have been genemted before. But the fact that new demands become clamorous, after the old demands have been met, does not always mean that new wants have been created by the satisfaction of the old. Sometimes the wishes underlying the new demands were there all the time, but were quiercent because we were actively engaged in getting our more ungent cravings assuaged. Wants-except the wants for necessaries - do not ordinarily disturb us much, when there is little chance of their becoming effective demands, because we do not pay much attention to them. They are mere idle wishes which leave us untroubled, like day-dreams.

The utility of Complements and Substitutes.-Supposing that no goods are so indispensable that the utilities of their initial increments are indeterminate, by theoretically adding up the satisfactions which may be attributed to the consumption of the goods included in an individual's scheme of consumption, we do not produce a sum which is the same as the amount of utility actually enjoyed. We should produce such a sum were all the things independent in value; but they are not, as we have already perceived. Many articles are bound together by complementary and substitutionary relationships.

Let us inquire what happens when we add together the value attributed to ten, and the value attributed to coffee, since tea and coffee are partial substitutes. The utility of tea is calculated on the supposition that a person has such a substitute as coffee. It is less than it would be if he had no coffee. Again utility is attributed to coffee on the assumption that there is tea to fall back upon. If, therefore, we add wether the satisfactions derived from tea and coffee, we get too small a surplus, for we leave out what would be lost by the withdrawal of all non-intoxicating stimulating beverages, supposing tea and coffee to be the only ones. 
On the contrary, adding the utilities attributed to complements involves adding some utilities twice over. An extreme example is afforded by boots. If I have a boot for the right foot only its value is insignificant, but the value of a pair of boots is high, so with a right-foot boot 'only in my possession I should set a high value on a corresponding left-foot boot. Now if I calculated the utility of a right-foot boot in the same way by estimating what I would lose if it disappeared and I were left with only the left-foot boot, and then added this utility to the utility likewise attributed to the left-foot boot, I should get a total utility greater than that actually yielded by a pair of boots. Less extreme, but similar in kind, are the illustrations which might be drawn from complements the members of which have more independent value, like bread and butter, tea and cream.

The basis of laws of utility.-The law of diminishing utility or satiable wants, its limitations, its corollary relating to the diminishing utility of income, and the other generalizations laid down above as regards utility may all be established by the direct introspective inquiry of a number of different persons, supplemented by observation of people's actions. The law of diminishing utility may in addition be confirmed by pointing out that utility varies directly as the urgency of demand, and that the most urgent demands will usually be attended to first.

Marginal Quality.- "Marginal " is unfortunately an ambiguous term which has a meaning other than, though related to, that set forth above. Clothed with it, "marginal " must be recognized as having an established place in the nomenclature of economic science. It has reference to the quality of things (including persons and services). When a thing is of such a quality that it is only just worth while using it, in view of all the circumstances, it is sometimes said to be marginal or to have marginal quality. 
Let me illustrate. I go into an orchard to pick up a dozen fallen apples for a pudding. The marginal use of apples to me in the circumstances is the difference made to the utility of the pudding by putting twelve apples into it instead of eleven. Now in selecting the apples I reject a number because they are damaged or inferior in some respects. When I have got my dozen, the apple which is the least satisfactory of the twelve is the marginal apple meaning the apple of marginal quality.

Take another illustration. If an employer engages 100 men for a particular purpose, the difference between the value to him of 99 men and the value to him of 100 men, who are identical in respect of efficiency, is the marginal value to him of labour of the kind in question, or the value to him of labour at the margin. This we have already learnt. Now the marginal man, meaning the man of marginal quality, in this case is the man who is only just efficient enough to be employed for the purpose in question when 100 are going to be employed. Evidently the 100 are not likely to be endowed with exactly the same efficiency.

Similarly we may say that the land which it is only just worth while to use, in view of its position or fertility, is the marginal land.

Similarly we may say, to put it roughly, that in any given industry the business or firm which is only just efficient enough to continue producing, in the long run, is the marginal business or marginal firm in that industry (see pp. 157-60).

This conception of the marginal thing, and the distinction between it and the conception of the marginal use of a class of things, must be thoroughly grasped before the student advances a step further. 


\section{CHAPTER V.}

\section{DEMAND PRICES, EXPENDITURE, AND CONSUMERS' SURPLUS.}

The law of demand price.-Demand is expressed in offers of things of value for things of value. Under modern conditions offers are ordinarily made in terms of money. Let us then speak of demand in future as an offer of money. Now observe that demand, say for coal, means neither a price, nor a quantity of coal, but the prices which will be paid for different quantities of coal. Demand then states the relation between the quantities that might be purchased and prices.

Because of the law of diminishing utility, people will almost always offer less and less per unit for additional supplies of a commodity for consumption in a given period of time; that is to say, assuming that the commodity is tea, price would need to be lower if $2 \mathrm{lb}$. per head were to be bought in the month than if $1 \mathrm{lb}$. per head were bought in the month.

To be rigidly exact, we should call a person's demand price for a given quantity of a thing, as above described, "marginal. demand price," to distinguish it from what the person would give, if need be, were the alternative his being deprived of the thing altogether. This latter payment would obviously be governed by the aggregate, and not the marginal, utility of the given quantity of the thing in question.

By combining the demands of all individuals buying in one market, we get market demand prices. What is meant by 
combining individual demands can be made evident by the following example :-

\begin{tabular}{|l|c|c|c|}
\hline Price. & $\begin{array}{c}\text { Amount that } \\
\text { A would buy. }\end{array}$ & $\begin{array}{c}\text { Amount that } \\
\text { B would buy. }\end{array}$ & $\begin{array}{c}\text { Compound demand, i.e. } \\
\text { combined amounts } \\
\text { that A and B } \\
\text { would buy. }\end{array}$ \\
\hline & 1 & 0 & 1 \\
5s. & 3 & 1 & 4 \\
4s. & 8 & 4 & 12 \\
3s. & 12 & 7 & 19 \\
2s. & & & \\
\hline
\end{tabular}

What is done here with two consumers could theoretically be done with twenty thousand. But it could only be done theoretically. It is of value to realize how market demand prices are compounded of individual demand prices, yet our knowledge of this will not enable us to draw up the market demand schedule at any time for any particular commodity. In general form, parts of a market demand schedule may be indicated nevertheless, after we have watched side by side variations in price and in amount sold. However, we must remember that the conditions of any society, including the relations between demands, are subject to ceaseless mutations ; and that, therefore, in sketching demand from nature we are delineating a thing that is changing as we draw it.

Because in almost all cases individual demand price descends as the quantity bought increases, in almost all cases market demand price will fall as the quantity sold increases, other things being equal.

Elasticity of demand.-One of the most important attributes of demand is what is called its clasticity. The term "elasticity" is applied in a special technical sense to demand. We say that demand is highly elastic if demand price falls very little as consumption is increased; and that it is highly 
inelastic if demand price falls rapidly as consumption is increased. Dr. Marshall has suggested that we should call the elasticity of demand "unity," so long as the amount demanded at a price multiplied by the price (that is the aggregate sum paid for what is sold) remains constant. If it were more or less elastic than this, we should say its elasticity was greater or less than unity as the case might be. Naturally a demand has different elasticities with reference to different quantities. I give below an example of a demand which has elasticity equal to unity at first, then elasticity greater than unity and finally elasticity less than unity :-
Amount Demanded. Price Offered.
Aggregate Paid
(i.e. the Product
of Figures in
Columns 1 and 2).

\begin{tabular}{|c|c|c|c|}
\hline 1 & $20 \mathrm{~s}$. & $20 \mathrm{~s})$. & \\
\hline 2 & $10 \mathrm{~s}$. & $20 \mathrm{~s}$. & Elasticity \\
\hline 3 & 6s. 8d. & $20 \mathrm{~s}$. & unity. \\
\hline $\begin{array}{l}4 \\
5\end{array}$ & $\begin{array}{l}5 \mathrm{~s} . \\
4 \mathrm{~s}, 1 \mathrm{~d}\end{array}$ & 20s.J & Elasticity \\
\hline 6 & 3s. $6 \mathrm{~d}$. & $\begin{array}{l}21 \mathrm{~s} . \\
\text { 2ud. }\end{array}$ & greater than \\
\hline 7 & 3 s. $4 \mathrm{~d}$. & $23 \mathrm{~s} .4 \mathrm{~d}$.) & unity. \\
\hline 8 & 2s. 10d. & $22 \mathrm{~s} .8 \mathrm{~d}$. & Elasticity less \\
\hline 9 & $2 \mathrm{~s}$. & $18 \mathrm{~s}$. & than unity. \\
\hline 10 & 1s. $6 \mathrm{~d}$. & $15 \mathrm{~s}$. & \\
\hline
\end{tabular}

It will be realized as we proceed how important the conception of elasticity is.

Diagrammatic representation of demand. -We may represent the individual or market demand for some commodity or service, as in fig. 3 , by a curve, which is usually lettered $\mathrm{DD}^{\prime}$. It is called a demand curve. It shows the relations between price and quantity bought, that is, the amount that will be bought at different prices in a given time. Price is measured upwards along OY and amounts bought are measured from left to right along $O X$. It is evident that the curve of market demand prices must descend, 
since all the curves of individual demand prices, of which it is compounded, descend. An example of composition of two demand curves will be found in fig. 14 on p. 207.

Of any two demand curves drawn to the same scale the steeper at any part is the less elastic. But we must be careful not to be deceived by appearances as to the elasticity of curves. A curve that looks steep might be highly elastic. The angle at which a curve descends at any point can be made anything we please by arranging the scales marked along $O X$ and $O Y$. Consider the curve in fig. 3. It is steeper at the left than at the right, but

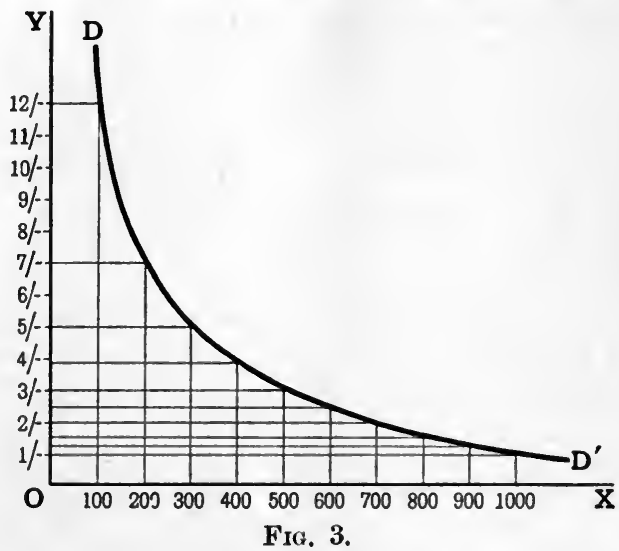

you will see, if you measure up the rectangles enclosed between the eurve and $O X$ and $O Y$, that it is more elastic at the left than at the right. At the extreme left these rectangles are increasing, but at the extreme right they are decreasing. The area of the rectangles represent price multiplied by quantity.

Let me make a sample calculation for you in order that there may be no misunderstanding.

$\begin{aligned} \text { The first rectangle } & =100 \times 12 \mathrm{~s} . & =1200 \mathrm{~s} . \\ , \text { second } ", & =200 \times 7 \mathrm{~s} . & =1400 \mathrm{~s} . \\ \text {, penultimate ," } & =900 \times 1 \mathrm{s.} 3 \mathrm{~d} . & =1125 \mathrm{~s} . \\ \text {, last } & =1000 \times 1 \mathrm{s.} & =1000 \mathrm{~s} .\end{aligned}$


The law of substitution or indifference, or equimarginal utility.-This law is one of the most fruitful in consequences of all economic laws. We shall remark later that it applies also to production and has an intimate bearing on distribution.

As regards expenditure, at any one time (p. 48), the law of substitution; indifference, or equi-marginal utility, affirms that we all tend so to regulate our purchases that the marginal satisfactions per unit of outlay yielded by different things become equal. It is reasonable to act in this way and most people are disposed to act reasonably. We all want to get as much satisfaction as possible out of our incomes. We get the most satisfaction out of them when we so spend our money that pennyworths of everything are yielding at the margin the same satisfaction. The proof of this proposition is simple. Suppose money spent per week on butter and sugar produces for me per week the utilities shown in the table beneath :-

\begin{tabular}{|c|c|c|c|c|}
\hline Pence. & $\begin{array}{c}\text { Aggregate } \\
\text { Utility of } \\
\text { Butter. }\end{array}$ & $\begin{array}{c}\text { Marginal } \\
\text { Utility of } \\
\text { Butter. }\end{array}$ & $\begin{array}{c}\text { Aggregate } \\
\text { Utility of } \\
\text { Sugar. }\end{array}$ & $\begin{array}{c}\text { Marginal } \\
\text { Utility of } \\
\text { Sugar. }\end{array}$ \\
\hline & 10 & 10 & 9 & 9 \\
1 & 18 & 8 & 16 & 7 \\
3 & 24 & 6 & 20 & 4 \\
4 & 29 & 5 & 23 & 3 \\
5 & 32 & 3 & 25 & 2 \\
6 & 34 & 2 & 26 & 1 \\
\hline
\end{tabular}

Let us read one line to be sure that we know what the table means. The third line says that threepennyworth of butter yields an aggregate satisfaction of 24 and a marginal satisfaction of 6 , and threepennyworth of sugar yields an aggregate utility of 20 and a marginal utility of 4 . Now 
imagine if you can, for the sake of argument, that I live on butter and sugar alone and have an income of $9 \mathrm{~d}$. a week. Imagine further that $\mathrm{I}$ spend $6 \mathrm{~d}$. of this on butter and the remaining $3 \mathrm{~d}$. on sugar. Then the marginal utility of butter to me is 2 and the marginal utility of sugar is 4 . If I reduce my expenditure on butter by $1 d$., I lose 2 units of utility, but when I spend on sugar the penny so saved I gain 3 units of utility. So there is a net gain of 1 unit of utility. On glancing at the table, you can verify that this is the position of maximum advantage for the expenditure of $9 \mathrm{~d}$. on butter and sugar. When $5 \mathrm{~d}$. buys butter and $4 \mathrm{~d}$. buys sugar, aggregate satisfaction is $32+23$, that is 55 ; when $6 \mathrm{~d}$. buys butter and $3 \mathrm{~d}$. buys sugar, aggregate satisfaction is $34+20=54$; when $4 \mathrm{~d}$. buys butter and $5 \mathrm{~d}$. buys sugar, aggregate satisfaction is $29+25=54$; and all other possible ways of distributing $9 \mathrm{~d}$. on the purchase of butter and sugar also yield less than 55 units of satisfaction. What is true in this case, where the income is $9 \mathrm{~d}$. and there are only butter and sugar to buy, must be true also of larger incomes and of many commodities. Hence it is proved that income should be so spent that the marginal return of satisfaction to a unit of expenditure becomes the same for all the commodities. That is to say, when a person pays $3 \mathrm{~d}$. a pound for sugar and 18. a pound for butter, if he has acted sensibly, the marginal utility of a pound of butter to him must be four times the marginal utility of a pound of sugar to him. My readers can furnish a geometrical demonstration for themselves.

This minute analysis establishes the fact that a person lays out his income to the greatest advantage when he buys such a quantity of each thing that his demand price for that quantity equals the market price, provided that he has made no mistake in constructing his demand schedules, in view of the utilities which different things yield him and of the amount of his income. 
If the price of the tea of the quality that I want is $2 \mathrm{~s}$. a pound and I would give :-

$4 \mathrm{~s}$. a pound for $1 \mathrm{lb}$.

2s. $8 \mathrm{~d}$. a pound for $2 \mathrm{lb}$.

2 s. a pound for $3 \mathrm{lb}$.

1s. 6 d. a pound for $4 \mathrm{lb}$.

I should buy $3 \mathrm{lb}$, for my demand schedule says that I should. But what has been proved is that when I buy 3 lb. of tea the utility per penny yielded by tea at the margin equals the utility per penny yielded at the margin by everything else, provided that I essayed to make the most of my income and did not go astray in working out what I could afford to give for different quantities of different things.

The law of equi-marginal utility, substitution, or indifference, is so-called because it alleges that every person will try to get equi-marginal returns from his expenditure; that he will seek to attain his end by substituting the more profitable for the less profitable expenditure whenever he sees an opportunity; and that, when he has brought about equimarginal returns, a diminutive accession to his income will be spent indifferently upon one thing or another.

Observations on the Law of Substitution.-Let me now recapitulate. I have shown that a person's demand prices measure the relative utilities of things to him. Let my demand prices for daily supplies of bread and potatoes be as follows :-

\begin{tabular}{|c|c|c|}
\hline Lb. & $\begin{array}{c}\text { Demand Price } \\
\text { for Bread. }\end{array}$ & $\begin{array}{c}\text { Demand Price } \\
\text { for Potatoes. }\end{array}$ \\
\hline 1 & $5 \mathrm{~d}$. & $4 \mathrm{~d}$. \\
2 & $3 \mathrm{~d}$. & $2 \frac{1}{2} \mathrm{~d}$. \\
3 & $2 \mathrm{~d}$. & $1 \frac{1}{2} \mathrm{~d}$. \\
4 & $1 \frac{1}{2} \mathrm{~d}$. & $1 \frac{\mathrm{d} .}{2}$ \\
5 & $1 \mathrm{~d}$. & $\frac{1}{2} \mathrm{~d}$. \\
\hline
\end{tabular}


Let the price of bread be $2 \mathrm{~d}$. a pound and the price of potatoes $1 \mathrm{~d}$. a pound. Then I should buy $3 \mathrm{lb}$. of bread and $4 \mathrm{lb}$. of potatoes, and the marginal utility of bread to me per pound would be twice the marginal utility of potatoes to me per pound, and the aggregate and marginal utilities derived from bread and potatoes would be related in the following proportions :-

Aggregate utility of bread (3 lb.) -10

$$
\begin{array}{cl}
\text { Marginal utility of } & \begin{array}{l}
\text { potatoes (4 lb. })-9 \\
\text { bread (per pound)-2 }
\end{array} \\
\text {, } & \text { potatoes (per pound) -1 }
\end{array}
$$

These numbers, remember, do not stand for "units of utility"; they merely indicate the ratios between utilities. The 10 is reached by adding the demand prices for bread up to the amount bought, that is $5 \mathrm{~d}$. $3 \mathrm{~d}$. and $2 \mathrm{~d}$., and the 9 is reached similarly by adding together $4,2 \frac{1}{2}, 1 \frac{1}{2}$ and 1 .

It must not be concluded that the demand prices of different people measure the utilities of things to different people. They do not because people differ in respect of tastes, intensity of wants, and wealth. Money has, therefore, different degrees of marginal utility to them. If a poor man and a rich man are bidding against one another for a piano and it is knocked down to the rich man because he offers most, we must not infer that the rich man's need was the greater. His need may actually have been the smaller, but, as he was richer and money had less utility to him, he could offer more for the piano than the poor man.

The marginal utility of money (which is sometimes spoken of shortly as the utility of money) is the marginal utility derived from such an amount of anything as a unit of money will buy. For illustration take the figures relating to a person's demand for potatoes given in the table on page 45 . Suppose he will buy $3 \mathrm{lb}$. a day if his income is 18s. a week, $4 \mathrm{lb}$. a day if his income is $30 \mathrm{~s}$. a week, and $5 \mathrm{lb}$. a day if 
his income is $60 \mathrm{~s}$. a week. Then, according to the figures in the table, the marginal utility of a penny to him would double if his income shrank from $60 \mathrm{~s}$. to $30 \mathrm{~s}$. and increase threefold if his income shrank from $60 \mathrm{~s}$. to $18 \mathrm{~s}$. This, you will understand, is merely a supposititious case put for illustration. Normally it might be that such changes in income would bring about greater or less alterations in the utility of money.

You are not of course compelled to distribute your income according to the law of substitution or equi-marginal expenditure, as a stone thrown into the air is compelled in a sense to fall back to the earth; but as a matter of fact you will, in a certain rough fashion, because you are reasonable. So it is correct to call your tendency to do so a law.

I have said that a person will act according to the law of equi-marginal expenditure " in a certain rough fashion". The fashion will be rough for numerous reasons. To measure preference, which fluctuates, is a delicate and perplexing task, and we may easily go astray. Again, we must recognize minimum sensibles or the utilities of degrees of expenditure about which the consumer will not trouble. A bachelor with $£ 1000$ a year will consume tobacco till its marginal utility to him is zero, because the pennies which he would save weekly by getting its marginal utility up to the general level of the marginal utility yielded him by more expensive things would not be worth the worry of deliberating. The utility of a few pence is to him below the minimum sensible. Much of the balancing of utilities which brings about equi-marginal returns, you must be particular to observe, moreover, is merely implicit. It only becomes explicit when relatively large outlays are involved. We do not ordinarily take any trouble about this balancing. We jump to conclusions without thinking about it.

The law of substitution, indifference, or equi-marginal re- 
turns, also helps to explain our actions when we decide how much to spend at one time and how much at another time. Very broadly speaking, we try so to arrange our saving and spending, cateris paribus, that we reap equi-marginal returns continuously. But into the question of providence numerous disturbing factors enter; so we must defer our consideration of this matter until we reach Chapter XXV.

Diagrammatic representation of equi-marginal returns. Let me illustrate the law of equi-marginal expenditure with a

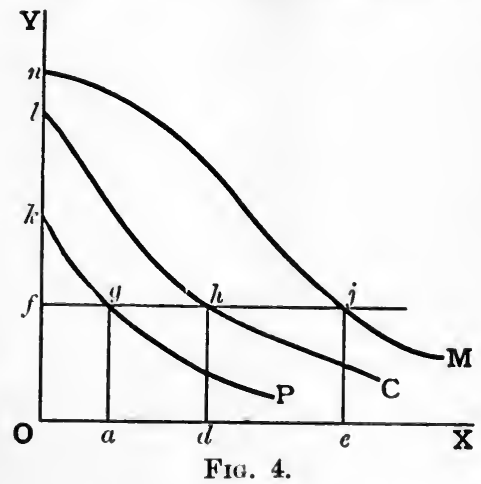

simple diagram. In fig. 4 measure units of money along $O X$ and units of utility or satisfaction along $\mathrm{OY}$. Let $\mathrm{P}, \mathrm{C}$, and $\mathrm{M}$ be curves indicating the utility derived weekly from consuming different quantities of porridge, coffee and milk respectively. Then, according to the law of equi-marginal returns in consumption, if a sum of money $\mathrm{O} a$ is spent weekly on porridge, $\mathrm{O} d$ will be spent on coffee and $O e$ on milk, because with these expenditures the marginal utilities derived from coffee and milk respectively are made equal to the marginal utility derived from porridge, that is to say $a g=d h=e j$. If the income were less, smaller sums would be spent on each article, but expenditure would still be so distributed that marginal returns were equal. 
Consumer's surplus of satisfaction.-The conception of consumer's surplus, or consumer's rent, has of late been made to play so prominent a rôle in advanced economic theory that something must be said of it even in an elementary treatise, though neither the value nor the difficulties of the conception can be fully appreciated by those who are only beginning the study of political economy. First I must deal with a matter of terminology. The doctrine has sometimes been designated indifferently that of "consumer's rent" or "consumer's surplus". I think it best to shun the use of the term "rent" in this connexion, because its use in this connexion necessitates defining "rent" in a way of which the appropriateness is questionable. I shall so define " rent" later that consumer's surplus will be excluded from the class of rents. Hence I shall speak hereafter of consumer's surplus and not of consumer's rent.

When I pay away money for anything, the marginal or final unit of expenditure is responsible only for my marginal satisfaction. The rest of the expenditure yields more than marginal satisfaction per unit of expenditure. The excess of satisfaction procured over and above the marginal satisfaction, multiplied by the amount of the thing purchased, may be called my "consumer's surplus of satisfaction". It represents what I should have lost, other things being equal, had the thing not existed. I should have lost it because I should have spent on a number of other things the money now devoted to it and should have gained from the money marginal satisfactions only, that is the increases of satisfaction got from slightly increasing my supplies of a number of other things. As regards the indeterminate utilities of indispensable supplies of things, and the relations between consumers' surpluses on substitutes and complements, the reader is referred to pages 36 and 53 .

Diagrammatic representation of consumer's surplus of satisfaction.-Let me illustrate with the aid of fig. 2 on page 31 . 
Suppose that I consume in a year a quantity $\mathrm{Oa}$ of some commodity, say strawberries this time. Let satisfaction be measured along $O Y$. Let the curve $U U^{\prime}$ show the variation of satisfaction with the amount spent per year on strawberries. It descends because of the law of diminishing utility. The total satisfaction got by me from the strawberries is obviously $\mathrm{O} a c U$. The marginal satisfaction derived from a small increment of strawberries, multiplied by the anount spent upon them, is Oacf. The area $f c U$ is my consumer's surplus of satisfaction.

If the reader has any difficulty in interpreting this figure he or she should turn to fig. 1 and after contemplating that figure think of the area $\mathrm{Oac} U$ in fig. 2 as made up of a series of very thin rectangles, standing vertically side by side, which get shorter the further their position is to the right.

The area $f c U$ is called the consumer's surplus of satisfaction derived from strawberries because it is the net satisfaction which results from my having strawberries. That is to say it expresses the difference made to my income of satisfaction per year by the discovery of strawberries, or the loss of satisfaction which I should sustain if strawberries could no longer be cultivated. This has to be proved ; and it can be proved in the following way. The utility of strawberries to $m e$ is indicated by the enclosed area in fig. 2, lettered OacU. Hence if the cultivation of strawberries be. came impossible I should lose an amount of utility equal to the area $\mathrm{OacU}$. But against this loss a gain has to be set. At any rate I should save per annum what I used to spend on strawberries per annum. Suppose I used to spend 10 s. per annum on strawberries ; then I save 10s. per annum. Now the utility obtained by the expenditure of the last shilling on strawberries is represented approximately by $a c \times \frac{0 a}{10}$, that is by $\frac{0 a c f}{10}$. And my income is so distributed according to the law of substitution or equi-marginal returns (see pages 43-8) that the marginal returns of a shilling upon whatever it is spent is the sane. Hence when I como to spend the $10 \mathrm{~s}$. that I used to spend on strawberries on other things I cannot get a greater utility for any shilling than $\frac{\text { Oacf }}{10}$ approximately. And I should so lay out the 10s., spending a little of it on each of a number of other things, that for no one shilling should I get a satisfaction appreciably less 
than $\frac{\text { Oacf }}{10}$. I should buy a few more cherries, drink some pints more of lemonade, consume a few more apples and so forth until the $10 \mathrm{~s}$. was accounted for. Hence my gain in satisfaction would be approximately the marginal satisfaction of spending multiplied by the amount $I$ save, that is an amount $\frac{\text { Oacf }}{10} \times 10$, which is equal to Oacf. But I have lost satisfaction OacU from the loss of the strawberries, as we have seen. Therefore the loss in utility from the loss of strawberries is. OacU-Oacf, that is $f c U$ which has been defined as consumer's surplus. Again in fig. 4 the consumer's surplus of satisfaction derived from porridge is $f g k$, that derived from coffee is $f h l$ and that derived from milk is $f j n$.

\section{The Measurement in Money of Consumers' Surpluses.} -Consumer's surplus is sometimes measured in money, and, as it is easy to misinterpret consumer's surplus when so measured, it will not be superfluous to say a few words about this expression of it. I pay, say, 6d. a pound for strawberries and buy $20 \mathrm{lb}$. a year. Suppose I would pay 18s. for the $20 \mathrm{lb}$. rather than go without strawberries entirely, that is to say, suppose the aggregate of my demand prices per pound for strawberries up to the twentieth pound (as shown by my demand schedule) amounts to $18 \mathrm{~s}$. Then my consumer's surplus derived from strawberries is $18 \mathrm{~s}$. less the 10s. I spend on them, that is $8 \mathrm{~s}$. I lose a consumer's surplus of $8 \mathrm{~s}$. when strawberries cease to be grown. That is to say, the disappearance of strawberries would have the same effect upon me as a reduction of my income by 8 . a year. It has been assumed in this argument that the readjustment of my expenditure would not appreciably affect the utility of money, and this assumption is permissible since the total sum spent on strawberries is small in relation to my total expenditure. Such a money measure of consumer's surplus would be inexact if I were treating of something upon which a large proportion of my income was 4 * 
laid out. But otherwise, consumer's surplus in money is the difference between what we do give and what we would give for a thing rather than be deprived of it altogether. This is manifest when the thing is a single article like a picture.

The money expression of the surplus derived by a whole community from consuming something raises new difficulties. It must, therefore, be introduced with the greatest caution. These difficulties emerge out of the circumstance that the marginal utility of money is not the same to all the people who consume the commodity, say strawberries. If the consumers' surplus yielded in a country by strawberries may be put at $£ 10,000$ a year, the loss of strawberries would have the same effect as the reduction of the national income by $£ 10,000$ a year, only on a certain hypothesis. The hypothesis is that the imaginary reduction of the national income would be effected by curtailing the incomes of people in proportion to their consumption of strawberries. However, if we take two commodities used by about the same classes in roughly the same relative degrees, and the consumers' surplus on one is $£ 6000$ a year and on the other $£ 12,000$ a year, the probability is that the community would lose twice as much through the withdrawal of the one with the greater consumers' surplus as through the withdrawal of the other. Certain important practical applications of this doctrine will become apparent in a later part of this book.

If we use the demand for a thing over a certain period as one factor in the expression of the consumers' surplus in money derived from that thing, we must be sure that units of the thing do not last longer than the stated period. The demand schedule for grand pianos in England in 1910 (if it were discoverable) taken in conjunction with their price would not show the consumers' surplus yielded by them in England in 1910, for many peoplc in England with grand pianos in 1910 would have bought them before 1910 . In a case of this 
kind it would be necessary to make allowance for the supplies of the article already in use when the period began over which the consumers' surplus was being reckoned.

Actually it is never possible to measure the whole of the consumers' surplus yielded by a thing over any period, but it is possible to measure approximately the effects of price variations upon it.

It has been objected, even to the doctrine of individual consumer's surplus, that the initial demand price for an article may be the whole of the consumer's income. Rather than die of thirst, a person would offer all that he possessed for a glass of water. We may at once agree that in a case of this kind the consumer's surplus enjoyed on the whole consumption cannot be measured, though absolute increases and absolute decreases of consumer's surplus up to a certain limit can be measured. The majority of cases, however, are not of this kind, because an article is seldom an indispensable means of preserving life or making it worth living. Deprived of cake, we can still feast on muffins and bread and butter, and deprived even of wheat we can still devise satisfactory moals by substituting for it rye, oats and potatoes. 


\section{GHAPTER VI.}

\section{VALUE, GOODS AND WEAL'TH.}

Yalue.-I have repeatedly employed the term "value". above but I have not yet defined it. Value may be value in use or value in exchange. The value in use of a thing is the utility derived from using the thing, and, as we have found it scientifically necessary to discriminate between marginal utility and total utility, we must distinguish marginal value in use from total value in use. Value in exchange means what a thing can be exchanged for. If what it can be exchanged for is stated in money, value in exchange is called "price". We have learnt that different things are bought in such proportions by different persons that the ratios which the marginal utilities of things bear to one another are the same for all the persons who buy them, and that things exchange for one another in the same ratios. Hence values in exchange are objective expressions of marginal values in use, which are subjective. Hence things that are scarce in relation to the demand for them have a high value in exchange though their total value in use may not be great. On the other hand, things which are plentiful in relation to demand have an insignificant value in exchange though their total value in use may be enormous. Some things, indeed, which are so plentiful that their marginal utility is zero, have absolutely no value in exchange. They may have immense aggregate value in use, but ordinarily we should take 
this for granted and hardly notice it, if we noticed it at all. It is only when the well runs dry that we become fully alive to the value of water.

Ethically "value in use" stands for the utility which a thing ought to have for us. It has been called "real value in use"; but this term has also been appropriated to signify the utility which we actually elicit from a thing in contrast with the utility which we expected.

Some writers have distinguished between elemental, form, place and time utility or value in use. Coal has elemental utility even when undisturbed in a coal-seam. It is given form utility when hewn and broken into pieces of convenient size. It has a maximum of place utility in the coal-scuttle by the fireside and its highest time utility in the winter.

Goods and wealth. - We are now prepared to define "wealth". It has a broad and a narrow reference in positive economics. Broadly it means anything which satisfies human wants, directly or indirectly, that is anything which has value in use. Thus broadly conceived, it is sometimes known as goods. Goods may be classified as follows :-

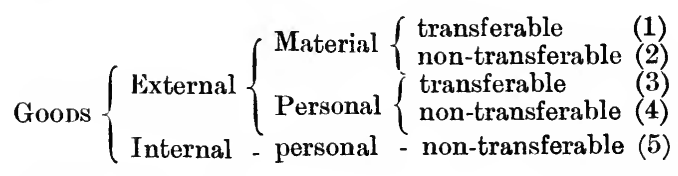

A "transferable" thing, is not always a "transportable" thing: it is merely a thing potentially eapable of being bought and sold.

We thus reach five classes of goods. A few examples will help the reader better than definitions to realize each class.

Examples of external-material-transferable goods are bread, butter, furniture.

Examples of exiernal-material-non-transferable goods are sunlight, climate, the dykes of Holland. 
An example of external-personal-transferable goods is the goodwill of a business which can be sold. This is personal because it consists in the habits of persons (the customers of the business). But, though personal, it is external to the person to whom it is wealth. It is transferable because it can be bought and sold.

An example of external-personal-non-transferable goods is furnished by so much of a business connexion as cannot be sold because it is attached to a particular person. Some of a tailor's customers, for instance, would transfer their custom to another firm when he retired, instead of dealing with his successor in the same shop. Such people are made customers by a personal connexion only. Another example is a nation's good repute.

Internal-personal-non-transferable goods consist in our powers, faculties, habits and tastes, which are of value to us - the dexterity, for instance, of violinist or carpenter.

"Wealth," I repeat, may be used as synonymous with "goods". This is its widest significance. Next in width is the conception of wealth as all goods except internal goods. It is argued for the exclusion of internal goods that it is well not to confound the customary distinction between man, on the one side, and the wealth to which his activities have reference, on the other side. More narrowly "wealth" may be understood in a variety of ways. It has been confined to the things satisfying human wants which are limited in quantity. Again it has been confined to such only of these things as are produced by labour. Yet again it has been said that transferability is an essential attribute of wealth. Nothing but convenience turns upon the dispute about what has to be included in wealth. I shall not select any particular definition, but I trust the context will always make it plain to my readers what I mean whenever I write "wealth".

We may record here the truism that external goods are 
goods only in relation to internal goods, and that many internal goods can be realized only through external goods. The value of a picture is acquired by seeing it with appreciation, and the taste for pictures affords us no enjoyment till pictures are seen. Man not only produces wealth in the ordinarily recognized ways, but also makes it in the sense in which Kant meant his doctrine that "man makes nature". The greater the appreciative power of a people the greater is their potential opulence. Shakespeare's plays are not wealth to barbarians. Education enhances appreciative power and it therefore makes wealth. In the light of this paragraph we shall at once admit the incontrovertibility of the statement that, while the demands for things create activities, activities themselves create demands for things. We shall also comprehend more fully that the value of a thing must vary with time, place and circumstances.

The notion that the attitude of man makes things recalls Ruskin's dogma that " all wealth is Life". Ruskin had in mind what men ought to want and not what they actually do want in any given stage of social development. In short his dogma belongs to economic ethics rather than to positive economics. But it is imperative to remind ourselves that people change their notions as regards the goods which are most worth having, and that progress, in one of its highest senses, is measured by the rate at which their notions approximate to true ethical conceptions. Sometimes wealth ethically conceived is called "real wealth," but this term is equivocal (p. 55) and is used more commonly in economics with another denotation (p. 58).

We may distinguish further between the wealth in which all share, which is social wealth, and private wealth, which needs no explanation. Social wealth may be such that none can be precluded from enjoying it-that is external non-transferable goods, whether material or immaterial-like a healthy 
climate and commendable social customs ; or it may be public property (transferable goods) like pictures in public galleries. Finally there is the contrast to draw between direct goods, or consumers' goods, or goods of the first order, which yield satisfaction directly, like bread, and indirect goods, or producers' goods, or goods of the second or higher orders or intermediate goods, of which class machinery is one of the largest sections. To illustrate the distinctions between goods of the second and higher orders, it is sufficient to say that a machine-tool for making machinery is of a higher order than the machinery which it makes, and that the machines which make the frying-pan are of a higher order than the frying-pan, which aids in the performance of the last productive process whereby some forms of food are rendered ultimate consumers' goods. "Higher," of course, simply means more indirectly connected with the creation of satisfaction. Goods and wealth can be at the same time direct and indirect, for instance the motor-car which takes the doctor on his rounds and at the same time affords him gratification. Personal wealth, even, may be direct or indirect or both, whether it is internal or external. Esthetic appreciation is only a direct good to those whose business is unconnected with the fine arts, but it is both a direct and an indirect good to the professional art critic.

Here I may set down that technically, in positive economics, real wealth means the goods which money wealth will buy, and real income means the goods which money income will buy.

Necessaries, Comforts and Luxuries.-Wealth is commonly classified into necessaries, comforts and luxuries, but these sub-classes of wealth have been defined in a variety of ways. Sometimes the distinctions between them are drawn from an ethical point of view. When the distinctions are so drawn, a condemnatory implication is usually read into "luxury," 
while necessaries are regarded as things essential to proper living. It is more convenient, however, for the purposes of this treatise to make the distinctions turn solely upon the reactions of different things upon efficiency. When we do this, we may divide necessaries and luxuries into two classes each, and entitle and define the four classes thus obtained, and the class of comforts, as follows:-

Necessaries of life are the things physiologically necessary to maintain existence and secure the continuance of the race. The definition is vague, observe, inasmuch as nothing is said of the average length of life to be assured and the extent of procreation. However it will serve.

Necessaries of efficiency are the things, over and above the necessaries of life, the consumption of which adds to the productive value of human agents a sum greater than the cost of - the things consumed. According to this definition, the price of an article is one of the incidents which settle whether it is a necessary of efficiency to any particular person or not.

Comforts are those things which add to a person's efficiency but add amounts which have less value than the cost of the comforts. Here again we observe that the price of a thing helps to determine whether it is a comfort or not.

Harmless luxuries are things which when consumed neither add to nor detract from a person's efficiency.

Harmful luxuries are things which detract from a person's efficiency.

The reader's attention need hardly be drawn specifically to the fact that this classification is not one which can be applied to wealth objectively. The classification has a subjective reference and a reference also to occupation. A thing which is a comfort to one person, may be a necessary of efficiency to another, and a luxury to a third. A thing which is a comfort to me at one time, or when I am engaged in one kind of work, may be a luxury to me at another time, or when I am engaged 
in another kind of work. It is worth while to notice that "harmful luxuries," as defined above, are not necessarily debilitating physiologically. They may simply induce laziness with reference to work. Golf, a most healthy form of exercise, may be a harmful luxury to some people.

Thinking in a hurry, we might conclude that wise people who realized the future, and knew exactly how their consumption would react on their efficiency, would aim merely at providing themselves with necessaries of existence and of efficiency. But we should be illogical if we deduced such a gloomy conclusion. The real income that we enjoy is the satisfaction that we get out of the things purchased with our money incomes, and the satisfaction derived from a luxury might far transcend that derived from a thing necessary for efficiency. Remember always, particularly when reading economics, that production is a means and not an end. Even the perfectly wise and perfectly good man might choose the luxury and forego the necessary of efficiency without slipping from his pedestal. He might choose to gratify literary tastes which would earn him nothing, instead of studying book-keeping though the latter might help him in his business. There is no greater mistake than to test every course of action by its effects on production, when we take up the moralist's position. It certainly cannot be said that in the world, as it is now, our highest welfare, or our welfare as we conceive it, is invariably promoted most when we do what magnifies our money income most. Remind yourself on reading this paragraph that political economy as a positive science recommends no course of action. It merely explains people's actions in a certain field and points out the effects which succeed different courses of action.

It follows from certain of the considerations advanced above that, though it would pay a slave-owner best, from the monetary point of view, to give his slaves necessaries and nothing more, 
the wage which it is most advantageous for the employer to pay is not to be taken as an amount sufficient only to provide necessaries of existence and of efficiency. It is not likely that the wage-earner would spend the whole of such a wage on necessaries of existence and necessaries of efficiency. In fact he would certainly not do so. At least a few comforts and luxuries would figure in his consumption. Hence some economists recognize conventional necessaries. By "conventional necessaries" they mean any things which a person will insist on buying before he has completed his supply of necessaries. Tobacco is to many a conventional necessary. Most men, however poor, will buy some tobacco. Conventional necessaries are recognized because they must be taken into account when we try to discover what wage will keep the operative at a level of efficiency which, in view of the wage, is most economical from the standpoint of cost of production. To avoid misinterpretation of this paragraph, I must add that neither conditions of efficiency, nor what employers would like, settle wages though they may enter into their determination. 


\section{BOOK III. \\ PRODUCTION OR SUPPLY.}

\section{CHAPTER VII.}

\section{NATURE OF PRODUCTION AND THE AGENTS OF PRODUCTION.}

What is production ?-Producing is making utilities. Widely understood it covers:-

1. Obtaining from land or sea, rivers or lakes, things which grow-farming and rubber-planting, fishing and sealing, for instance.

2. Obtaining from the earth, air, or water, things which do not grow in the ordinary sense -coal-mining, diamond-seeking and salt-mining, getting power from the wind, and nitrates from the atmosphere. Some of the things obtained are taken from stores which can be used up; others are not.

3. The manufacturing or making-up of things.

4. Transporting things.

5. Arranging for the distribution of things as opposed to their transportation-i.e. the performance of the commercial functions of disposing of goods among those who want them.

6. The direct furnishing of services to consumers-domestic service, singing and acting.

Certain comments are needed upon this tabulation. We have not distinguished between things and the natural powers 
by which their acquisition is facilitated. The reader may bear this distinction in mind, remembering, however, that it is not always easy to draw. Is coking-coal a thing or a natural power? There is no essential difference, from an economic point of view, between manufacturing power out of the Falls of Niagara and manufacturing petrol.

It is of value for some purposes to separate the industries which simply gather natural products from those which cultivate what they gather. An orchid-seeker pays no regard to future supplies. A deep-sea fisherman does, and is careful not to over-exhaust a particular fishery, especially at breeding time. But the deep-sea fisherman does nothing active to cultivate a fresh supply. The farmer, on the other hand, does; he breeds live-stock, and ploughs and harrows his land, and sows seed.

By the extractive industries we mean those which take away from a stock which can only be reproduced, if at all, after a very lengthy period. The mining industries are the chief extractive industries. Fishing need not be regarded as extractive, since the food supply for as many fishes as we are likely to want is practically inexhaustible. Farming is not classed as extractive because the elements taken out of the land by a crop can be restored. Land which is carefully worked, and allowed occasionally to lie fallow, is continually brought back by the forces of Nature to its original state after being exhausted by each harvest.

Industries which obtain power from water and air are peculiar in that they tap a recurrent supply, the amount of which in the future is not affected by its use in the present. The use of the potential power stored in a high-level lake is, of course, an exception.

Quite narrowly interpreted, to the exclusion of the direct furnishing of services to consumers and of commercial work, " producing " is applied to the operations needed to get a thing, 
other than mere gathering. So farming would be producing, but not deep-sea fishing.

The economics of production comprises the scientific observation and analysis of the manner in which wealth is created, and the drawing of generalizations relating to it. The creation of wealth, liberally conceived, involves the performance of commercial functions as well as others. Commercial functions are the functions of buying and selling, and bringing goods to the notice of customers, and anticipating consumers' demands and conditions of supply; whereas industrial functions, broadly regarded, are the functions of growing, extracting or manufacturing anything. Commercial work is inseparably connected with industrial work. Industry is broken up into parts and the parts are united by commercial links. A firm manufacturing machinery spends energy in seeking out and buying materials and in discovering where machinery is wanted and arranging for its sale. The end of production is to give to the ultimate consumers things that they want when they want them; and mere manufacturing, farming and mining, do not alone bring this end about. When we glance at production as a whole we at once detect that it consists in the growing, extracting and making of things-in industry as we have said-and in arranging that the things made, and the things used in making them, shall be appropriate to the needs of the community, and shall be so distributed that each person, as consumer or producer, shall be able to purchase with the means at his disposal what he wants most rather than what he feels indifferent about-in commerce, as we have already decided to call it. The word "person" in this statement must be held to cover associations.

The actual carrying of things over sea and land, that is transportation, we include under industry or the making of things. So to include them will not seem inappropriate, 
since production even in a factory consists to an appreciable extent in the transporting of things. Ultimately, indeed, producing means merely assembling different things in certain relations. To determine where to carry things, so far as the carriage takes place outside works, fisheries, farms or mines, is one of the functions of commerce; and we may observe here that the decision where to carry things may be formed before they were produced as well as after.

There has been much profitless hair-splitting over the question what is, and what is not, productive labour. What is productive labour, depends upon what we mean'by production. If by production we understand simply the creation of tangible things, or things that contribute to the making of tangible things, direct services performed for consumers, in so far as they do not contribute to the efficiency of such people in production, thus narrowly conceived, must be designated "unproductive". But, broadly, all is productive labour which yields, or is intended to yield, something of value. It embraces all services which we are prepared to pay for. If we make the distinction between productive and unproductive labour turn on results, labour which has been misapplied so that it is wasted is unproductive. If a company started to cut a canal, and was then compelled to desist because the project was not feasible, the labour already expended would have been unproductive. But the intention was not to use labour unproductively.

\section{Manufacture specializes the possible uses of materials.} -Each stage of production limits the possible uses to which anything that is being worked up can be put. Raw cotton may be made into fine cotton wool for surgical and dental uses, sewing cotton and a multitude of different things. When it is spun, its possible use as cotton wool is eliminated, and, according to the tenuity, toughness and twist, of the yarn produced, so is its possible introduction into certain fabrics 
and sewing cottons. When it is woven, its use as sewing cotton is eliminated, and also its use for fabrics of other qualities. As a fabric it can still become many different articles; but finally as a cotton shirt, say, it is specialized to one purpose or a very few purposes.

Suppose we represent some material (for instance wheat or iron-ore, or cotton) by the letter " $\mathrm{X}$ " and the possible consumers' or producers' goods which $\mathrm{X}$ can become by the small letters of the alphabet. Suppose, moreover, we represent a manufacturing process by " $M$," and the performance of a manufacturing process on $\mathrm{X}$ by multiplying $\mathrm{X}$ by $\mathrm{M}$, so that $\mathrm{XM}$ means material after undergoing one manufacturing process and $\mathrm{XM}^{2}(=\mathrm{XM} \times \mathrm{M})$ means the material after undergoing two manufacturing processes, and so on. Then we may represent the specialization of the possible uses of a thing, as it passes through stage after stage of manufacturing, as follows :-

The possible uses of $\mathrm{X}$ are $a, b, c, d, e, f, y, h$.

$\begin{array}{llll}", & , & , & \mathrm{XM},, a, b, c, d, e, f . \\ ", & , & , & \mathrm{XM}^{2}, ; a, b, c, d . \\ " & ", & , & \mathrm{XM}^{3}, a, b, c . \\ " & , & , & \mathrm{XM}^{4}, \quad a, b .\end{array}$

One significant conclusion which follows from this analysis of production into processes is that an immense change can be brought about in the proportions of different finished things in a given community by an alteration of the last stage of production alone. The re-arrangement of production which is rendered essential by changes in demand or in conditions of supply need not as a rule be carried far back in the chain of productive processes; and as re-arrangement reaches back so usually it becomes more trifling. This conclusion has an important bearing on the responsiveness to demand of a community on its productive side. It has been said that when 
production becomes complicated, differentiated and roundabout, so that the making of a pocket-handkerchief involves the raising of coal, smelting of ore, construction of machinery of many sorts and so on, society is rendered less adaptable to modifications in demand, because altering the supply of pockethandkerchiefs means altering so much in the productive system. That this view needs qualification the above analysis renders patent. Moreover many productive instruments can be devoted to more than one purpose. No illustration of this point is requisite. Think of the variety of work which can be done by any loom, or sewing machine, or lathe.

Joint and alternative supply. - Things may be produced jointly in a fixed or a variable ratio; and a thing produced jointly may have another source of supply where it may be produced independently or in a different joint relation. Wool and mutton are produced jointly, but we may breed for mutton or for wool. Wheat and straw are produced jointly, but there are other kinds of straw besides wheat straw. Gas and coke are produced jointly, but in some places there is natural gas stored in the earth which can be tapped.

Alternative supply is found wherever a set of factors can produce more than one thing though only one thing at a time. This has been illustrated above. A loom may turn out fine cloth or rough cloth. The principle of substitution settles to which purpose the loom is put.

Notice the affinities between joint and alternative supply on the one hand and joint and alternative demand on the other hand (p. 28).

The Agents in production and their efficiency.-The absolutely indispensable agents of production are labour and land. For convenience "land" is to be understood comprehensively to denote the whole of animate and inanimate nature, exclusive only of human beings; which is of any use 
economically. It is, however, usual to say now that the agents of production are land, labour, capital and enterprise, though to exercise enterprise is to labour and though capital is not an original, irreducible, element in production. When among the agents in production labour is distinguished from enterprise, "labour" means executive power and "enterprise" means initiating, directing and designing power.

Under primitive conditions the executive agent must direct himself. When he does so he is both labour and enterprise. A few workmen still direct themselves, even in advanced industrial communities. Nevertheless, on the whole, modern industry is initiated and directed by other persons who (1) on the one hand decide what undertakings to start and on what scale, and start them and govern their policy-and thereby exercise what is known as the function of undertakers, entrepreneurs, or "enterprisers" as the Americans put it-and (2) on the other hand plan the methods of producing the things decided upon, organize and direct the production, and establish and maintain relations with the markets for buying and selling-and thereby exercise the function of managers. The second function splits up into two, namely industrial managing and commercial managing, as we have already remarked. The first function, too, may be conceived as having an industrial side and a commercial side. We must remark also that the duties of undertaking and the duties of managing shade off into one another. Commonly entrepreneurs are the ultimate managers; but, as recent specialism has brought to the front a class of business men who are almost solely undertakers or entrepreneurs, it will be as well to use "undertaker" or "entrepreneur" with a connotation exclusive of the detailed managing of a business as contrasted with the laying down of its policy.

In the problem of the supply of labour of different kinds, including directing labour, we shall be involved when we come 
to explain rates of wages (pp. 309-13). So nothing need be said of this problem in the present chapter. But upon the nature and determinants of the efficiency of labour a few comments may be ventured.

Productivity is measured by the value of what is produced. Other things being equal, therefore, the more a community succeeds in discovering and developing the most valuable powers latent in its population the more efficient will it be. An educational system, which is such $(a)$ that the potential ability of each child is disclosed and $(b)$ that capacity and character are elicited and appropriately trained up, is highly productive. In addition the productivity of a community is determined by the way it acquits itself in placing persons at the work most suited to them.

The economic value of labour is a function of physical strength and endurance, health, rapidity of action, skill, resourcefulness, intelligence, perseverance and even of trustworthiness. How the demand for some of these qualities is being affected by progress we shall observe later (pp. 85-8, 325). Under speedily changing conditions, adaptability is also of importance-may be of paramount importance-in certain callings.

The efficiency of labour is governed by climate, the home life, the duration of work, wages and their spending, and labour's outlook. A cool bracing climate is invigorating. Work which is interesting is educative; work which is monotonous, or very heavy, or very tiring, devitalizes the labourer in physique, character and intelligence. Gloomy surroundings, polluted air, and insanitary conditions about the place of work or the home, breed listlessness if not actual disease. Much social betterment work is, evidently, productive, even in the narrow sense, as well as in the broad sense of adding to the amenities of life. Wages and their spending have obviously a direct bearing upon efficiency, as we have 
already noticed on pages 58-61. The outlook of people also has an influence on their effectiveness, subtle but potent. The ambitious operative, devoid of prospects, is apt to work without spirit. Hopefulness inspires men to contribute of their best.

Hereafter I shall have to lay stress on the requirement that production should be appropriate to the needs of society. Production is only kept thus suitable when it is responsive to changes in demand. A condition of its ready reaction to such alterations is that provision should be made for bringing the factors in production speedily to the places where they are most wanted for the purposes dictated by demand. Hence the need of geographical and trade mobility of labour. The expression defines itself broadly. These kinds of mobility may be called horizontal and contrasted with vertical mobility, signifying movement of individuals between grades of labour, of which I shall write more fully on pages 309-13. The relative sizes and local dispersion of different classes and sections of labour may be modified through the training and geographical disposal of the rising generation.

Geographical factors may contribute lavishly to a country's riches. But I must not attempt to enumerate exhaustively the natural agents and conditions, exclusive of labour, which are of service directly or indirectly to the human race. It is better, other things being equal, to have fertile than unfertile land: and a climate which ideally fosters crops without debilitating human beings, and stores of coal and ore, and waterpower and fisheries, are endowments secondary only in worth to a sturdy and gifted racial stock. The accessibility of a country's natural resources is, again, of consequence, as are also its geographical circumstances relating to facilities of transportation, immunity from catastrophes having a natural origin (such as earthquakes and floods), and security from foreign aggressions. 


\section{CHAPTER VIII.}

\section{CAPITAL.}

ALL will agree that capital is an agent in production, though it is not an original element, but all will not agree as to what capital is. The term "capital" is current in distractingly discordant, though related, senses. It has not been found feasible to harmonize them in an all-embracing conception which sacrifices none of the popular ideas associated with the term.

Provisionally, in considering what is capital, I shall ignore so-called personal capital, in order that our discussion may not be harassed at the start with more perplexities than we are absolutely compelled to admit. Ultimately I shall weigh its claims to inclusion.

Capital may be regarded from the social and from the individual point of view. We shall commence our researches from the social point of view.

What is social capital?-(a) I examine first the view that social capital consists in instrumental goods. Capital, none will dispute, is correlative to income. It implies both productiveness and prospectiveness. It is wealth which yields an income, or aids in the production of an income, or is intended to do so. This highly indefinite statement is sufficiently exact to begin with. Nobody denies that factories and machinery, cargo-vessels, fishing-smacks and grainelevators, manure and the drainage of farms, and vertical holes in the ground leading to coal-measures, are a part of 
social capital. These things constitute, at least by virtue of their main purpose, wealth used in order to produce more wealth or to earn an income of wealth. To the extent to wh ch they are so used, they are the goods of the second and higher orders (see p. 58), which have been called instrumental goods. Their peculiarity is that their value is indirect.

But when we come to scrutinize these goods minutely we become aware that some of them have direct as well as indirect value; that some of them serve occasionally as goods of the first order. I may instance the ship which carries cargo but at the same time passengers, some of whom are simply at sea on a pleasure cruise. Such a ship is both an instrumental good and a direct good. And when this vessel enters a harbour and comes into one of the dock 3 , is the dock wealth of the first order or wealth of one of the higher orders? When the tourists land it is wealth of the first order, but when the other passengers land, and the cargo is got out, lo! it becomes an instrumental good.

Hence we are driven to recognize that instrumental goods and goods with direct value do not make up mutually exclusive classes.

(b) To be strictly logical, then, we must admit, it would seem, that the use, or intended use, of wealth settles whether it is capital or not, if we insist on clinging to the idea that capital must be instrumental. The distinction between capital and other wealth becomes fundamentally a psychological one. If I eat my breakfast with my attention concentrated on what I have to do afterwards, and say to myself as I eat it "I must make a good breakfast because I have heavy work to do this morning and I don't know at what time I shall get lunch," my breakfast is indubitably capital, since it is eaten with a view to my productive efficiency. But even then there will remain a dash of non-capital wealth about it if $I$ have not succeeded perfectly in sinking the epicure in me. Whether 
wealth devoted to production which fails of its purpose may be called capital after the event, is a puzzle which I leave the reader to solve after referring him to page 65 .

(c) By a natural transition we are next brought to the view that all wealth is capital because all wealth affects income. Some writers escape the conclusion that strictly the ground of distinction between wealth and capital is a psychological one-to wit the intention which underlies each act in consuming wealth-by approaching the question of what constitutes capital along another road. They put the problem in this way: Taking the members of a community just as they are, with their attachment to luxuries, their providence and imprudence, what part of their wealth is a direct or contributory cause of the magnitude of their future income? Any part of their wealth, in the absence of which future income would be less, these writers call "capital". The answer which they find to their interrogation is that no part of existing wealth fails to exercise a favourable influence upon future income directly or indirectly, except in so far as the community made mistakes in the past and acquired things which they would rather be without, an exception which for general purposes we may set aside as over-subtle. Hence all woalth is social capital.

The reason advanced for this judgment is as follows. If a community were deprived of some of its existing direct wealth, it would straightway insist on producing it, or something similar to it. To do this would involve some diversion of labour from the manufacture of things which are a direct aid to production, and the diminution of these aids to production would cause a diminution of future income.

A reference to primitive conditions will make fully comprehensible this identification of capital with all external wealth. We ask "What was capital to Robinson Crusoe?" meaning by his capital that part of his wealth which helped to make his income high. The answer is, generally speaking, all that 
Robinson Crusoe possessed. If he had not saved a store of food one year he would have had to collect food somehow the next year, instead of fashioning the plough to which he then devoted some of his energy. If at another time his furniture lacked a chair and table, he would have made them instead of constructing the canoe which on its completion raised his income. It is evident that Robinson Crusoe's future income at any time was a function, as the mathematician would put it, of all that he owned.

(d) Other writers reach the same conclusion that all wealth is capital by yet another path. They argue that all wealth is capital because it produces utilities. If capital is everything that produces income, and real income is utility or satisfaction, and all wealth yields utility mediately or immediately, they maintain that all wealth must be capital. The distinction between capital and income, as it strikes them, is the distinction between the present value of wealth regarded as a stock (which is capital) and the value of the utility which accrues to the community periodically, that is from year to year according to customary reckoning (which is income). $\mathrm{My}$ piano yields me an annual income of utility out of the music that I get from it. The value of the piano as capital is the sum of the discounted values of the incomes yielded by it for as long as it lasts. So a loom yields an annual income, primarily of textile goods but ultimately of their utility, out of the aid that it is in production. The value of the loom as capital is the sum of these annual receipts, discounted, for as long as it lasts. This notion of capital is clear-cut and leaves nothing in doubt from the point of view of classification. But does it at the same time happen to be the most serviceable conception? the reader should ask himself.

\section{Are free gifts of Nature and personal wealth, social} capital? - In connexion with these four broad conceptions of capital it now remains to ask two questions:- 
Are agents which are free gifts of Nature capital? On every principle of defining capital discussed above some natural agents would be admitted into the class of capital, provided that goods unmixed with labour were not ruled out, as they would be if we declared that nothing but wealth could be capital and that all wealth was produced by human endeavour. Observe that we could not make use of the time-worn phrase, "land (meaning natural agents), capital and labour are the factors in production," were natural agents a part of capital. If you decide that capital should embrace natural resources you had better make a point of designating them "natural capital".

Can any wealth which is personal, that is which resides in individuals (see p. 55) be social capital? Natural endowments of capacity should hardly be reckoned as capital if external natural agents are not so reckoned. We had better resolve to reject both, on grounds of convenience. But consider the following case. As I spend wealth in making a typewriting machine so I may spend wealth in training myself to be a typist. If the type-writing machine is capital, is not my acquired type-writing dexterity capital? The affirmative response is logical; but as our attitude to the dead metal in which type-writing power is embodied (that is a type-writing machine) must be different from our attitude to the conscious, volitional organism in which type-writing dexterity is embodied (that is the typist), it complies with the requirements of social science, to mark a boundary line between machines and skilled operatives in some, at least, of our classifications. So, if you like to call the typist's dexterity and similar wealth "capital," let us agree to entitle it "personal capital".

Industrial Capital.-The reader will probably complain that political economy is for ever creating perplexities which the plain man never feels ; and political economy certainly does share with philosophy and all sciences the merit of casting doubt on things ordinarily passed unquestioned, and of com- 
pelling the student to form judgments for himself. He must decide for himself what view to take of capital. The next paragraph may, however, remove some of his embarrassment.

For practical ends it is desirable to introduce the term "industrial capital" and consent to a conventional definition. I should make the class of industrial capital a part of the class of non-personal goods which have been produced by labour. Of the latter I should include all purely instrumental goods and all things which are being used wholly as instrumental, or in the main as instrumental and only incidentally as consumers' goods, like cargo vessels which carry a few passengers for pleasure. On the other hand I should exclude all consumers' goods, pure and simple, and all things which figure in the main as consumers' goods but incidentally as instrumental or producers' goods, like private motor cars which sometimes whirl their owners away to business. Where there was appreciable division of function, as in the case of railway trains which convey numerous holidaymakers, in addition to people travelling to make a living, I should frame a rough estimate of the division, if I were making an enumeration of the industrial capital in a country. The things under dispute could not bring about a high percentage of error in the total. "Industrial " is, naturally, to be understood broadly to cover agriculture and all production.

Classification of social capital.-Social capital has been divided into:-

(1) Auxiliary capital, which covers everything productively auxiliary to consumers' capital.

(2) Consumers' capital, on which consumers live while producing. Machines and factories are auxiliary capital, while houses, clothes and food are consumers' capital.

Social capital has also been divided into :-

(1) Fixed capital, which serves a purpose continuously like machines. 
(2) Circulating capital, which serves its end but once, like leather, which, when made into boots, is no longer material for making into leather goods.

Social capital has yet again been divided into:-

(1) Specialized capital, which is suited only for a single use or a very limited range of uses. Examples are afforded by combing machines and blast furnaces.

(2) Unspecialized capital, like factories which are suited for more than one industry, and railway trucks which can carry goods of many sorts. Specialism is naturally a matter of degree.

Private capital.-Private capital is capital regarded from the individual point of view. Upon its nature I shall not descant at any length. An individual's wealth consists in his possession of goods, or share in their possession, and in his claims to goods represented, for instance, by money. The goods of which he owns the whole or the part comprise :-

(1) Personal goods.

(2) Non-personal goods used, or intended to be used, instrumentally, which must be capital to him as well as to society.

(3) Non-personal goods used, or intended to be used, as consumers' goods, $(a)$ by himself, or $(b)$ by others on payment of a consideration to him.

Non-personal consumers' goods for sale, or hire, or actually hired out, are indisputably capital from the individual point of view, because their owner gets no direct satisfaction out of them but utilizes them, or intends to utilize them, to furnish him with an income. Non-personal consumer's goods which are being consumed by their owner have been dealt with in the discussion on social capital. So also have personal goods, but we must add now to our previous treatment that external personal goods, like the good-will of a business, which have an exchange value cannot logically be torn away from the class of private capital. 
Money is potentially what it will buy. Looking at it in this way, we cannot declare whether it is capital or not to its owner until we have decided what constitutes social capital, and perhaps not until we know the purpose for which the money is intended. If it serves as a working balance for its owner's business it is certainly capital.

An individual's "business capital" has a perfectly definite meaning. It denotes $(a)$ his money devoted to business, $(b)$ his goods which are used instrumentally, and $(c)$ his consumers' goods which he lets out to others for a profit or intends to sell. We dissever from his business capital the consumer's goods used by himself and his money which is not allocated to business. Whether you call these possessions, barred out from business capital, "capital" of another kind or not, is hardly a matter of vital significance. All that a man has is, of course, potentially business capital to him, because he can dispose of all that he has (except a minimum needed for subsistence till an income accrues to him) and devote the proceeds to business. An individual's circulating capital is all his business capital which does not consist in premises and plant.

Production with capital is a round-about process.On contrasting production with capital and production without capital you will find that the former involves getting things in a roundabout fashion. The first hunter chased his game, or lurked in ambush, and killed it when within reach with any handy substance of sufficient hardness. In the next stage of civilization the hunter, we may imagine, spends some time fashioning a rough stone implement beiore setting out in search of game. In short he aims at getting the game in a roundabout manner. When he does this he is having recourse to instrumental capital. Or, if we like to take capital in a broad sense, we may say that he has recourse to capital as soon as he begins to consume the store of food set by to 
maintain him while he makes his stone implement. In a more advanced stage of civilization man's method of procedure becomes even more roundabout. He begins his hunt, so to speak, by mining for ore, which he afterwards smelts and shapes into weapons of the chase.

The peculiarity of a community working with much capital is not that it has laid by large stores of consumable commodities for future use. It will produce most of its consumable commodities as it goes along. Its peculiarity is that a large percentage of its people are engaged in making instruments, and the things of which instruments are made, and in repairing and setting up instruments. By "instruments" I mean instrumental capital, fishing-boats, machinery and factories and industrial plant of all kinds. In such a community those engaged directly in turning out consumers' commodities are lavishly supplied with mechanical aids. Contrasting such a capitalistic community with a community of the same size without much capital, we discover that most of the population of the latter produce consumers' goods, but turn out a smaller quantity than the former, though far fewer of the population of the former community are directly employed in making consumers' goods.

It goes without saying, nevertheless, that we must not conceive of all economic advance as rendering production more roundabout. Many important inventions are important because they show us short cuts in production and consequently abridge the productive process. These inventions are improvements on previous mechanical ideas. Each step in the assumption of new tasks by machinery, however, renders production more indirect or roundabout; and, generally speaking, the elongating effect of invention on the productive process has more than offset its curtailing effect.

A process is not more economical because it is more roundabout. But it happens that the more economical ways of 
doing things are frequently the more roundabout. And we naturally apply first the least roundabout of the ways of doing a thing with which we are acquainted, other things being equal. The peculiar economies associated with the use of machinery will be brought out in Chapter IX. 


\section{MACHINERY AND DIVISION OF LABOUR.}

\section{The economies of substituting machinery for la-} bour.-Why does it pay to use any engines, machinery or implements at all? It pays for the following reasons :-

(a) The stupendous forces of nature can be pressed into the service of man when engines exist to transmit them and machines for them to drive. A vast amount of highly valuable work is now done for the performance of which the strength of the most powerful animals would be totally inadequate; and for the application of animal, other than human, forces to production mechanical appliances are equally indispensable.

(b) For much work human limbs are insufficiently rigid or insensible, or are not untiring enough or delicate enough.

(c) Machinery can work faster than human limbs can move.

(d) Machinery works more accurately than the human being, because a machine exactly repeats its movements, whereas even the most dexterous operative cannot depend upon exactly repeating his movements. In the power-loom the shuttle is hit with the same force at every stroke; so the tension on the weft is kept always the same and the fabric comes out even. No hand-loom weaver could throw the shuttle with the same velocity every time, or, after the invention of the fly-shuttle, give always the same jerk to the picking-peg which makes the hammers hit the shuttle. To test this conclusion inductively, compare pieces of hand-loom 
fabrics and power-loom fabrics in respect of the regularity of the web.

But just as some machine production is superior to handwork, so some hand-work is superior-almost infinitely soto machine work. The most pleasing pictures cannot be produced by machinery. However, to the objection that the use of machinery banishes artistic quality from our products, and therefore undermines taste, and brings about ugliness in our surroundings, it may be replied that the bad effects are not caused by the proper use of machinery but by its abuse. Little artistic feeling can be expressed in making plain druggets, sackcloth and kettles. And machinery can repeat artistic designs cheaply, and thus bring them within the reach of the masses. Where the line should be drawn between this mechanical reproduction and the production of original artistic work of his own by the artisan, each community must decide for itself and express through demand. This matter raises issues which will be discussed in the concluding section of the present chapter.

What becomes of the displaced labour?-When the production of anything is made easier by the introduction of labour-saving machinery, what becomes of the labour no longer required to turn out the article in question in its old quantities? Thus, suppose a community used to buy 100,000 pairs of stockings a year and 1000 hands were engaged in making them. When a machine was introduced which enabled the 100,000 pairs of stockings to be turned out by 500 hands, what would become of the remaining 500 hands?

Ultimately, if not immediately, the whole of the 500 would be found active in production for the following reasons -

(1) After the appearance of the labour-saving machinery stockings would be cheaper and more than 100,000 pairs a year would be bought. Conceivably, as much labour as before, or even more than before, might be engaged in 
making them; and in any event less than 500 hands would be dismissed.

(2) Extra labour might be needed for machine-making for the stocking industry. However, we must allow that it might not, as the new machinery might be so simple that less labour would be called upon to construct new machinery for the larger output of stockings than was called upon to construct the old machinery for the old output.

(3) Any displaced labour which was not absorbed by machine-making would be used to provide other goods (hats and ribbons and rides in hansom cabs) which could not be got before because everybody who worked was fully occupied in producing what people then succeeded in getting. Most people would be found ready to be better off if they could see their way to it.

(4) Even if we argue on the absurd hypothesis that all people were surfeited with their real incomes before the introduction of the labour-saving machinery, it will be found that any displaced labour would still be re-absorbed. It would be used to provide more leisure for the rest of the community. So the case is identical with that just considered. People would buy more leisure if they would not buy more commodities. It is true that the work to be done could be done by fewer people than before, but these fewer people would refuse to work as hard as they did before. Their earnings would buy more, and as they wanted no more commodities they would buy more leisure, that is to say they would work shorter hours. Actually, people would probably buy a few more commodities and a little more leisure.

(5) The imaginary case could be put, in response to the last argument, that the operatives might continue working the old time, but save their additional wages instead of spending them. But the savings when invested would employ labour, as they would also when hoarded, since it is tangible valuables which have been produced that are hoarded. 
The whole of the above reasoning has reference to the effects not merely of machinery but of all inventions which cause a reduced demand for labour for some particular purpose.

For a time some operatives may lose their places when new machinery appears. But new inventions are slowly adopted as a rule, and at first, owing to their imperfections, the saving in labour effected by them is usually small. Moreover it must be remembered that a re-direction of the labour of the rising generation alone can bring about great changes rapidly, especially in a growing society. An unrecruited industry shrinks at an increasing pace, and in a decade its shrinkage must be considerable. The amount of labour displacement, if any, caused by new machinery depends upon the rate at which the new machinery is introduced. The duration of the unemployment caused, if any, depends upon the powers of enterprise and capital to respond to a new situation, and people's capacity to adjust themselves to new trades.

Economies of specialized labour and machinery.Specialism is sometimes spoken of as "division of labour," for traditional reasons. But "specialism" is perhaps the more appropriate term now that machinery bulks so portentously in a modern economy. If the term "division of labour." is employed, it must be understood that "labour" stands for" processes and that division of labour covers division of machinery, so to speak.

Consider first the produclive advantages of specialized labour. The man who undertakes many offices never acquires expertness at any one. If he forms habits of working, they never become thoroughly ingrained. Usually he has to keep on thinking how to execute each task, and therefore he works slowly and laboriously and wastes energy. If you ride a bicycle, contrast your early struggles to ride with your performances after the habit of riding became fixed, and you will fully realize this 
economy of specialism. Again the man who has inany duties assigned to him wastes time in passing from one job to another.

Enough has been said to show that the productivity of labour should rise as labour is specialized. But before leaving the advantages of specializing labour I must remark that tho specialization of labour may lead to inventions which inaugurate further economy. Specialized labour in contracting a habit tends to abbreviate a productive process and reduce it to a co-ordination of a few simple movements. So it mechanizes processes and renders it possible for machinery to assume them. Moreover specialized workers who can concentrate their attention are more likely to hit upon mechanical ideas than workers whose attention is diffused.

Now consider the economies of specialized machinery. Think of a machine as a de-humanized man and you will at once apprehend that "division of machinery" as well as division of labour must help production. A sewing-machine adapted for hemming cambric handkerchiefs and sheets cannot be particularly appropriate for either class of work. And time is wasted when the sewing-machine is turned from the one class of work to the other and re-adjusted accordingly. Clearly specialized machinery must be more productive than unspecialized machinery. The former is more closely adapted to its ends and, when there is enough for it to do, it can be worked more uninterruptedly.

Effect of specialization and machinery on labour.The productiveness of a method of production is not the sole test of its value. To get many commodities is not the only end of life. It might, in the best sense, pay a community to reject the most productive method of making something because it degraded human nature.

Adam Smith said that in his day a workman in a pin-factory made the eighteenth part of a pin. One of his critics 
commented that the man was made worth the eighteenth part of a pin in being confined to such a limited task. Was the critic right? It is certainly important that we should inquire-especially in view of the minuteness of specialization in modern industry-whether human nature is degraded by specialization. But this is not a question upon which an economist is necessarily qualified to offer an opinion. The issues involved are largely psychological and social. So my aim here must chiefly be to indicate the considerations to be weighed. When I pass judgments I shall be speaking tentatively.

The division of labour which makes work mechanical robs it of interest. But it has been remarked that the man may think at his work, if not about his work, provided that it is not very exhausting. The lively intelligence of many of the old hand-loom weavers was commonly recognized. Apart from any compensation of this kind, however, work which is merely mechanical must be narrowing. But we must not jump to the conclusion that specialization which restricts the sphere of a person's attention is therefore narrowing. It does not necessarily render work more mechanical. Intensity of interest may take the place of extensity of interest, and the former may arouse intellectual powers which were unresponsive to the latter. When a man toils at some special detail of a manufacturing process, he may find in it an amazing intricacy which has a fascination; and only he who sees this intricacy can discover how to improve the process. It must, however, be confessed that the rank and file have lost something in so far as specialization has taken from the artisan the need of being an artist. Whether this is to be deplored or not, from the point of view of society as a whole, raises questions outside the special domain of economics. Is it good that a Van Dyck should have his paints, canvases and brushes prepared for him? When painters gave up the artisan part of 
their work, specialism created a number of new non-artistic offices. But the world is the richer in great pictures.

Fortunately the mere fact that a particular task is mechanical, in the sense that it demands the constant repetition of some few simple movements, renders it likely that a mechanical contrivance will be invented for its performance. But inventions do not as a rule, in their first shape, at once eliminate all mechanical work. Indeed they sometimes create a need for the tedious repetition of certain human actions to supplement them,- -consider, for instance, feeding and receiving deliveries from semi-automatic machines. Generally speaking, I should say that invention in its first stages, while calling for some labour of greater intelligence than that which had previously been employed, frequently entails a certain amount of work for which a very low grade of labour is efficient enough. Through improvements, however, it is likely that much of this work will bo assigned eventually to machinery.

The adoption of machinery invariably causes some substitution of intelligance for dexterity. The person who was in effect a machine by reason of his dexterity gives place to one who can understand and direct a mechanical process. In a mэchanical age the demand for labour tends increasingly to take the form of a demand for capacity to control machinery, that is for specialized mechanical skill of a kind which implies both general intelligence and powers of adaptation. Machinery alters fast and the operative's understanding must keep up with its evolution. Machinery calls for more trained intelligance, less dexterity on the whole, and, in transitory phases of development, for much labour which need not possess either intelligence or dexterity. The most significant thing is the usurpation by intelligence of the position originally held by dexterity (which means the man-machine).

I must add, lest this argument leave one-sided impressions, that, in striking a balance between the advantages and disad- 
vantages of machinery, both objective gains, in increased tangible income, and subjective gains or losses, in terms of the satisfaction derived from work, must be taken into account. The objective gains are immense.

Some people are still only half-reconciled to production with power-driven machinery because the conditions of life which prevail where its conquests are most complete-the conditions of life in huge dreary towns in the midst of smoke which destroys vegetation and intercepts the sun's lightare peculiarly repugnant to them. But these depressing conditions are removable. Smoke-consuming devices are becoming less costly. We are awakening to the possibility of making industrial towns beautiful. And the interweaving of transportation facilities, combined with the standardization of machinery, is constantly magnifying the relative economies of producing many things away from the very large towns. To-day when machinery breaks down standardized parts may be sent to take the places of the parts which have given way. 


\section{CHAPTER X.}

\section{THE GROW'TH AND SPECIALIZATION OF BUSINESSES.}

I HAVE outlined the nature of production in my three previous chapters, but some detail has yet to be picked out in my rough sketch. Looked at more closely, production is discovered to be divided up into industries and each industry into businesses. There are the industries of dairy-farming, herringfishing, boiler-making, boot-making, and so on. And constituting these industries are multitudes of businesses.

Despite conventional usage, I am going here to use the terms "a business" and "a firm" as perfect synonyms, and apply them in all industries, whether farming, manufacturing or what not, unless another meaning is implied by the context when I speak of a business.

I want now to draw attention to certain features of these small producing systems or businesses. They have many interesting features, but I must not notice them all at once. There are the commercial, or buying and selling, relations between them which I pass over at present. To these relations we shall apply our analysis in due time. Again, there are the great types of industrial organization labelled "Joint-Stock Companies," "Co-operation," "Kartels," "Trusts," and so forth, the study of which must be relegated to a future chapter. To the existence of this diversity of industrial form I shall be sedulously blind until that future chapter is reached. Indeed, I shall go to the length of as- 
suming that it does not exist, and premise that every business in every field of industry is a private business under the control of a single employer, its owner.

The growth of businesses.-For the moment I would have my readers concentrate upon one thought only, namely that law and not chance governs in the main the size of each fully-grown business in each industry. There is no tendency in most industries for one business to swell out to enormous proportions and so feed on its successes that it crowds out other businesses and devours the whole market. Up to a point a firm tends to grow because the larger it becomes the more economically can it produce, other things being equal. Beyond that point further growth entails less economical production.

Let us try to watch in imagination the experiences of a growing business. For simplicity suppose it produces one article only. Take a village shoemaker with a small connexion who does all his work himself, and does not provide himself with more than an insignificant quantity of specialized machinery. He does not buy a sewing-machine, let us suppose, because he could only work it for, say, ten hours a week, and it would not pay to buy one for such limited use. But, when our shoemaker's connexion grows, he engages an assistant. The two men specialize and, therefore, turn out more than twice as much as either could when working alone. It might now pay the shoemaker to acquire a sewing-machine, beczuse it could be kept running for more than twenty hours a week. Finally, after engaging more and more assistants, it pays him to have other kinds of machinery, say even a machine to sew on buttons, because there is enough work to keep even it running for a long time each working day. It pays him also to specialize his machinery to a great extent-to have say one sewing-machine for making the uppers of ladies and children's boots, and one for making the uppers of men's boots, 
No proof is needed that more machinery per head of labour will be introduced as the business enlarges. The men who sew the uppers of boots together use sewing-machines for the purpose as much in the later stage of development of the business as in the earlier stage. But for the three men, say, who used to sew on buttons, one man and a machine are finally substituted. Hence there is more machinery per unit of labour in the business when it is larger. You may imagine that there exist potentially illimitable possibilities of specializing machinery. Fresh mechanical ideas can be worked out and applied as sufficient work is provided. It is the economies associated with the introduction of machinery, and the specialization of labour and machinery (see pp. 81, 84), which bring about group production, that is production by large groups of factors in such a manner that each group works as a unit or systematic whole.

Is there any end to the growth of a business? Assuredly there is. If it never stopped increasing, its magnitude would finally transcend the employer's powers of control. It would become unwieldy, and unresponsive to the needs of its circle of customers. Then cost of production would rise, because of the inadequacy of the direction under which the business functioned. So we may generalize and affirm that the potential size of a business is governed by :-

1. The capacity of the employer.

2. The character of the market-whether it needs careful attention or not and necessitates constant modification in the work turned out by the factory.

3. The complexity of the work done in the factory.

When his factory has reached the maximum size the employer's enterprise need not be checked. He may put in a manager and start another factory and control the policy of both. In doing this he is still further specializing himself; and he may, of course, discover that he has over-reached his 
powers. All along he has been specializing. He has been successively $(a)$ self-directed, undertaking, unspecialized workman; (b) undertaking manager and specialized workman; (c) undertaking manager; and $(d)$ undertaker.

I am generalizing here, remember, about the potential sizo of the individual business, and by that I mean the size to which it can attain, provided the employer is not starved for want of capital, or want of orders when he can produce cheaply enough to deserve them. I desire now to keep your mind fixed exclusively upon the economies of producing, given the requisite agents-economies of producing apart from problems of marketing-for reasons which will transpire shortly. I have been asking in effect, to use a physiological analogy, what governs the size to which an organism can attain provided it gets a sufficiency of the right sort of food, only the organism about which $\mathrm{I}$ am inquiring is a firm which is an economic organism.

The limit of growth.-Now scrutinize minutely our answer to the questions why a business grows and why it does not grow indefinitely. Our.answer was in effect this. When a business grows the executive agents become more highly specialized and so more valuable, and more machinery per man can be used. The employer, too, becomes more highly specialized up to a point, and so more valuable. But beyond this point the employer can specialize no more. If the business still grows, the field to which he has to give attention is extended and his attention must be diffused.

Broadly regarded, specialism implies two things. It implies on the one hand a limitation of the variety of the proximate objects to which a person's efforts are directed. And it implies on the other hand a limitation of the quantity of things with which the agent deals. In order to avoid an ambiguous terminology, we had better not call the second process specialization. It is best to call it, say, con- 
centration. The opposite of concentration is diffusion. As a business grows, the employer's attention as a manager is diffused, but, so long as he is specializing at the same time, he gets liberated from other duties and can manage more factors in production. After a time, however, he cannot relieve himself of any more functions, and as the business goes on growing his attention is more and more distracted. The effectiveness of his management per unit of the factors organized therefore begins to diminish. It is true that the larger the business becomes the richer it becomes in latent economies by way of specialism among its factors and the use of machinery. But these latent economies do not automatically become actual. The employer designs them. He cannot design any more if he has too many things to think about already. Consequently many of the latent economies may remain latent. And all the time as the business expands the employer's oversight is being diffused and his control per unit controlled is being weakened. The time must come, therefore, when a further expansion of the business results in a balance of loss.

So, to sum up as regards the simple illustrative case which we took of a business which produces one kind of article only, we may say (1) that after a certain point has been reached in the enlargement of a business, other things being equal, its marginal expenses must rise, and (2) that the position of equilibrium, respecting its size, is reached when its marginal expenses equal price. The influences which retard the operation of the tendency towards this position of equilibrium are discussed on pages 96-7. Marginal expense means the addition made to the total expense by incrementally enlarging the business.

It might be objected that the employer would insist on getting a price a little above the marginal cost of production in his works because he would want something for himself for the extra trouble to which he was put by undertaking the 
production of the last increment that he turned out. Strictly this objection may hold good, but the extra income that the employer would want for himself would be negligible because the extra trouble involved in the production of the last increment would be negligible. We are not evading a difficulty when we affirm that the trouble of working an industrial capital of $£ 10,010$ is not recognizably greater than the trouble of working in the same way an industrial capital of $£ 10,000$.

We may note in passing that what is called the marginal return of a business may be obtained from the marginal expense by dividing the unit of money, with reference to which returns are being measured, by the marginal expense. Thus, if we are measuring returns with reference to sums of $£ 1$ and the marginal expense of a pair of slippers in a business is 2s. 6d., the marginal return in that business (per £1) is 8 pairs of slippers.

The normal magnitude of the business. - A diagram will help some of my readers to understand that the position of equilibrium

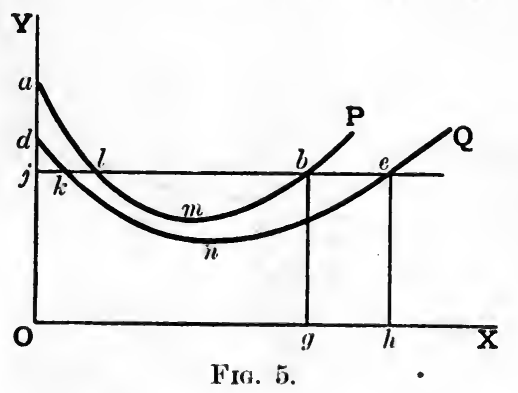

as regards the size of a business is reached when inarginal expenses equal price. In fig. 5 measure along $\mathrm{OX}$ units of produce of a business, and along OY measure marginal expenses apart from the earnings of the employer for the work that he does. Let us call these expenses employer's marginal expenses. We assume con- 
stancy in the money costs of factors in production and in the price of the product. The curve $P$ is the curve of employer's marginal expenses of the output of a particular business. It first descends for reasons explained above and then ascends. The size of the business in units of output will be $\mathrm{O} g$ if $b g$ equals price. The curve $Q$ relates to a more capable employer. If the first business is of the size $\mathrm{O} g$, his will be of the size $\mathrm{O} h$ because $e h$ must equal - that is, of course, tend to equal- $b g$.

Note that $\mathrm{O} g$ must be such that $l \mathrm{mb}$ is substantially greater than $a j l$ as otherwise the employer would make little or nothing for himself. The determination of what he makes for himself we shall deal with in the part on the distribution of wealth.

\section{The law of substitution, indifference, or equi-marginal} returns.- This will be a suitable place to point out that, just as an employer tries to make his business of such a size that his marginal costs as a whole equal price, so he tries to use factors in production of different kinds in such quantities that the marginal return of each of them equals its cost. Employers' marginal costs of production, as a whole and in relation to each factor in production, may not be explicitly recognized by a wide circle in the business world, but that, with or without names, they play leading parts becomes palpable when we discern that factors in production are not grouped chaotically and that businesses seldom reach unwieldy dimensions.

When we try to envisage the tasks of industrial and commercial directors, it soon becomes apparent that both can be brought under the law of substitution, indifference, or equimarginal returns. The producer, who is farmer or manufacturer, has to maximize the returns obtained from a given expenditure on material or land, Jabour, instruments and accessories; and, just as $I$, in spending my income, get the best results when my marginal returns per unit of expenditure on different things are equal, so he must get the best results 
when his marginal returns per unit of expenditure on each agent of production are equal.

The proof given on pages 43-8 applies here, but let us take a specific example nevertheless. A manufacturer, say, is making steel. If he adds $£ 2$ a week to his wages bill to increase his staff of labourers, suppose his weekly product will be raised by one ton of steel. If he adds $£ 2$ a week to his interest account to increase his capital, suppose his weekly product will be raised by two tons of steel. Then he will borrow more capital and possibly reduce his labour. And so he will proceed until a unit of additional expenditure will have the same effect on his output whether it purchases labour or capital. It should be superfluous to warn you that the employer's office of grouping and marshalling the agents in production seldom becomes a sinecure.

Industrial, including agricultural, development is constantly necessitating rearrangements of the factors in production: every invention or alteration in the costs of different factors renders re-adjustment economical.

We need not pause to demonstrate that the man of commerce will act like the industrial organizer. The former prospers in the degree in which he so distributes the supplies of an article between different places that the prices paid to him in different places, less his expenses, become equal.

Expansion and contraction of businesses.--In no industry do the individual businesses spring up to their full sizes in a few months. They take years, sometimes even generations, to attain maturity. The rate at which a firm grows depends upon its ability to win its way in the market or earn the confidence which is the source of its borrowing powers. Businesses attain their maxima in size much more rapidly in some industries than in others (see p. 126). And just as businesses may grow up slowly so they may die down slowly. As it has been appropriately said, an industry is like a forest 
and the businesses in it are like the trees. Every industry contains some young and growing firms, some which have reached maturity, and others which are dwindling as they lose their hold on the market. The generation which made a firm passes away, and its successors in control may be less fit than their predecessors to hold their own against the competition of pushing rivals. The rising generation is always knocking at the door. But the decaying business is not obliterated suddenly ; for years it may maintain a position, by force of the effects of the old management surviving in its organization, by force of its old prestige which advertises it, and by force of the habits which some people have formed of buying from it.

In connexion with the growth of businesses the observation may be recorded that businesses are not equally elastic in all industries. It would be as well to draw a distinction between the "walled industries" and the "un-walled industries". Businesses in the former are like shell-fish which, in order to assume ampler proportions, beyond a certain limit, must discard their shells and grow others. The "walled" business may have at one time too much space and excessive provision for motive power, to allow for possible expansion; while at a later stage in its history it may be cramped and inadequately supplied with power, though not so awkwardly situated that it would pay it to embark on extensions. Hence in businesses in the walled industries marginal costs are seldom in the neighbourhood of price, though it is still true and relevant to say that in the exaggerated long run they tend to be.

Specialization of businesses.-In previous paragraphs I have traced the way in which a business finds increasing possibilities of using machinery and specializing its factors as it grows. I have now to point out that businesses themselves may specialize, and that in doing so they find yet further possibilities of using machinery and specializing their factors. 
Let us suppose in the first place that the whole of an industry is in one place.

As the market for the industry enlarges, increased output must be got through the emergence, at any rate after a time, of new businesses. But will not the new and old firms be as much alike as Tweedledum and Tweedledee, the new firms introducing no fresh economies? The answer is in the negative, at least as regards the bulk of the industrial world. Businesses will probably begin to specialize, and specialism among businesses heralds economies. It eventuates in more specialized management, more specialized labour, more specialized machinery and more machinery per head. Its economies induce the adoption of as much specialism of businesses as there is scope for, provided that certain considerations connected with marketing do not prevent it. The scope, you will realize, is furnished by the size of the industry, just as scope for specialization among the factors of a business is furnished, other things being equal, by the size of the business.

But remember that these economies may be counteracted. Increased demand for material might raise the cost of material and the larger industry might have to draw upon inferior agents. These are matters which we reserve for consideration in our next chapter.

That the more specialized business means more specialized management is self-evident. To demonstrate that it means also more specialized labour, take for example a firm with 1000 hands which used to make motor cars and bicycles. Say 500 hands worked mainly at motor cars and 500 hands at bicycles. Now let the business confine itself to manufacturing motor cars. The employer can manage at least 1000 men under the new conditions since he managed 1000 under the old conditions. In fact under the new conditions he might manage more because his task might present less 
variety. But let him have, nevertheless, only 1000 men. Clearly there can be more division of labour among the operatives constructing motor cars when they work in groups of 1000 than when they work in groups of 500 , and clearly their machinery can be more specialized. And in the former case, since scope is afforded for fresh machinery when scope is afforded for more specialism of labour, more instrumental capital per head of the operatives employed will be drafted into motor-car manufacturing.

We have not yet completed our enumeration of the economies which may result from the expansion of an industry. It may cause, not only specialism of businesses within the industry, but also specialism in subsidiary industries, such as machine-making, for which the industry in question is the market, and a fall in the cost of carriage.

The specializing of businesses has been going on apace. Compare the engineering works of Boulton \& Watt, when James Watt the inventor was a partner-a business typical of its time-with engineering works of to-day. Boulton and Watt manufactured almost everything that is made of the baser metals; to-day an engineering firm may produce nothing but boilers, or textile machinery, or locomotives, or machine tools. Go back three-quarters of a century and you find the cotton factory which spun many kinds of yarn, and made it up into numerous sorts of fabrics, the typical factory in the cotton industry. To-day you will find, to take one example, a mill devoted to nothing but spinning, and spinning only a certain narrow range of yarns. There is prodigious scope for specialism of businesses in industry: but in agriculture the scope is restricted for obvious reasons.

In the argument above I have supposed that the whole of an industry is in one place. Now suppose it is scattered, parts being in one country and parts in other countries. Still some business specialism would probably remain which was depend- 
ent upon the aggregate size of the industry. So the size of the industry abroad, as well as its size at home, may determine business specialism. International specialism is possible in sections of industries as well as in whole industries. But when the industry was scattered there would be much less business specialism than when it was concentrated in one place, because of the cost of carriage between places far apart and the inconvenience of arranging for sales to and purchases from distant markets.

The time-worn, but still undisputed, economic dictum that division of labour is limited by the extent of the market merely affirms indirectly that specialism (division of labour broadly interpreted) is limited by the extent of an industry; but it is less equivocal, though less direct, than the latter statement, inasmuch as the market must be understood to embrace the foreign market as well as the home market.

Specialism by product and specialism by process.Two kinds of specialism may be contrasted, namely, specialism by product and specialism by process. By specialism by product I mean a limitation of the classes of things turned out by a business. By specialism by process I mean a limitation of the number of processes, in a chain of manufacturing processes, which a business undertakes.

If in the worsted industry a business which turned out twenty kinds of cloth gives up producing five of them and supplies only fifteen kinds, we may say that it has specialized by product.

Again, in the worsted industry we may distinguish between the processes of $(a)$ wool-combing, (b) spinning, and $(c)$ weaving. If we find a worsted industry each business of which, as a rule, spins the yarns that it wants for weaving and combs all the wool that it wants for spinning, we may say there is no specialism by process. But when we find a worsted industry, some businesses of which comb only, while 
other businesses spin only and yet others weave only, we may say there is specialism by process. The conditions of specialization by process I shall explain on pages 125-6.

\section{Internal and external economies and the localization} of industries.-There is a generally recognized distinction between the internal and the external economies of a business. The external economies are those in which all businesses in an industry can share, such as the degree of business specialism objectively possible, the conveniences offered by subsidiary industries and facilities for marketing and carriage. The internal economies of a business are those economies which are peculiar to it. The external economies of an industry in any one place become more fruitful, as I have already insisted more than once, $(a)$ with the growth of the industry in that place, and $(b)$, under certain conditions, with growth of the industry in other places with which the place in question is in trading contact. That is to say the external economies of a business are partly local and partly international.

It is of no small interest to observe that recent progress has tended to reduce the proportion of external economies which are narrowly local, as I have hinted on page 88 . Specialization by process is only possible among factories scattered over a wide area when transportation facilities become cheap and adequate. And there are other conditions of late development which are extending the area within which certain external economies can be enjoyed.

The question of the localization of industries is a gigantic one, but we can only afford time for a hasty glance at it.

(a) The localization of industries is determined partly by physical conditions. Coal-mining can only be carried on where there are coal mines. Iron-smelting is done cheapest in the vicinity of ore and coking-coal. And the climate of some places is an aid to certain industries.

(b) It is determined partly by means of transportation. 
Importing and exporting industries gain from being near ports. And all industries which serve a wide area gain from being on a line of railway. Again, notice this point. If a railway line is laid down between $A$ and $B$ and the bulk of the traffic runs from $A$ to $B$, industries will tend to appear in $A$ or $B$, the traffic connected with which runs in bulk from B to A. You will understand at once that the cost of transportation over a line falls as the density of its traffic rises, within limits, while the conveniences offered by the railway in frequency of service and other ways (conveniences which have an economio value) are magnified. You will also have comprehended that much which has been written above of specialism in production relates equally to the production of the service of "transport". The fall which so constantly takes place in the price to consumers of manufactured products is not uncommonly due in an appreciable degree to a fall in the cost of carriage which an increasing volume of traffic has rendered possible. It is means of transportation which do more than anything else to make a country function as one economic whole. Under primitive conditions each small locality tends to be largely self-supporting economically, that is to produce for itself most that it wants. But it must be remembered that means of transportation have been provided under the inducement of military, political, and general social requirements, as well as of economic ones.

(c) The localization of industries has also been determined in part by the whole complex of economic conditions, including commercial conditions, supplies of labour, and international exchange. 


\section{CHAPTER XI.}

\section{THE LAWS OF INCREASING AND DECRFASING RE- TURNS.}

WE are now sufficiently prepared to understand the celebrated laws of increasing and decreasing returns. Though the next chapter has an important bearing upon them, I shall anticipate and treat of them at once while the contents of my two previous chapters are fresh in the reader's mind.

These laws have been given various forms, and there is little agreement about their exact meaning. It might be as well to recognize several laws of increasing and decreasing returns. Making our enumeration as wide as possible, we might say that there are non-evolutionary laws, which can be framed abstractly or realistically, and evolutionary laws (p. 7).

Meaning of increasing, decreasing, and constant returns.-The phrases "increasing returns," "decreasing returns " and "constant returns," in their reference to industries, have the following significations ordinarily. There is said to be increasing, decreasing, or constant returns, when an enlargement of an industry results in a rise, a fall, or constancy respectively in the returns per unit of cost (including the normal earnings of the employer) of the marginal business (pp. 38, 159), which returns in strict theory (p. 105) should be identical with the marginal returns of typical businesses in the industry (p. 94).

But how, the reader may interject, can we measure the quantity of the output of a firm and the quantity of factors 
in production? The output may be of several kinds and the factors must be of several kinds.

As regards the output there need be no difficulty for the purposes of the present demonstration. We may simply suppose that the industry turns out one kind of article only. But as regards factors in production there is a difficulty because the factors must be of more than one kind. There are employers, operatives, material or land, and possibly capital. We must reckon their quantities with the aid of some common measure, and money is the only one available. We therefore measure productive factors by their value, assuming that the money cost per unit at which each class of factor, including the employer, can be obtained is constant. We also assume that employers will rearrange the proportions between their factors in production when new opportunities for specialism render alteration desirable.

When you think of the quantity of productive factors as computed in this way, you will instantly apprehend that to say that the marginal return of a business rises, is to say that the marginal cost in the business falls and vice versa.

Observations on increasing and decreasing returns. - Decreasing returns might mean that the marginal return, not of the individual business but of the industry, falls as the size of the industry increases, that is to say that the additions made to the total product of the whole industry diminish in amount as the industry gets bigger (seo p. 162). Similarly increasing returns might mean that such marginal returns, instead of diminishing, increase, and constant returns might mean that they keep constant. There is nothing to prevent us from interpreting the terms in this way, but in common economic usage, for considerations of convenience, "decreasing returns," "increasing returns," and "constant returns" with reference to an industry have not got these meanings. The returns which they connect with the size of the industry are commonly taken to be the returns of the marginal business per unit of cost (including the normal earnings of the employer), or, what comes 
to the same thing in very abstract theory, the marginal returns of typical businesses.

The reason why the phrases "increasing returns" and "decreasing returns" are usually interpreted as having this reference, in connexion with the laws associated with these terms, is that it is desired to bring these laws directly into relation with the prices of things, and the prices of things freely produced are commonly regarded as governed inter alia, as we shall learn, by the returns of the marginal business per unit of cost (including the normal earnings of the employer), which in rigid theory should equal the marginal returns of the typical or normal business.

Let me prove that the output of the marginal firm per unit of cost (including the normal earnings of the employer) must theoretically equal what the marginal returns of any normal or typical business tend to be. To affirm this equivalence is to say that the marginal cost in a typical firm will equal the cost (including the normal earnings of the employer) per unit of output in the marginal firm. It can be demonstrated from fig. 5 on page 94 that the second statement is true. Let the curve $\mathbf{P}$ relate to the marginal firm and $Q$ to any other firm. Ogbma represents the cost of employed factors in the marginal firm ; and $l m b-a j l$ represents the earnings of the employer in this firm. It is evident on inspection that

$$
(\mathrm{O} g b m a+l m b-a j l) \frac{1}{\mathrm{O} g}=b g=e h .
$$

This somewhat difficult discussion must be introduced here for the sake of accuracy, but the reader who does not grasp it at once is exhorted not to worry about it on a first perusal of this book.

\section{The non-exolutionary laws of increasing and decreas-} ing returns.- The laws of increasing and decreasing returns, whether abstractly or realistically enunciated, may be taken to refer, as we have seen, to the conditions under which increasing and decreasing returns are met with.

Abstractly the law of increasing returns may generally be phrased as follows :- 
The expansion of an industry, provided that there is no dearth of suitable agents in production, tends to be accompanied, other things being equal, by increasing returns.

The kernel of the proof of this law has been furnished in the two chapters immediately preceding this chapter.

As the industry gets bigger more specialism and more machinery per head tend to be introduced into it and its subsidiary industries, and the means of transportation connected with the industry tend to get more economical. Also the commercial work interlaced with the industry tends to get more economical, as we shall see. Consequently increasing returns tend to follow. And in the defined circumstances there cannot be any positive counteracting tendencies because we have supposed that there is no shortage of suitable agents in production. If there were such a shortage, and it was not very serious, there might still be increasing returns. As it is practically certain that some of these tendencies to a lower real cost of production would have scope and be effective, we should be perfectly safe in affirming that the expansion of an industry under the stated conditions would be invariably accompanied by increasing returns.

Abstractly the law of decreasing returns may generally be expressed thus:-

The expansion of an industry, provided that additional supplies of some agent in production which is essential cannot be obtained, is invariably accompanied, at once or eventually, by decreasing returns, other things being equal.

The proof of this is simple. Let all the factors in production but one essential factor increase and note the result. Suppose the quantity of instrumental capital is fixed and labour and material increase. Labour can become more specialized as its quantity is augmented, but the gain secured through this specialization must ultimately be counteracted because each operative will be progressively deprived of me- 
chanical aids. The case of the more intensive working of a fixed quantity of land is evidently similar.

Of course, decreasing returns might appear when additional supplies of all the agents in production could be obtained, provided that the available extra supplies of some essential agent became increasingly inferior in quality or limited in quantity.

When the law of increasing returns and the law of decreasing returns are understood more realistically, the former is taken to assert that increase of capital and labour in manufactures leads generally to increasing returns, and the latter reads that increased efforts to obtain natural products lead generally to decreasing returns.

So expressed these laws may be regarded as founded on an inductive examination of actual productive activities made in the light of the abstract truths which have already been enunciated. The tendency for decreasing returns to rule over our efforts to raise natural products is due to the fact that a prominent part in their creation is played by nature, and that the best and most favourably situated land and mines and fisheries are limited in quantity (see Chap. XXVI.).

The exolutionary law of increasing returns.-The evolutionary law of increasing returns results from induction applied historically; and it may be supported deductively with the aid of theories of progress. It states that increasing returns are obtained from manufacture over long periods of time apart from enlargements of the market, and that the tendencies to decreasing returns in the yield of natural products are likely to be substantially counteracted. The cause is invention and increased knowledge.

Let me illustrate the counteracting of diminishing returns diagraminatically. In fig. 6 measure "doses of labour and capital" along OX. A "dose of labour and capital" means a sum of money spent on different productive agents to the hest purpose. Suppose 
that the money value of each class of agents in production remains constant, so that a dose of labour and capital means a fixed quantity of generalized producing power as one might say. Measure marginal returns in wheat along $\mathrm{OY}$. For some country let

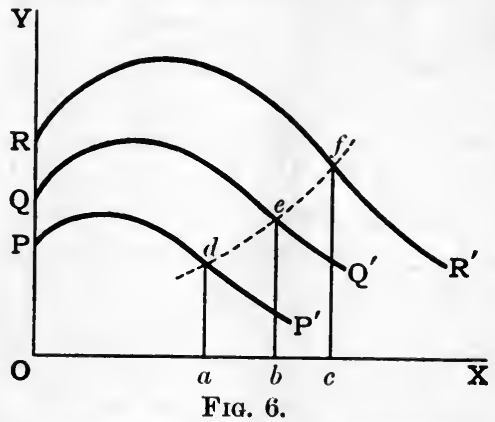

$\mathrm{PP}^{\prime}$ be the curve of return at the end of the 17th century.

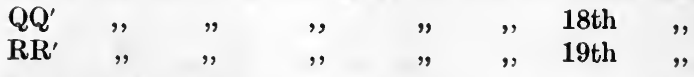

Owing to improvements in agriculture (that is to the evolutionary law of increasing returns in its application to agriculture) we suppose that the curve for a later century lies above that for an earlier century. We may give as examples of improvements the substitution of the three-field system for the two-field system, enclosures, drainage, rotations of crops, agricultural chemistry.

Let the marginal return in the first period be ad, in the second $b e$, and in the third $c f$. We allow, you will observe, for an increasing need of larger supplies of wheat. Then, as the marginal returns rise over the centuries (as shown by the dotted line) evolutionarily there has been increasing returns. But, nevertheless - and notice this point particularly - wheat production has been subject to decreasing returns in each period.

The descent of each of the eurves $P^{\prime}, Q Q^{\prime}$ and $R^{\prime}$ indicates the rate of decreasing returns in each period. 


\section{CHAPTER XII.}

\section{MARKETS AND COMMERCIAI، FUNCTIONS.}

What are markets? - In a complete subsistence economy where each family produces for itself absolutely everything that it needs - to discover which, if it ever existed, we must go back to the Stone-age and the cave man-no exchanging takes place. But actually wherever there is a community, however primitive, there is some bartering. With the introduction of more and more division of labour, the volume of this bartering grows. Economic progress means inter alia specialization, and not merely specialization by product but also specialization by process (see pp. 100-1); and it is of importance to notice not only that each step in specialization by product magnifies the place of marketing in the social economy, but also that each step in specialization by process creates the need for the marketing of commodities which were not previously bought and sold. If farmers ground up all their wheat there would be no market for wheat. But when specialization by process appears and one man is farmer only and just grows wheat, while another man is miller and flour-dealer, the former will want to sell some wheat and the latter to buy it. Hence wheat will become an article of commerce and a wheat market will be established.

And what precisely is a market? Economically interpreted the term "market" refers, not to a place, but to a commodity, or commodities, and buyers and sellers of the same who are 
in direct competition with one another. Hence we may as appropriately speak of world-markets as of local markets. There is a world-market for tea, since most nations are competing with one another in the purchase of tea.

Dealers are not brought into direct competition with one another unless they are dealing within the same range of quantities. The village grocer is not directly in competition as a buyer with any wholesale buyer of tea. He directly competes with other retailers in buying from wholesale tea dealers. So we may distinguish between wholesale markets and retail markets.

Evolution of markets. - There are various stages in the evolution of markets, the significance of each of which is well worthy of consideration. The chief of these are :-

(a) The localization of markets.

(b) Deáling by sample.

(c) Dealing by grade.

(d) Differentiation of markets.

(a) The localization of markets saves much of the time which used to be spent by buyers and sellers in moving about to meet one another. For the localized market there is usually a market place. Here goods are displayed, if the market is of a simple kind. When buyers and sellers are crowded together in one place, competition between them is naturally rendered much more effectual than it can possibly be when they are scattered and have to travel about to bargain with one another. So in the localized market one price at one time for one commodity is likely to rule. A large district may maintain several localized markets of the same kind. In each there is competition, and between them there is also competition. In a sense, therefore, they make up one market. A producer will send his goods to market $B$, which is farther away, rather than to $A$, which is nearer, if he learns that prices have been ruling so much higher in the more distant market that it is worth his while. 
The area normally served by a localized market is dependent, of course, upon the provision of transportation facilities.

(b) The system of selling by sample contributes substantially to public convenience. It saves the carriage of bulky goods to the market. Also it enables more persons to deal on the market; for the market in which samples only are inspected is not cumbered with loads of goods. Further it enables dealers to get into closer and more continuous contact with one another. Hence the market in which samples are substituted for the actual goods for sale draws on a wider area of supply, and competition within it becomes more thoroughgoing in its action.

All goods cannot in the nature of things be sold by sample. But many natural products can be so sold. . Handfuls of wheat taken indiscriminately from the year's harvest of lands of the same quality, in the same district, sown with the same seed, are likely to be the same. Again things produced in the same mechanical way from the same materials-say pigs of iron from the same tapping of a blast furnace-are likely to be strikingly similar to one another. And yet again, some things may be satisfactorily sorted into classes specifically with a view to selling by sample.

(c) The adoption of selling by grade is a step in the development of certain markets which may have the most far-reaching consequences. Organized dealing in "futures" may be the goal eventually reached. For selling by grade the various qualities of the gradable commodity are arranged in separate classes, to each of which is given a distinguishing mark or name. Sellers usually try to sort their goods into the same grades, and an attempt is made to keep these grades the same continuously over a lengthy period. When grading has been effected, a buyer can purchase without seeing samples, by simply referring to the name or mark of the grade which he wants. 
The introduction of dealing by grade yet further enlarges and perfects a market, for the same reason that the introduction of buying by sample enlarges and perfects a market.

(d) The original market is the mixed market. As the area which a market can serve extends with improvement in the means of carriage and communication, it first grows in size and then, under pressure of the claims of commerce, begins to differentiate, that is, to split into sections-into the fruit and vegetable market, the cattle market, the textile market, the hardware market, the colonial produce market, and so on. Additional differentiation accompanies the insinuation of selling by sample and grade, for reasons which will become palpable as we proceed.

Future dealings.-On the markets for some things which are highly gradable-for instance on the exchanges for wheat, coffee, copper, coal, tea, oils, rubber, and numerous other commodities which are in the raw state or near the raw statefuture dealing has been so elaborately systematized that the buying and selling of future supplies has been rendered almost as simple as the buying and selling of present supplies. The things which are directly bought and sold on the exchanges where future dealing has been thus promoted are documentary guarantees to deliver certain quantities of the commodity in question at certain times. By means of these tangible tokens, the future supply is brought representatively on to the market. Just as a trader can purchase bills payable at sight, or bills payable after six months or so, and in this way can buy gold for delivery now or in the future; so he can purchase a contract for immediate, or future, delivery of cotton, or wheat, or certain other commodities. There is this difference, however, that the purchaser of a produce future cannot be sure of the exact quality of the commodity which will be delivered against it. Consequently the chances are that he will ultimately sell his future back instead of taking delivery of the article. 
The term "futures" is sometimes reserved for contracts for future delivery which circulate on a highly developed produce exchange. I shall hereafter use the term in this restricted way. Other contracts relating to the future I shall designate descriptively, or by such terms as "future transactions," "future business," "future dealings". "Futures" is sometimes used as a generic term to denote "options" also. An option is a right to conclude a bargain on a future date at a fixed price. It is single, a "put" or a "call" (i.e., a power to sell or to buy), or double, containing both powers.

The advantages of transactions in futures are said to be two: $(a)$ that they steady prices; and $(b)$ that they enable the persons who use, or deal in, the articles in which there are futures to avoid certain risks. Whether such advantages are derived from the use of futures or not, we shall consider later in this chapter.

Technicalities of dealings in futures. - In order to limit the variety of the contracts entered into on a highly organized future market, every "future," which has reference really to a range of qualities of a commodity, is made to relate directly to one of the qualities, or grades, only. But certain other grades are declared to be deliverable against any future on payment of allowances to or by the purchaser according to the inferiority or superiority, as the case might be, of the grade delivered to the grade which is the basis of the future contract. Allowances are settled on some agreed principle. Again, with the same object in view, that is with the object of curtailing the variety of future contracts, they are made to refer on the same market to a limited number of agreed periods. On one produce exchange, for instance, in January you would find January futures, February futures, March futures, and so on ; and all futures for a stated month would contain exactly the same provisions as regards the time and notification of delivery.

It will be at once evident that on a highly organized future market elaborate regulations must be observed. The object of most of these regulations is, as I have said, to simplify business by substituting uniformity of method for variety. 
There are two classes of buyers of futures. There are those who buy with a view to their future needs for particular grades of the commodity. When a buyer of this class has purchased a future there is no guarantee that the particular grade required by him will be delivered against it. It is best for him, therefore, if he has bought a June future, to receive some time in June the value of the future, that is the value of what would be delivered against it, instead of the commodity that would be delivered against it, which might or might not be what he wanted. The money could be used to purchase the exact grade of the commodity that he wanted. The alternative would be to take delivery of the commodity, which would probably be of the wrong grade for his requirements, and then sell it with a view to purchasing what he wanted.

There are other buyers who are not seeking the produce to which futures refer but are trying to make a profit out of buying at a low price and selling at a high price. If they took delivery they would have to sell what they received. It is therefore a convenience to everybody concerned that they should directly receive, in place of the commodity, what it would fotch.

On highly developed markets-future markets and the Stock Exchange-a system of periodic settlements has appeared and with it dealing in differences. I can explain the latter best by means of an example. If Jones buys from Smith an amount of May futures in some commodity, he has only to pay Smith periodically any sums by which the value of the futures may have fallen between settlement days. Similarly, Jones receives from Snith any sums by which the futures rise. If the futures were bought on 1 January for $£ 1000$ and settlement days fell on 11,25 January, 8 February and so on fortnightly, and the futures were worth, according to market quotations, $£ 1100, £ 1200$ and $£ 1150$ on these dates in order, then Smith would have to pay Jones $£ 100$ on 11 January, and $£ 100$ on 25 January, and Jones would have to pay Smith $£ 50$ on 8 February. If the futures were cancelled on 8 February. Jones would have received $£ 150$ on balance, which is just the difference between the value of the futures when he bought $(£ 1000)$ and their value when he withdrew (£1150). As dealing on differences enables people to enter into large transactions, if they have enough capital to cover possible adverse differences, it 
has increased the volume of dealing, including speculative dealing. It performs the important service of periodically testing the solvency of the market and removing those who are not in a position to meet their liabilities.

Markets for capital.-To complete our condensed account of markets, something must be said of markets for capital. We may distinguish between the market for invested capital and the market for investing capital. The bulk of the former is embraced by stock-exchanges. A typical stock-exchange is perhaps the most highly organized of the markets of the world. It is so highly organized because the things bought and sold on stock exchanges, that is shares, are perfectly graded, so to speak. No produce can be quite perfectly graded. But shares may be regarded as perfectly graded, because the several units of a stock of a given kind are in effect identical. Any one ordinary share of a given company is just as good as any other ordinary share of the same company.

The market for capital for fresh investment is curiously unorganized. The stock exchange is not the market for such capital; it is, on the contrary, the market in which invested capital is bought and sold. Through operations on the stock exchange the ownership of the invested capital changes hands. But the quantity of invested capital is not thereby altered though its value may be changed.

Capital is directed to new investments through private information, advertisement, the circulation of prospectuses, financiers and investing companies. The degree in which banks sink their money in industrial undertakings is limited, as we shall observe later, because they may require their money back again at short notice and it is not easy at short notice to sell an interest in a newly projected railway, say, without risk of loss. In some countries banks do more in the way of directly financing industry than in others. In all countries they largely finance commerce-and so industry indirectly- 
by discounting bills and in other ways. In most countries investing companies are not responsible for much of the fresh investment in industry which goes on from year to year. They have absorbed far more of this work in the United States than elsewhere.

Price steadiness and its effects.-Before trying to answer the question, Does speculation steady prices? we must dispose of two preliminary questions, namely, (1) What is meant by price steadiness? and (2) In what does the value of price steadiness consist, if it has any value?

If the price of one commodity changes less frequently than the price of another, we may say that the price of the former is steadier than that of the latter, other things being equal. Again if the price of one commodity varies by smaller percentages than the price of another, we may say that the price of the former is steadier than that of the latter, other things being equal. What shall we say, however, if the price of one thing varies less frequently but more violently than the price of another thing? And there are other differences in character between price variations to take into account. Obviously, if we are to admit of any measurement of steadiness, we must agree upon what weight to attach respectively to frequency of change, the average extent of change, the range of change and the average of departures from the average. A number of conventional indices of price steadiness are used which we must not examine here.

Are steady prices (it being assumed that the purchasing power of money remains constant) preferable to unsteady prices? In facing this question, we can avoid the perplexities arising from the vague implication of the word " unsteady," by contrasting absolutely unvarying prices with prices that vary in any way whatever but yield the same average. Such a contrast is sufficient for our present purpose. We are dealing not with price variations over periods of years which may involve 
substantial alterations of supply, but with market fluctuations from hour to hour, day to day, and week to week.

After a few minutes' thought it will become abundantly apparent to the shrewd observer that unvarying prices (when the purchasing power of money remains constant) must be best for the community. Take, as a tangible case to generalize from, the price of some consumers' commodity. Unvarying price results, under the condition defined above parenthetically, when the supplies of this commodity are distributed in time proportionately to demand. And such a distribution produces a maximizing of the satisfaction which can be yielded by the commodity, other things being equal, because it produces equi-marginal returns in time. The reader who is still in doubt may refer back to pages 43-8. Fitful price movements enforce irregularity in consumption which is wasteful of satisfaction.

Does speculation steady prices?-It is arguable deductively, but only on certain assumptions, that speculation steadies prices, whatever plausible measure of steadiness be taken. The proof runs as follows. A developed market is constituted of experts, of men who devote themselves to studying the foreshadowings of supply and the signs of change in demand. When an expert thinks price is going to rise he buys at once for future use. In consequence of his action, price does not rise so much in the future as it would have done otherwise, provided that the expert was right in his anticipation. When the expert thinks price is going to fall he limits his purchases as much as possible-that is to say, he holds up as much present demand for the future as he can. In consequence of his action, price does not fall so much in the future as it would have done otherwise, provided that the expert was right in his forecast. Now the expert bases his decisions upon a study of the facts of demand and supply after a long acquaintance with the facts. "In consequence he will 
more frequently be right than wrong, if he is a man of judgment. If he is not a man of judgment, and is more frequently wrong than right, he will dissipate his resources in time, and voluntarily leave the market ultimately, or be driven from it by his losses. Hence, through a survival of the fittest, the majority of the experts on the market are likely to be men of judgment who study the market and are more frequently right than wrong. Hence their dealings tend to reduce the range of price variations and to reduce the average variation from the mean price.

This deductive proof that speculation (which is aided, be it remembered, by futures on produce exchanges) tends to steady prices rests on two assumptions. The one assumption is that the dealers are experts with knowledge of market conditions. The other is that they do not tamper with the market.

By "tampering with the market" I mean dealing with the deliberate intention of altering the level of prices for one's personal profit. The man who makes a great demonstration of selling so as to depress prices, in order that he may buy cheap ultimately, is tampering with the market. The man who "corners" a commodity, that is gets a dominant control over supply so that by withholding his supply he can force up price, is tampering with the market. Tampering with the market unsteadies prices; the speculator who tampers with the market aims at altering prices to benefit himself.

Now it is known that the market is tampered with from time to time. And it is conceivable that this tampering may tend to unsteady prices more than other business in futures teads to steady them. I should conjecture, however, that under present conditions the steadying influences preponderate. Nevertheless there appears to be no doubt that tampering with the market is commoner than it used to be. The cause is said to be the large scale organization of financiering which the 
past few years have witnessed, particularly in the United States.

When a person, whether he is tampering with the market or not, acts in such a way that prices tend to be depressed, he is called, in the expressive slang of the market, a "bear "-a bear tears down with its claws. When his action tends to have the opposite effect he is called a "bull"-it is a matter of common knowledge that a bull tosses with its horns.

The deductive argument which proves that speculation steadies prices depends not only on the supposition that the market is not tampered with, but also on the supposition that all the dealers are experts. But all the dealers on organized markets are not experts. The general public speculate in produce futures as well as in stocks; and, as the majority of these outside speculators cannot pretend to any expert knowledge, they are not likely to be more frequently right than wrong in their shots at prevision. They are sheer gamblers; and the gambler is just as likely to lose as to win. Moreover, as the outside public are peculiarly sensitive to rumours and are liable to react to extremes and yield to panic, the weight of the influence of the public on the market is now heavily on one side and now heavily on the other side. It is just as likely to make unduly low prices lower as higher; and, if it makes them higher, it is just as likely to make them too high as to bring them to the right level. Speculation by the public is consequently a force which should extend the range of price variations and increase their number. However, it is probable that this disturbing factor on a developed market is of small importance in comparison with the influence of dealing by experts.

The marketing function.-I shall now try to make explicit certain general ideas which are implicit in the foregoing, in addition to adding some fresh material.

Commercial functions, broadly conceived, are of two sorts. They consist in :- 
(1) The arranging of purchases and sales.

(2) The undertaking of the risks incidental to producing in anticipation of demand.

We have already remarked that the first function would be non-existent in a thorough-going subsistence economy. Its purpose is to find the most appropriate buyers for sellers and sellers for buyers.

You may think of a market as bounded by, or constituted of, producers of an article on the one hand and consumers of it on the other. The producers are, say, Smith, Jones and Brown, and the consumers are Johnson, Thompson and Robinson. The product, suppose, is pig iron. Johnson buys from Brown at, may be, 30 s. a ton, while Smith is ready to sell at 29s. a ton though Johnson does not know it. The commercial man finds out this useful fact for Johnson, or for himself if he is a dealer and not merely an agent working on commission, and makes a profit out of the knowledge. But the bulk of the gain cannot be reaped by the commercial men, because, as we shall see on pages $147-8$, by competing with one another, they are forced to transfer much of it to the community as a whole. So the commercial man insures that the buyer shall buy at the lowest price possible. He also insures that the seller shall sell at the highest price obtainable, since he equally prevents a commodity from selling at $28 \mathrm{~s}$. when it could realize 29s. Further the commercial man creates value by insuring that each buyer shall get the articles produced by the firm which is turning out just that quality of the article which meets most exactly the buyer's requirements.

The risks of anticipating.-The performance of the function of anticipating is unavoidable under any conditions. Even cave-men must frame estimates of their needs before they produce, and in framing their estimates they may make mistakes. Robinson Crusoe when alone could not engage in 
the office of exchanging, but he could not flee the responsibility of anticipating.

The economy of every advanced community is based upon anticipation. The organization of this anticipation is one of the most remarkable features of recent economic development. In a modern community we expect to find our wants foreseen. This is the age of the "ready-made" article. We may order our suits to measure, but we choose the cloth from stocks already accumulated and paraded for our inspection.

Now guessing, however scientifically, at the future wants of a community is hazardous because change in fashion is not exclusively prescribed by shopkeepers, and incomes have their ups and downs, and the relative quantities demanded of different things depend upon their relative costs which alter from time to time. Upon the distribution of the risks incidental to anticipating demand under various conditions, a ponderous treatise might be penned. Now it must suffice to point out that with progress they have apparently tended increasingly to rest upon specialized commercial men.

Distribution of the risks of anticipating. - Let us take a particular case, by way of illustration, and consider the possible distribution of the risks involved in preparing a country's supply of cotton prints for the summer. Remember that I am tracing possibilities now and not attempting to describe the custom of the trade in any particular place.

We may begin with the wholesale provider in the home trade who does not produce. Such a house has to prepare its stock of prints for the spring. It may get some guidance as to what will be wanted from the retailers, but most of the retailers will probably stock their shops by choosing from the stocks of the wholesale houses. Now the manufacturers (that is weaving firms, which, we shall suppose for simplicity, do their own printing) may anticipate themselves to some extent, and the wholesale house may choose from their supplies and order what they want if it has not been produced. In this case manufacturer and wholesaler share in the venture of prophesying 
about demand. Or the manufacturer may produce only on the order of the wholesale dealer. In this case the hazard of anticipating retailers' demand rests exclusively with the wholesale dealer. Generally speaking it may be said that the latter system tends to be the rule in so far as wholesale dealers stand between manufacturers and retailers.

But even in the latter case the manufacturing business (that is, in our example, the weaving firm which prints) is not without its share of risks, apart even from those connected with the cost of making up material. The risks which $I$ have in mind now are those created by fluctuations in the price of material, that is, as regards our example, in the price of yarn, assuming that the manufacturer does not spin his own yarn. Now the weaver would naturally try to shift these back on to the spinner or forward on to the dealer. When the weaver is asked to quote for deliveries of particular cotton fabrics at intervals as they are needed, before quoting, he may try to get, and succeed in getting, quotations from spinners for the yarns that he needs, to be delivered as he needs them, and base his quotations upon these quotations of the spinners. Or the weaver might induce the wholesale dealer to give him the order on the understanding that prices should vary with certain market quotations of yarn; and then buy yarn as he required it.

'I'he history of the risk may be followed up even beyond the spinner if any of it is passed back to him. The spinner is speculating if he quotes prices for future deliveries of yarn without knowing what his raw cotton is going to cost him. He might avoid speculating by buying at once all the cotton that he needed to execute the order ; but if the price of cotton were generally expected to fall he would be ill-advised to do so. And if he did so, the community would lose, because the price of cotton when it was high would be raised still higher, and the range of variation in the price of raw cotton would be stretched out. Or, as there are futures in cotton in many cotton markets, the spinner might buy futures in cotton in quantities and for periods to suit his orders for yarn. But to do this would not be to protect himself completely, because the price of futures, as explained in the chapter before this, varies with the price of some one grade of cotton which might not be the grade that he wanted. If the grade that he wanted rose in relation to this basis grade, against its special rise in price the spinner would 
not be insured. So, broadly speaking, we may say that futures provide him with a hedge against a general rise in the price of cotton, but not against a special rise in the price of the exact kind of cotton that he needs. However, the spinner could escape the whole of the risks which we have been analysing, if he could contract with some cotton broker to have delivered to him at stated periods stated quantities of the exact kind of cotton that he desired at a price fixed when the contract was made. In this way the spinner would shift those of his risks connected with fluctuations in the price of material back on to the broker, as the weaver shifted his corresponding ri $\mathrm{ks}$ on to the spinner. The broker in turn could hedge against the bulk of the risks involved in his contract by buying futures on the cotton market, or entering into some of the numerous future transactions which are there embarked upon. He might even make arrangements with other brokers by which he distributed all or some of the risk associated with the "points on or off," that is the risk that the special kind of cotton that the spinner wanted might rise more than basis grade rose. I do not propose to weary you by tracing the element of risk back to the grower of cotton. Of course, when production does not reach back to any market or markets in which futures are used, the shifting of some of the hazard involved in anticipating on to dealers in futures is not feasible ; but there are still dealers in the material to be reckoned with and the producers of it. Our particular case might have been rendered more complex by the inclusion of arrangements for export.

In the distribution of the risks involved in anticipating, tendencies to uniformity seem to be operative. But naturally in different industries, under different conditions, different arrangements must be expected to be established. We may perhaps venture on two generalizations. The first, already suggested, is that these risks are increasingly settling on specialised commercial men. The second, which is more doubtful, is as follows. On the one hand, the risks of losing through making mistakes in anticipating the needs of consumers tend to be rolled, or shifted in bulk, on to wholesale and retail dealers since they are more likely to forecast demand correctly than manufacturers. On the other hand, the risks which are run when the future prices of raw material are guessed at, as they are likely to be when finished goods are ordered for 
delivery far ahead, are probably tending on the whole to be shifted back to the initial stage in the productive process, and if possible to dealers in the raw material, who are in a more favourable position than those who work up the raw material, or those who deal in the finished product, for forming correct judgments about future demand and supply in relation to it. But to this second generalization the exceptions are so numerous that it must be regarded as tentative and as having only a limited field of application.

Differentiation of productive systems. - It will be an aid to our understanding of commercial functions in their relation to industrial ones to make some. analysis of a complex productive process and suggest some ways of explaining how and why it differentiates, and when it differentiates how its parts are held together ; though, bear in mind, we shall be dealing with a group of facts animated by so many conflicting dispositions that it will be almost impossible to find our way to any definite conclusions having a moderate degree of universality.

Let $A$ and $B$ be two industrial processes involved in transforming some material into finished goods- $A$ and $B$ being respectively, for instance, steel-making and boiler-making, or silk-throwing and silk-manufacturing, or timber-sawing and cabinet-making. Let small letters stand for the commercial work of buying and selling. Let brackets mark the boundaries of businesses.

Then the following are examples of the types of business organization that are possible :-

$$
\begin{aligned}
& (a, \mathbf{A}, \mathbf{B}, b) \\
& (a),(\mathbf{A}, \mathbf{B}),(b) \\
& (a),\left(\mathbf{A}, a^{\prime}\right),\left(b^{\prime} \mathbf{B}\right),(b) \\
& (a),(\mathbf{A}),\left(a^{\prime}, b^{\prime}\right),(\mathrm{B}),(b)
\end{aligned}
$$

These are only examples. The reader will see that other combinations are possible. To save space I have not set out all of them.

Let me now explain, recurring to our example of the cotton industry. A and $B$ stand respectively for cotton-spinning and cotton manufacturing (that is weaving). The letter " " " means the commercial function of buying raw cotton, " $b$ " means selling cotton fabrics, " $a$ " " means selling yarn, " $b$ " means buying yarn. The formula $(a, \mathrm{~A}, \mathrm{~B}, b)$ means that a single business takes responsibility for the purchase of its raw material (through a buyer, perhaps, who 
is a member or employee of the firm), assuming the risk of flucturtion in price ; both spins and weaves; and sells direct, as it can, to retailers after it has produced. The formula $(a),(\mathrm{A}, \mathrm{B}),(b)$, means that a wholesale house $(b)$, which may engage in the home trade or foreign trade, places orders with the spinning and manufacturing firm (A, B) and that the latter arranges for its supplies of cotton to meet its orders through an independent cotton-broking firm (a) which takes the risk of fluctuation in the price of the cotton needed. In the next formula $(a),\left(\mathrm{A}, a^{\prime}\right),\left(b^{\prime}, \mathrm{B}\right),(b)$ spinning and manufacturing are represented as having separated into independent businesses. The spinning firm sells its yarn through its seller and the manufacturing firm buys its yarn through its own buyer. According to the next formula $(a),(\mathrm{A}),\left(a^{\prime}, b^{\prime}\right),(\mathrm{B}),(b)$, an independent yarn agent $\left(a^{\prime}, b^{\prime}\right)$ has appeared through whom (A) disposes of its yarn and (B) buys its yarn. There would of course be many yarn agents and many spinners and so forth ; and the yarn agents might be simply agents (that is intermediaries taking no risks) or they might be dealers in yarns taking risks.

It seldom happens that one type of organization alone triumphs in an industry. Usually several types will be found side by side.

I have already suggested the conditions under which specialization by processes appears in an industry, but I have not analyzed them in detail. Apart from the economies of specialization, outstanding conditions, all of which need not be present, would seem to be (1) that the industry should be concentrated in a small locality, so that marketing at a common marketing centre wastes little time and cost of transport is not high ; (2) that it should be as easy for a manufacturer undertaking one of the later processes in the complete chain of production to get satisfactory material by purchasing it as by producing it; and (3) that the half-finished article turned out by one of the early processes should be used for many purposes. But the phenomena of industrial and commercial differentiation have been little explored. Integration sometimes takes place where one would expect further differentiation; and one must remember that the possibility of collecting large groups of capital for its enterprises profoundly affects the form which an industry assumes.

When commercial functions tend to specialize out from the productive system, and be assumed by independent businesses, they 
do so largely because of the advantages of business specialism. One leading case from which this particular specializing tendency is absent is that in which producers are turning out special products which they dispose of in private markets. By a "private market" I understand a group of customers who buy from a particular firm because they have formed the habit of thinking that its goods yield the best value for the price. Articles which sell by the name or mark of their makers are selling in private markets. Most of the habitual buyers of these articles have become prejudiced in their favour and will not be satisfied with substitutes, though the substitutes may be quite as good. Evidently a producer of such articles will not sell through brokers who are selling also for rival producers. On the contrary he will try, through the agency of his own travellers, to seize and to hold as much of the market as he can. Businesses which have to win their private markets naturally grow slower than others ordinarily, though they may attain ultimately a greater size, other things being equal.

The sales of articles which can be easily classified on inspection are not much affected by the reputations of their makers. A firm producing such articles may therefore sell more satisfactorily and more economically through independent agents or dealers than through its own salesmen. It goes without saying that it is much more difficult to create a private market in producers' goods than in consumers' goods, because producers as a rule are more expert, more critical and more alert to seize an advantage, than the ultimate consumers.

\section{Reactions of commercial organization on industrial organiza-} tion.-A complete scientific analysis of commercial organization should trace its reactions upon industrial organization, but in this treatise only the most condensed summary of these reactions can be offered. Industrial specialization by process, we have already learnt, is dependent upon the possibility of creating satisfactory markets in between industrial processes. The existence of such markets is essential to the preservation of continuity of production, after an industrial process has differentiated into independent businesses. Hence much industrial specialization of businesses with its vast economies is dependent upon commercial organization. The separation of industrial functions from commercial functions also brings about larger industrial businesses (with their greater 
internal division of labour) by enabling the employer to concentrate his attention on his industrial functions. Moreover it brings about a closer correspondence between capacity and task in business. A producer of blankets for export, say, who had to buy his material and sell his blankets unaided by commercial experts, and carry all the risks of these commercial operations, might fail as a blanket-manufacturer, though he might be ideally efficient in performing the industrial part of his mixed offices. Another blanketmanufacturer whose factory was badly organized and managed might keep his firm going profitably by virtue solely of his talent as a man of commerce. When commercial functions split away from the industrial, the fittest to survive industrially tend to survive as heads of producing businesses, and the fittest to survive commercially tend to secure all the commercial work; and the community in consequence is made much the better off. The reactions of commercial organization on the form of industrial organization will be cursorily noticed in the next chapter. 


\section{CHAPTER XIII.}

\section{TYPFS OF PRODUCTIVE ORGANIZATION.}

IN a single chapter on so intricate a subject, to deal adequately with which wide experience would be requisite, I cannot do more than suggest some leading reflections.

Agricultural systems. - In the organization of agriculture the simplest arrangement is for the cultivator to own the land which he cultivates. This plan has its recommendations: "give a man secure tenure of a rock and he will turn it into a garden, give him a nine years' lease of a garden and he will turn it into a desert". But the scheme has its drawbacks also: and both recommendations and drawbacks are relative to time, place and circumstances.

While peasant proprietorship insures that assiduous attention shall be paid to the land commonly, it cannot insure that the land shall be treated in an enlightened fashion and with adequate capital. And when it is not supplemented with some form of co-operation, a deplorable lack of economy in marketing and in the distribution of the produce results. Moreover, under paasant proprietorship, there may be a danger of excessive division of holdings. And the abler peasants will find it impossible to acquire all the land that they could manage, because of its cost to buy outright; and many who are best qualified to cultivate the land may have no chance of getting any at all. Some of these disadvantages of peasant proprietorship may be minimized by associating with it a leasehold system. 
In its effect on character and social life also, there may be flaws in small-scale occupying ownership. A free peasantry, owning their little estates, with their fine characteristics, may nevertheless be prone to self-sufficiency and parsimoniousness. The vice of excessive thrift may spread among peasants whose holdings are their own property. The land may be made a fetish and everything may be sacrificed to it-affection, happiness, culture and leisure. That the magic of property turns sand into gold, does not settle the question from the point of view of humanity.

Metayage is a system intermediate between peasant proprietorship and the leasehold system. Under it farms are united in estates over which rights are exercised by persons whom we shall call landowners, though the land may not by custom be theirs to do with just as they like. Broadly understood, metayage exists in a variety of forms in many parts of the world, and in some of these forms it shades off into the leasehold system. I shall first treat of it as it is found traditionally sanctioned by custom and unaffected by other systems of tenure.

The landowner furnishes a portion, if not the whole, of the capital, and the character and extent of the cultivation is generally made a matter of arrangement between him and the cultivator. Though the liberty of the cultivator is restricted, and there may be a fear lest methods of farming should become stereotyped, the enterprise of the cultivator may actually be stimulated, and given opportunities, by a good landowner, whose intelligence will probably be more highly trained than that of the average peasant.

As the landowner is a partner, he appropriates some of the produce as his remuneration. His share is some agreed proportion of the whole. It has been objected to metayage that, as the landowner takes a certain proportion of the produce, the inducement to the cultivator to do his best is partially 
obliterated and he will, therefore, work the land less intensively. The second ploughing of a field, say, would add 10 bushels of wheat to the produce. If the cultivator received the whole of the ten bushels it might be just worth his while to plough the field a second time. But if he received only a proportion of the result, say a half, the other half going to the landowner, it would not. This objection might be fatal were details as regards the working of the holding not settled by arrangement between the landowner and the farmer. It would not seem, however, to be serious practically, especially in view of the tendency to excessively intense cultivation, as regards the application of labour to the land, on small holdings. And metayage has the merit of providing that the burden of the payment made to the landlords by the cultivators shall be automatically reduced in bad years, as it is not when farms are leased at a fixed annual charge. Theoretically under metayage the size of the farm is readily adapted to the capacity of the cultivator, though actually tenacity of custom has curtailed adaptability in this respect.

In America it is common for the hiring-charge for land to be a proportion of the harvest, and under the conditions of agriculture where it prevails the advantages of the arrangement are said to exceed its disadvantages.

The leaseholder is left with a freer hand than the metayer, but he is seldom permitted to alter the character of his farm, for instance by breaking up pasture, without the consent of his landlord, and is naturally required to keep the state of the property up to a certain level. Whether the greater liberty which the leaseholder enjoys is a gain or a loss from the public point of view, or his own, depends in chief upon the initiative, resourcefulness and knowledge of the cultivators. Freedom to make endless mistakes and muddle into embarrassments is a doubtful boon.

For the attainmont of the most fruitful results from the 
leasehold system, it is essential that the land should be leased for a period which will be lengthy enough to make it worth the farmer's while to spend himself and his resources liberally upon the land. It may be added that arrangements for compensation for unexhausted improvements, which are equitable both to tenants and landowners, have the good effect of preventing the waste of time, land and capital, which otherwise is unavoidable when a lease is drawing to a close and the farmer is chary about investing fresh capital in the land and is anxious to squeeze out of it every atom of value.

With all its good points, the leasehold plan is unsuited to the remote districts of new countries, where farms have to be made out of rough land, unless the lease is an exceedingly long one. A large reward must be offered to persuade the cultivator to endure the toils and discomforts, and face the dangers and solitude of the pioneer.

As regards the size of a farm, nothing need be added to the principles already laid down with reference to businesses generally. The size of a farm depends broadly, and should depend, on the nature of the farming (whether, for instance, it is arable, dairy or fruit farming, or market gardening), and upon the ability of the cultivator. The fact that each farm must be equipped with a house and farm buildings limits the degree in which the division of an estate into separate tenancies can be modified; and custom and tradition--markedly in old countries-limit it as well.

Prixate businesses and companies.-In private businesses I include partnerships, but for simplicity I shall speak as if every private business had one head only. Among types of business management the firmest lines of demarcation separate private businesses from the companies which are controlled by elected boards of directors. But all companies are not essentially of the latter class. A business may be dominated by one man, or two or three men, though it has 
been clothed in the dress of a company in order to dissociate the owners' private property outside the business from liability in respect of business debts, provide for distribution of profits among persons who are not active in the business but have an interest in it, or get fresh capital easily, or for other reasons.

The peculiar merits of the organization of production in private businesses are (1) that the man at the head of each business is continuously incited by his self-interest to secure efficiency and economy, and (2) that any man who can find the capital can start any business that he likes and, consequently, that new men keep pushing into the arena where the fittest survive.

The second merit is strictly qualified in industries for a start in which the possession of much capital is requisite, as few would be wealthy enough to initiate a business, and, of those who were, only a small proportion would care to put so many eggs into one basket.

In the public company deliberate selection largely takes the place of the kind of selection just described; and the choice of leaders must frequently be made on more or less slender evidence. The choice may not be a leap in the dark, but it is a leap in the twilight. But is not the selection which takes place in a régime of private businesses equally a leap in the twilight? We must grant that it is, but those who leap choose themselves; and many choose themselves so that selection goes on continuously. A man thinks he has it in him to be an entrepreneur and he takes his chance. He may be right, and he might never have been singled out for the position by his fellows. He may be wrong, in which case his personal losses force him to dismiss himself. The fact that a man has the imagination and independence of mind to be ambitious, faith in his powers of succeeding as an entrepreneur, the perseverance to force his way, and the courage to face the inevitable risks when he 
is prepared to take the final step, is the best augury possible that he is endowed with the right qualities for filling satisfactorily the position to which he aspires.

But the public company has its strong points. It can rapidly get control of a capital which is beyond the reach of most men who are in business on their own account. Control over capital is a matter of predominant importance in certain trades. It may be conjectured, therefore, that public companies in these trades might be more enterprising and more efficient than private firms. Again for risky businesses it may be easiest to get capital from many people in small sums. Moreover the public company can enlist at a moderate cost the aid of the best information and business judgment by electing upon its board of directors the men whose advice it would like to have. Mistakes will be made; but for two directors who may be valueless one may be of immense service. It may be true that the most successful employers in a particular trade cannot ordinarily be brought into a company which competes or intends to compete with them, but different sorts of business are strikingly similar in their broad underlying characteristics.

It is notable that the policy of the public company, by reason of its constitution, may be different in type from that of the private business or private company. The salaried manager must frequently compromise more than the private employer because of the over-ruling judgment of his directors ; and the directors, too, must compromise when they differ among themselves. Policy has to be justified in the public company. There are advantages in this ; rashness gets nipped in the bud. But there are disadvantages; there is divided responsibility; and a man may have acquired a wonderful instinct of sound and original judgment and yet have remained quite incapable of analysing the reasons which led him to his conclusions, or of persuading others to share his views. 
Under modern conditions private businesses and public companies seem to have their respective spheres. When a moderate capital is adequate and constant attention to changing detail is vital, when customers have to be enticed and are easily lost and changing fashions have to be met, the private business is likely to be the most efficient, for one reason, if for no other, that prompt decisions are necessary and management cannot be reduced to rule. When great economies can be reaped by large scale organization, or when management can be systematized, and urgency does not commonly prevent resolutions as regards strategy and tactics from being taken at leisure, the company organization is likely to achieve its best results both absolutely and relatively to those achieved by private businesses. One plausible generalization would seem to be that, other things being equal, an industry which is flanked by developed markets is more suitable for company organization than one which is not, because in the former commercial risks, as I have called them (see pp. 119-26), may be avoided. Such are the mutations in every productive field that at one time in an industry the company may gain ground and at another time the private business.

Finally, notice two points. The first point is that it is one thing for a company to take over a thriving concern, which may make its profits out of an unvacillating private market, and another thing for a company to create a business. The second point is that the company and the private business may be equally efficient in a given set of circumstances. The one triumphs in one way and the other in another way.

Co-operation.-Broadly speaking, co-operation partakes of the company type of organization, but it has peculiar features of its own. Of co-operation there are many kinds.

The title "distributive co-operation" is reserved for the cooperation which begins with an association of consumers. It 
relates primarily to the retailing of goods, but, as we shall see, it has been extended backwards to production. The common principle is to divide profits (after payment of all expenses including interest on capital, which is remunerated at a fixed rate, and the cost of any social activities) among members in proportion to their purchases from the stores, and make a trifling charge for membership. Where distributive co-operation is highly developed, wholesale co-operative societies have been established which bear to the retail stores the same relations as the latter bear to their members. The retail stores are members of the wholesale and draw from its profits shares which are proportional to their purchases from it. Wholesale societies purchase in the open market and produce for themselves in their own factories some of the articles which they sell. Their production is not, however, to be called "productive co-operation," as that term is conventionally attached to a type of co-operation which has yet to be sketched. But the principle of productive co-operation, with modifications, is applicable to these productive shops of the wholesale societies. It is applicable also to the work of distributing goods; and actually a portion of the profits made by some stores are divided among their employees. Needless to say, profit-sharing may be, and has been, introduced into businesses other than co-operative (see p. 331).

In the competitive struggle a co-operative store holds a strong position, because its membership furnishes it with means of gauging the extent of its market over and above those which are at the disposal of a private shop, and also because the bulk of its market is a private one, as I have expressed it (see p. 126). Moreover, its members are anxious to do what they can to further the interests of the store, either for the sake of magnifying the profits in which they share or for general social reasons. Many co-operators will buy from their stores articles which are not exactly of the kind that 
they want rather than go elsewhere; and in some places where co-operation is very powerful and the members of a store take great pride in it (and perhaps regard it as embodying an important social movement) the store actually sets the fashion. So a co-operative store largely escapes those losses which are incurred by private shops when customers' needs have been incorrectly anticipated.

An obvious criticism of distributive co-operation is that, in the degree in which it relies upon the circumstances favourable to its prosperity enumerated above, it tends to encourage inappropriateness in production, to suppress initiative in demand, and to prevent the displacement of the inefficient manager. The co-operator might contend, however, with some reason (1) that much of the variation in demand is purely capricious, and does no good to anybody, and causes waste, and (2) that inappropriate provision to meet the wants of consumers is prevented in so far as the members of a store are a closely knit social group the individuals in which meet together, for business purposes, recreation and social pleasures and duties, and are thus enabled to bring their influence to bear upon the management of the store. Who, it may be asked, are most likely to understand what their customers really want, private shop-keepers who see their customers only over the counter, or the managers of co-operative stores who associate with their customers at social and educational gatherings?

It is noteworthy that distributive co-operation is used as an ageney for thrift. When higher prices are charged in cooperative stores than in private shops, the payment of some extra pence on weekly purchases is not felt, but the lump sum -received on their withdrawal in the form of dividends is felt. Plainly, however, there is a danger to guard against here. All that was paid in higher prices may not be returned. Some part may be lost in careless management. 
Some of the principles of distributive co-operation have been applied in such businesses as the Army and Navy Stores and the Civil Service Stores in England.

"Productive co-operation" refers strictly to the production undertaken by associated groups of workmen, who may act through an elected committee. It has met with only limited success. Securing capital has been a difficulty; also securing capable managers. And not infrequently the inevitable limitation of the manager's authority has been a serious handicap. However, there are some flourishing co-operative businesses of the productive class. In trades where little capital is needed, and where efficiency depends largely on the application and care of the individual workman, so that in private businesses much supervision is essential, co-operative groups of wellselected men, imbued with the right spirit of mutual help for the accomplishment of a common purpose, may be expected to reap prosperity, and have indeed done so.

"Labour co-partnership" means a fusion of some degree of productive co-operation with the ordinary business types. The employees are represented on the board of management and receive a share of the profits. We may express its character by saying that it implies both control-sharing and profit-sharing. A scheme which provides for profit-sharing only is not, properly speaking, labour co-partnership. Of profit-sharing I shall treat later under the heading of distribution. Labour co-partnership has met with a larger measure of success than complete productive co-operation. Where it has been found advantageous-for instance where a business gains from having an individuality, to retain which it is important that the workmen employed should not be constantly changing and should do their best for the firm-it is said to produce both contentment and an interest in the business which has a high economic value. In very large businesses it is difficult to apply-and these are the concerns where 
profit-sharing has the least value, particularly when the labourcost is low,-but in such businesses, it might be applicable, with modifications, departmentally.

People may unite for the attainment of limited ends by cooperation. Small producers are placed at a disadvantage in competing with large producers in certain respects in particular, and in these respects they may combine so as to enjoy co-operatively the economies of large-scale operations. Thus small farmers may own specialized agricultural machinery jointly, and may buy seeds and manure jointly, and jointly arrange with railway companies for the carriage of their produce. The co-operative dairy also seems to have removed a disability under which the small dairy-farmer was labouring.

Co-operative credit consists in using the credit and resources of a group to meet the needs for capital of members of the group. The pooled credit of a group is naturally much greater than the aggregate of the individual credits in the group, because all become sureties for each. However, in some cases the liability of members is limited. Other advantages of cooperative credit are that providence is encouraged, and that the members of the co-operative groups informally see to it that loans are properly used, or are at once called in, and that bad debts are not contracted. Co-operative credit is provided through agencies known as people's banks, or popular banks, or Raiffeisen banks (after their founder) in certain agricultural districts in Germany and elsewhere, or agricultural banks, or Schulze-Delitzsch banks (after their founder) in certain urban districts in Germany, but many of the last have become large joint-stock organizations which retain little of their original character but the name.

Co-operation has been extended to house-owning. Copartnership tenants' societies are associations through which the occupiers of houses on a given estate own the houses in 
common. Shares may be paid for in instalments. If any one desires to leave the estate he can sell his share. The superiority of this arrangement to the ownership of just his own house by an occupier is $(a)$ that the risk of loss on a group of houses is less proportionally than the risk of loss on a single house, and (b) that the estate may be laid out to suit the tastes of the occupiers.

Classes of monopolies.-Monopolies may be classified into, (1) natural, (2) social, (3) legal, and (4) voluntary.

The monopoly which takes its origin from the fact that the sources of some valuable natural product are strictly limited may be called a natural monopoly.

Social monopolies, as I have called one class of monopolies for convenience, arise out of the peculiar position of certain businesses in the social economy. Sometimes there is no room for more than one business, or a very few businesses, to provide a given service. It might not be possible for two railway lines connecting two small places close together to pay; and even if it were, two lines would be less economical than one line. Competing gas companies cannot be permitted to lay their pipes in the same streets. The offices of providing public utilities which must be monopolized in a given district, like the furnishing of gas, are frequently undertaken by public authorities; and, if they are not, they are usually controlled. The problem of their control we shall discuss in Book VII (pp. 351-2).

In addition to thorough-going monopoly among the socalled "social monopolies," we must notice the commingling of monopoly and competition, and what is hardly monopoly but rather a limitation of rivalry in such a degree that competition either is not, or is not likely to be, fully effective. There is competition between rival railways, but competition is not as a rule untrammelled in the provision of transportation as it is in the provision of boots. The "social monopoly" we 
may define as the monopoly which in a given social system is inevitable for economic reasons.

Legal monopolies are those created by law. Patents and copyrights are the obvious examples. The justification of these, when they are conferred on inventors and authors, is indicated on pages 353-4. Some of the social monopolies enjoy legal support. A railway company must usually get authority from the State to build a line, because it may have to acquire some of its land by compulsory purchase, and it might be objected to as a nuisance or danger by certain people.

Voluntary monopolies may arise (a) from the absorption by one business of other businesses, or the economic destruction of rivals, or $(b)$ from the purchase of competing businesses, or from more or less voluntary agreements. The first method is practically impossible if there are many businesses.

Among industrial combinations we may broadly contrast (1) those which leave an appreciable part of the individuality of the combining units untouched, and (2) those which destroy it. Commonly the former combinations are termed "kartels" and the latter " trusts".

Trusts and kartels.-The formation of a trust-by which we understand here the complete merging of several businesses in one big business, which, however, may have its constituent works widely scattered-is a colossal task, beside which the establishment of a loose combination to maintain prices is insignificant. For the appearance of a trust, therefore, an ordinary cyclical period of bad trade hardly creates sufficient incentive. Commonly it is found requisite (a) that big economies should be expected from large-scale organization, or $(b)$ that big profits should be expected from the addition of a large volume of capital to that already invested in the industry, or $(c)$ that a substantial monopoly revenue should be expected from the strict regulation of output or discriminative 
prices. Further, the conditions are not unfavourable for the formation of a trust if the industry is of such a kind that its efficiency is not appreciably reduced by centralized management. Even when the gains aimed at are chiefly derived from the regulation of prices, the trust may be preferred to the kartel because all control in the former is unified.

Immediate gains may be reaped from centralized management on both the industrial and commercial sides of a business. On the industrial side economies are speedily effected (i.) by shutting down antiquated or badly situated works, or (ii.) by enlarging others and adding thereby to internal specialization, or (iii.) by specializing the several works. The same improvements might be brought about eventually under competition, but only in a far-away future. On the commercial side, the trust, as the kartel which has a central sales association, corrects the overlapping of arrangements for selling. In short, it suppresses all commercial functions which have as their object the expansion of the sales of a particular firm rather than the enlargement of the market as a whole. The trust may concentrate on a policy of evoking demand; which it is of doubtful value for any one firm to attempt under competition, because rivals would share in the profits if the attempt were successful. The kartel may make this its policy also, but it may be restrained by the difficulty of persuading its constituents to put money into such a venture. It should be observed here that the industry the marketing of whose products is complicated and requires unremitting attention to detail-because of incessant alterations in fashion-is calculated to flag under centralized management, since constant industrial rearrangements must be made, and continuous and minute acquaintance with the by-ways of the market is required of its directors.

As the trust has a more laboured birth, so it has a more stable existence than the kartel. An ordinary period of good 
trade will seldom, if ever, of itself be sufficient to disintegrate it. But it does not follow that once established it is bound to be permanent. The trust is so recent as a commonplace economic phenomenon that it is impossible to establish inductively how permanent it is likely to be. A priori, however, we may speculate as follows. Leadership in the trust may tend to lose its first enthusiasm and alertness. The removal of competition may make way for indolence, or at least a self-satisfied conservativism. Moreover, in the absence of the struggle for existence among organizers in the industrial field which the trust has conquered, the survival of the fittest will hardly operate with thoroughness. The level of capacity of the trust's leaders and managers may, therefore, tend to decline in time. At first the trust would draw its leaders from those who had demonstrated their fitness by rising to the top under competition. Upon this question the reader may be referred to pages 132-4.

Apart from this handicap in the matter of organization it is possible that the character of the fixed capital managed by a trust might not keep pace with invention. Under competition in a growing industry, new businesses, fitted with the latest appliances, compel the renewal of the old-fashioned plant against which they compete and thrust fresh ideas upon inert employers. A monopoly might find that it paid best to persevere with its old machines, even if it possessed the insight to realize the economy of new inventions. In this event a growing divergence between actual and possible costs of production would be witnessed. After a time such a divergence should be sufficient to draw the attention' of business enterprise to the industry. Competition might then appear on a small scale. Energetic and resourceful capitalists would be anxious to engage in the industry. In these circumstances the trust, if it were devitalized and no longer exercised its original fascination over shareholders, would 
tend to disintegrate. In its disintegration the industry would not be destroyed to give place to a new one. The control of the old would pass into many hands at the market price of its shares, and the industry would then undergo reconstruction.

Generation and stability of trusts and kartels. - The simplest form of combination is an agreement among producers to regulate prices. If the object is merely to introduce discriminative prices, there is no reason why the combination should not stop at price regulation. If, however, the object is to get larger profits than those reaped under competition, reactions will probably follow which necessitate the assumption of some control by the combination of the supplies to be placed on the market. Production is apt to outstrip the sales which are possible at the agreed prices. Hence stocks tend to accumulate ; and the growing stocks alarm the manufacturers and undermine their determination to keep prices up. Moreover, if there is doubt about the stability of the agreement as to prices, individual producers will be unwilling to cut down their output appreciably. They will be fearful lest others should not follow suit, and should snatch an advantage were the compact repudiated. Hence the regulation of prices frequently involves, or brings about, the control of sales or output. Control of the latter takes the form of assigning particular markets to particular firms, which is only possible in very exceptional cases, or apportioning a certain output to each of the several combined firms. Hence one disadvantage of the kartel is that, though it may purport to leave production free, it frequently imposes rules which seriously restrict the growth of the firms with the greatest vitality. In order to remove this objection, the transfer of the whole or a part of a firm's authorized output or assigned market, may be sanctioned. But these transfers, even when freely permitted, do not take place to the extent to which business would naturally pass from one firm to another under free competition. Transfers must be bought, but business which one firm captures from another under competition it gets for nothing. By the kartel's policy the business of the decaying firms may be made remunerative. They suffer less, relatively, than the advanced firms from restriction of output, because the output of the former would probably decline in any event. 
One merit which the kartel has over the trust is that the former allows of individual initiative in the management of production; though, as we have seen, initiative is at the same time discouraged, because its fruits are limited by the protection of the weak firms against the strong. A kartel is easily formed; because no vast financial operations are required to bring it into being. It is as easily dissolved; because its dissolution does not necessitate any industrial rearrangements. At most, selling functions have to devolve from a central office to the separate businesses; and the capital embarked in a central sales association is not relatively considerable.

The generalization would seem to be warranted that kartels, particularly those which have not discriminative prices in view, are more likely to appear in times of depression than in times of prosperity. When trade is bad, competition among sellers is keen and prices are driven down. Producers may strive to escape from this "cut-throat" competition by agreeing to offer their goods unitedly or not to sell below a certain price. What, it may be asked, do they gain from this action? The answer is (as the theory of monopoly price to be expounded makes plain), the power to select a price, which, with the sales possible at that price, may be more remunerative to them than the price and output which would be reached under the play of competition. When trade recovers, the inducement to combine on the part of the stronger firms is weakened, or removed. Its place may even be taken by a strong incentive to shake themselves free from the fetters on their enterprise. A widening market is the opportunity for the pushing and alert. In brisk times the most strenuous firms will probably chafe at, and possibly break through, the regulations of the kartel which directly limit the output, or the marketing sphere, of each of its constituent businesses.

As regards the generation of trusts, there are two chief sets of circumstances in which the condition marked (b) on page 140 - that is the prospects of large profits from large fresh investments-may appear. The one set is found-to state it in extreme form-when establishing the industry on a much larger scale would so appreciably lower the cost of production that the commodity would come in touch with a new range of demands which are highly elastic. The other is found when the industry is passing through something 
of a revolution, in the matter of productive methods, which will prove very costly. As regards the second case, under competition the revolution might take very many years to complete itself. Its expense would retard its consummation. A company with enormous resources could carry the revolution through rapidly ; and by doing so it might make prodigious profits. As regards the first case, there is no assurance that competition will bring about a refounding of the industry on a new scale in a reasonable time, if it will at all. It is presupposed that the industry is at a position of equilibrium, but that actually another position of equilibrium exists for a much larger output. It is presupposed, further, that the distant position of monopoly equilibrium is the more advantageous for the monopolist, though it may yield a smaller rate per cent on capital. Evidently a deliberately planned campaign on a magnificent scale may be needed if this second position is to be seized. 


\section{BOOK IV.}

EXCHANGE OR THE EQUILIBRIUM BETWEEN DEMAND AND SUPPLY.

\section{CHAPTER XIV.}

COMPETITION, BARTER AND THE PRICE OF NON-REPRODUCIBLE THINGS.

ThE economics of exchange is commonly taken to consist essentially in the theories of rates and quantities of exchange in the home and foreign trade. The theory of rates of exchange is known as the theory of barter when no money is used. When money is used, it is known as the theory of price, in its relation to the home trade, and the theory of international values, in its relation to foreign trade. We shall see as we proceed that there is a close analogy between all these theories, and particularly between the theory of barter and the theory of international values.

The complete theory of rates of exchange is sometimes called "the theory of value". But it is best not to give it this title, because by some writers the theory of value is conceived as covering also the branch of economics known as distribution, that is the economics of the sharing of wealth. We shall observe in due course that there is not only an intimate connexion, but also an underlying identity, between the theory of exchange and the theory of distribution. 
In this chapter I shall discuss the essentials of the theory of barter. But before doing so I must define competition. I have frequently referred to competition already, but so far I have relied upon my reader's general notion of what is meant by it. This seems as suitable a place as any to fix our ideas about it, as competition dominates most of the exchanging done in the world.

Competition.-There is economic competition (a) when would-be buyers bid against one another and (b) when wouldbe sellers bid against one another. The act of bidding is to be conceived broadly, and all factors in production, as well as other things, are to be regarded as objects of purchase and sale for the purpose of this definition.

The reader will mark that competition may be one-sided or two-sided. As one-sided, it is competition between buyers or competition between sellers. As two-sided, it implies both.

When we define competition in this way we realize immediately that it does not imply selfishness, or the dominance of self-interest, any more than demand does. The purchaser of a picture may want it to present to his native town. One man may compete against another for a position because he covets it, not for the sake of money, of which he may have as much as he wants, nor for the sake of power, for which he may not care, but in order that he may play that part which he esteems himself fitted to play. As things are, admittedly, such a man may be a rarity. In most of us mixed motives prevail. Many a young man chooses his work with some feeling of its importance in the world in which he lives and with a half-heroic intention to make it more valuable. But at the same time he may look forward to advancing his material interests-which include the interests of any family that he may have and possibly of friends -and he may be possessed of a desire for power (see pp. 17-18). 
Of the value of competition and the degree in which it needs control I shall treat in Book VII of these Outlines.

Under competition one price only can be charged for the same commodity at the same time in the same place. If three grocers, Brown, Jones, and Robinson, are trying to sell in a district a certain kind of tea, Brown at $2 \mathrm{~s}$. a pound, Jones at 2s. $6 \mathrm{~d}$. a pound and Robinson at 2s. $8 \mathrm{~d}$. a pound, and if Brown could supply all the tea needed, all consumers who knew of the fact would buy of Brown, and if the fact were fully known Jones and Robinson would sell no tea. In order to sell any tea, Jones and Robinson would have to drop their price to $2 \mathrm{~s}$. Because of the competition of Brown, neither could extort more than 2 s. a pound from me, even were my desire so intense that rather than abandon tea I would buy a certain amount at $4 \mathrm{~s}$. a pound. If Brown could not supply all the tea needed, nor Brown and Jones together, and Robinson would not, or could not, sell for less than 2s. $8 \mathrm{~d}$. a pound, all the tea would sell at 2s. 8d. a pound. The public would first flock to Brown's shop, and by competing with one another would force the price up to $2 \mathrm{~s}$. $6 \mathrm{~d}$. When the price rose to $2 \mathrm{~s}$. $6 \mathrm{~d}$. they would shop indifferently at Brown's and Jones's, but, as the supply of tea would still be insufficient, they would compete with one another and force the price up until it rose to 2s. 8d. and Robinson's supply came into the market.

Hence under competition one price must rule in a market for one commodity, whatever the height of the initial demands of the consumers and whatever the differences between the prices at which sellers are willing to sell if need be. Nobody would insist on selling at the lower price when he was offered the higher price-that is ordinarily. What is true of tea in the above example is true of everything else when competition rules; and it remains true when there is no money to express prices in and they are consequently quoted in terms of other things. 
The theory of barter. - Very few words are needed to explain this theory. Take the case of two savages one of whom possesses a store of apples and the other a store of nuts. Call the one with apples $\mathrm{A}$ and the one with nuts $\mathrm{N}$. If the fact is that

the initial utility of nuts to A

the marginal utility of his apples to A

is greater than

\section{the marginal utility of his nuts to $\mathrm{N}$ the initial utility of apples to $\mathrm{N}$}

exchange will begin. Thus if A would give one apple for ten nuts rather than have no nuts (which means that the initial utility of a nut to $\mathrm{A}$ is $\frac{1}{10}$ of the marginal utility of his apples), and $\mathrm{N}$ would give forty nuts for an apple rather than have no apple (which means that the marginal utility of his nuts to $\mathrm{N}$ is $\frac{1}{40}$ of the initial utility of apples to him), both would gain from effecting an exchange.

Exchange will continue until the ratio between the marginal utility of apples and the marginal utility of nuts, is the same for $A$ and $N$. Up to this point exchanges can be arranged which are beneficial to both, but after this point is reached further exchange would inflict loss on one or both of them. These conclusions follow, you will observe, from the law of substitution, indifference, or equi-marginal returns, in its application to the relations between two persons who can effect substitution through barter only.

It is of interest to observe that the final rate of exchange is indeterminate, if we suppose that equilibrium is reached by means of a number of separate exchanges which may be effected at different rates. If $\mathrm{A}$ got the best of the bargain in each exchange as a rule, the final rate of exchange would be more favourable to $\mathrm{A}$ than it would be if $\mathrm{N}$ got the best of the bargain as a rule. In the former case the final rate of 
exchange would be a higher price of apples in nuts than in the latter case.

It is also of interest to note that, just as the final rate of exchange is indeterminate when the distribution of the advantage resulting from each exchange in a number of exchanges varies, so are the quantities of apples and nuts which would have changed hands when the exchange was complete. Fewer apples and more nuts would have changed hands if A got the best of the bargains on the whole than if $\mathrm{N}$ did.

Suppose now that there are many savages with apples and many with nuts, and that each savage goes about from one person to another trying to get the most favourable rate of exchange-in short suppose there is competition. In this event the higgling of the market would bring about one rate of exchange at which all would trade, and the position of equilibrium would become determinate. It would be such that the ratio between the marginal utility of apples and the marginal utility of nuts would be identical to all after each had exchanged as much as he liked at that ratio.

It would be a valuable exercise for the reader to work out numerical examples of exchange between two people. Start by drawing up tables of the marginal utilities of different quantities of nuts and apples to $\mathrm{A}$ and $\mathrm{N}$, and then consider how they would act and what would be the effect on the utility enjoyed by each.

The theory of barter looks more tangled when we suppose that the parties to the barter can by working acquire more of the things which they are offering for exchange. When we suppose this, we have to allow for a balancing between the marginal dissatisfaction involved in working and the marginal satisfaction got out of its proceeds after barter has taken place. Yet more complexities appear when we posit that each person can work at producing different things, either apples or nuts, or some of each, or other things. Into these complications 
we need not enter here, because of the principles to be applied in allowing for them sufficient will be learnt from the treatment which follows of price determination when goods are produced by free agents.

As most of us give up the practice of barter before we leave school, it might be thought that to analyse it is wilfully to baffle the student. But it is not so. Apart from explaining equilibria in barter, the theory lies at the foundation of some of the most difficult problems of international exchange and distribution. As, however, it is not for this work to discuss these knotty problems, but for treatises on advanced economics, the reader who does not propose to engage in an exhaustive study of economics is advised to read no more of this chapter except the last section.

Diagrammatic treatment of barter.-I shall now represent diagrammatically the case of barter considered first above.

In fig. 7 measure quantities of nuts along $O X$ and quantities of apples along OY. Suppose that the bartering has to be effected at one rate of exchange only and that $A$ and $B$ begin by tabulating their offers at different rates of exchange. Let the curve OA indicate the quantities of apples that A would give for different quantities of nuts, and let $\mathrm{OB}$ indicate the quantities of nuts that B would give for different quantities of apples. The final position of equilibrium is given by the intersection of the curres. $\mathrm{O} h$ of nuts will be paid for $\mathrm{O} g$ of apples.

Let us now imagine that business is done in a series of exchanges of small amounts, one apple, say, being sold at a time. Consider the case of $\mathrm{A}$ and suppose he invariably gets the worst of the bargain and has always to pay as much as he would pay. By the time he had purchased $\mathrm{O} f$ of nuts he would have paid altogether, say, $\mathrm{O} g$ in apples. In this way we get the curve $\mathrm{O} a$. We suppose that when $a$ is reached B will not sell any more nuts at terms which A could offer. This curve $\mathrm{O} a$ and its continuation is known as $\mathrm{A}^{\prime} s$ indifference curve. It is called A's indifference curve because it indicates exchanges, which would yield neither advantage nor disadvantage to $\mathbf{A}$. 
The curve the first part of which is $\mathbf{O} b$ is B's indifference curve. At the point $b$ bartering would stop, we suppose.

Now actually in the course of successive barters A might get the best of the bargain at one time and $B$ at another time. There are therefore a number of stopping points, or positions of equilibrium, besides $a, m$ and $b$, namely $s, t$ and many others. It can be proved that all such points make up a curve. Let $a m b$ be this curve. It is known as the contract curve.

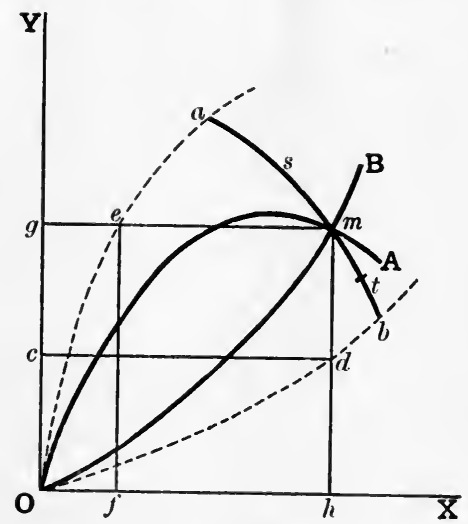

Fig. 7.

The contract curve and indifference curves are mentioned here mainly because they will be met with in some advanced works on economics, in the treatment for instance of certain problems of distribution and foreign trade. They are fundamental technicalities which have a place in the currency of advanced parts of the science of economics, though their use without comment is unusual.

In order to make this analysis quite complete, I may add that $\mathrm{O} a$ and $\mathrm{O} b$ on being continued would eventually meet. Their intersection would mark a quantity of trade which could not come about voluntarily but which, if enforced, would leave neither A nor $\mathbf{N}$ the better or the worse off.

The price of fixed stocks.-The explanation of the price 
of fixed stocks of things, that is of things which are not reproducible, like old-masters and rare editions, presents no difficulties. If the stock consists in just one thing the person who would give most for it gets it, and at a price just exceeding what the next highest bidder would have paid. If the stock consists in several things which are exactly similar to one another, the price at which they sell is approximately or exactly the demand price for their quantity. Let the ruling demand prices for specimens of an old stamp be as follows :-

$$
\begin{aligned}
& 1-18 \mathrm{~s} . \\
& 2-15 \mathrm{~s} \\
& 3-12 \mathrm{~s} \\
& 4-11 \mathrm{~s} . \\
& 5-10 \mathrm{~s} .
\end{aligned}
$$

Let there be four specimens in the market and suppose they are put up to auction together. Then these four will sell under competition for more than $10 \mathrm{~s}$. and for $11 \mathrm{~s}$. at most. There can be only one price. It cannot be more than 11s. for only three would be purchased at more than $11 \mathrm{~s}$. It cannot be as little as $10 \mathrm{~s}$. because five would be purchased at $10 \mathrm{~s}$. If the price showed a disposition to settle at $10 \mathrm{~s}$. the competition of buyers would force it up.

Of course, if the demand price for five specimens differed from that for four by a farthing only, the price when four were sold would be exactly the demand price for four. 


\section{CHAPTER XV.}

\section{THE LONG PERIOD AND SUPPLY PRICES.}

We are now approaching the problem of the normal prices of reproducible things under competition. Normal prices are said to be governed by demand and supply. The statement is true if vague. It means that the price of a thing is settled on the one side by demand prices (that is by the prices which will be paid when different quantities of the thing are to be had), and on the other side by supply prices (that is by the quantities of the thing that will be produced when different prices are paid).

We have learnt all about demand prices. In this chapter we shall ask what settles the supply prices for the various possible outputs of a thing in the long run. In the next chapter we shall treat of the balancing of demand prices and supply prices.

But before indicating how supply prices are governed I must say a few words of the meanings of "normal " and "long period". In economics these terms and what has been intended as the synonym of the latter, that is the phrase "in the long run," are used technically.

Normal or long-period effects.-The normal refers technically to what tends to happen in the long run, or in what is known as the long period. By the effects of a cause in the long period we understand what would be the ultimate results, apart from any exceptional conditions, $(a)$ if time 
were given for all the actions and reactions consequent upon the operation of the cause to work themselves out, and $(b)$ no other change took place.

Most of our generalizations above about demand and production relate to the long period. Nevertheless a specific illustration, now that the time has come to make this conception explicit, will not be out of place. Consider the consequences in the long period of an increased demand for felt hats. At first, as the industry of felt-hat-making had previously been organized to meet a demand smaller than the new demand, the prices of felt hats would rise. Labour, capital and enterprise, would therefore flood into such hatmaking, because it would have been rendered relatively more attractive. The outcome of the flooding of capital, labour and enterprise into this hat-making industry would be an increased annual supply of felt hats and a fall in their price. This inflow of the factors of production into the kind of hat-making contemplated, and the consequent fall in the prices of its hats, would go on until this hat-making industry was no more attractive relatively than other industries.

Let me repeat that the most would not be elicited all at once from the incorporation of large fresh supplies of the factors in production. At first the new labour would be untrained and unskilled. And at first, full use would not be made of the improved opportunities of producing economically afforded by the increase in the size of the industry, a comprehensive account of which has been given in Chapter X. It is only, however, when the tardier effects have had ample time to come about, and in the supposed abeyance of any other tendencies affecting our hat-industry, that the longperiod results of the increased demand for felt hats on their price, and on the magnitude of the felt-hat-industry, are said to be reached. Strictly speaking, they are never reached. To this point $I$ shall return in a moment. 
Long-period effects on demand are the effects brought about, after demands have had to be readjusted, when time has been given to the community to accommodate itself perfectly to the new disposal of income. As in conditions of supply, so in conditions of demand, long-period results are never quite realized.

When I say that a long-period result is the result which would be arrived at (apart from exceptional conditions) if time were given for every one of the direct and indirect consequences of a change to appear, on the assumption that meanwhile no other independent changes occurred, I make it at once evident that it must always be impossible to point to any existing situation and say "This is a long-period result". Long before the normal position of equilibrium consequent upon some alteration, say in demand, is attained, other independent variations in economic conditions will have been sprung upon the community and the direction of the tendency to a new position of equilibrium will have been altered. And immediately after the new direction of economic tendencies, another diversion will occur; and so on ad infinitum. The world's shots at long-period results are like shots at a target which moves constantly but irregularly. Before any 'shot can get home, the target has assumed a new position. Longperiod results do not actually exist: their universe is the abstract.

Is a discussion, then, of long-period results valueless? Is it viciously abstract, that is so abstract as to be of no practical use? The negative answer is the right one. A consideration of normal equilibria is serviceable for these reasons:-

(a) It accounts for what actually is, and explanation is of practical value. Just as the irregular movements of a body can be explained only by the tendencies created in it by variations in the attractive forces bearing upon it, so economic events can be explained only by the tendencies created from 
time to time by variations in the impulses and circumstances by which society is governed. The complete explanation of economic phenomena can be found only in a study of tendencies.

(b) Though normal positions of equilibrium are never exactly reached, they are reached approximately in the generality of cases, particularly as regards broad economic movements.

So we may confidently maintain that the imaginary forms which the theoretical economist deals with are the moulds, so to speak, of the actual, whether their impress is immediately perceptible or not.

Determination of supply prices.-In the argument which follows, for the sake of perspicuity, I am going to cling to my early assumption that every business is a private business ruled by a single employer.

There is one point of some importance in relation to an investigation of supply prices which had better be specifically noted though it is implicitly covered by the foregoing section. It is that we need not trouble to consider businesses which are growing up, or decaying, or are failures, which would never have been started if the future could have been foreseen. The costs in these businesses have a negligible influence upon normal price. The enterprising man who starts a business is prepared to work for years for a small income in the hopes of getting a larger income when he has established himself. For years the uncertainty of his market, the smallness of his factory, and his being pinched for capital, so that he has to do without plant which is almost indispensable, may keep his expenses high. He sells, nevertheless, and must sell, at the same price as the fully-grown firms with which he is competing-for under competition there can be only one price in one market at one time. He sees his compensation in what his earnings will be when his business reaches its prime. We may at once draw the conclusion that the earnings of the 
fully established man in a trade will be governed inter alia by the length of time that a man must wait before he can expect to get them, and by the degree of probability that he ever will get them.

The young business is like the young man just starting in a profession where he does not employ labour, say that of the barrister. The latter's earnings are not governed at first by what he would work for if he was never to get more briefs than he did at first. The fees paid to barristers are not fixed by our aspirant's costs of living. He may spend more than he earns. They are determined, so far as they are settled from the supply side, by what the barrister would work for when he was fully established in his profession.

The position of decaying businesses is similar to that of growing businesses. . They must make what they can, in view of the prices established by the competition of more vigorous businesses, and try to be satisfied, or decide to discontinue. The business which miscarries for any reason is in the same position as the decaying business as regards its influence on price.

We fix our attention exclusively, then, on the mature firms which maintain their position satisfactorily in the industry. Let us call them "normal firms," and remind ourselves of the sense in which "firm" is to be understood (p. 89).

The next point to notice is that different employers produce at different expenses per unit of output (apart from their own earnings for the work that they do) even if we take only fullydeveloped businesses which are prosperous (normal firms) into account. Consider the felt-hat-industry. Suppose that at a particular time it is organized to turn out a weekly supply of 10,000 hats. One normal firm might produce hats at an average expense (that is expense per unit of output) of $5 \mathrm{~s}$. But it does not follow that every normal firm would be producing at an average expense of 5s. per hat. Indeed it 
is practically impossible that every one of them should. Some of the employers would be cleverer and more painstaking than others, and more successful in getting the most economical labour, plant, material and accessories for their money and in organizing their works.

Now add on to the expense per unit of output of each normal employer an amount per unit which makes a just sufficient inducement to have attracted him into the industry. That is to say, add to the expense per unit of output of each employer his supply price of himself per unit of output. Call the expense of production of each firm per unit of output, plus the necessary payment per unit of output for the employer, "complete cost of production per unit of output".

It is obvious that the highest of these complete costs of production per unit must be the supply price for a weekly output of 10,000 hats. If more were paid, other people would be attracted into the industry and additional capital would be invested in the industry, so that a greater output than 10,000 hats would be reached. If less were paid a sufficiency of labour, capital or employers would not be attracted into the industry to turn out continuously 10,000 hats a week.

The firm with the highest complete costs per unit of output is called the "marginal firm" (p. 38). There may be more than one. Broadly speaking the marginal firm in an industry of a given size is the firm which is just efficient enough to maintain its position when the industry is of that size. Sometimes the marginal firm is called the "representative firm," but it is probably better to reserve the latter term for any fully-grown firm which is satisfactorily maintaining itself.

We have to use the conception of the "marginal firm" because the profits made for themselves by employers of super-marginal capacity may be a great deal more than the profits for which they would be willing to go on with their work. They earn as much as they do because prices must 
be sufficient to enable economically inferior men, with whose services the community could not dispense, to make a living.

We may now lay down the proposition that the supply price of a commodity for any given output of an industry is the complete cost of production per unit of output of the firm which is marginal for such an output of the industry. This supply price is commonly called the "marginal supply price" or "marginal cost of production". It is usual to write simply "cost of production" for complete cost of production per unit of output. I have used the longer expression in order to guard against every chance of misunderstanding.

The reader may demur at first to this conclusion, despite my elaborate argumentation. Why, he or she may ask for instance, should not the people who produce cheapest get all the trade and furnish the whole 10,000 hats, to recur to our previous illustration? The answer is that these people are not unlimited in number and that the amount of the work each can undertake is limited (see pp. 90-4 and Ch. XXVII). Why, again, it may be objected, do not consumers buy the hats produced cheapest and wait for more of the cheap ones? Because, the response runs, the stream of cheap hats would not be adequate.

This is the ordinary mode of representing the,determination of the supply prices of things which are continuously produced under group production. And it has the merit of tracing the supply prices of such things to the supply prices of the factors which produce them. But this the reader will probably not realize until he has studied distribution in Book VI. I must point out, however, that the supply price of an industry of a given size tends to be equal, not only to the complete cost of production per unit of output of the marginal firm, but also to what the marginal cost of production (apart from the employer's reward) of each normal firm, which has all the business it can do, tends to be. The reader 
who has thoroughly mastered the teaching of Chapter $\mathrm{X}$ will at once recognize the correctness of this statement. What these marginal expenses will be manifestly depends on the supply prices of all factors in production, including employers. So either statement leads ultimately to the conclusion that the marginal supply price of a given output of an industry is the sum of the marginal supply prices of the factors necessary (in view of the state of industrial organization) to provide just that output.

The bulk of the intricacies which have troubled us above, are caused by group production, that is by the organization of production in groups containing many people and large quantities of other factors in production. When an individual works alone the problem is much simplified. Into this case we need not enter, as it is solved incidentally in the foregoing.

Cost of production has many meanings.-The student may escape much mental confusion by noting the contrasts drawn below and deciding whenever he meets with the term "cost of production" in which of the following senses it is put forward. It is commonly used quite loosely.

Cost of production may refer to the disutilities or dissatisfactions involved in production, but it is usual to speak of these as real costs. Money cost of production is sometimes termed "expenses of production".

Total or aggregate cost (money or real) may refer to a business or to a whole industry.

Marginal cost (money or real) in its most common references may mean either of the following :-

1. The addition made to the costs of a business by the production of the last increment. In this no payment for employing need be included (pp. 93-4). It might be called "marginal costs (or expenses) of a business" or "private marginal costs". . 
2. The costs (including the employer's necessary remuneration) per unit of output in the "marginal firm". It would save confusion if this were called "Complete costs (or expenses) per unit of the marginal firm".

Besides these meanings, a third meaning of marginal cost must be recognized for certain purposes in advanced economic analysis, namely the addition made to the aggregate costs in an industry (including employers' normal remuneration) when the industry is incrementally increased in size. This might be called " marginal costs of an industry" or "collective marginal costs". We have used the conception, or its analogue the marginal returns of an industry, in dealing with increasing and decreasing returns in the small print on page 105. 


\section{CHAPTER XVI. \\ NORMAL PRICE.}

Equilibrium of demand and supply.-Now that we have learnt how demand and supply prices are arrived at, it will be easy to explain the settlement of price in the long period or long run, which is known as normal price.

In the table that follows I have stated the supposed marginal demand prices for different quantities of hats per week, and the supposed marginal supply prices when the industry is organized in each case to supply the same quantity per year :-

\begin{tabular}{|c|l|l|}
\hline $\begin{array}{c}\text { Number of Hats } \\
\text { per Week. }\end{array}$ & $\begin{array}{c}\text { Marginal } \\
\text { Denand } \\
\text { Prices. }\end{array}$ & $\begin{array}{c}\text { Marginal } \\
\text { Supply } \\
\text { Prices. }\end{array}$ \\
\cline { 2 - 3 } 9,600 & 5s. 8d. & 5s. 4d. \\
9,700 & 5s. 7d. & 5s. 3d. \\
9,800 & 5s. 4d. & 5s. 2d. \\
9,900 & 5s. 2d. & 5s. 1d. \\
10,000 & 5s. 1d. & 5s. \\
10,100 & 4s. 11d. & 4s. 11d. \\
10,200 & 4s. 8d. & 4s. 10d. \\
10,300 & 4s. 7d. & 4s. 9d. \\
10,400 & 4s. 5d. & 4s. 8d. \\
\hline
\end{tabular}

The prices in the second column descend because of the law of diminishing utility. Those in the third column may ascend, or descend, or keep the same, or do first one thing and then the other. They will ascend if decreasing returns rule 
in the industry, descend if increasing returns rule in the industry, and keep level if returns are constant.

It will readily be perceived that, in the case of which the relevant circumstances are tabulated above, 10,100 hats will be produced weekly and the price will be $4 \mathrm{~s}$. 11d. Suppose more were turned out, say 10,200 . Then some employers would be manufacturing at an average cost of $4 \mathrm{~s}$. 10d. and selling at $4 \mathrm{~s}$. 8 d., which would not be good business. Consequently the industry would contract until an output of 10,100 hats a week was reached. Suppose that 10,000 hats a week were turned out. Price would then be 5s. 1d. and the full costs of the marginal firm 5s. Consequently the industry would be exceptionally profitable and would attract extra supplies of capital, organizing power, and executive labour. So its annual output of hats would rise. As the supply of hats rose, the price would fall. The reactions described would cease when the output had advanced to 10,100 hats a week and the price had dropped to 4s. 11d.

So we may generalize that the price of a commodity will be the price at which equal quantities are demanded and supplied, provided that an incremental addition to the supply would mean a supply price above the demand price and an incremental reduction of the supply would mean a supply price below the demand price. There may be more than one such price but it is very unlikely. It is least unlikely when demand is highly elastic.

Let us next propound the question, What happens in the long run if demand rises? A rise in demand means that the demand prices in our table are raised. Obviously consumption will be increased, but how price will be affected will depend upon whether supply prices fall, rise, or keep constant with an increased output. If supply prices fall price will fall, if they rise price will rise, if they are constant price will be constant. The effect on price of diminished demand, that is a fall in demand, is settled similarly. 
Equilibrium of demand and supply diagrammatically treated.-Consider fig. 8. Units of output are measured along OX and units of money along $O Y$. Ignore at first the dotted line. $D$ is the demand curve and $S$ the supply curve. Both curves express long-period or normal conditions. As S descends we have increasing returns. The position of equilibrium is given by the intersection of $\mathrm{D}$ and $\mathrm{S}$. So the normal output will be the anount $\mathrm{O} a$ and the price will be $a c$. The sum $a c$, observe, is the marginal demand price for an amount $\mathrm{O} a$ and also the marginal supply price (that is the supply price of the marginal firm) for an amount $\mathrm{Oa}$.

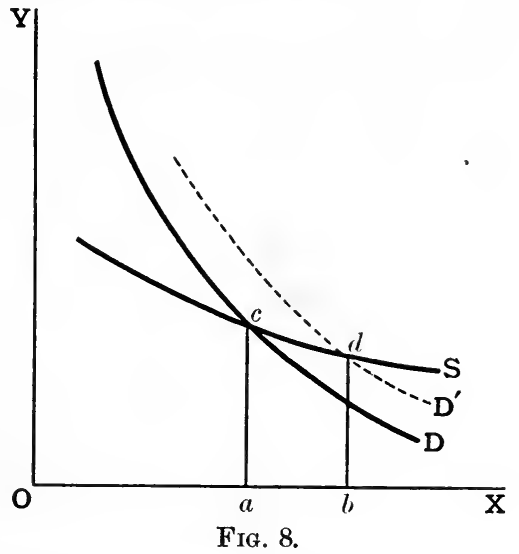

Now suppose demand rises. A rise in demand can be represented by raising $\mathrm{D}$ to a higher level. Let the new demand curve be $\mathrm{D}^{\prime}$. Then the new output in the long run will be $\mathrm{O} b$ and the new price will be $b d$. Price falls because $\mathbf{S}$ descends to represent increasing returns. If $\mathbf{S}$ rose (to represent decreasing returns) price would have risen. If S were horizontal (to represent constant returns)price would have been constant. But for every conceivable inclination of $\mathrm{S}$ the output would be increased.

A brief contemplation of demand and supply curves in relation to one another will disclose the fact that more than one position of equilibrium is possible. It need not be demonstrated that multiple 
positions are only possible if supply is subject for some outputs to increasing returns. As D must descend-we may ignore any exceptions-S can only cut it more than once by descending also.

Now carefully scrutinize fig. 9 , in which $I$ have represented four types of equilibrium. You will observe that if the output were Om a slight increase of output would cause loss to the producer, since cost would then exceed price. Hence a slight increase of output would be followed by a reaction to $\mathrm{O} m$. You will observe also that a slight contraction of output would mean exceptional profits since cost would be below price, and therefore that a reduc-

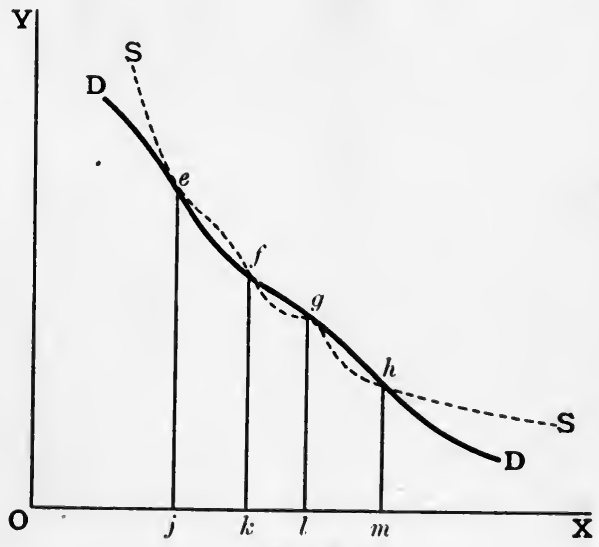

Fra. 9.

tion of the output to less than $\mathrm{Om}$ would be followed by a reaction to $\mathrm{Om}$. Because slight departures from the output $\mathrm{Om}$ in either direction would be followed by reactions to the output $\mathrm{Om}$, the point $h$ marks a position of stable equilibrium. The point $f$ marks a position of complete unstable equilibrium. With the output $\mathrm{O} k$ normal profits are earned. But if the output were slightly increased abnormal profits would be earned, since price would exceed cost. Consequently capital and labour would be attracted to the industry and it would go on expanding. Again if the output became slightly less than $O k$ less than normal profits would be earned (for cost 
would exceed price) and labour and capital would be discouraged from entering the industry and some labour and capital would be driven out of it, so that the industry would go on contracting. It is because small departures from the output $\mathrm{O} k$ in either direction are not followed by reactions back to $\mathrm{O} k$, but by further departures from $\mathrm{O} k$, that the position marked by $f$ is called a position of "complete unstable equilibrium ".

Positions $e$ and $g$ are so unlikely that they may practically be ignored. But to make our analysis exhaustive they must just be noticed. Consider the point $e$. An output less than $\mathrm{O} j$ means loss, so the industry would tend to contract if the output fell below $\mathrm{O} j$. An output greater than $O j$ would equally mean loss, so the output would tend to shrink again to $\mathrm{O} j$ if it had become somewhat greater. Consequently $e$ marks a position of partial stability and partial instability. It is stable as regards increases of output and unstable as regards decreases of output. Consider now the point $g$. This, you will notice, is also a position which is partially stable and partially unstable. It is stable as regards decreases of output and unstable as regards increases of output.

\section{Joint, composite and alternative demand and sup-} ply.- Joint demand has been fully described on page 28 . Here I shall deal with joint demand for two things which are demanded in a fixed ratio and are not the objects of other demands. The remaining cases enumerated on the pages mentioned above are too complicated for treatment here; but with the principles applied in this section and those already illustrated the reader is equipped to deal with them himself.

In the simple case in which two things are demanded in a fixed ratio-say the blades and handles of knives of a particular kind - the combination of a knife-blade and a knifehandle is the unit of demand. The supply prices of this unit are the sum of the supply prices of each of its constituents. Thus the supply price of 100 knives with handles is the supply price of 100 handles plus the supply price of 100 blades. You will readily see after these few remarks how the prices of knife-blades and knife-handles are settled. 
Joint supply has been described on page 67. Here I take the simple case in which the sole supplies of two commodities are derived from their joint production in a fixed ratio. To find the price of the constituents of a joint supply - say gas and coke - you proceed mutatis mutandis as in the case of joint demand. The unit of supply is so much gas plus so much coke, and for demand you keep adding to the demand for a unit of the gas the demand for such a quantity of coke as is made when the unit of gas is made. When one of the products jointly produced sells for much less per unit than a corresponding unit of the other, the former is commonly termed a by-product.

Upon composite demand and composite supply only the briefest comments need be made. All market demand is composite and so is all market supply, apart from monopoly of demand and supply respectively. Market demand is compounded of the demands of different people, which may or may not imply demands for different purposes. The composition of demand has already been dealt with; and so has the composition of supply. The supplies of some things may come not only from different firms in the same trades, but from different trades.

The chief point to notice about alternative demand and alternative supply, which are explained on pages 28 and 67 , is that the ratio between the prices of things which are substitutes, or are supplied alternatively, tend approximately to constancy. If tea got scarce, people would consume more coffee, so that the ratio between the prices of tea and coffee would not alter much. If the demand for barley rose, more cultivated land would be devoted to growing barley and less to growing other things, so that the ratios between the prices of barley and those of other crops would not alter much.

Diagrammatic representation of joint demand and joint supply.-I take only the cases treated above where things are jointly demanded, or supplied, in fixed ratios. 
Consider fig. 10. Money is measured along $\mathrm{OY}$ and units which represent a knife-blade, or a knife-handle, or both, along OX. D is the joint demand curve for the blades and handles of knives of a particular kind. $S_{2}$ is the supply curve for blades. $S_{1}$ is the supply curve for units consisting of a knife-blade plus a knifehandle-that is to say, the distances between $S_{1}$ and $S_{2}$ are the supply prices for handles. Then $\mathrm{O} b$ of handles and $\mathrm{O} b$ of blades will be sold. The price of a blade will be $a b$ and the price of a handle $c a$.

Consider fig. 11, which is meant to relate to two articles jointly produced, like wheat and straw, but in an unalterable ratio. For short I shall call the articles " $\mathrm{P}$ " and " $\mathrm{Q}$ ". Let units along OY

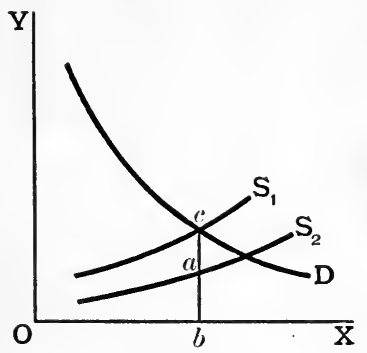

Fig. 10.

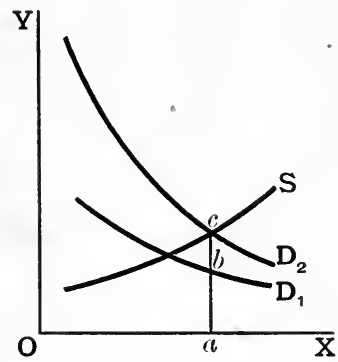

FIG. 11.

represent money and units along $\mathrm{OX}$ units of $\mathrm{P}$, or units of $\mathrm{Q}$, or units consisting of so much $\mathrm{P}$ and so much $\mathrm{Q}$, the proportion being the ratio in which $P$ and $Q$ are jointly produced. Let $D_{1}$ be the demand curve for $P$. Let $D_{2}$ be the demand curve for the combinations of $P$ and $Q$ the units of which are measured along $O X$; so that the distances between $D_{1}$ and $D_{2}$ are the demand prices for $Q$. Let $\mathrm{S}$ be the supply curve for the combinations of $\mathrm{P}$ and $\mathrm{Q}$. Then $\mathrm{O} a$ units of $\mathrm{P}$ and $\mathrm{O} a$ units of $\mathrm{Q}$ will be produced and the price of $\mathbf{P}$ will be $a b$ and the price of $Q$ will be $b c$.

Of course, $\mathrm{O} a$ does not necessarily mean the same amount when it refers to $P$ as when it refers to $Q$, since in fig. 11 the ratio between a unit of $P$ and a unit of $Q$ is the ratio in which $P$ and $Q$ are jointly produced. 


\section{CHAPTER XVII.}

\section{THE SHORT PERIOD AND SUB-NORMAL PRICE.}

I HAve fully explained at the beginning of Chapter XV what is denoted by the expression "long period". It is a technical expression with a definite meaning. "Short period" is another technical expression which is tending to get a definite meaning. In studying the operation of causes in economics we have to distinguish between (1) instantaneous effects, (2) effects in the short period, and (3) effects in the long period.

The short period.-Broadly speaking, short-period results mean the results which are met with-or would be in the absence of fresh independent change-when we disregard consequences which are not appreciable until after a long interval. This statement will do to start with, but it is too vague to handle scientifically. To make the conception of the short period precise we must deal separately with demand and supply.

I apply it first to supply. As regards supply, short-period results may be described as the results that can be attained with existing factors in production as they were at the time of the change which necessitated their re-arrangement. We may think of the factors in production as classes of producing power each of which is capable of being crystallized into various forms. Men may become skilled colliers or skilled bricklayers. A piece of land may become pasture or an orchard. A ton of pig-iron may become a boiler or typewriters. Some crystallized factors may be de-crystallized and 
then re-crystallized into new forms at different degrees of loss and with different degrees of rapidity. Other crystallized factors cannot be given new forms at all. A highly skilled jeweller cannot easily turn to another occupation, but a linenweaver can easily become a skilled cotton-weaver. An automatic shell-machine can shape only shells for guns, but the aid of the same sewing-machine may be enlisted to make either blouses or pillow-cases. Side by side with the crystallized factors there is the new producing power-the rising generation, the season's cotton and the ore just being dug out -about the final form of which we may exercise boundless choice. Short-period supply prices mean the costs at which modifications can be contrived in the relative supplies of things with the existing factors, crystallized or not, just as they are.

Suppose there is a sudden increase in the demand for crêpe. The short-period supply-prices would be the costs at which supply could be increased by different amounts with the existing factors in production available just as they were; or, as we may put it with approximate correctness, before there was a sufficient interval of time for more specialized machinery to be made, more factories to be built, and more labour to become skilled in the crêpe industry.

This conception of the short period in relation to supply is now generally accepted by economists, but there is less agreement about the application of the idea to demand. Probably short-period effects on demand are best understood to mean such partial readjustments of systems of demand as would take place, when readjustments were necessary, before the ingrained habits of people changed and before experience had fully taught how systems of consumption should be remodelled. The reminder may not be superfluous that a system of consumption may express the wants of a business for productive purposes as well as a person's needs for consumer's goods. 
You will realize that short-period positions of equilibrium are not perfectly attainable actually, though they are more closely attainable than long-period positions of equilibrium.

Sub-normal prices.-The prices reached at short-period positions of equilibrium are known technically as sub-normal prices. These we proceed to investigate on the side of supply.

Increased outputs in the short period are obtainable only at enhanced costs of production. This will be evident when it is remembered that the additional outputs can be procured only by working uneconomical hours, or at uneconomical speeds, or with unskilled labour, or with antiquated machinery, and, possibly, in over-crowded workshops, or in workshops suddenly brought into requisition, which are not well adapted to the work done in them, and possibly with material not up to the average of that ordinarily used in respect of suitability. Hence the effect of increased demand must be a rise of price in the short period.

In order to understand the theory of sub-normal equilibrium when demand drops, it is necessary to introduce a distinction into the costs or expenses of production. Costs may be divided into prime costs and supplementary costs. The prime costs of, say, a particular chair are the specific costs incurred on behalf of that particular chair and of no other chair, apart from the general costs of maintaining the factory in which it was made. More precisely, we may say that the prime costs of a business are the costs which cease when the business stops for a short time. Interest charges on the plant, much depreciation, rent of premises, and salaries continue, but cost of material, coals and lighting, and weekly wages cease for the time being. These costs which cease are the prime costs. The costs which continue are the supplementary costs.

Armed with this distinction we now ask, What is the effect on price of a collapse of demand in the short period, when demand is not expected to react back after a brief interval to 
a position above its original level? The answer is, a fall in price.

Factories, to take one type of production, are organized to turn out a larger product than can be sold at the normal price after the collapse of demand. The industry cannot be suddenly reduced in size commensurately with the reduction of demand, and it would not be desirable that the industry should be permanently reduced in size were the shrinkage of demand temporary only. It is inconceivable that it would pay the employer so to contract his output instantly that price would not fall. In contracting his output he does not save much more, if any more, than prime costs. He might conceivably produce as much as before and keep some of his product to market in the future, but by this stratagem he would not elude loss, because of the cost of the capital locked up in the stock. Producers of perishables, of course, cannot lay by stock; and those who are serving a fleeting fashion would be chary about doing so. When the collapse of demand is judged to be permanent, producing much for stock is naturally out of the question'; but for a time in this event it will pay to produce amounts which sell at prices below the full cost of production, because the alternative is to discard some fixed plant which is not nearly worn out and so lose even more.

Some features of sub-normal conditions. - It is worthy of remark that the reaction of supply and price on a temporarily attenuated demand may be of several kinds. The reaction actually experienced in any case is determined by the character of the industry. It may take the form, other things being equal, $(a)$ of a large contraction of goods offered and a small fall in price, or $(b)$ of a small contraction of goods offered and a large drop in price. A tendency to the latter reaction is certainly created in any of the following circumstances, of which the first two relate to supply while the last relates to demand:- 
(i.) When the proportion of fixed or supplementary charges in the industry is high.

(ii.) When the commodity is a perishable, so that the employer cannot stock any of his produce.

(iii.) When failure to satisfy present demand does not augment future demand. Employers would be loath to satisfy a demand at a loss in the present if the same demand, or the bulk of it, could be satisfied at a profit in the future.

Finally I may draw attention to the way in which an industry gradually settles down to a new position of equilibrium after a permanent alteration in demand. Say demand increases. Then price leaps up suddenly. This is the immediate effect. Then price tends to subside, at first rapidly, then much more gradually, until finally the price of the new position of equilibrium is reached, which may be above, below, or the same as, the old price. The correctness of this account as descriptive of a tendency will be apparent. The accommodations incidental to making the best use of existing factors take place much more rapidly than the accommodations which entail new specialisms and the re-specialism of such old factors as can be re-specialized. Both accommodations, of course, go on pari passu. But in the first few months long-period effects are inconsiderable, while after very many months short-period effects are inconsiderable. Gradually, extra supplies of good labour attracted to the industry are trained into first-class efficiency ; gradually their arrangement is improved; and gradually more machinery and engines are built to meet adequately the new needs of the industry.

The course of events consequent upon a reduced demand is analogous. A sudden drop in the price will tend to be followed by a rise, at first comparatively speedy and then more tardy, for reasons which the paragraph above will at once suggest. 


\section{CHAPTER XVIII.}

\section{THEORY OF MONOPOLY PRICES.}

Fundamental ideas.-There is complete or partial monopoly in the supply of a thing when there is absence, or unusual hindrance, of competition in the supply of that thing. The monopoly may be in the hands of an individual, but if the supply is large it is more likely to be in the hands of a group of people or a public authority. Hereafter, nevertheless, for convenience, I shall speak as if the monopolist were always a single person.

I shall first expound the theory of price under conditions of monopoly on the assumption that monopoly is unrestricted. Throughout I shall be dealing with the long period unless I make a statement to the contrary. Afterwards I shall allow for the limitations of a monopolist's power.

In considering monopoly price there are two chief cases to distinguish between. The one is the case in which only one price can be charged. The other is the case in which more than one price can be charged.

Naturally the monopolist who is guided solely by selfinterest, will aim at furnishing a supply which is such that a slight increase or decrease of it would diminish his gain over and above what he would get under competition for the work that he does. Let us call this gain "monopoly gain or revenue". Outputs which satisfy the condition just laid down are said to mark positions of monopoly equilibrium. Now, in 
any industry there may be more than one possible position of monopoly equilibrium. The self-seeking man armed with a monopoly of metallic rigidity would naturally select the one which yielded the greatest monopoly gain, if he knew of its possibility.

Determination of price in the absence of price discriminations.-For detailed exposition I take first the case in which only one price can be charged. Suppose that the conditions relating to some industry may be represented roughly by the figures in the table appended, whether the industry is monopolized or not. What employers would get under competition for the work that they do is included in aggregate costs, and the aggregate cost for each output is taken to be the marginal cost for that output multiplied by the output. Marginal cost means cost per unit of output in the marginal business or the marginal cost in each business, that is the marginal cost which would settle price under competition (see pp. 161-2).

\begin{tabular}{|c|c|c|c|c|c|}
\hline Output. & $\begin{array}{c}\text { Marginal } \\
\text { Cost. }\end{array}$ & $\begin{array}{l}\text { Aggregate Costs } \\
\text { of all factors. }\end{array}$ & $\begin{array}{l}\text { Demand } \\
\text { Price. }\end{array}$ & $\begin{array}{l}\text { Aggregate } \\
\text { Receipts. }\end{array}$ & $\begin{array}{l}\text { Aggregate Re- } \\
\text { ceipts less Ag- } \\
\text { gregate Costs. } \\
\text { (Monopoly } \\
\text { Revenue.) }\end{array}$ \\
\hline Tons. & $\mathfrak{E}$ & $\mathfrak{E}$ & $\mathfrak{E}$ & E & $\mathfrak{E}$ \\
\hline 1000 & 10 & 10,000 & 12 & 12,000 & 2000 \\
\hline 1100 & 9 & 9,900 & 11 & 12,100 & 2200 \\
\hline 1200 & 8 & 9,600 & 9 & 10,800 & 1200 \\
\hline 1300 & 7 & 9,100 & 8 & 10,400 & 1300 \\
\hline 1400 & 6 & 8,400 & 6 & 8,400 & - \\
\hline 1500 & 5 & 7,500 & 4 & 6,000 & -1500 \\
\hline
\end{tabular}

For the sake of argument we assume that variations of less than 100 tons in the output are impossible and that all the output must be sold. There are then two positions of monopoly equilibrium, namely when the outputs are 1100 and 
1300. Small departures from either of these outputs diminish monopoly revenue. As an output of 1100 yields the greatest gain, this is the output which the monopolist will choose if he knows of the conditions attending such an output or strongly suspects their existence. With such an output price would be $£ 11$. Under competition the price would be $£ 6$ and the output 1400 tons. Of course the monopolization of an industry might raise or lower supply prices, instead of leaving them the same as we have assumed. In Chapter XIII we have discussed the possible effects of monopoly on cost of production.

One way of defining a position of monopoly equilibrium is to say that it is a position which is such $(a)$ that the addition made to aggregate receipts by an incremental addition to the monopoly's output equals the addition made to aggregate costs (including normal remuneration of employing) by an incremental addition to the monopoly's output, and (b) that departures from it in either direction mean that the loss involved exceeds the gain involved.

Price discriminations. - We have to consider next the less simple case in which more than one price can be charged. When more than one price is charged at the same time, one or more of the following classes of discriminations or preferences must be created :-

I. Personal discriminations or preferences.

II. Income

III. Trade

IV. Local

$\begin{array}{ll}, & , \\ , & ,\end{array}$

"Discrimination " and "preference" are used here indifferently to mean the same thing.

A personal discrimination is any- discrimination which is not of class II, III, or IV. When its sole ground is 
economic, it means charging one man more than another merely because he will pay the higher price if he must; and it may pay to exact the higher price from him and others similarly placed. Personal discriminations have been sternly resisted by the public in every field and no monopolist would openly attempt to impose them.

Income discriminations are difficult to apply and are very uncommon. Usually in economic relations the income of the purchaser is not known. Discriminations roughly proportional to income may, however, be resorted to indirectly when different qualities of a thing are supplied, provided that the higher qualities are naturally, and almost exclusively, acquired by the wealthier classes. The prices for the higher qualities may be fixed disproportionately high in view of the excess of their cost over the cost of the lower qualities. First-class railway fares may be, or could be made, a case in point. Income discriminations are sometimes admitted with advantage into the principles of payment for semi-public services. Doctors' fees, for instance, are frequently charged on different. scales for patients of different classes the demarcations between which are certain levels of income.

Trade discriminations mean selling goods at different prices according to the trades to which they are sold. The term is not a very appropriate one, but it is as suitable as any other that could be found. It is seldom feasible to enforce trade discriminations, because usually it is easy to hide the ultimate destination of goods. Scales of railway freight charges may be regarded as exemplifying trade discriminations. What the railways sell is transportation, and, when it is needed for the delivery of goods, they sell it cheaper, for example, to coalowners than to the manufacturers of pianos.

Local discriminations exist when a thing is sold cheaper in one place than in another. Local discriminations in the same country in the charges for transportable things are limited by 
costs of carriage. If excessive internal local discriminations were introduced, businesses would naturally be founded to carry things from places where they were sold cheap to places where they were sold dear. As railway transportation is not itself transportable, local preferences in railway rates have been common.

Local discriminations of an appreciable amount in the world's trade in transportable things are quite possible. A monopolist may sell abroad at any price which differs from the home price by cost of carriage between the foreign market and the home market, if the monopolist produces in a free trade country. And if he produces in a protectionist country, his foreign price may fall below his home price by cost of carriage plus the amount of the tariff on the importation of such goods as he produces. Were the foreign price to drop below this level, the goods would be sent back to earn a profit out of the high home price.

Dumping.-When a complete or partial monopolist sells his goods at a lower price abroad than he does at home, he is said, in the slang of the market, to be "dumping," provided that the price charged abroad is less than the cost of production (including normal profits) per unit of output of the monopoly business or of the marginal business among the businesses covered by the monopoly.

Dumping is of three kinds :-

1. Dumping to win foreign markets.

2. The dumping of surpluses.

3. The dumping of things deliberately produced to be dumped.

Dumping to capture foreign markets is a hazardous speculation. The intention of the monopolist who practises it is to sell very cheap until competitors have been driven out of the foreign market, and then to raise the price to recoup himself for the losses incurred during the dumping and to make a 
profit. But when the price is raised the competitors may be attracted back again. Fish may devour ground-bait, but refuse bait on the hook.

The dumping of surpluses is common, but genuine surpluses cannot be very large ordinarily. A "surplus" in this connexion denotes output over and above what the monopolist would have produced $(a)$ if he had correctly estimated demand and cost of production, or $(b)$ if it had been easy to adapt his output to demand. Demand cannot be accurately anticipated, and the derangements caused by altering the output of a very large business may be expensive. Hence surpluses arise from time to time. It may be better for the monopolist that they should be sold abroad for something less than their full cost of production instead of being placed on the home market. Their absorption by the home market would depress the home price.

Producing to dump is a totally different matter. It implies that it may pay the monopolist to make permanently such local price discriminations as the existence of distinct nations renders feasible, even if the lowest price is beneath cost of production, as defined in the first paragraph of this section (p. 179).

The reader must bear in mind that some degree of monopoly -in the form of specific agreements among producers at least-are requisite if any discriminative charges are to be adhered to. Competition would at once destroy them.

\section{Determination of prices when discriminations are pos-} sible.-That preferential or discriminative charges will be made by monopolists when they can be made, follows at once from the fact that in all cases the monopolist can magnify his gain by making them. If the monopolist can deal separately with two or more groups of purchasers, he will try to sell to each group at such a price that his profits are maximized. It is exceedingly unlikely that his gains will be maximized by selling to each at the same price. 
It is in adaition so exceedingly unlikely as to be practically impossible that his output would be the same when he charged one price as when he charged more than one. In the latter case his sales might exceed or fall short of his sales in the former case. The substitution of discriminative charges for a single monopoly price, especially if it brought about larger sales, might prove beneficial on the whole to the community, apart from the circumstance which we shall investigate next, that is selling continuously some part of the produce beneath normal cost of production, as we may express it broadly.

The contents of the first paragraph of this section prove that discriminations will probably pay the monopolist, but not that producing to dump may pay him. To prove the latter we must show that in some circumstances discriminations may pay even if it is intended to sell continuously some portion of the output at less than cost of production (including normal profits) per unit of output of the monopoly business or of the marginal business among the businesses covered by the monopoly.

Sales at a price beneath cost of production, so defined, may be pecuniarily advantageous to the monopolist provided that the price is no less than the addition made to the aggregate costs of the whole output of the monopoly (including normal remuneration for employing) by an incremental addition to the output. This will be evident when you realize that such sales would depress the monopolist's average cost of production.

This is a significant corollary from the theory of monopoly prices ; and there is another corollary closely related to it which is of practical moment. It is that some enterprises which would never be remunerative if one price only were admissible could be rendered remunerative by discriminative charges. The reader may easily establish this proposition for himself after the foregoing exposition. 
Monopoly price diagrammatically explained.-In figs. 12 and 13 let $\mathrm{DD}^{\prime}$ and $\mathrm{D}_{1} \mathrm{D}_{1}^{\prime}$ be the demand curves respectively for two groups of purchasers $\mathrm{P}$ and $\mathrm{Q}$ of a monopolized article, whether they reside in the same country or not. For simplicity suppose that production is subject to constant returns, so that the cost of production is a constant. Iet the cost of production be $\mathrm{O} a$, which equals $\mathrm{O} p$, and suppose that the difference between the monopolist's aggregate costs and his marginal costs multiplied by the output is the same for all outputs. The monopolist will try to sell to each group of purchasers at such a price that his gains from that group of purchasers are a maximum. That is to say he will try to sell to group $\mathbf{P}$ a quantity $\mathrm{O} g$ which is such that the rectangle ae is the largest which can be introduced between $a \mathrm{D}, a b$ and $b \mathrm{D}$; and to

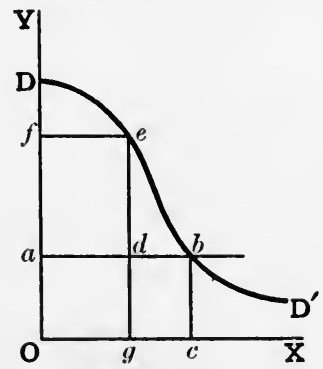

Fig. 12.

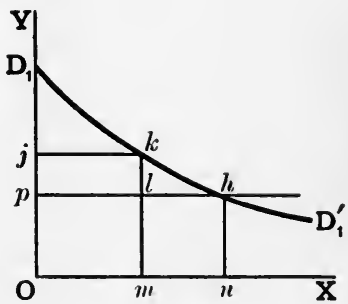

FIg. 13.

sell to $Q$ a quantity $O m$ which is such that the rectangle $p k$ is the largest which can be introduced between $p \mathrm{D}_{1}, p h$ and $h \mathrm{D}_{1}$. It is exceedingly unlikely that $\mathrm{O} f$ should equal $\mathrm{O}$ j. The monopolist secures the richest reward when he sells to $\mathrm{P}$ at a price $\mathrm{O} f$ and to $\mathrm{Q}$ at a price $0 j$. Under competition the price would be $\mathrm{O} a$.

Evidently $\mathrm{Og}+\mathrm{Om}$ may be greater or less thau sales at a single monopoly price, and $\mathrm{D} f e+\mathrm{D}_{1} j k$ may bo greater or less than the consumers' surplus left when a single monopoly price is charged, according to the slopes of $\mathrm{DD}^{\prime}$ and $\mathrm{D}_{1} \mathrm{D}_{1}^{\prime}$.

Figures can be constructed to show what may be expected when production is subject to increasing or decreasing returns, and the conditions under which some of the output may be sold at a price beneath cost of production, as defined in the section above. 
Restrictions experienced by monopolists.-It must be allowed, in qualification of what has been said above, that a monopolist has seldom a free hand to settle price. He must pay some regard to public opinion. Unpopularity might eventually cause a loss far greater than the profits which would be resigned on the monopolist's deciding not to embark on an unpopular course of action. More or less satisfactory substitutes for the monopolized article may be discovered if people are goaded into seeking them. Again when competition is not impossible, rival producers may be tempted into the field if the monopolist makes his gain per unit of output excessive. Finally there is a greater chance of interference by public authorities when monopolists totally disregard the public interest. Hence unpopular discriminations will usually be avoided by monopolists, and they will choose a large output (meaning a low price) if no very substantial addition would be made to monopoly profit by restriction of output.

A monopolist's power is further curbed when consumers are allied. A compact union of consumers may force the monopolist to sacrifice a great part of his monopoly revenue. By combining, consumers establish what may be called a consumers' monopoly. When any service or commodity is consumed by one person or one firm only, since competition is then absent on the side of demand, there is monopoly of consumption.

It is barely necessary to point out that a public authority which worked a monopoly would not be likely to aim at monopoly revenue, as above defined, even within the limitations just mentioned. If the industry, or service, which it monopolized were used by all classes, it would pay some regard to consumers' surplus (pp. 49-53). From demand and supply schedules (were they obtainable), it would be easy to work out theoretically what the price, or prices, should be on any understanding that so much monopoly revenue was to count as equal in advantage to so much consumers' surplus. 


\section{CHAPTER XIX.}

\section{INTERNATIONAL TRADE.}

Ir is emphatically not cost of transport which differentiates foreign trade from home trade. There is always cost of transport in the home trade, and the cost of transport in the home trade between Aberdeen and London is considerably greater than that in the foreign trade between Dover and Calais. The real reason why there is a theory of international values distinct from the theory of home values is that labour and capital flow much less readily between country and country than between different parts of the same country. Indeed, we can demonstrate the theory of international exchange if cost of transport to markets be disregarded; and there are certain conveniences in disregarding this cost of transport. But if you think it a violent procedure to suppose that carriage to consumers costs nothing, you can simplify the problem without altering its character by reckoning all costs of transport in cost of production.

International immobility of labour and capital.Workmen are unwilling to emigrate to foreign lands for many reasons. They do not like to be severed from their country-men. They are naturally repelled by the manners and customs of a foreign people, which are strange to them. They know they will feel foreign in a foreign country, and fear that as foreign they will be isolated. The Englishman wants to remain an Englishman for reasons which he cannot make articulate, and also because he finds it pleasanter to live 
under the social conditions which governed his up-bringing and to which he has grown accustomed. Some races are much more adaptable than others, but, generally speaking, people cling to their national homes like limpets to rocks, whatever their race. Again there are the difficulties of learning new languages, which add to the checks on the world migrations of labour between places where different languages are spoken.

The people of a country naturally feel fewer objections to emigrating to the colonies of their own countries than to emigrating to other countries or the colonies of other countries, but there remain objections to expatriating oneself which the reader will at once appreciate. Where one community has originated as an off-shoot from another, as the United States has from England, so that there is some identity of racial characteristics and a sharing in a common past, the two communities are not felt as foreign to one another in any very high degree.

Internationally, capital is not so immobile as labour, but it is comparatively immobile nevertheless. Many capitalists are timid about investing in industries abroad. They are unwilling to place their money where they cannot watch its use, and under laws and customs with which they are unfamiliar. But they do not feel the same reluctance to invest in foreign public funds. Consequently "international securities," which consist largely in public stock, and are so called because they have a world-wide reputation, play some part, though a small one, in the distribution of capital throughout the world's industries. They serve in a slight degree as international reservoirs of capital. Suppose that in France the yield of first-class industrial stock rises from 4 to 5 per cent while the yield of public stock keeps constant at $3 \frac{1}{2}$ per cent. Then, it may be, little capital will be drawn into French industries from England, where we assume industrial interest to be less. But some money will come out of the French funds to enter the French industries. The yield of the 
French funds will, therefore, be raised. English money will consequently flow into the French funds, and liberate more French money for investment in French industries. It would seem that the attractions of international securities, combined with improved credit, the spread of information, and increased travel, which is breaking down international distrust, has endowed capital with an enormous access of mobility in the last half century.

\section{Permanent international trade starts when there are} differences between comparative values.-Broadly speaking, the existence of commerce between countries, the ratios of exchange between countries (that is international values), and the quantity of international business, are determined by the conditions which govern the comparative values of different things in each of the trading countries.

We may begin by laying it down that nations cannot trade with one another unless comparative values differ. This doctrine will not at once carry conviction, nor even compel understanding. It could not be expected to do so, since it is the concentrated conclusion derived from an analysis of innumerable cases. It will not be superfluous, therefore, to show its application to a single simplified case. We shall imagine (1) that there are two nations only, namely England and Germany, (2) that there are two commodities only, apart from gold which is used as money, namely wheat and blankets, (3) that capital and labour are internationally immobile, (4) that there is no cost of carriage, (5) that all production is subject to constant returns, and (6) that both countries have the same kind of money.

Before intercourse is opened let this be the state of affairs :-

England produces wheat at $£ 1$ a bushel.

" " blankets at $£ 2$ a bale.

Germany produces whent at $£ 5$ a bushel.

$" \quad, \quad$ blankets at $£ 10$ a bale.


In each country, but not between the two, prices measure real costs of production, as we have discerned.

Now, if our doctrine be true, no enduring trade should result when intercourse is opened between England and Germany, because the ratio of $£ 1$ to $£ 2$ is identical with that of $£ 5$ to $£ 10$. Trade will begin, but will soon come to an end. Consider in detail what happens. England clearly will export goods and import nothing but money (gold bullion). The level of prices will, therefore, rise in England and fall in Germany (see Chapter XX). Finally blankets and wheat will cost respectively $£ 3$ and $£ 6$, say, in both Germany and England. Then trade must cease because neither Germany nor England would gain thereafter from exporting either wheat or blankets. We have therefore demonstrated that if the ratios between the costs of production in any two lands are identical (that is if their comparative values are identical), enduring commerce between them is impossible.

We have also demonstrated that a country does not necessarily export an article to another country if it can make the article with substantially less labour or less capital, other things being equal, in each case, than the other country. And we may go even further and pronounce that a country may be beaten in its home markets by goods from abroad which it can manufacture for itself at a lower real cost, incredible as it may appear. England might possess exceptional advantages for the manufacture of steel, with which Belgian facilities in the same respect could not compare, and yet English steel might be undersold in England by Belgian steel. It should be evident to us that it might be so, when we remember that England might enjoy even greater relative advantages for the manufacture of cottons. These she would export to Belgium, and Belgium, having to pay in something, might find it most convenient to pay in steel. 
Next suppose that the initial state of affairs is different. Take it that these are the facts :-

England produces wheat at $£ 1$ per unit.

$\begin{array}{ccc}\text { Germany produces wheat at } £ 5 & , & , \\ , ", & ,\end{array}$

Then for a time, as before, Germany imports both wheat and blankets. But the time comes, as a result of the passage of money between Germany and England, when wheat stands at $£ 2$, say, in both countries, blankets costing $£ 2$ in England and $£ 4$ in Germany. Then it no longer pays England to export wheat though her export of blankets may continue. Very soon, however, as the transference of money continues, wheat is costing more than $£ 2$ in England, but less than $£ 2$ in Germany. Thereafter, in consequence, it pays Germany to export wheat. Here at last are the conditions of enduring trade. Thus we discover that permanent trade is induced by international differences between the ratios which the costs of production of commodities bear to one another. If any commodity traded in cannot be produced at all in one of the countries, we may say that its cost of production in that country is infinity.

International yalues. - I have shown by these examples when lasting commerce may be expected and when it may not. But I have not shown what its amount will be, and what the rates of international exchange will be. The settlement of these matters is more difficult to understand, but it can be explained in a general way without the aid of mathematical symbols.

Let us confine our argument to the simple case in which there are two nations only, England and Germany, and only two commodities, wheat and blankets, but let us remove the assumption that all production must be subject to constant returns. 
At the position of equilibrium (a) Comparative values must be identical in the two countries and (b) the value of the exports must equal the value of the imports. Upon proposition (b) I shall comment at length in due course. Proposition (a) follows from the proof already given that if comparative values differ, it will pay traders in either England or Germany, or both, and cannot damage traders in either, to extend operations, or coniract them, until comparative values are the same in both countries. When the two countries begin to trade the relation between comparative costs in the two countries begins to alter, if the production of both commodities in both countries is not subject to constant costs. For a land increases its output of what it exports and decreases its output of what it imports. An alteration in the relation between comparative costs, brought about by foreign trade, may of itself be sufficient to cause eventual identity of comparative costs. If it is not, or if the production of both commodities in both places is subject to constant costs, the production of one commodity in one of the countries, say of wheat in England, will cease, after trade has reached a certain annual magnitude, and the value of wheat in England will then steadily fall as trade expands and England imports more and more of it. If still comparative values are not brought to identity, the production of blankets in Germany will stop, Germany's imports of blankets being such in amount that home manufacturers cannot profitably put any on the market. When this happens and commerce still expands, a position of equilibrium, in which the comparative values of wheat and blankets in England and Germany are identical, must finally be reached. Proof has been furnished by the theory of barter on pages 149-52.

Complicate the imagery by admitting all the countries of the world instead of two only, by supposing that traders in each try to get on the lowest terms what their customers want, and by recognizing the multitudes of commodities with which 
our needs are satisfied and the conditions of their supply, and there is presented the intricate problem of international values as it actually is. To solve it theoretically innumerable equations would be required. The principles of the solution have been brought out in our simple hypothetical exposition.

It is worth while noting how very seldom it happens that the production of anything is confined to one land alone. If England exports a commodity to France which is not produced in France, it will usually happen that some third country, with which both England and France trade, will produce it also. The cases in which a people has a monopoly in the production of anything are limited. Almost always the exporter has to compete in the market of a foreign country with the home products of that country or with the products from a third country.

Summary of conclusions and a corollary.-To sum up and reiterate, we conclude:-

(1) That permanent trade appears when there are differences between the ratios of the values of things in different countries.

(2) That at the position of equilibrium the ratios between the values of things must be the same in all countries.

(3) That the aggregate value of each country's exports must equal the aggregate value of its imports. Upon this statement I shall have to pass some explanatory and qualifying remarks later.

The introduction of cost of carriage and import and export duties (commonly called tariffs) makes the problem more involved but does not alter its character. To be quite exact, we must say that traffic begins between two nations when values differ after cost of carriage to consumers and tariffs, if there are any, have been allowed for. Of tariffs I shall speak in Chapters XXX and XXXIII.

The special case of foreign commerce known as "dumping" has already been dissected (pp. 179-81). The reader is in a 
position to decide for himself the extent to which the principles of international trade here expounded apply to it.

The doctrine of comparative costs, better termed the doctrine of comparative values to make it unambiguously cover importations by a country of things which it cannot produce, or ceases to produce, is sometimes interpreted with the wider reference as laying down proposition (1) above; but it is not unusually regarded as affirming both propositions (1) and (2).

If the theory of international trade, as roughly outlined above, is fundamentally correct, it will be immediately evident that a people's trade may decline contemporaneously with the people's economic advance, though it is not likely to do so. Thus, imagine a fictitious labour-capital unit which measures productive efficiency and suppose the real costs of production in our two countries are as indicated below when there is no trade:-

Germany produces 1 blanket with 10 labour-capital units

$\begin{array}{cccc}\text { England produces } 3 \text { blankets } & , & , & , \\ , " \quad, 3 \text { bushels of wheat } & , & , & ,\end{array}$

Then Germany will export wheat to England and England will pay in blankets. Now suppose that industrial advance, mainly affecting agriculture, takes place in England, with the result that eight bushels of wheat can be grown with the expendi. ture of ten labour-capital units and four blankets can be manufactured at the same real cost. What will be the effect? Trade between Germany and England must entirely cease, as soon as industrial organization has accommodated itself to the new conditions. Yet England who has lost her commerce has really progressed.

Diagrammatic representation.-Let us draw our theory of foreign trade to a head with the aid of a diagram.

Consider fig. 7 on page 152, ignoring at first the dotted lines. Let 
the curve B represent England's offer of blankets to Germany for wheat. Let the curve A represent Germany's offer of wheat to England for blankets. The position of equilibrium is given by the intersection of the curves. At the position of equilibrium England will export $\mathrm{O} h$ of blankets to Germany and Germany will export to England to pay for the blankets $\mathrm{Og}$ of wheat. The ratio of exchange between blankets and wheat in both England and Germany will be given by the equation.

Value of $\mathrm{Og}$ of wheat = value of $\mathrm{O} h$ of blankets.

We have, of course, ignored cost of transport and all other countries and all other commodities.

In order to make plain what exactly each curve means, I will now state in detail the information which the point $m$ on the curve $B$ conveys. If at the position of equilibrium England is still producing some wheat as well as blankets, the point $m$ means that when England has produced $\mathrm{O} h$ of blankets, over and above what she needs for herself, and has produced what wheat she requires after importing $\mathrm{Og}$ of wheat, then

\section{$\frac{\text { marginal cost of production of wheat in England }}{\text { marginal cost of production of blankets in England }}=\frac{\mathrm{Oh}}{\mathrm{Og}}$}

But if at the position of equilibrium England has ceased to produce any wheat, the point $m$ means that when England has produced $\mathrm{O} h$ of blankets, over and above what she needs for herself, and has imported $\mathrm{O} g$ of wheat, then

$$
\frac{\text { value of wheat in Fngland }}{\text { marginal cost of production of blankets in England }}=\frac{\mathrm{O} h}{\mathrm{Og}}
$$

In this case there is no marginal cost of production of wheat in England as it is not produced there. Of course the value of blankets in England will equal their marginal cost of production there.

Each point on the curve B has to be similarly interpreted. And the curve A has a corresponding meaning. These curves would seem to be packed as full of information as Lord Burleigh's nod in Sheridan's Critic.

The reader may be left to decide for himself, after considering the possible conditions of demand and supply in the two countries, what are the possible and likely shapes for the curves $\mathbf{A}$ and $\mathbf{B}$.

As in the home trade, so in the foreign trade, multiple positions of equilibrium are possible, and a position of equilibrium may be 
completely stable, partially stable, or completely unstable. How to represent them, the ingenious student may discover for himself.

Finally I may suggest a means of exhibiting on this diagrain the gain resulting from the foreign trade, and its distribution. Let $\mathrm{O} b$ be England's indifference curve (see p. 151) that is a curve representing the exchanges which would leave England neither gaining nor losing from the trade. Then at the position of equilibrium England's gain from the trade would be the value of $m d$ of wheat. If she gave $\mathrm{O} h$ of blankets for $h d$ of wheat, she would neither gain nor lose, but as she gets $h d+m d$ of wheat. for her exports of $\mathrm{O} h$ of blankets she gains $m d$ of wheat. In certain unlikely circumstances Od and the curve $\mathrm{B}$ might coincide.

If $\mathrm{O} e$ is Germany's indifference curve she gains from the trade the value of $e m$ of blankets.

The balance of trade.-Do imports pay for exports? is a question frequently asked. In the long run they must, when all goods and services, apart from gifts, loans and interest on loans, are included, if people do not fail to meet their current obligations. To take a case free from complexities, this is to say that in the long run my expenditure must equal the value of the goods that I get, apart from gifts, loans and interest on loans, if $I$ do not fail to pay my bills. But, naturally, the value of 'what I buy or hire any one year need not equal the payments that I make in that year, because of the existence of credit. Under a strict system of cash on delivery there would, however, be exact correspondence at all times between receipts in goods and payments for them. Credit, you may appropriately regard in this simile as a loan made by shopkeepers to their customers. The loan is repaid when customers pay their bills.

Notice carefully that I have excepted gifts, loans and interest on loans, from my equation relating to foreign trade. Gifts, which, of course, are not paid for, come into a country from the relatives and friends of persons who have gone to reside abroad. Most of the gifts may take the form of money, 
but the money is spent on goods, and the country which has sent the money must ultimately meet the obligations represented by the money and export goods of like value. Debts and interest on them we must exclude because they may not be repaid for many years, if they are repaid at all.

The vigilant reader will not jump to the conclusion that there must otherwise be correspondence in the long run between those imports and exports which officials can watch and record in statistics. To expect this would be as unreasonable as to expect correspondence between my expenditure and the tangible things that enter the portals of $\mathrm{my}$ dwelling. There could not be such correspondence because, in addition to providing for meals at home, I occasionally dine at a restaurant, and I engage domestic servants, go to the theatre, pay subscriptions to clubs, and sometimes travel.

The officially unrecorded goods and services provided for Frenchmen, say, by foreign countries are as follows :-

(1) Unrecorded valuables which enter France by post.

(2) The goods and services which are not directly imported but are provided for Frenchmen abroad. The balance of trade means the balance of economic obligations conferred by different nations through their members upon one another. The Frenchman on a visit to London is still a constituent part of the French nation. Again there is the provisioning of French ships abroad.

(3) Services done for France which are not recorded in statistics of things imported by France. For example the sea-carriage done by English ships for French account, and any agency and financial work done in a foreign country for French account.

We may notice, in reference to the large balance of imports in English trade, that England has enormous investments abroad and that she earns a fortune annually for agency and financial work and shipping services. 
An additional step in justifying the proposition that imports and exports balance is taken by those who put claims into the balance sheet. Thus if France makes a loan to Japan, France exports credit documents (money, broadly regarded, which was borrowed to be spent and becomes goods when it is spent) and receives in return bonds of equal value stating the amount of the debt. The bonds, it is said, should be included in French imports. When interest is paid on the loan, credit documents enter France and discharges or receipts of equal value go out. These discharges or receipts, it is said, should be included in French exports. The interest, paid in money, becomes ultimately, as the loan became, merchandise or services. Most credit documents, receipts and bonds, we may observe, come into a country through the post and cannot be seen.

This way of justifying the proposition that exports just pay for imports seems to me to rob the proposition of most of its significance. It is made to declare simply that business men will see to it that their accounts and documents relating to foreign commerce, as well as those relating to home commerce, are all in order.

The term "invisible imports and exports" is used to cover (1) all goods and services provided internationally which are not recorded in official trade returns, and sometimes in addition (2) all credit documents, bonds and claims which pass between countries. Invisible imports and exports are not designated " invisible " because they cannot be seen, but because they are not recorded in official trade returns. Many of them can be seen and felt, even eaten or worn, as we have discerned.

Effects of foreign loans on imports and exports.-A few words may be said here of the effects of foreign loans, to prove that we are right in regarding a loan made to a foreign Government or a foreign business as a loan of goods. The loan is first made in money, broadly regarded, but the money is borrowed to be spent. Suppose, as a simple illustrative case, 
that people in England invest $£ 1,000,000$ in Australian industries. Then we may say that England has lent $\$ 1,000,000$ to Australia. The level of prices is raised in Australia in consequence, and it will not be restored to the normal level till the money has left Australia. It will leave Australia to pay for the additional imports which are attracted by the high level of prices. Those additional imports may come from anywhere. But if they come from any other country than England, that other country will be so placed with its extra money that it, too, attracts additional imports. Finally, by direct or roundabout trade, the normal level of the world's prices must be recovered through an additional exportation of $£ 1,000,000$ to England. England's exports are encouraged till this happens by her low level of prices after loaning $£ 1,000,000$. So we see that in effect, directly or indirectly, England has lent Australia $£ 1,000,000$ worth of goods. When the loan is repaid, if it is ever repaid, it is repaid in goods,-transparently not in the same goods, but in other goods of the same value.

A similar portrayal of interest payments will reveal that they, too, are in effect payments in goods made directly or indirectly through the medium of money. The argument will become more convincing to the reader after he has studied the chapters on money which follow.

The economic advantages of foreign trade are patent. And so are the general social advantages which result from foreign intercourse. What, if any, countervailing economic or social disadvantages there may be, which call for State restraints on trade, we shall consider in Chapter XXX. 


\section{BOOK V.}

\section{MONEY AND THE MECHANISM OF EX- CHANGE.}

\section{CHAPTER XX.}

\section{THE THEORY OF MONEY.}

Few human errors in the past in the economic field have been more mischievous than those arising from false theories of money. Yet the subject presents no very formidable difficulties, if it is properly approached.

The best approach to an understanding of the uses of money, its functioning and the determination of its value, is by way of its evolution. I do not mean that we should trace the history of money from age to age, though from so doing a great deal that is of practical importance, and a great deal which throws light on the evolution of money, might be learnt; but that we should begin with the simplest imaginable use of money and follow the logical order of development in its use, which is not necessarily the historical order.

Inconyeniences of barter and emergence of money.Money originated logically in the inconvenience of barter. As in course of time members of a community become more and more dependent upon one another economically, the quantity of exchanging which must take place between them increases. In a simple subsistence economy-that is in a social state in 
which each family produces all or most that it wants-the amount of exchanging effected is insignificant. Social development implies a growing dependence of person on person economically; and long before the amount of necessary exchanging involved in this economic dependence becomes at all considerable, the inconveniences of barter become intolerable.

The fundamental inconvenience of barter arises from the fact that for each act of barter a double coincidence of wants is a prerequisite. If $I$ have sandals to barter, I must find a person who not only wants sandals but also possesses what I require, say, turbans. Endless time may be spent in seeking such persons, and the chances are that I shall have to give up the quest and rest satisfied when I can sell my sandals for any articles which come within measurable distance of what I want. And I may, in addition, have to sell at an unfavourable rate of exchange, because I may not succeed in discovering a person who cares much for sandals among those who have at all what I require. And those who take my sandals may equally have to put up with a second-best satisfaction of their wants. In the circumstances they and I may esteem ourselves fortunate in not having failed utterly to attain our ends at a reasonable cost.

The enormous difficulty of getting satisfactory results out of bartering will be still further appreciated when we dwell upon the awkwardness, under that system, of accommodating units of sales to units of purchases. If a grazier requires numerous small articles, his task in marketing by barter is almost impossible of performance even with the utmost patience. With a sheep he would bo able to purchase a great deal, but unless he divided up the sheep he would have to find somebody who both required a sheep and possessed, or would get for him by yet further processes of this vexatious bartering, the multitude of small articles to obtain which he was ready to sacrifice his sheep. 
With these fundamental defects of the system of bartering, other annoyances are connected. The chief of the latter arises from the fact that bartering does not naturally provide a common denominator of value, so that the values of different things may be known and compared. Under barter every commodity is exchanged directly for a multitude of different things. Knowing the value of wheat, say, means knowing how many spades a bushel of wheat will purchase, how many fowls, how many blankets, and so on to the end of the catalogue of the exchangeable things which exist. Were the wheat always bought with iron, in a short time a regular market price of wheat in terms of iron would become settled and recognized, and individuals who wanted to buy or sell wheat would, therefore, be furnished with an index, by reference to which they could decide whether they were offering or being offered, as the case might be, a reasonable price. Under the rule of barter, on the contrary, endless higgling over every purchase must inevitably occur, and an immense amount of time must be wasted in consequence.

The impossibility of doing business speedily and satisfactorily by means of barter constrains people to sell things for some other thing which they do not require in the hopes of selling the latter again for what they do require. When any commodity is made to render an indirect service in this way, it is being employed as money, in the broadest sense of the term, that is, as a medium of exchange.

We can imagine that, as a result of a sort of natural selection, certain articles are promoted to serve the purpose of media of exchange. The fittest for the purpose survive and get established as the customary media of exchange. In this process of survival the application of money to purposes other than effecting exchanges plays a determining part. The medium of exchange is naturally singled out to store up value, unless it is obviously unsuitable for that purpose. Money, 
which can be kept for long periods without fear of its losing in value, is, therefore, found preferable to money which cannot.

Choice of the money commodity. - It is easy to perceive for the possession of what qualities an article would be chosen for money. To be moderately convenient the money commodity must be characterized by the possession of the following leading attributes:-

(1) General acceptability (if we may call this an attribute). The article must be in common demand in the initial stages of the development of money, because otherwise it would not be easy to make purchases with it.

(2) Transportability-because the medium of exchange has to be carried about, or driven about, to do its work as money. Transportability involves that money should contain in a convenient bulk and weight an amount of value which is reasonable in view of the wealth of the community. Other things being equal, the more rapidly the medium of exchange can be transported, and the less the trouble occasioned, the better.

(3) Cognoscibility and homogeneity.-The article must be readily recognizable for what it is so that persons accepting it may not be deceived easily. This requisite implies homogeneity, that is, that the article should not exist in a multitude of qualities.

(4) Divisibility.-This is a quality which is practically, though not logically, essential. Divisibility here means that the article can be divided up without losing in value. Much value is destroyed when precious stones are broken up, but little, if any, value is destroyed when metals are broken up. It is evidently an advantage for money to be furnished in small and large units. If there existed precious stones of a certain kind, of which there were always just the most appropriate supplies of all sizes, they would serve famously as money, provided that the value of a stone bore a constant relation to 
its size. But the relation between the value and weight of precious stones of any kind cannot be a fixed one, since they differ in quality, and the demand for and supply of stones of any given size vary from time to time, and increased demand for the smaller stones cannot be met, without loss, by breaking up larger ones, and increased demand for larger stones by fastening smaller ones together. We may, therefore, agree that divisibility, in the sense given to it above, is essential.

(5) Storability, including imperishability.-The money commodity must be comparatively imperishable, because if I take it in exchange for my goods I may have to retain it for some time before I use it again to make purchases. Again, it must be of a convenient bulk for storage, and not require constant attention like flocks and herds.

(6) Fixity of value.-The money commodity must be fairly constant in value, as otherwise loss may be incurred through accepting it.

Metals, and particularly the more precious metals, are admirably endowed with the qualities enumerated above. They are widely acceptable, recognized without difficulty, divisible without loss of value, easily transportable, comparatively imperishable, easily stored, and finally more constant in value than the majority of other things.

Their comparative immunity from oscillations in value follows to a large extent from their comparative imperishability over long periods. A large part of the stock of each of them in use to-day was mined in the more or less remote past. The more precious the metal, other things being equal, the larger is the proportion of the supply which is inherited from early times; for the more precious the metal the more carefully is it preserved. Because of the continued existence of accumulations, variableness in the amount of gold mined from year to year exerts less influence on the value of gold than it 
would otherwise. It is true that the annual supply of a precious metal cannot in the present-and could even less in the past-be accommodated to fluctuations in demand; but this is a matter of little moment when the demand for the metal in question is not subject to substantial fluctuations. A steady appreciation or depreciation of the value of a money metal is less troublesome than oscillation in its value, because the former could be allowed for, whereas irregular ups and downs cannot.

The final choice of a metal or group of metals to serve as money depends upon the wealth of the community, and must depend upon it if the only or the chief circulating money is the money metal. Gold would be too valuable as a standard in early stages of civilization. The value of the normal unit of purchase in early stages of civilization is so low that the coins in commonest use if formed of gold would need to be absurdly tiny. If a man's income expressed in gold is only one pennyweight of gold per week, his buying in terms of gold would plainly be out of the question. Imagine the attempted division of that pennyweight of gold into fifty, or even twenty, equal parts.

Similarly, copper is certainly not of sufficient rarity to serve as the standard of value for Western civilization at the present time. Imagine the loads of copper which we should have to carry about, under existing monetary conditions, if there were no coins of a more precious metal.

Determination of the value of money.-Though gold is out of the question when the money metal is being naturally selected under primitive conditions, I am going to suppose that gold is the metal chosen. I am going to be illogical to this extent because, in writing of the use of money in an imaginary world of primitive conditions, my main purpose is really to solve the monetary problems of more advanced conditions. And in the most advanced conditions gold is 
invariably found to be the standard of value. So I shall imagine that gold is the metal selected in the world of my fiction, in order that the propositions established may have application, without a change of terminology, to circumstances familiar to us.

I assume now, for purposes of exposition, that all money is gold money. The standard coin, we suppose, is an ounce of gold of a given fineness. There may be smaller coins, but I intend to express the quantity and value of money in terms of this coin, which I shall call the money-ounce. We assume further that bullion can be turned into money-ounces, and the latter into bullion, at the will of the possessor.

I must begin my theorizing by impressing upon the reader as forcibly as I can that the exchange value of natural money (that is what it will purchase) must equal its exchange value as a commodity or commodities. Though gold be chosen for money, it still remains a commodity which has value as a commodity. That is to say our money-ounce must buy just one ounce of gold. If it would buy more than an ounce of gold, people would melt down some of their gold ornaments and works of art to use as money, and devote less gold in the future to the arts and jewellery. They would do this, which we suppose to be possible, because their gold would have higher value in the form of money-ounces than in other forms. Correspondingly if a money-ounce would buy less than an ounce of gold it would pay to transform some money-ounces into ornaments and works of art-and we premise that this is possible. So, to put the generalization subjectively, in terms of our imaginary case, the marginal utility of a moneyounce to a person (that is the marginal utility of anything that it purchases for him) must equal the marginal utility of an ounce of gold to him, if he possesses any gold in forms other than money-ounces.

The equation that we have established, however, will not 
alone solve the problem of the value of money. We have shown that the purchasing power of a money-ounce must equal the exchange value of an ounce of gold-that is to say, we have shown that gold must be so distributed between money and commodity uses that this equation holds-and we know that the exchange value of gold varies directly as its quantity; but we have yet to show how purchasing power is connected with the supply of money-ounces.

Let us take for granted that all exchanging is conducted with money-ounces, that no credit is given, and that no moneyounces are saved up. Then the quantity of exchanging to be done over a given period must be one determinant of the purchasing power of money. The quantity of money must be another, and the frequency with which it changes hands in effecting exchanges over the given period must be another.

The frequency with which money changes hands in a given time to make purchases is called its "rapidity of circulation" or "velocity of circulation". Let us suppose that it is possible to speak of the average rapidity of circulation of money as a whole, and thus escape the complexity arising from the fact that one money-ounce might change hands more frequently in a given period than another money-ounce.

By "quantity of exchanging to be done" is meant the sum of the values of the exchanges effected, expressed as a multiple of the price of some article. Thus let the price of a peck of wheat be the unit. The sale of a peck of wheat counts as one unit of exchange. The sale of a horse, when a horse is worth 1000 pecks of wheat, counts as 1000 units of exchange.

The solution of the problem of the purchasing power of money, then, as so far expounded, is as follows. (a) The quantity of exchanging to be done, in a year, say, divided by a figure obtained by multiplying the number of moneyounces in use by their average rapidity of circulation in a 
year yields the purchasing power of the money-ounce when there are the supposed number of money-ounces in use. This must be so because, on the assumptions made, the moneyounces must buy up, and just buy up, the goods offered for sale in the period. (b) Gold will be so distributed between money and commodity uses that the purchasing power of the money-ounce will equal the exchange value of the ounce of gold. The reader will see that allowance can easily be made for hoarding.

We may bring our delineation a stage nearer reality by allowing for the effect of credit. The bulk of the exchanging in the modern world is effected by means of credit. The credit instruments are bank-notes, cheques, bills of exchange, and token money. We shall consider later in more detail the characteristics of these several instruments; now we simply note their bearing on the purchasing power of money.

Evidently the effect of the appearance of credit money will be to increase the media of exchange, lower the purchasing power of money, drive gold from the currency into the arts, and depress the marginal utility of gold. These results will follow whether credit instruments bear a fixed ratio to metallic money or not. As we shall observe in due course, there is a good deal to be said for the view that credit money tends, in any one state of trade, to bear a comparatively fixed ratio to metallic money.

The theory of money just expounded is sometimes known as the quantity theory of money. It need not be given a title since there is no other plausible theory to distinguish it from. It is sufficient to describe it as the theory of money. Sometimes the title "quantity theory of money" is reserved to indicate the views of those who maintain that the value of money varies directly, and in the same degree, as the quantity of the money-metal circulating as money, because, as they contend, the quantity of credit money bears a fixed relation to the 
quantity of money-metal circulating as money for any given state of trade.

Finally, to complete our theory we must allow for the supply of gold. It is sufficient to say that gold when mined will be mined in such quantities that its supply-price per ounce will tend to equal a money-ounce. If its supply price could not be made as low as a money-ounce at any time it would not be mined. The amount of gold produced each year is obviously governed inter alia by the rate at which the existing stock wears out.

After a little thought the reader will perceive that this theory of money fits into the ordinary theory of the determination of the value of things by demand and supply.

\section{Symbolic and diagrammatic expression of the theory of the} value of money.-Using symbols, we may put our first results as follows. Let

$\mathbf{P}=$ purchasing power (that is value) of a money-ounce.

$\mathbf{T}=$ trade, i.e. quantity of exchanging to be done, in a year.

$\mathbf{M}=$ quantity of money-ounces.

$\mathrm{V}=$ velocity of circulation of money-ounces.

That is to say, the money work to be done is $T$, and the monoy power to do the work is $M \times V$. Hence, inasmuch as the money power is only there to do the money work-that is to say, the money power must be used up in doing the money work-the value of money is given by the following equation :-

$$
\mathbf{P}=\frac{\mathbf{T}}{\mathbf{M V}}
$$

The magnitude of $M$ is determined (1) by the supply of gold and (2) its distribution between money-ounces and the arts. Its distribution between money-ounces and the arts is given by the following equation :-

$$
\mathbf{P}=\mathbf{G}
$$

when $\mathrm{G}=$ the exchange value of an ounce of gold bullion.

Allowing for credit money, write

$$
\begin{aligned}
\mathbf{M}^{\prime} & =\text { credit money. } \\
\mathbf{V}^{\prime} & =\text { its velocity of circulation. }
\end{aligned}
$$


Then our first equation becomes

$$
\mathbf{P}=\frac{\mathrm{T}}{\mathbf{M V}+\mathbf{M}^{\prime} \mathbf{V}^{\prime}}
$$

If for a given state of trade $\mathbf{M}+\mathbf{M}^{\prime}$ bears a constant relation, $\mathbf{K}$, to $\mathbf{M}$, and $v$ is the average rapidity of circulation of $\mathbf{M}+\mathbf{M}^{\prime}$, then $\mathbf{K} \mathbf{M} v$ may be written for $\mathbf{M V}+\mathbf{M}^{\prime} \mathbf{V}^{\prime}$ in the above equation.

Finally we must add to our equations :--

$$
\mathrm{S}=\mathrm{P}
$$

if $S$ is the marginal supply price of an ounce of gold.

To express the settlement of the value of money by means of demand and supply curves, we should have to compound a demand curve for gold bullion and a demand curve for money-

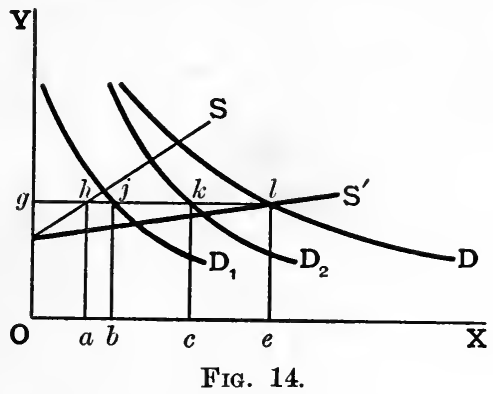

ounces. The former would show how many pecks of wheat, say, would be given per ounce for different quantities of bullion for use in the arts. The latter would show how many pecks of wheat a money-ounce would buy when there were different quantities of money-ounces in existence. The supply curve would indicate what the supplies of bullion would be for different values of bullion in wheat, when allowance was made for the existing stock of gold, its rate of wear and tear and the cost of procuring it.

Let me illustrate by means of a diagram.. In fig. 14 along $O Y$ measure pecks of wheat and along OX ounces of gold. Then the curve $D_{2}$, which represents the different quantities of wheat for which a money-ounce would exchange when there were different 
quantities of money-ounces, is the demand for gold as money in terms of wheat. $D_{1}$ is the demand for gold in the arts, and gives the exchange value in wheat of gold in the arts when there are different quantities of gold in the arts. $D$, which is compounded of $D_{1}$ and $D_{2}$, is therefore the total demand for gold stated in terms of wheat.

Assume that the stock of gold, after a year would be reduced 25 per cent in consequence of wastage, if the stock were not recruited. Assume also (1) that demands are rigid and have been for some time, and (2) that the conditions of supply of gold are the same from year to year and have not altered for some time. Let $S$ be the supply curve relating to gold. Let $S^{\prime}$ be a curve obtained by multiplying the abscissæ of the curve $S$ by the ratio of 100 to the rate of wastage of gold (that is by $\frac{100}{25}=4$ ); so that $S^{\prime}$ is $S$ pulled out fourfold to the right, so to speak. Draw $g l$ through $l$ (where $\mathrm{S}^{\prime}$ and D intersect) parallel to $O X$.

Then, at the position of equilibrium,

$\mathrm{O} e$ of gold is regularly in use.

$\mathrm{O} c$ of gold is used as money.

$\mathrm{O} b=c e=$ quantity of gold used in arts.

$\frac{\mathrm{O} e}{4}=\mathrm{O} a=$ wastage of gold by wear and tear each year.

$\mathrm{O} a=$ amount of gold produced annually.

The distribution of the annual supply $\mathrm{O} a$ between the arts and money depends (on the assumption made) upon the relative wastage of gold in each.

Observe the following points which are deducible from the above argument. If the wastage of gold increased, or the supply price of gold fell, there would ultimately be a settlement at a new position of equilibrium. In the former case the annual supply of gold would be greater but the amount in use would be less. Exactly the opposite consequences would follow from reduced wastage. A fall in the supply price of gold would mean more gold in use and larger annual supplies.

Functions of money summarized.-Money serves not merely (1) as a medium of exchange, which is its most important use, but also (2) as a standard of value, (3) as a 
store of value, and (4) as a common denominator of value. In elfecting exchanges it is ipso facto constituted a common denominator of value. In thus rendering the values of all things comparable with one another, money fulfils one of its most important functions (see p. 19). It is merely convenience which causes money to be used as a store of value. We could as easily store precious stones. As regards the standard of value, we must observe that this need not circulate. It is sufficient if representatives of it circulate. This is discussed in the sections on paper money which follow.

Appreciation and depreciation of money.-Money is said to appreciate when its purchasing power rises. It is said to depreciate when its purchasing power falls. By the foregoing it has been proved that, if the quantity of money remains fixed, an increased supply of commodities (including all purchasable things) causes an appreciation of money, and a decreased supply of commodities a depreciation of money. Likewise, if the quantity of commodities remains fixed, an increase of money causes depreciation of money and a decrease of money appreciation of money. The latter proposition is sometimes expressed quantitatively in technical language by saying that the elasticity of demand for money is unity (see p. 41). For, whatever the quantity of money in use, about the same amount of exchanging will be done, since the supply of money may be regarded as not affecting the supply of commodities. Hence, to take two examples, if the quantity of money doubles, its purchasing power per unit falls 50 per cent, and if the quantity of money is halved, its purchasing power per unit doubles. That is to say the demand for money has elasticity unity. We have posited in this paragraph that an alteration in the supply of commodities, however it may be measured, is accompanied by an exactly corresponding alteration in the amount of exchanging to be done, the method of computing which has been already described on page 204 . 
The terms "appreciation" and "depreciation" (of money) are sometimes confined to ascents and descents of purchasing power due to causes affecting the supply of money. But this limited application of the terms " appreciation "and "depreciation" with reference to money is uncommon, and it would be best, therefore, to avoid it. If we wish to allude to the effect on prices of purely monetary influences, we can speak of the appreciation or depreciation of money caused by variations of monetary power.

Index numbers of prices. - The question naturally arises as to whether it is possible to measure variations in the purchasing power of money. At first blush it might seem impossible to do so because the prices of things are constantly moving in different directions at different rates. We may, however, get over the difficulty by averaging. The average, of course, is nothing more than a conventional standard. Should the price of tea advance 50 per cent and the price of coffee fall 50 per cent, we may say that their prices, taken together, have neither risen nor fallen, if we agree to mean by this that the prices when counted together in a certain way in an average have neither risen nor fallen. It is found a great convenience to mean by the rise or fall of prices in general the rise or fall of some average price. Figures indicating the periodic rise or fall of some average price, determined in the mannor stated below, are known as index numbers of general prices.

When we take prices as a whole it is impossible to average them all, because the number of distinguishable sorts of commodities is legion if different qualities of the same commodity be taken separately. But we may select, from the totality of articles used in the world, a certain typical group of things and average the prices of these. If the group is properly typical, that is to say if it includes representatives of most classes of commodities, the probability is that the average price of the typical group will vary in practically the same way and degree as the average price of all commodities, which, as I have said, cannot be calculated. Commodities may be said to be of the same class, when they are subjected to pretty much the same influences from the sides of both demand and supply.

The averaging may be effected in a variety of ways. We may take 
the arithmetic mean or the geometric mean, for example. Again, we may or may not weight our average, that is to say, attach a special importance to the price variations of certain commodities by multiplying their prices by certain numbers which are roughly proportional to the degree in which income is spent upon each of these commodities. But I must not examine the problems of averaging and weighting here. It must suffice to point out that the arithmetic mean is usually good enough, and that for general purposes weighting is found to be unnecessary if the typical group of commodities is well selected. In the various sets of general index numbers of prices which have been calculated, the number of commodities taken varies, but it is never less than about twenty.

I shall now give a calculation of index numbers of a fow commodities, so that there may be no misunderstanding of the manner in which index numbers are constructed. It must be remembered, however, that this is merely an example, and that the number of commodities used in the example is quite inadequate. The average I shall employ is the arithmetic :-

\begin{tabular}{|c|c|c|c|c|c|}
\hline & \multirow{2}{*}{ 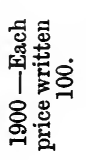 } & \multicolumn{4}{|c|}{$\begin{array}{l}\text { Percentage rise or fall of each } \\
\text { price, as compared with the cor- } \\
\text { responding price in } 1900 \text {, plus } 100 \text {. }\end{array}$} \\
\hline & & 1901 & 1902 & 1903 & 1904 \\
\hline Tea & 100 & 105 & 110 & 114 & 112 \\
\hline Wheat & 100 & 98 & 97 & 99 & 95 \\
\hline Pig-iron & 100 & 117 & 115 & 110 & 103 \\
\hline Cotton & 100 & 102 & 98 & 104 & 97 \\
\hline Sugar & 100 & 96 & 100 & 98 & 91 \\
\hline Coal & 100 & 99 & 105 & 109 & 110 \\
\hline Total & 600 & 617 & 625 & 634 & 608 \\
\hline Average & 100 & $102 \cdot 8$ & $104 \cdot 1$ & $105 \cdot 7$ & $101 \cdot 3$ \\
\hline
\end{tabular}

The index number is sometimes given as the total and sometimes as the average. In this case 1900 is the standard year, so called $14 *$ 
because the prices in all other years are expressed as percentages of prices in that year. The average price may be the average of prices at the end of each month, or each week, or at any selected intervals. If we liked, of course, we could construct monthly, or weekly, or even daily index numbers.

What is sometimes called regulating deferred payments by a tabular standard of value means arranging that payments in the future shall represent agreed amounts of purchasing power as shown by some system of index numbers adopted for the purpose. Thus if the above table represents the adopted system and I borrowed $£ 600$ in 1900 I should pay back $£ 634$ in 1903 apart from interest. For some considerations bearing on the tabular standard see pages 242-3.

For special purposes it may be found desirable to construct special sets of index numbers of price movements. For instance, if we want to show variations in the purchasing power of workingclass incomes, we must begin by drawing up a budget of average working-class expenditure, so that we may know how much of working-class income is spent on rent, how much on clothes, how much on bread, meat, coal, and so forth. This budget must be used in selecting our typical group of commodities. We should probably find it necessary to weight our average in this particular case, in order tu make allowance for the large percentage of income which is spent on certain articles.

The system of measurement by index numbers can be applied to things other than prices; index numbers of foreign trade, for instance, and of wages are largely used. 


\section{CHAPTER XXI.}

\section{THEORY OF BANKING AND CREDIT MONEY.}

I sHaLL attempt to expound the correct theory of the much misunderstood subjects of credit money and banking (which are inter-related) by the use, as in the previous chapter, of simple fanciful conditions. This artifice may seem overabstract, but the adoption of any other would probably leave the reader without a clear conception of the principles by which credit money and banking are governed. A modern monetary system, including the banking in relation to it, is necessarily so involved that, in trying to follow a description of the system, the reader who is making his first acquaintance with it would be apt to lose grasp of the theory interwoven with the description, or to overlook the theory altogether, or even to misread it. I have, therefore, decided to expound the fundamental doctrines of credit before proceeding to detailed facts as they are, which are easy enough to read when the light of analysis is thrown upon them. Nobody is likely to understand a complicated machine who has not made a preliminary study of the principles of mechanics.

Banking creates a loan fund. - My fiction can be set out in a few words. I have already supposed in the previous chapter that a natural money, consisting in money-ounces of gold and fractional coins, is in use. It matters not for the present whether these natural coins are made up privately or are freely and gratuitously issued by the Government (with a stamp upon them to indicate what they are) when the requisite 
bullion is supplied by anybody. I now add, to my preliminary supposition, that the Government starts a banking business. This banking business accepts money on deposit, and derives a profit from its deposits by lending to people engaged in business, or to Governments, or to others who have security to offer. There will be a fund to put out on loan, because ordinarily people will have bank balances. I still suppose that the only money is the natural money.

If a man is saving up at the bank, and intends when he has saved enough to invest his savings in industry, his balance at the bank will be left to accumulate until it has reached a certain figure, when it will be withdrawn. Now, as a lot of people will be saving in this way, and all will not withdraw their savings to invest at the same time, there must always be in the bank a large sum which represents the accumulating savings. And, normally, people will wait till their bank balances are well ahead of $£ 100$ before they withdraw, say, $£ 100$, so as to have a sum of money handy in case of emergency.

If a man is not saving but uses the bank for convenience, he will have to keep at the bank a working fund for his business and a reserve for expenditure. His balance at the bank will only drop to zero in exceptional circumstances. In his balance and the balances of others we see another source of loans.

Were there no bank the sum represented by the balances lying at the bank would be hoarded privately, because people would save up in the same way, and keep working funds to carry on their businesses and reserves for expenditure in the same way. We assume that the establishment of the bank would not affect the habits of the people in this respect. But some part of the sums hoarded privately for the purposes mentioned could not be loaned because they must be instantly available. This part might be banked on the understanding 
that it was to be instantly available; but, as it is inconceivable that all such deposits would be withdrawn at the same moment, some portion of them could be safely loaned.

The basis of the loaning which results from depositing in banks is identical with the basis of insurance. It is the aggregate uniformity revealed among individual uncertainties. Any one of a given thousand persons might meet with an accident in a given year. No one of them could be sure that he would not be injured in that year. So each must make provision for mishaps which may never befall him. But, in spite of this complete uncertainty, it is quite certain that no more than, say, twenty of the 1000 will meet with an accident in the course of any one year. If the risks of all the 1000 are borne jointly, therefore, it will be sufficient for the group to make provision for twenty accidents in the course of the year instead of for 1000 . This is what is done in effect by insurance companies.

Similarly, when we turn our attention to the basis of bank loans, it becomes plain, to take one example, that if each individual must have, say, $£ 20$ immediately available, 1000 individuals need not have $£ 20,000$ at hand. In spite of each person's uncertainty about his possible need of money on the instant, it is quite certain that no more than $£ 1000$, say, will be wanted in the course of the year by the group of 1000 people.

How much may the bank lend?-How much of its deposits may the bank lend? Evidently just so much as will leave it with "till money" adequate to meet the normal withdrawals of money by the public. For the moment we may ignore fluctuational movements in depositing money in banks and taking it back. Deposits flow in and out, there always being a margin, and loans flow in and out, and the latter must be accommodated to the former so that a safe margin of till money is always left. 
To generalize roughly, we may say that if the banking habits of the people remain constant, and the national income remains constant, the bank will have a fund to invest which is equal to the smallest amount to which its balance of deposits drop in their ups and downs. Practically, I need hardly add, it would not be safe to invest so much because bank deposits might conceivably sink to an even lower level without a business revolution, and, even if they did not, the bank would be left with just nothing in its till when the bottom limit of deposits was touched. As a matter of fact, since deposits fluctuate seasonally, a bank can loan more at one time of the year than at another time, if a portion of the larger sum loancd is paid away for a very short period only.

The till monsy which the bank decides to keep is called its banking reserve. It must be distinguished from the gold reserve, which will be noticed later. In the simple case which we are analysing, as there is no currency but gold, the whole of the banking reserve must be gold. But it will not be actually, for actually the currencies of countries with a gold standard contain notes and token money as well as gold coins.

It is very important to understand that most of the money lent by banks goes back into circulation, even the loan which is "locked up," as it is expressed, in building a factory or laying a line of railway. The gold itself does not become bricks for the factory, and railway embankments and tunnels. The gold is ultimately paid out as salaries, wages, rent, interest and profits, even when it is used to buy articles like bricks and steel rails. It is always passed on to persons. So most of the money put into banks gets back into the pockets of the people.

Banks in loaning trade in credit. So far we have not supposed that the bank of our imaginary circumstances has tried to coin its credit, or, in more literal language, to issue notes. But it has made use of its credit in loaning some of its deposits. 
If its credit had been shaky - that is, if people's trust in the bank had not been firm-it would have run great risks in lending a high percentage of its deposits. At any moment distrust of the bank might have been generated and have spread, and large numbers of people might have demanded their deposits back again. What, then, could the bank have done but close its doors if it had passed the bulk of its deposits on to borrowers who could not return the loans at once? When a bank lends its deposits it is trading on its credit. Its credit is the fount of all its business. Hence the absolute necessity that a bank should take the most scrupulous care to preserve and foster its credit. Manufacturers and traders are put to great inconvenience when their credit is bad, but they may, nevertheless, get along somehow. But without credit a bank cannot get along anyhow. Banks which are not Government institutions lay their foundation of credit in large subscribed funds and in the reputations of those responsible for their direction, and aim at extending their credit by fair and prudent dealing.

A plausible fallacy.-Now, I must expose a plausible fallacy. In stating it, I am going to speak of sovereigns, instead of money-ounces as heretofore, so as to have a familiar term, but I still preserve the fiction that no money other than gold coins is used, and that there is no foreign trade.

The argument to be scrutinized may be put in this way. Suppose a bank is opened and the money left deposited in it settles at $£ 100,000$. The bank, let us say, finds it safe to loan 90 per cent of its deposits. It therefore lends $£ 90,000$ (that is, 90 per cent of its deposits of $£ 100,000$ ). The $£ 90,000$ loaned is deposited. Of this new deposit of $£ 90,000$ it lends $£ 81,000$ (that is, 90 per cent), and the $£ 81,000$ lent is redeposited. Of the new deposits of $£ 81,000$ it lends $£ 72,900$ (that is 90 per cent), and the $£ 72,900$ is deposited; and so on. It can be calculated that the deposits at the bank which were 
$£ 100,000$ will become, through its loaning always 90 per cent of its deposits, $£ 1,000,000$.

These are the ultimate deposits, we may be told. And as we assume that 90 per cent of the deposits will be loaned, the loans will ultimately be $£ 900,000$. So in this case the bank would lend ultimately nine times as much as its original deposits, according to the contention which we have to examine.

That such a result, or even the semblance of it, exists only in the imagination can be proved, without specific recourse to facts, on the testimony of common sense. We have learnt in the section just preceding that the $£ 90,000$ loaned would tend sooner or later to figure as an access to money income. But as money income became ampler, general prices would ascend and gold would be expelled from the currency into the arts. Consequently there would be a smaller supplement to money income than $£ 90,000$. Let $£ 60,000$ be added. Now only a fraction of this would be deposited, and left on deposit, in the bank. The fraction would be the proportion which the original level of deposits in the bank bore to the original level of money income, which would not be high. Put the fraction at one-twelfth. Then the first fresh deposits, of which 90 per cent could be loaned, would be, not $£ 90,000$ as is presumed above, but merely one-twelfth of $£ 60,000$, that is $£ 5000$. Our figures, you will remember, are merely illustrative. We need not carry the arithmetic farther.

Observe, in conclusion, that as the loaning by the bank raises prices in the ratio in which its loans ultimately increase money income, and as its loaning rises in exactly the same proportion, the additional loaning which its first loaning renders possible, makes absolutely no addition to the real value (that is, value in commodities) of the loaning done by it. The real value of its loan of $£ 90,000$, for instance, at the time that it was made, would be exactly the same as the real value of the sum out on loan at the time when the loan was increased to 
$£ 90,000+£ 5000$ in the manner described above. This theory of loaning is not altered in character by allowing for the institution of credit money.

Theory of credit money.-I shall take credit money to consist in bank-notes and cheques. I shall begin by supposing that there are no cheques, and confine my attention to bank-notes.

The credit of a bank can be made profitable otherwise than through the lending of its deposits. A bank may use its credit to float promissory notes and get them substituted to some extent for the metallic currency. We may call this coining its credit, because its credit becomes the basis for a kind of circulating money which does the same work up to a certain point as the currency.

Let us imagine that our bank suddenly realizes that the community which trusts it will be willing to accept promissary notes (that is bank-notes) of certain denominations in place of metallic money to some extent, and that by issuing such notes it may largely increase its available funds. Actually, no sudden discovery would need to be made. The issue of notes might come about insensibly and gradually. The bank's ordinary trading bills and receipts for deposits would have a high value, and might be traded in, and pass from hand to hand. Thus its credit could be informally coined before it issued any paper with the deliberate intention of keeping such paper circulating to economize its cash. But in this treatise we must avoid entering into the origins of banking-I say "origins," because banking began in more than one way-and the evolution of its complete modern functions. I refer to the evolution of banking merely in order to prevent the logical order of thought followed in this chapter from creating wrong impressions as to the nature and sequence of historical facts.

When our bank has embarked upon the policy of issuing 
notes, the urgent question arises as to the compass of its power to issue them. What are the limits of a note issue?

In trying to answer this question let us assume provisionally that public confidence in the bank will remain unshaken so long as the bank meets the calls made upon it. Now a few moments' thought will suggest the conclusion that, if the public feel no doubt about the security of the notes, the note issue will be limited only by the habits of the people in respect of the relative uses which they.make of notes and coin, in the absence of any foreign trade. Coin is most convenient for some purposes and notes for others. It is possible to lay it down, therefore, that at any one time the requirements of the people call for a certain proportion of coins to notes in the media of exchange. In affirming this proposition we must bear in mind, however, that the habits of people are modifiable in the matter of the extent to which they will handle credit money. We are supposing for the moment that there are no such things as cheques. .

Imagine that people generally would find it convenient to make one-fifth of their payments with notes. And suppose the rapidity of circulation of coins is twice that of notes on the whole. Then we should have the following equation :-

$$
\text { Value of notes }=\frac{\text { value of coins } \times 2}{4}
$$

This is to say the value of the notes in circulation would be one-half of the value of the coins in circulation. It is very important to notice that the relative rapidities of circulation of coins and notes must be allowed for when we are calculating the demands for coins and notes. If notes were of the same denominations as coins, they would have, theoretically, the same rapidity of circulation as coins. But when the former are of the higher denominations only, they have a lower rapidity of circulation because they serve ordinarily for 
the larger transactions only. It is even more important to notice that it does not follow from the above equation that the new currency, including the notes, would be one-and-ahalf times the old currency. It would be less than this proportion of the old currency because the purchasing power of money would fall as the quantity of money increased, and gold would, therefore, be driven out of the currency into the arts.

If the due proportion of notes to coin as defined above is transcended, and notes become relatively in excess, as judged by the requirements of the community, people will go to the bank to obtain coin for their notes until the right proportion is recovered. If the notes were largely in excess, this demand for coin in exchange for notes might exhaust the coin at the disposal of the bank and force the bank to close its doors.

The governors of our hypothetical bank could form a rough idea from their experience of what the proportion of their notes to their reserves of coin ought to be. They would have to keep on the safe side to provide against any local concentration of notes. A purely fortuitous massing of notes in one place might cause a dangerous run on the bank for coin in that place, though it might be that the notes, if evenly spread over the whole district served by the bank, would actually be inadequate to meet the needs of the people. Our bankers would also have to bear in mind that large amounts of cash might be withdrawn for foreign payments for which notes are worthless. But this is a matter reserved for later treatment. Now we assume provisionally that there is no foreign trade. Let me reaffirm and re-emphasize the proposition that, in the circumstances supposed, the relative demands of the public for notes and coin mark the upper limit of the safe issue of notes. We shall observe later that the issue of notes has been extensively regulated by Governments; and also that the importance of notes has paled within the orbit of the all-dominating cheque. 
The source of the gain from the issue of notes is similar to that from the loaning of deposits.

The theory which has been worked out above with reference to bank-notes holds also of cheques in all its fundamentals. A cheque seldom effects more than one payment, but as we shall see later, it is strictly analogous to a bank-note. It is taken in place of cash and notes. A bunk may lend money by giving a person a right to draw upon it by cheque up to a certain amount instead of giving him notes and cash. In effect the bank would have done the same if it had printed notes for the person in question for the sum for which he is granted power to draw.

The reserve held by the bank to meet the claims of its depositors we have called the "Banking Reserve". The banking reserve may of course contain notes up to a certain proportion. The bullion reserve (or the gold reserve as it is called when gold is the only kind of bullion needed in the reserve) is what its name implies. The significance of the banking reserve in the home trade we have already grasped, but we have yet to consider in chapter XXIV its management in view of trade cycles and the importance of the bullion reserve with regard to foreign trade.

Functions and yalue of banks.-To conclude this chapter a few words may now be said by way of summarizing the advantages of banking to a country apart from its foreign trade. In the first place banks bring about an economy in the use of gold in currencies by issuing notes, instituting cheques (as we shall see more fully later) and lending deposits, as we have seen. In the second place banks by lending their deposits place purchasing power in the hands of business men and thus provide capital for business. Much of the money lent must be lent for short periods only (pp. 214-5), because circumstances might at any moment give rise to a sudden withdrawal of deposits, and because it might be necessary to restrict 
loans in order to check a drain of bullion, as will be explained in another chapter. But bank loans for trading liberate some of the capital previously used in commerce, and the liberated capital can be transferred to industrial purposes. Finally, banks are a convenience to the public in that they serve as places of safe deposit. The conveniences which their cheque systems offer will be dwelt upon later.

The whole of the economy of an advanced community is bound up with its banking system. Only a fraction of the business of the world is now done without recourse to bankers' advances. This being so, the stability of banks and their prudent, and at the same time enterprising, management are essential to a country's prosperity.

Interdependence of banks and bank amalgamation,-It is of interest to notice that the safety of a bank is linked up with the stability of other banks. Modern business is based on credit, and it is in credit that banks deal. If credit suffers a shock the business world is shaken to its foundations. Nothing administers a more irresistible shock than the failure of a bank. If one bank of good repute closes its doors there is a run on other banks. Moreover, the failure of the one bank may cause the bankruptcy of business firms in whose losses other banks would be involved. Hence it is policy for banks to support one another. There is a fear lest banks should get to rely upon enjoying this support if need be, and so be induced to undertake speculative business which they would not touch otherwise. But if any bank does this, it runs the risk of losing its credit, and with it its business, even if it would be supported by other banks during a run. Rumour gets hold of the most profound secrets, and always tells more than there is to tell.

The larger a bank the more can it distribute risks and the more confident can it feel about its security. Hence we find a tendency in most advanced countries for the large bank with branches to take the place of the small independent banks. It has been urged, however, that it is advantageous for each large industrial district to have among its banks some peculiarly its own, which are under 
the management of a local directorate. Such banks might have many branches and be very large ; but of necessity their eggs would repose in a limited number of baskets. Much of the business of such a district, it is alleged, cannot be properly financed by a bank managed by a board elsewhere, because the board would not be sufficiently in touch with local affairs. The bank controlled olsewhere might appoint a local board for the local business, but the local board, with delegated authority, which was responsible to another board, cou!d hardly be expected to act with the same freedom as a local board wielding ultimate power. 


\section{CHAPTER XXII.}

\section{FORMS OF MONEY.}

Classification of money.-Like most terms popularly current, "money" is elastic in meaning. Broadly it is applied to all media of exchange, but usually a more restricted denotation is ascribed to it. How its denotation has been limited may best be considered after we have classified the media of exchange.

Media of exchange, or instruments of exchange, may be classified in a variety of ways. We may begin by distinguishing between different kinds of instruments of exchange according to their source as follows :-

(1) Instruments of exchange issued by Government; the coinage and any paper money put in circulation by the Government.

(2) Instruments of exchange issued by banks, but regulated and more or less certified by Government, like Bank of England notes which are legal tender except at the offices of the Bank of England.

(3) Instruments issued by banks and not recognized by Government, for instance the bank-notes of private and jointstock banks in England other than the Bank of England.

(4) Instruments created on the joint responsibility of banks and their depositors, namely cheques.

(5) Instruments created by private individuals, for instance bills of exchange.

The surmise is well-founded that the less the risk of failure to 
meet obligations on the part of the persons or bodies responsible for media of exchange, the more will the media circulate, that is to say the more frequently on an average will each unit of the media change hands in a given time. Hence, other things being equal, we should expect to find money instruments of classes (1) and (2) circulating more freely and widely than those of class (3), and those of class (3) circulating more freely and widely than those of classes (4) and (5).

Another important distinction to draw, as regards credit media of exchange, is that between a general promissory note, which is intended to circulate, and a document which indicates that a debt remains to be settled with reference to a particular transaction and is not intended to circulate, though actually it may change hands several times. Of the latter class are bills of exchange and cheques. Of the former class are bank-notes. One might hastily conclude that all media of exchange in class (5) must be of the latter kind, but this is not so. The issue of metallic tokens of small denominations by private persons and associations other than banks used to be not uncommon; and during crises in the United States large firms have occasionally paid wages with promissory notes of small denominations which were designed to take the place of money locally for the time being.

Sometimes the name "money" is confined to those media of exchange which are counters of exchange, that is to such of them as circulate and were fashioned to circulate. This restricted reference of "money" is probably in accord with general usage. Cheques and bills of exchange are excluded. But if we qualify. the connotation of "money" in this way, we are left without a convenient term to convey a wider meaning. Probably it.is best to use the word both widely and narrowly and leave it to the context to bring out its exact implication. I shall so use it.

The term "legal tender" has been introduced above. Legal 
tender may be at once defined as all money which can bo offered in limited or unlimited quantities in full discharge of debts. All Government money is legal tender, and some of the money of which the issue is regulated by governments may be legal tender-such as Bank of England notes. An example of limited legal tender in England is afforded by token money (to be defined later) which has an intrinsic value less than its face value. No person is compelled to take in discharge of a debt more than 1s. worth of copper coins and $£ 2$ worth of silver coins. This limitation protects creditors against any form of payment which is a nuisance, makes it difficult for false-coiners to put spurious coins into circulation, and checks the over-issue of token money. As we already have the term "legal tender," there would seem to be no convincing reason for allocating the term "money" to this small class of media of exchange.

Money in its widest sense means media of exchange. Money in its narrowest sense means legal tender. Money in its most common sense means circulating media of exchange which (1) are legal tender, or (2) are customarily taken as its equivalent, namely the bank-notes which are not legal tender. Money in this sense may be called circulating money. Currency usually means the money issued by Government.

"Standard money" is another term in monetary phraseology the implication of which must be noted. It is best to confine its reference to the money in which the standard of value (to be defined next) is embodied. The standard of value means the commodity, or group of commodities, whose value settles the purchasing power of money. Gold is the standard of value in monometallic systems of money on a gold basis; gold or silver indifferently are the standards of value under Bimetallism (which will be explained soon); and if any country took as its fundamental coin one which contained a fixed quantity of gold and a fixed quantity of silver, 
the standard of value would be the value of some unit of gold plus the value of a quantity of silver which bore a statutory relation to the quantity of gold. This last system has been called symmetallic.

Money composed of the standard of value, provided that it has a commodity value approximately equivalent to its monetary value, is sometimes called "natural money," with which all other media of exchange are contrasted under the designation "artificial money". Thus a sovereign and a half sovereign in England, and the 20 mark piece in Germany, are natural money. We may define a coin which forms a part of natural money as a certain weight of a given metal of a given fineness marked with a Government stamp to indicate that it is what it purports to be. It would be possible to have metallic natural money unstamped by the Government, if the term "money" is used broadly, and such unstamped money has existed. But its use causes endless trouble and irritation since every person has to discover for himself how much of the standard metal each lump of it offered to him in exchange possesses. It is usual for Governments in stamping pieces of metal, and thus constituting them standard coins, to introduce a complicated design in faint relief and to mill the edges of the coins. They do this with the object of checking the frauds practised by dishonest persons who extract metal from coins and then put them back into circulation. When coins are so stamped and milled, shaving their edges and rubbing their surfaces leave traces in smoothed edges and defaced designs.

It is necessary that the regulations relating to the coinage of natural money should lay down limits above and below the theoretical weight of the coins within which the weight of the coins must lie when they are issued.

Free and gratuitous coinage and Gresham's law,Coinage is said to be free when the Government will coin 
without unreasonable delay any amount of the standard metal on the demand of anybody who brings bullion for the purpose. It is not free if the Government coins entirely on its own initiative, buying the requisite bullion.

Nevertheless it is not essential to the system of free coinage that it should be customary for individuals to take bullion to the Mint to be coined. England is rightly said to bave a system of free coinage, but it is usual for peop!e to carry their bullion to the Bank of England and reeeive at once its value in coins or notes, less a small commission charged by the bank. If taken to the English Mint, gold realizes $£ 317 \mathrm{~s} .10 \frac{1}{2} \mathrm{~d}$. an ounce, but the officials at the Mint may keep a person waiting for some time before delivering him his coins. The Bank of England ordinarily pays $£ 317 \mathrm{~s}^{-} 9 \mathrm{~d}$. per ounce and pays on the nail. The Bank gets its bullion coined as necessity arises.

Coinage is said to be gratuitous when the Government, as in England, does the work of coining without making any charge. If the fee demanded by Government is exactly equal to the cost of coining it is known as Mintage or Brassage. Any exaction in excess of this is known as Seigniorage. Debasing a coinage means imposing or increasing a seigniorage.

The disadvantage of gratuitous coinage when coinage is free is that the work done by the Government in coining may become like Penelope's. As Penelope's web woven in the day was unravelled at night, so coins minted the one day may be melted down the next, or long before they are worn out. Some people may find it less troublesome occasionally to melt coins than to buy bullion, if a gold coin contains just about as much bullion as it will buy. If coinage is not gratuitous, the bullion value of a coin is, of course, less than its face value by the amount of the charge imposed by the Government for making the coin; and the melting of coins is consequently discouraged. But a slight loss is sustained on melting a number of coins even when they have been minted 
gratuitously. Coins which are not fresh from the Mint must have lost some weight with use, and coins just minted might have come out in weight near the bottom legal minting limit. When a large pile of coins is melted, however carefully selected the coins may have been, the loss sustained may become considerable. Consequently there is much less conversion of standard coins into bullion under a system of free and gratuitous coinage than one might at first expect.

The great merit of free and gratuitous coinage consists in its securing that the bullion value of coins shall be kept closely equivalent to their purchasing power. This equivalence is an incalculable convenience in international trade, as we shall learn.

Gresham's law lays it down that bad money drives out good money when the two exist side by side. Its application to natural money under the plan of free and gratuitous coinage is immediately evident. The coins first selected for melting, or exporting, would naturally be the new full-weight coins because they would contain most metal. Hence we realize at once the importance of keeping the standard coins of a country at a high level of perfection. The withdrawal of light and defaced coins from circulation is usually effected by laws declaring that when a coin falls below standard weight by a certain percentage, or when it has been defaced in certain ways, it shall not be legal tender, that is pass legally by "tale" as it is expressed.

Gresham's law applies only in a modified form to systems of coinage which insure that coins shall have a purchasing power in excess of their intrinsic value. Such coins would never be melted or exported. But it would still be found that the worst coins would be parted with most readily. Gresham's law also applies in the modified form to classes of money other than standard money. People would be disposed to retain notes of undoubted value and pass on as soon as pos- 
sible any which seemed to be in the least likely to depreciate. Gresham's law is so called because it was emphasized with reference to the coinage in a report made by Sir Thomas Gresham in the reign of Elizabeth, but it had been formulated more than once before his time.

Credit money.-Strictly speaking all money which has a face value greater than its intrinsic value is credit money, because its acceptance is dependent upon the credit of the Governments or persons who put it into circulation. However, it is customary to confine the term to money which is not made of the standard metal. Credit money consists in bank-notes, token money, cheques and-if we use "money" in the widest sense-bills of exchange. Bank notes are engagements to pay bullion which are put into circulation by banks, and are therefore based on the credit of the banks issuing them. Token money consists in promissory notes of small denominations stamped on metal. At the present time they are issued as a rule by Governments only. The silver and copper coins in England and the nickel coins in America, Germany and elsewhere, are token money. Cheques are orders issued by depositors requiring bankers to make specified payments. Though extensively used in many countries, cheques naturally circulate hardly at all. They depend for their value on the good faith of the persons drawing them, which means broadly their credit, and on the credit of banks. Cheques, for many purposes, are even more convenient media of exchange than bank-notes. They can be made of any value and created at will, and have certain other advantages also. Certified cheques are cheques on the face of which it is notified that the bank will meet them. Bills of exchange are merely promises to pay, which may be legally enforced if payment is possible.

I shall now describe the economical system of cancelling indebtedness by means of cheques. When two persons who bank at the same bank have dealings with one another, 
they can discharge their money obligations without using, or causing to be used, any currency at all. The one can give the other a cheque; and the cheque when paid in merely effects an alteration in the accounts of these two customers in the banker's books. And just as the cheque system may be and has been used to economize currency in transactions between individuals, so its essentials may be and have been applied to economize time and the use of money in the dealings of banks with one another. The institution through whose agency the principle of the cancellation of indebtedness is thus applied to banks in their relations with one another is known as the clearing house. In the clearing house the accounts of banks against one another are made up. Debts and credits are cancelled out against one another as far as may be, and balances only are paid. Thus, suppose there are two banks, A and B, and it is found that customers of $A$ have presented cheques to customers of B for $£ 1000$, while customers of B have presented cheques to customers of $\mathrm{A}$ for $£ 2000$. On the clearing house the one debt is deducted from the other and $B$ pays over the balance of $£ 1000$ to $A$. If $A$ and $B$ are in different towns they can be represented by agents at some central clearing house where the same principle can be applied. Thus in England the clearing house in London is used as a central clearing house, while the local clearing houses, which are found in most large towns, are used for local business. The chief office of banks with branches naturally serves as the clearing house for the mutual indebtedness of the branches. Through the clearing-house plan, an enormous economy of cash has been contrived and an enormous economy of time. It has been adopted by businesses other than banks, for instance by railway companies.

Governmental limitation of note issues. -The limitation of note issues by Government is a matter for discussion in public economics, but $I$ think it would be a convenience to notice it at 
once. It goes without saying that some banks have pursued a dangerous policy or been badly managed. It equally goes without saying that confidence in banks has been a variable, and that sometimes, even for no apparent reason, the public has been seized with a distrust of a particular bank. Bank failures are, therefore, comprehensible. The distresses caused by large note issues on the occurrence of such disasters constituted one of the reasons which induced many Governments to control the note issue. Another reason was the desire to stop banks from encouraging over-trading by excessive note issues in times of good trade. The English Bank Act of 1844 confined the note issue of those banks which had a note issue to about the amounts at which they stood at the time of the passing of the Act. Banks established after 1844 were not to be permitted to issue notes, and a note-issuing bank on amalganating with another bank was to forfeit its note issue. Banks might also surrender their note issues voluntarily for a consideration. A proportion of any issues so forfeited, or surrendered, was to be added to what is known as the "fiduciary note issue of the Bank of England". In its bearing on the Bank of England, the Bank Act divided it into two departments, the issue department and the banking department. The issue department was allowed to put out a certain quantity of notes without keeping any reserve. It is these notes which make up the fiduciary issue. The Bank was authorized, however, to put out notes over and above a fiduciary issue, provided that it kept a pound-for-pound reserve. This pound-for-pound reserve could not be touched by the banking department. The influence of the Bank Act in determining the amount of credit money has been greatly reduced by the development of the cheque system. The Bank Act imposes no restriction on cheques ; and, with or without restrictions on the note issue of banks, in course of time cheques would have driven bank-notes in bulk from the field. The Bank Act may have had some effect in checking over-trading (as we shall see in Chapter XXIV.). But it left banks helpless in face of a serious trade collapse, if they were completely stripped of their cash resources, though their credit might still be good. Gold could not be obtained rapidly from abroad ordinarily. Hence it became usual for the Government to sanction in extremities the issue of notes by the Bank of England in contravention of the Bank Act. Happily necessity for such 
action has not arisen since 1866, partly because of the displacement of notes by cheques and partly because of the improved knowledge in the light of which banking is directed.

In most advanced countries note issues are strictly controlled in some fashion, but provisions for emergency issues are not unusual. When easy provisions are made, emergency issues naturally get to be depended upon. Dependence upon them, in circumstances which are not exceptional, has, however, been discouraged in various ways. If the quantity of credit money is narrowly limited, the money of a country is made needlessly costly.

Inconvertible money.-Just as a bank may issue paper money, so a Government may issue paper money of its own, as we have already noticed. In doing so, it must be scrupulously careful to exercise restraint lest some holders of notes should find a difficulty in changing them for bullion. All paper for the redemption of which in bullion on demand no arrangements are made, is termed "inconvertible" or "irredeemable" paper money. There is little objection to irredeemable paper money if its issue is so stringently limited that neither trouble nor expense is met with in getting it converted. If it is not easily convertible, for obvious reasons it will depreciate, that is to say, the value at which it changes hands will become less than its face value.

What is said here of inconvertible paper applies of course to all inconvertible artificial money, whether made of paper or not. "Inconvertible paper" is the term in common use because all inconvertible artificial money of high denominations has been made of paper, and it is the inconvertible money of high denominations which has been the chief source of currency troubles. A debased currency is similar to inconvertible paper.

A country can suffer few graver disasters than to be reduced to the use of a depreciated inconvertible currency ; and experience has shown it to be hazardous to introduce inconvertible paper to any substantial extent.

One disadvantage of using only irredeemable paper is found 
in the absence of a par of exchange with other countries. The meaning of "par of exchange" in this connexion will become plain from what follows. Par of exchange is lacking because an inconvertible currency fluctuates in value independently of the value of bullion. The value of gold is approximately the same all the world over, and when the value of the currencies of countries are kept at par with the value of gold, international trade is facilitated. You can imagine how awkward trading between Glasgow and London would be if two different systems of money, which varied in value independently, were used, one in each place. A Glasgow man who sold goods in London would have to keep his eye on the rates of exchange between the two systems of money, and he would never know what the value of money obtained in London would be when it reached Glasgow. If the values of money in the two places moved together, the selling price of Glasgow goods in London would rise when the purchasing power of money in Glasgow fell. In this event the Glasgow exporter to London would run no risk of incurring loss in the manner just described.

All inconvertible paper is naturally viewed by the farsighted with apprehension. They fear that it will be issued in excess even when it is not, and their fear is not groundless. Governments which have recourse to it are strongly tempted to escape the unpopularity of taxing the people openly by taxing them covertly through the emission of more notes. It is so easy to get from a printing press any extra resources that are wanted urgently. As more irredeemable paper is put out, beyond a certain amount, it depreciates, and as it depreciates public confidence in the currency is shaken and it depreciates still more.

What is the basis of the value of inconvertible paper money? Would an inconvertible paper currency have any value at all after it had been issued in such quantities that all other money 
was driven out of use, and if so, why? Evidently some value would be retained by such a currency, providing that it were declared legal tender for certain purposes, for instance, for the payment of taxes. In this event, it would in effect be convertible into discharges of the obligation to pay taxes. Could it have a value greater than its value for this purpose? Or, to ask the same question in another form, could it have a value if it were legal tender for nothing? The correct answer would seem to be that it need not have a value, but that it might have on the ground of the probability of its being taken, to some extent at any rate, for the payment of debts, or because people trusted to its being redeemed at some price sometime. In these events we may say that its value is founded on custom, or confidence in the Government's sense of equity. But, as the custom, or the confidence, may break down at any moment, such a basis is extraordinarily insecure. There is always the chance that the value of the inconvertible paper may relapse to zero and a natural money evolve to take its place.

Currencies may be exclusively paper but convertible.-It must not be supposed that a currency which consists entirely of paper and tokens must necessarily be an inconvertible currency. An exclusively paper and token currency might be so designed as to be ideal. It has, indeed, been recommended that gold coins should be withdrawn from circulation in England, and notes substituted for them, the notes being convertible directly into bullion, instead of into bullion through the medium of sovereigns. Such a substitution of paper for sovereigns would mean an enormous economy in the cost of the monetary system. Much gold is lost annually through the wear and tear of gold coins. We do not select one of the most expensive of metals for utensils and instruments for rough household and industrial use; and prima facie there is as little to be said for condemning such a precious metal to the rough work of circulating from hand to hand in order to effect 
the distribution of commodities. If we could see the day's experience of a sovereign, its hammering on rough counters and scraping in pockets against the hard edges of heavier coins, keys, and what not, we should be amazed that the annual loss on gold coins is no greater than it is, and that a less costly monetary system has not been devised.

The plan outlined ensures all the advantages which are derived from a natural commodity money, while avoiding the disadvantages inseparably linked with its use. The disadvantages include not merely the cost of wear and tear already described, but also the wastage of minting work through the annual melting of a number of recently issued coins. Under the system described the increase of the currency, when an increase was desirable, would be brought about by the play of ordinary market forces. When the monetary value of the paper sovereign rose above the market value of the amount of bullion which a real sovereign theoretically contains, it would pay people to take bullion to the bank and receive in exchange for it paper money of the full monetary value of the bullion. Correspondingly, if the market price of bullion rose above its monetary price, people would carry notes to the bank and demand in exchange for them bullion of the full legal value. As a matter of fact, to-day, bullion for export in large amounts is obtained in this way. Instead of getting sovereigns from the bank, exporters take their theoretical equivalent in gold ingots. The ingots would really contain slightly more gold than the sovereigns, and what is demanded abroad is not the bag of sovereigns but the gold contained in them.

The arguments for a thorough-going system of convertible paper money are, you will realize, very forcible. But as custom rules currencies with a rod of iron, I should not like to prophesy how the sudden introduction of such a system would be received. A step towards it in England would be the issue of notes of smaller denominations than £5. Many 
countries have relied more upon convertible paper money than England has done.

An even more revolutionary proposal has been put forward, namely that all coins should be made token coins exchangeable against the standard of value, say gold, but that the gold should be periodically re-rated in value, under the guidance of index numbers of general prices, so as to keep the purchasing-power of money constant. An international agreement would, of course, be required to carry such a scheme into effect. On the question of steadiness in the purchasing-power of money some remarks will be offered on pages 242-3.

Bimetallism. - A monetary system is said to be bimetallic, as we have seen, when its standard of value is either of two metals which for currency purposes are made interchangeable at a fixed ratio. It is essential to a bimetallic system that both metals should be legal tender and that both should be freely coined. In all binetallic systems which have been tried or recommended in the Western world, the two metals have been gold and silver. Bimetallism was given a trial in the United States many years ago, and it was in operation, first in France and then in a group of countries known as the Latin Monetary Union, in which France, Belgium, Switzerland and Italy were the most prominent, from the end of the eighteenth century till the early "seventies".

It is contended that possibly if one very large country, and certainly if several large countries, adopted bimetallism at some ratio which at the time of its adoption was not very far removed from the market ratio of gold to silver, the latter would be brought to, and continuously kept at, equivalence with the ratio adopted for currency purposes. The theoretical proof of this contention may be briefly put.

Suppose the ratio decided upon is 1 to 25 , and suppose that after bimetallism is adopted, say by the United States, France, Germany and England simultaneously, the market ratio becomes the same through the admission of some silver into the currencies of these countries. Now imagine a large output of silver from the mines which tends to bring the inarket ratio to $1 ; 26$. Immedi- 
ately silver would flow into the currencies of the four bimetallic countries because it would have a higher value as money than in the arts. As the market was depleted of its supplies of silver in this way, the market value of silver would rise. At the same time, gold would be set flowing from the currencies of the four bimetallic nations into the market for obvious reasons. These currencies would be increased by the introduction of the silver, and the purchasing power of all money, including gold, in the four countries in question would fall. When the purchasing power of gold fell, its value in the market would be more than its value as money, and gold money would, therefore, be melted down to sell as bullion. The increase of gold in the market, brought about in this way, would naturally cause a fall in the market value of yold. So in the case supposed, and in all similar cases, the value of silver would advance in the market and the value of gold would descend until a ratio of 1 to 25 (the bimetallic ratio assumed) was reached. Moreover the same compensatory action would take place with reference to the currencies of both gold-using and silver-using countries outside the bimetallic union.

If, instead of silver, gold were suddenly produced in excessive quantities, so that the market price of gold tended to fall relatively, the actions described above with reference to silver would take place with reference to gold until the ratio of $1: 25$ was restored.

So we perceive that through the compensatory demand for gold and silver for money in the bimetallic countries the relative market values of gold and silver could be kept constant throughout the world.

Those who are not convinced of this should study the compensatory demands for things which are natural alternatives in a high degree, such as beef and mutton. It will be discovered that the ratio between the values of such natural alternatives tends to vary less than the ratios between the values of other things (see p. 168).

Are there any limits to the adequacy of these compensatory currency demands for gold and silver? Assuredly there are. If silver were produced in vast quantities at a cost of less than $\frac{1}{25}$ of an ounce of gold for an ounce of silver, and the complete substitution of silver for gold in the currencies of the bimetallic countries failed to bring the value of silver up to $\frac{1}{25}$ of the value of gold, the bimetallic countries would become monometallic on a silver 
basis, and the market value of silver in gold would drop below $1: 25$. The opposite result would be induced if gold were the metal which became very cheap and the above conditions were repeated, mutatis mutandis. It is argued, however, that the displacement of either metal from the currencies of four leading countries, if both metals were substantially represented in them, would throw such a mass of the metal in question on to the market that the reducing of the bimetallic countries to monometallism would be exceedingly unlikely. And if the danger were imminent, it is pleaded, silver and gold could be re-rated in terms of each other. But rerating would be very disturbing to trade, and so would the mere expectation of re-rating. We must remember, too, that the increasing economy in the use of metal for money, for which the development of credit money is responsible, curtails the powers of currencies to absorb metal'and so to maintain a fixed ratio between gold and silver.

Why bimetallism has been advocated.-International bimetallism has been recommended for a variety of reasons, all of which would not be approved by every bimetallist. The chief of these reasons are: $(a)$ to secure a par of exchange between gold-using and silver-using countries; $(b)$ to stop the fall in the value of silver ; $(c)$ to render the standard of value less fluctuating ; $(d)$ to prevent prices from falling. These reasons I shall now examine seriatim.

(a) Of the meaning of par of exchange, and the inconvenience which its absence causes, I have already spoken on pages 234-5, in dealing with the subject of inconvertible money. When the gold value of silver is constantly varying, an uncertain and speculative element is introduced into trade between gold-using and silver-using countries. By the time a merchant in a gold-using country is paid in silver for his exports, the price of silver may have dropped in such a degree that much of his anticipated profit is wiped out. And the same risk is run by the merchant in the silver-using country. The interruptions of the smooth course of trade occasioned by these circumstances would cease under successful international binetallism.

As regards Indian trade, the difficulty which we have been con. sidering was largely removed by the closure of the Indian mints to the free coinage of silver in 1893 and the adoption of gold as a stand- 
ard for regulating the minting of silver. The action on the part of the Indian Government also turned one point of the argument which we shall consider next, in its application to India.

(b) In the early "seventies" the gold value of silver began to fall. After a time some Governments which held substantial stocks of silver were anxious that the fall should be stopped, and so were those who had interests in silver mines. Moreover it was contended that the depreciation of silver was operating as a barrier to trade between gold-using and silver-using countries. Their argument ran that customary prices ruled commonly in the silver-using countries, and that when the silver prices charged for Western manufactures had to be advanced, in consequence of the depreciation of silver, much of the market in the silver-using countries fell away. To what extent this contention corresponded with facts, cannot be said to have been finally settled.

(c) For reasons put forward on pages 201-2 the value of gold with reference to things in general fluctuates very little in short intervals, apart from the fluctuations caused by trade cycles (see pp. 254-5). A strong case cannot, therefore, be made out for taking measures to stop the non-cyclical fluctuations in the value of gold. It is true that these fluctuations would be less under bimetallism provided that silver did not fuctuate in value to a substantial extent more than gold. But in view of this proviso, it might be that the bimetallic union of gold and silver would unsteady, with reference to short intervals, the purchasing power of gold.

(d) A serious fall in prices measured in gold began in the early "seventies". To this numerous incidents contributed. Germany adopted a gold standard in 1873, and several other countries about the same time, or shortly afterwards, did the same or made greater use of gold for currency purposes; and France and certain other countries restricted their use of silver for currency purposes. Moreover the last quarter of the nineteenth century witnessed important economic improvements which affected very many branches of production and would in themselves have caused a depression of general prices, other things being equal. It is true that a counteracting influence was brought to bear through the developments of banking, which added to the percentage of credit money, but the causes which tended to magnify the demand for gold were 
too strong to be counteracted in this way. By 1896 a fall of about 40 per cent in general prices had been experienced in England. The general disposition of prices can be read easier in England than in other advanced countries, because in the latter the alterations of tariffs are a disturbing influence. After 1896 prices rose largely in consequence of the immense outputs of gold from South Africa. Hence the argument for international bimetallism which was based on falling prices ceased to be applicable after 1896 . The advance of prices after 1896 probably did more than anything else to weaken the agitation for international bimetallism.

Are rising, falling, or steady prices best ?-A fall in general prices the degree of which corresponds to the degree of general productive progress may have commendable features, because it means that the benefits of progress are disseminated throughout the community without readjustments, or frequent or considerable readjustments, of the distribution of money income, for instance without constant alterations in the rate of wages. A fall greater than this which involves reduced money wages is serious, however, because it is not likely to be understood generally that the purchasing power of earnings is rising though money earnings are falling. On the other hand it may be contended that prices which fall in any degree are undesirable, because they hide the gains which every section of the community is deriving from progress; and it must be admitted that the uncertainty about the future which varying prices cause, and the certainty that falling prices will not fall in the ideal degree defined above, make it very unlikely that falling prices will be quite innocuous.

People who believe in making monetary arrangements which force up prices are known as inflationısts. They think that climbing prices are necessarily good for trade. And admittedly a rise in prices which is due to a recovery of demand after a collapse (see Chapter XXIV.) is good for trade. But a rise in prices which does not reflect any alteration in demand is apt to deceive the business world and bring about over-trading (see again Chapter XXIV.). It is questionable, however, whether monetary arrangements which induced a long-enduring ascent of prices, and a steady one apart from trade cycles, would after a time have any direct stimulating effect at all, because the rise due to currency causes would be expected and allowed for. And if a community took measures to keep prices 
advancing at an appreciable rate, what would be the logical end? I leave my readers to judge.

Finally I must draw attention to the matter of investments which take the form of loans of definite sums of money or of a purchase of annuities. Whether it is desirable or not that the money value of an investment of this kind should appreciate, other things being equal, so that the investor shares in the benefits of progress, it is quite certain that it is not desirable that it should depreciate if the depreciation is not foreseen. An elevation of prices would ease the burden of monetary obligations contracted when the appreciation was not foreseen, but at the expense of the creditors, who could reasonably complain of injustice had the rise been brought about deliberately. This paragraph has a bearing on the proposal to settle the re-payments of loans by a tabular standard (see p. 212).

Most persons of sober judgment who have studied the question would, no doubt, agree that prices which neither rise nor fall in general, and are undisturbed by fluctuations, are best on the whole for a community. The reader may remind himself at this point of our observations on pages 116.7.

Trimetallism, symmetallism, the gold=exchange system and the limping standard. - If three metals were used in a currency as alternatives, the system would be trimetallic. As we have already learnt, symmetallism means that the standard of value is a fixed quantity of one metal plus a fixed quantity of another. Symmetallism with reference to gold and silver was recommended as a compromise between monometallism and bimetallism. Its adoption would have raised the value of silver and general prices, but it would not have brought about a par of exchange between gold and silver.

The system adopted in India (see pp. 240-1) is sometimes known as the gold exchange system. It is in use also in Austria and the Philippines. The standard of value under any schemes which provide for both gold money and silver money, and the re-rating of the one in terms of the other, is said to be a limping standard. 


\section{CHAPTER XXIII.}

\section{THE FOREIGN EXCHANGES AND RESERVES.}

Some definitions.-I must preface my account of the foreign exchanges with some definitions. Bills of exchange may be regarded as signed promises made by persons who have received goods or services to pay their stated value to the persons who have provided them. Bills are said to be drawn by the people to whom the money is owing and accepted by those who owe the money. They are used in both the home and the foreign trade. When drawn on people abroad they are known as foreign bills. A bill may be payable at sight, or after a certain period. A bill payable after a certain period is said to attain maturity when the time arrives for its payment. It is said to be discounted on being sold to a third person for what it will fetch. What it will fetch for purposes of international payments (to be explained below) depends inter alia on the length of time that the bill has still to run and the rate of interest at which it would have to be finally discounted to realize money in the country of its acceptance; but, when the rate of interest at home is less than the rate of interest where the bill is accepted, it may be discounted at a lower rate of interest and held by the person who buys it to await maturity. Dealers in bills are known as bill-brokers.

The foreign exchanges. - The machinery whereby payments are effected in foreign commerce is known as that of the 
"foreign exchanges". Payment is made in the first instance with bills running for certain periods, or with cheques, which, for our purpose now, may be regarded as bills payable at sight. Many payments can obviously be made by the return of bills.. The bill drawn by Schmidt of Berlin on Jones of London for $£ 10,000$ can bo bought by Schulze of Leipzig and used by him to pay a debt of $£ 10,000$ owing to Robinson of Manchester. In this case everybody is paid when Robinson has collected the $£ 10,000$ from Jones, directly or indirectly. The advantage of the transaction in paper is that the cost of remitting gold is avoided.

The price of foreign bills payable at sight cannot in ordinary circumstances mount above, or fall below, their face value in bullion by more than the cost of sending bullion. The face value of a bill payable at sight, plus the cost of carrying the bullion equivalent of its value to the country on which it is drawn, is known as the upper specie point. The lower specie point is the face value of the bill minus this cost. These definitions will serve generally, but they are ambiguous inasmuch as the cost of carrying bullion may mean either the actual cost at the time or the ordinary cost. In order to avoid the ambiguity, we may speak of "actual" and "normal" specie points.

When do the foreign exchanges tend to pass the specie points? The answer to this inquiry must shape itself according to the meaning given to specie points. Let us take the specie points as settled by the actual cost of transmitting bullion at the time. Then the price of bills in or on a country can pass above or below the specie points respectively when bullion is difficult to obtain for bills on demand in that country, or when it is supposed that it is likely at any moment to be made difficult, or impossible, to obtain bullion on demand. An example may be cited from the foreign exchanges in the United States at a time during the conflict 
between North and South. Foreign bills rose above specie point in the United States because there was a strong demand for means of investing abroad, and the fear lest an embargo should be placed on the exportation of gold was prevalent. In this case, the prices of bills on the United States, in regions where they would otherwise have been at the lower actual specie point, would have tended to drop below it. I may add that, where there is a sudden demand for cash, foreign bills may sell below their specie points for as long as it takes to fetch gold from abroad.

If we take the specie points as settled by the usual cost of transmitting bullion, we must add to these causes of the passage of the price of bills beyond the specie points any causes affecting the cost of conveying bullion, such as war.

Within the limits of the specie points the prices of bills at sight vary according to the supply of bills and the demands for them, that is in a large measure according to the balance of trade. It should be noted that as one country can pay another in a roundabout fashion, by exporting bills of a third country which are in demand in the creditor country, the prices of sight bills on a given country in any two other countries cannot ordinarily differ by more than the actual cost of carrying bullion between those other countries.

When the prices of bills at sight rise above par value, that is their face value in bullion, they are said to be at a premium, and when they fall below par value they are said to be at discount. When such bills on a country rise to a premium, the exports of that country are penalized and its imports are subsidized; because on the one hand paying the country for its exports is made expensive, and on the other hand the value of the payments made by it for imports is enhanced by the premium on the bills in which payment is made. Similarly when sight bills on a country are at discount, its exports are encouraged and its imports are discouraged. 
A premium on foreign sight bills in a country, with its natural accompaniment a discount on such bills on a country, is an indication of a shortage, or expected shortage, of bills for meeting the country's obligations abroad, which may necessitate a withdrawal of bullion. But as the country's exporting is enlivened while its importing is repressed in these circumstances, the state of trade which gives rise to a departure of bullion is automatically corrected. It is also artificially corrected sometimes with the object of expediting the recovery of normal equilibrium. Artificial methods of amending the state of trade are known as the "correctives" (see below).

The balance of trade and the foreign exchanges are said to be favourable, or unfavourable, to a country when bullion imports, or exports, respectively, tend to resuit. This use of terms is a survival of the times when it was commonly thought advantageous to attract bullion to a country.

Some nations have, or have had, inconvertible currencies, of which I have spoken in Chapter XXII. When bills are drawn in an inconvertible paper currency, the above exposition holds except that "face value in the inconvertible currency" must be substituted for "face value in bullion". The value in England of a sight bill at par drawn in the inconvertible currency of another land is the number of sovereigns which in that land would buy the amount of inconvertible currency stated on the bill.

Methods of stopping foreign drains of gold.-We shall see in the next chapter that the banker must keep a sharp eye on the general state of trade. He must also watch continuously the balance of international indebtedness, in so far as he is responsible for any of the bullion reserve. Naturally the balance of indebtedness in foreign trade is constantly fluctuating. At any moment a community may find that it has imported so much that its exports will not discharge its indebtedness to other communities. It has then no option but to 
pay in gol 7 if its creditors will not wait. It cannot pay with any other sort of money because all its other sorts of money have a national value only. Bullion is the sole international money. It is because gold may be demanded at any time for foreign payments, that a very much larger bullion reserve must be husbanded than would be requisite in view merely of the home trade. The standard money is gold, we assume.

When a leakage of gold from the country is felt, the bank answerable for the bullion reserves-we assume provisionally for simplicity that there is one only-would naturally be anxious to lose as little gold as possible. When it has means either of arresting a foreign drain, or of rapidly increasing its stock of bullion on the appearance of a foreign drain, the expenses of its business are much less than they would be otherwise-because a smaller reserve of bullion is adequate.

Three courses of action are open to the bank with reference to foreign drains of gold :-

I. It may put difficulties in the way of those who need gold, that is to say, it may temporarily decline to deliver gold on demand, unless a customer can prove an unavoidable need for gold.

II. It may offer to buy gold at more than its market value until the strain is over.

III. It may raise the bank rate, that is the rate at which it lends money and discounts bills.

I take the third artifice first. Raising the bank rate has $(a)$ an immediate and $(b)$ an ultimate effect. Immediately, operating directly on international flows of gold, it checks the drain and attracts some gold to the country. Ultimately it tends to remove the cause of the drain.

It checks the drain immediately for the following reason. The discounting of bills is costly when the bank rate is high. Hence a rise in the bank rate induces a number of people who hold maturing bills on England to retain them until they 
reach maturity, instead of getting them discounted and drawing gold out of the country. This effect relates only to maturing bills, that is to bills which have to be met at some future date (for example, to bills for one month, three months and six months) and not to bills payable at sight. A bill is said to attain maturity when the day is reached on which it has to be paid.

Raising the bank rate attracts gold because a country with a relatively high bank rate is a profitable market for investment, especially for short loans.

Ultimately the high bank rate tends to remove the cause of the leakage. When the bank rate is high, borrowing is discournged by the heary cost of borrowing; and, when less accommodation is sought from banks, there is less money to circulate and prices in the country consequently tend to fall. When home prices fall, the country becomes a better market to buy in, but a worse market to sell in. Consequently exports are stimulated and imports are checked. So the balance of indebtedness to foreign countries may be wiped out, and in its place a balance may be created on the other side of the international account. The need of reducing the amount of bank money out on loan, with a view to rectifying the balance of international indebtedness, is one resson why much bank money must be lent for short terms only. The reader who has forgotten how a displacement of the balance of international trade tends to amend itself is advised to resd again the last two paragraphs on page 246.

Because mising the bank rate suppresses the ettux of gold at once and corrects the state of trade which caused it, mising the bank rate to guard the reserve is technically known as applying a corrective. The term "correctives" refers to all methods of artificially bringing the halance of international indebtedness to the position and amount which are judged desirable. We shall have to consider oventually the effect 
which frequent and considerable elevations of the bank rate are likely to have upon home enterprise and commercial life generally.

The other two devices for stopping a drain suffer from certain defects. Paying for gold more than the market price of gold is expensive, and it has little or no effect upon the balance between imports and exports. It does not, therefore, tend in itself to reform the state of trade which caused the drain. The latter flaw is also found in the method of putting difficulties in the way of paying gold on demand. This action, moreover, is apt to shake the confidence of the public in the bank and so to be followed by serious reactions, even in normal circumstances, for instance by the private hoarding of gold and-because of the doubt about getting gold on demand-by a depreciation of bills drawn on the country.

- If we revise our fiction and suppose there are many banks in a country, our theory remains unaltered in substance, but difficult questions of the relations between banks are raised.

Reserves. - I shall now briefly notice certain problems of reserves. As regards foreign trade, the bullion reserve alone matters immediately, but I have reserved for treatment here certain problems of the banking reserve also, because they are so closely bound up with those of the bullion reserve.

Is a single reserve system, or a multiple reserve system best ? England, we know, which holds a pre-eminent position in the banking world, for one reason because there is never any doubt but that the Bank of England will pay gold on demand without question, has a single reserve system. Other English banks deposit the bulk of their reserves with the Bank of Fngland and retain only so much in their own coffers as is needful for till money for everyday business. The single reserve arrangement, which was not deliberately planned in England, but was brought about by the prestige and the peculiar position, in relation to the Government, of the Bank of England, has merits and demerits.

One obvious merit of the single reserve system is that it enables the banking of the country to be conducted with smaller banking 
and bullion reserves than would be needful otherwise. Just as the depositing of the cash savings of private persons (which are their reserves) in banks reduces the amount of cash which must be kept idle in hoardي, because the bank which holds the resources of many persous can average risks (see pp. 271-2), so the depositing of the reserves of banks in one bank reduces the aggregate amount of cash which must be held in reserve. Each bank must be prepared for the worst, but the bank which guards the banks' reserves need not be prepared for the worst to happen to every bank at the same time. This advantage cannot be gainsaid. But connected with it there is fear of a countervailing disadvantage. Act the depositing banks never so prudently in deciding upon the extent of their reserves, a disaster to banking might result from rashness on the part of the bank in which the reserves were deposited. The latter might retain insufficient cash in its coffers and be unable to pay back the bankers' deposits on demand. If the note issue were limited Ifor ordinary times, and in the difficulty supposed a larger issue of notes could be kept convertible, the stoppage of bank payments might be warded off by an emergency issue of notes. In more than one country there are arrangements for emergency issues of notes.

Under the single reserve system the responsibility of each of the depositing banks, as regards maintaining adequate banking reserves, is as great as it would be were they to hold their own; and the cost to them per unit of reserve kept is also as great provided the reserve bank pays no interest on bankers' deposits. The Bank of England never pays interest on any deposits.

Under the single reserve system there is unity of control as regavds the bullion reserve, which is the most vital part of the reserve. Undoubted advantages are associated with unity of control. Responsibility when it is shared is in danger of being evaded. Moreover, under the single reserve system, the bullion reserve is centralized and its amount can be seen at a glance. Under a multiple reserve system, the bullion reserve might drop below the danger point and nobody might notice what had happened.

It is true that the reserve bank might find some difficulty in forcing other banks to restrict loans and raise their discount rates when gold was being drained from the country. Had the depositing banks placed adequate reserves with the reserve bank, they 
might be inclined to argue, when the reserve bank put up its discount rate in order to attract gold, that the reserve bank should have kept a larger part of its reserve in gold, and that they were not obliged to spoil their businesses for a time by following suit and so contributing to the cost of the reserve bank's folly. This difficulty, of course, is not met with if all the banks of the country are dependent in any way on the bank with the bullion reserve and must follow its lead, or if there is an understanding that they should do so which is observed.

In the matter of the single gold reserve system, against the advantages associated with unified control, these disadvantages must be weighed, (1) that the security of the banks reposes on the judgment of one bank only, and (2) that other banks are relieved of a responsibility the exercise of which must have valuable reactions on the prudency of banking.

The questions of the magnitude of the bullion reserve and the magnitude of the banking reserve raise many issues. The smaller the reserve the more economical is the banking system. But the smaller the reserve the more jealously must it be guarded. The smaller the reserve, therefore, the more instantaneous must the action of banks be in raising discount rates when there are signs of a heavy home demand for cash, or of a foreign drain. And the smaller the reserve, the higher must discount rates be raised with reference to cash or bullion withdrawals of a given magnitude, because the briefer is the time for which heavy withdrawals could be endured. Frequent fluctuations of bank discount rates, and considerable fluctuations, are, however, very disturbing to business. It may be pleaded that they are only disturbing to business when business wants disturbing, that is when it is running on such lines that gold is being driven out of a country, or when business has become too speculative. But this plea does not hold of all circumstances. The withdrawals might be caused by the collapse of confidence after a bank failure, when there was no over-trading. Or there might be withdrawals of gold for export which were not connected with the business that the country had been doing. Another country might want gold for a particular purpose. In neither case can the sudden imposition of a high bank rate be regarded as a needful sedative to the business of the country. It must be realized that the bulk of the business done in an advanced community in- 
volves the discounting of bills, or bank accommodation. And even in cases in which a check on trading is desirable, it is not always in the interests of trade to check it suddenly. It may be desirable that my bicycle should be stopped if it is running away down a hill, but if it is stopped with a jerk so that I am thrown violently, as bad a disaster as could be may be the consequence.

At least the reserve must be sufficient to prevent any chance that banks will be drained dry. Of the disasters caused by the suspensions of cash payments by banks, I shall speak on page 262 .

We must always remember that it is the function of a reserve to be paid out when necessary. To affirm, therefore, that safety is secured if the reserve is never permitted to fall below a certain limit, is like affirming that poverty would be avoided if everybody always kept sixpence in his pocket, -as the United States in the matter of banking reserves has learnt to its cost. Any regulation of reserves must take the form of providing that in normal times they must be of a certain amount. 


\section{CHAPTER XXIV.}

\section{TRADE AND CREDIT CYCLES AND CRISES.}

I MUST now leave for a short time questions exclusively about money and bring to your notice the curious variations to which trade is subject. I have not drawn attention to them before because they are inextricably intermingled with the activities of banking. They may be caused, or at least encouraged, by the granting of credit by banks on too liberal a scale at a low rate of interest; and, however caused, they create tendencies which are a menace to the safety of banks, and may have to be arrested by the banks in a manner which will be described.

Synchronism and periodicity of fluctuations in trade. -Everybody knows that production does not flow along uninterruptedly. It has its ups and downs. Periods of brisk business are followed by periods of stagnation. Some unsteadiness in trade we should naturally be prepared to find, for there are vicissitudes in all human affairs; but certain peculiarities characterize the broad fluctuations of trade which one would not expect and which call for explanation. These peculiarities we may designate "synchronism" and "periodicity".

Good times in the different industries tend to synchronize, or come more or less simultaneously. And so do bad times. There are numerous exceptions, but the rule seems to be that most industries are every now and then depressed together, and every now and then flourishing together. Moreover 
synchronism appears to hold internationally. When commerce is sluggish in one country it tends to be sluggish also in other countries.

The periodicity of fluctuations in trade means that the intervals between the fluctuations are not of quite uncertain duration. Regularity is far from being perfect, but it is sufficient to warrant the assertion that trade fluctuations exhibit a degree-a comparatively high degree-of periodicity. They are like the disturbed oscillations of a pendulum when a $b$ kitten is playing with it. It used to be claimed that the time normally occupied by a trade cycle was ten or eleven years. But departures from this duration are not uncommon; and it has recently been suggested that the wave length of a trade cycle really inclines to be about twice or three times a period of approximately three and a half years. Thus the cycle, it is said, may be expected to cover seven years at least and, should it exceed this length, to extend to about ten and a half years. But, unfortunately, the evidence which has been collected and sifted so far is too scanty to justify an unhesitating generalization. Of commercial fluctuations prior to the nineteenth century we are comparatively ignorant, and it is not known how far the cyclical movement reaches back.

The objective explanation.-The objective explanation of trade cycles looks primarily to external events. To substantiate this explanation, it is necessary to discover among the external events influencing the state of trade some which are subject to cyclical variations, and to such cyclical variations that they can be brought into correlation with the cyclical variations in trade. Such a set of cyclical external events is supposed to be constituted by climatic conditions. The explanation of the trade cycle which lays special, or exclusive, emphasis on climatic variations is popularly known as the sun spot theory because inquirers were led to elaborate this explanation when it was observed that the number of the sun 
spots changed more or less regularly and that there seemed to be some correspondence between the period of their change and the period of change in trade. It was suggested that sun spot variations afforded an index of the quantity of heat emitted from the sun from time to time, and so of climatic variations generally.

I may remark here that it is universally allowed that external events other than the climatic, such as wars, new discoveries, and the opening of new markets, affect the state of trade. But as these incidents do not occur as a whole cyclically, in themselves they explain, not the regularity, but the irregularity, such as it is, in the changes from bad to good, and good to bad, trade.

There are three chief steps in the argument of those who believe that business oscillations can be attributed ultimately to climatic causes.

(a) It is supposed in the first place that there is what is called a solar period, or some law of recurrent alteration in the amount of the sun's heat, and that this period fits into the period of the trade cycle. As regards this supposition, the theory recently put forward is highly significant, namely that the climatic conditions of the world vary in a cycle of about ten and a half years, broken by sub-cycles of about three and a half years each.

(b) It is argued secondly that climatic variations affect the world's supply of food. Variations in the amount of heat emitted from the sun could obviously do so directly and indirectly-indirectly through the influence of the sun on the rainfall. That the harvests of a particular district vary with the climate of that district has been proved. But it has not been proved beyond question that the harvests of the world vary substantially with the solar period. When the sun gives out more heat than it does ordinarily, harvests are made richer in some districts but poorer in others-for, to take an 
example, dry localities are benefited, while wet localities are damaged, by a greater rainfall-but over the world as a whole the increases might conceivably tend to counteract the decreases.

(c) Thirdly it is argued that supplies of food determine the effective demand for other things. Into the ramifications of this argument we cannot enter. It might even be, of course, that alterations merely in the relative supplies of food obtained from different districts, without any alteration of the world's supply, would so disturb the world's trade as to bring on depression or its opposite.

So runs the attempt at objective explanation. It might be protested that the harvests could only disturb the demand for certain other goods-not the demand for all other goods. But to this the reply can be made that industries are dependent upon one another nationally and internationally. Every nation functions economically as a whole, and in no insignificant degree the whole world functions economically as a whole. Throughout an economic system of interrelated parts retarding and stimulating shocks are instantly transmitted. If the market for boilers contracts there is less demand for steel and coal and ore and the plant with which boilers and steel are made. Thus bad trade is passed on, and as it leaves in its wake reduced aggregate earnings, so that the demand for consumers' goods is reduced, the trade of providing them tends to become bad also. Throughout the world, too, the economic shock is spread. When American trade begins to droop, America buys less from England and English industries lose orders and begin to droop in turn. If over-trading starts in America, she imports more, and English trade becomes brisk. Similarly the strain of a financial crisis is transmitted from country to country.

But objective events alone, however exhaustive our 
enumeration, will not account for all the features of the phenomena of trade unsteadiness. They will not account for over-trading. They will not account, again, for the fact that once bad trade has begun it generally continues for a certain time, despite changes for the better in external events. Some influence must certainly be allowed to the effect of business conditions on the state of mind of business men, and to the reaction of the latter on the formerthat is to subjective incidents. This brings us to the subjective explanation, some part of which at least would be accepted, as a necessary part of a complete theory of the trade cycle, even by those who are most firmly persuaded that the objective explanation is substantially sound.

The subjective explanation.-The first point that I shall notice in the subjective explanation has a bearing on the synchronism of trade variations. It is the doctrine that people incessantly and insensibly mould one another's ideas and colour one another's minds when they are repeatedly brought into contact as interrelated parts of a system. It is very difficult to resist falling into the mood and adopting the outlook of one's business acquaintances. Enthusiasm and despair are both catching. According to this theory of the communication of moods in the business world, there is a subjective explanation, as well as the economic one already given, of the generality of good trade, or the generality of bad trade, at one time in the industries of a country.

I shall now go on to particularize the kinds of action and reaction which are said to subsist between these subjective facts and the state of trade. A check on demand is supposed not only to stop some trade but also to throw those who are engaged in the businesses affected into a state of mental depression, and so to cause trade to become worse than it need be. In short the view is that bad trade induces a temporary paralysis of enterprise. Similarly it is claimod that a rise in 
demand, at the same time that it excites activity, generates in business leaders a state of mental exhilaration, and so causes trade to be more active than it should be. The business man who happens not to be mistaken about market demand may very well be mistaken, when he is sanguine, about the share of the trade which he personally will secure. Trade can easily become much more active than it should be through the granting of long credits by business men to one another and the provision of accommodation by banks. When people are sanguine they are disposed both to ask for and grant excessive credit.

Further, it is alleged that these supposed abnormal psychological states of a community, which result in judgments about business prospects exaggerated one way or the other, tend to endure for some time after their objective causes have been removed. Rapid recovery from them is said to be unusual. Hence it is argued, not only that bad trade may continue after any objective causes of bad trade have been removed, or after events have occurred which ought to have made trade better, but also that over-trading can be brought about by good trade, and may tend to be brought about by good trade. The argument runs as follows. When trade is good, demand is lively and prices rise. Business men then make efforts to get the output increased, with the object of snatching profits from the high prices. Their action, producing effects which work on sanguine minds, stimulates trade and trade becomes even better. Finally it may be found that the demand for goods at the high prices had been overestimated, and that the prices which can be obtained in view of the enlarged output mean loss.

On the strength of these hypotheses, the theory has been ventured that subjective influences alone, their action upon business and its reactions upon them, quite apart from any indirect consequences of the supposed climatic cycle, will 
account for the trade cycle. The case for this theory has already been put in fragments, but I will sketch it again as a whole. Assume the existence of a trade collapse. Most people are depressed and their depression continues after its cause has already been removed. Consequently when they recover their spirits, as they do naturally after a time, business prospects are found to be brighter than they thought. Trade then revives rapidly, people are wonderfully encouraged, and trade gets better and better, till it is better than it should be, as we may put it. Ultimately, through the psychological effects of economic activity, the community, unless checked, is rushed almost automatically into feverish trading which culminates somewhere in collapse. Commercial stagnation supervenes. From this in time recovery is made as before and the cycle starts anew.

This theory, which offers a subjective explanation of the trade cycle which would be complete in itself, cannot be regarded as established. But that commercial undulations must be ascribed in part at least to subjective causes there can be no reasonable doubt.

Are trade fluctuations increasing?-The more a community functions as a whole, the more likely, other things being equal, are general states of business animation or depression. And the more production is guided by anticipation, the farther astray can production go, other things being equal, and the more excessive can over-trading become. Now economic progress means, inter alia that a community functions increasingly as a whole and that its production is increasingly governed by anticipation. Hence it would seem that trade fluctuations might be expected to assume greater dimensions in the future.

This conclusion, however, I am not prepared to accept. It is not unlikely that trade depressions and their opposites may diminish in intensity in the future, though doubtless it 
might not be possible to prove that they have diminished in the past. Psychological forces may be dissipated by experience; and those which bear on the trade cycle may tend to vanish as we get to allow for their periodic recurrence and to realize their transitory nature. Far-sighted employers may be expected increasingly to choose depressed times, when prices are low, for laying the foundations of new enterprises. Prompter, ampler and more accurate information, will reduce the chances of business miscalculations ; and production may get steadier also because steady production becomes more and more economical as a community progresses, largely in consequence of the waste involved in letting expensive machinery lie idle. Finally we may confidently look for improved foresight on the part of banks throughout the world and the exercise by them of yet greater prudency in controlling credit.

The question whether a shorter period will tend to take the place of the average period which the past reveals in cyclical variations, through the rush of modern business, speeded up by the telegraph and the telephone, is too problematical for discussion here. It is possible under both theories of the trade cycle.

Banking in relation to trade cycles.-The degree of over-trading is dependent upon the amount of credit media of exchange created through the agency of banks. When trade is brisk money circulates more rapidly than when trade is sluggish, more credit is given by business men to one another, more bills are offered for discount, and larger overdrafts are obtained from banks. So prices are bound to ascend. The demand for credit from banks naturally forces up both the rate of discount and the charge for accommodation, because the limited supply of cash will not support a credit superstructure of an unlimited size; but the rise in bank rates may not be sufficient to stop over-trading. Banks in fixing their rates must keep a watchful eye on the state of trade. 
After a period of depression there is a fear that they too, in competing with one another for business, may catch the speculative frenzy.

When trade collapses, appropriate action on the part of banks is a matter of profound national concern. Loss of confidence at a time of trade collapse may create an excessive demand for cash. If cash cannot be found, even solvent firms may be driven into bankruptcy. At such a time it is desirable that banks should lend freely when undoubted security is offered them, but at a high rate of interest, so as to economize the cash available by discouraging those who do not pressingly need assistance, and attract gold to the country. Many years ago bankers were apt to lose their nerve when trade collapsed, and seek a deceptive security in a refusal to grant accommodation. The result was almost invariably a financial panic, the path of which was strewn with bankruptcies, or a crisis as it is commonly called. In the losses connected with the bankruptcies the banks shared. As banks in England now act more tactfully and are legally free to do what is needed, the crisis in England has become a rare occurrence. It is vital at all times, and particularly at times of tottering credit, that the ability of banks : to meet their obligations should be above suspicion. No greater disaster can befall a business community than the suspension of cash payments by some important bank. All business is so interwoven with banking that the stoppage of payment by a bank completely disorganizes trade; and it shakes to its foundations the credit upon which modern commerce depends. 


\section{BOOK VI.}

DISTRIBUTION OR THE SHARING OF WEALTH.

\section{CHAPTER XXV.}

\section{INTRODUCTORY AND INTEREST.}

Analysis of distribution.-The economics of distribution, it is sometimes said, explains people's incomes. The assertion is broadly correct; but the economics of distribution is concerned primarily, not with incomes, but with the earnings of the several factors in production, and the relation of these earnings to one another and to human efforts. Some people are born wealthy while others achieve wealth. The economics of distribution is not concerned primarily to show how, by laws of inheritance or otherwise, it is made easier or more difficult to be born wealthy. It is concerned primarily to show why a man's income from his accumulated wealth, whatever its form, is what it is; and why his earnings are what they are.

The economics of distribution, we may say, accounts for the sharing of the wealth produced by a community among the agents, or the owners of the agents, which have been active in its production. The agents of production are commonly classified into (1) land, meaning all natural agents; (2) labour ; (3) capital ; (4) organizing.

Sometimes it is said that land earns rent, labour earns wages, capital earns interest, and organizing earns profits. 
There is, however, a lack of agreement among people in their use of the terms " rent," "wages," "interest," and " profits". Thus, a part of employers' earnings is not infrequently spoken of as "rent of ability," while another part is quite as commonly called "wages of management". Again, the term "profits" is not unusually confined to payments made on capital. These ambiguities will have to be removed as we proceed.

There are different ways of expounding the theory of distribution, but they are not equally lucid. The way which seems to me least baffling to the beginner, is that which takes the problem of distribution piecemeal. I shall, therefore, take the problem piecemeal at the start. Finally, I shall point out that the theory of the payment made for any one agent in production is, in essentials, identical with the theory of the payment made for any other agent in production-that is to say, to take one example, that the theory of the interest paid for capital is in essentials identical with the theory of the wages paid for labour. I say " in essentials," be it remarked. Individual characteristics stand out in each theory, because capital and labour are different in nature, though they bear striking resemblances to one another in that both are agents or factors in production.

The payment which I shall explain first, is payment for capital, that is interest. To interest, the rest of this chapter will be devoted.

Gross and net interest.-It will be as well to point out at once that "interest" is an equivocal term in economics. In order to lay bare the exact nature of its ambiguity it is necessary to analyse the complex payment denoted by "interest" in its widest sense. The payments included are:-

I. Payment for the loan of capital, when no risk, no inconvenience (apart from that involved in saving) and no work is entriled upon the lender. 
II. Payment, to cover risks of loss, which may be $(a)$ personal risks, or $(b)$ business risks.

III. Payment for inconvenience of the investment.

IV. Payment for the work and worry involved in watching investments, calling them in and re-investing.

I shall now illustrate these payments with comments. When money is lent to a business man, without the pledging of property to cover its value adequately, certain risks are run. The borrower may prove dishonest or incapable. Hence, there is a personal risk. The business in which he is engaged is bound to be in some degree speculative. Hence there is a business risk. Some businesses are more speculative than others. Taking up a new invention may be highly speculative. And even the most humdrum of businesses are risky to some extent. No firm can be certain of always passing unscathed through the industrial and commercial readjustments rendered necessary by alterations in demand, or in conditions of supply, or in the lines of foreign trade.

Competition settles in a rough fashion the level of payments against business risks in the several industries and trades of a country. Theoretically, these payments should be of such an amount that on an average their annual sum in any given industry would equal the business losses incurred annually in that industry on an average, apart from those losses for which unusual incapacity or dishonesty were answerable. The business risks and personal risks incurred by those lenders of capital to a business who have prior claims upon the assets of the business, because they hold debentures or preference stock, for example, are, manifestly, less than the risks run by ordinary shareholders.

Apart from risks, the perfectly convenient investment is one in which the investor can place large or small sums, leave them as long as he likes, and withdraw them at a minute's notice without loss. There is a paucity, if not a 
complete dearth, of investments of this kind in every country, which is not to be wondered at. If the borrower can force the investor to take back his money at any time, the investment is not ideally convenient. If the money is irrevocably locked up for a long time, the investment is exceedingly inconvenient. Borrowers who are so placed that they must get their money on terms unacceptable to lenders will obviously have to pay something , for the inconvenience of the terms which they offer.

The explanation of many very high rates of interest is that the lender is called upon to do a great deal of work. The man who lends money on note of hand not only incurs heavy risks, but is also compelled to devote most of his time to making inquiries, giving discharges for money returned, and arranging to put it out again. The book-keeping alone involved in his business is far from a negligible item. A substantial proportion of the interest paid to a person who lends small sums on notes of hand is ascribable to the work done by him. But, no doubt, a substantial proportion is due also to the fact that his business would be distasteful to many small capitalists. In view of this, there is a very limited supply of money for the purpose to which he devotes his means. The earnings of such a money-lending business are, therefore, as a rule, appreciably above those of callings which require in those practising them about the same capacity and diligence. In the light of this discussion the reader can explain for himself the rate of interest charged by pawnbrokers.

After full allowance has been made for payments of classes II to IV a balance will be left over. This is payment of class I, which is termed " pure interest," " net interest" or " economic interest". The rate of interest paid on Government Stock of the highest repute is the nearest approximation to it. "Gross interest " is used of the sums actually disbursed for capital, which may include payments of all four classes enumerated above. 
Demand for capital.-Our next purpose will be to explain the rate of pure economic interest. Take the case of a cabinetmaker who has only a few necessary tools. Suppose he produces an amount of furniture which leaves him a net income of $£ 50$ a year. He could largely increase this if he had more tools and some simple machinery. Let us suppose that $£ 100$ spent on tools and machinery would increase his income by $£ 50$ a year. Suppose, further, that by setting aside $£ 10$ a year he gets a fund sufficient to keep the tools and machinery in repair and renew them when they wear out. Then $£ 100$ of capital is worth to him $£ 40$ a year net. Another $£ 100$ would be worth less than $£ 40$ a year, inasmuch as he would devote the first $£ 100$ to satisfying his most urgent requirements. But it would still be worth a great deal, say $£ 30$ a year net. Similarly another $£ 100$ would make a difference of something less than $£ 30$ to his net income, and yet another $£ 100$ of capital would still have value to him, though a less value, and so on. The schedule stating these values of different quantities of capital to this cabinetmaker may be called his "demand schedule for eapital".

Other producers similarly have uses for capital. When we combine the demands of all of them we get the total productive demand for capital in the community.

In addition to the demand for production, including trading, there is also a demand for capital for consumption, as we may call it, using "consumption" narrowly. This demand is, however, unimportant in comparison with that for production. There are some people, with expectations of future income, who are short of income in the present and wish to realize their good fortune before it actually reaches them, perhaps in order that they may enjoy themselves at once, or perhaps in order that they may enter professions, the training for which is expensive and the rewards of which are long deferred-but the demand for capital for professional training 
is, strictly speaking, a productive demand, if "productive" be broadly defined. Now these demands for capital by consumers are subject to the same law as the demands for capital to aid the production of wealth directly. That is to say, the rate of interest that would be paid for a large sum is less than the rate of interest that would be paid for a small sum. This is so because the borrowed money would be put to the most valuable uses first. We therefore perceive that capital is subject to the law of diminishing utility, whatever the purpose for which it is demanded.

The union of the productive and consumptive demands for capital makes up the community's aggregate demand for capital.

Why capital is sayed.-We have next to analyse the forces of supply. The supply of capital depends upon the power to save and the will to save.

The will to save is governed by complex influences. In order to understand their operations we must ask why people save. People save for one or all of the following reasons :-

I. To provide for heavy expenses which are foreseen, and for expenses necessitated by circumstances affecting future needs which are not foreseen, though they are recognized as possible or probable.

II. To provide against the chance or certainty of a diminution, or cessation, of the income out of which these expenses would normally be met.

III. To afford the person who is saving a chance of seizing opportunities in the future.

IV. For the sake of direct gain.

These reasons for saving, we shall scrutinize in their inverse order in the paragraphs that follow.

Upon saving for the sake of getting interest no words of comment are called for. As regards the third reason given above for saving, there is said to be a mysterious tide in the 
affairs of men,which, taken at the flood, leads on to fortune; but a sum of money is frequently needed to take it at the flood. Men get chances of entering into profitable partnerships, of starting new branches of work, of being enterprising at the right moment and extending their operations, or of carrying out original ideas of value; and generally some private capital is required to enable them to seize these chances, or make the most of them.

As regards the first and second recorded reasons for saving, we scarcely need remark that almost every earner of an income has at some time to make arrangements to meet a series of possible, probable and certain obligations reaching far into the future-there are, for instance, the expenses of marriage, of the education of children, and of illness, accident and death. In making these arrangements he has to take into account his present income and his reasonable expectations of future income, bearing in mind that incomes do not always rise as they might reasonably be expected to do, that they may be stopped without warning by the early demise of those who earn them, and that though a man's premature death may put an end to his income, the needs of those for whom he had made himself responsible may continue-of wife and family for instance. The very uncertainty of the future makes it imperative that a prudent person should save more than calculable probabilities seem to enjoin. $\mathrm{He}$ must be prepared for the worst, in so far as he cannot insure against the worst.

Does a rise of interest always increase saving?-This question is by no means easy to answer. A rise in interest obviously increases that amount of saving which is induced by the allurement of gain in the form of interest. But does it always increase the store laid by for some other reasons? Consider the case of a man who is trying to save a sum sufficient to provide a permanent income adequate for his needs 
when he retires and for such endowment of his wife and children as he thinks he ought to make. Suppose he wants an income of about $£ 500$ a year. The higher the rate of interest the smaller is the capital sum which will yield this income. Despite, however, cases of this nature, the general impression scems to be that, when the net rate of interest ascends in advanced countries at the present time, the tendencies to increase saving exceed the tendencies to decrease saving.

We may note here that, whether a rise in the rate of interest soon causes an augmentation of the savings of a community or not, (1) a relative rise in the rate of interest paid in any industry attracts a greater proportion of the country's capital to that industry than before, and (2) a relative rise in the average of interest in a country attracts a greater proportion of the world's capital to that country than before.

Saying and the power to saye. - The power to save, other things being equal, is measured by income. Let us now consider how saving increases with an increase of the power to save.

Perfectly adaptable persons who were not poor before, when they became better off, would save, other things being equal, the same proportion of income as before. They would do so because the claims of the future upon them, measured in terms of money, would rise in the degree in which their incomes rose. A man who wanted to leave an income of $£ 100$ a year to his wife, if she should survive him, would ultimately want to leave her $£ 200$ a year, in all likelihood, were his income to double. He would probably want to do so because he and she, if they were perfectly adaptable, would tend to acquire a standard of living twice as high as their old one if their income doubled. But fow people are perfectly adaptable. When incomes are rising fast, standards of living get left behind. Careful people then save a higher proportion of income than they did before; while careless people, though they save no 
less in amount than they did before, save a smaller proportion of income than they did before, because they do not at once realize that the provision which they have made for the future is inadequate in view of the higher level of their incomes. This conclusion, observe, relates only to those who were not poor before they became better off. Those who had becn very poor would probably save a higher proportion when they became better off. When they were very poor, any saving at all would have been so onerous, and adequate saving would have been so hopeless of accomplishment, that they would probably have saved little and taken risks which, with ampler means, they would avoid.

I should conclude generally that the chances are that a wealthy community will lay by a higher proportion of its annual income, other things being equal, than a poor community.

Against many of the burdens which might, or must, fall upon him, and against many accidents which would prevent his bearing them, a person can insure. And every person who is not affluent, apart from his current earnings, will naturally be induced to insure to some extent by the great advantages offered by the system of insurance.

Insurance and saving. - Security is attained immediately when we insure, whereas it is necessary for most people to sare many years before a sum is accunulated which is sufficient to be of much service with reference to the risks of which an account has been given above. Moreover, the individual attains security more cheaply by insurance than by making independent provision. A person who stands alone has to be prepared for the worst, and immediately. But, when he joins with other people in an insurance scheme, it is sufficient if he and the other individuals in the group lay by amounts adequate to meet probable eventualities. The sum that each pays per year is called the premium. My promiums on an accident policy are calculated on the general chances at different ages of accidents entailing different degrees of incapacity. They are not very high 
because though I may be permanently put out of effective economic action by a bad accident the year after insuring, very few of the thousands of people insuring in iny office will suffer so grave a mishap so promptly. If I did not insure, but saved independently, I should have to put a large sum aside the first year to be prepared for the worst ; and, if the worst happened, I should be less fully prepared for it even then than I would have been had I insured.

It does not follow from this account of the economy of insuring that the development of insurance in a country tends to reduce the amount of money saved annually. It is quite likely that it tends to increase what is saved annually. Without the facilities afforded by insurance offices, some people would be scarcely provident at all. They would barely save anything, either because they had not the needful strength of will, or because the accumulation of appreciable resources for the future seemed to them too hopelessly beyond their means. Again, insurance offices have created a custom of insuring to which a number of happy-go-lucky people naturally conform, though they would never be thrifty if left to themselves.

Finally, we must observe that insurance cannot meet all needs for saving. There are some chances which are incalculable and indefinable, and others which are non-insurable because insuring against them would substantially multiply them. As regards the latter class, it is plain that if we could insure against losses of income attributable to indisposition to work, some of us would fall victims to the malady of indisposition to work from which otherwise we should have been immune. Again, it is desirable to save so as to have a sum of money in hand to enable us to take advantage of any good openings to fortune which may offer. For the means to seize such opportunities, insurance will not avail.

\section{Interaction of demand and supply.-After having an-} alysed the conditions of demand and supply, it is a matter of no difficulty to perceive how they act upon one another and produce a market rate of interest. Look at the table below in which I have placed examples of demand and supply side by side. For simplicity I assume that there are no risks of loss, that returns are steady and that no inconvenience, or appreciable work of investing, is entailed on those who provide 
the capital. When needful, allowance can easily be made for any of the omitted factors. I have also supposed, for the sake of argument, that the volume of capital in a country would disappear at the rate of 10 per cent per annum if it were not renewed. The table relates to the long period.

\begin{tabular}{|c|c|c|c|c|}
\hline $\begin{array}{l}\text { Rate of } \\
\text { Interest. }\end{array}$ & $\begin{array}{c}\text { Annual Savings } \\
\text { in Million } £ \text {. } \\
\text {. }\end{array}$ & $\begin{array}{l}\text { Amount of Capital } \\
\text { Ultimately Saved } \\
\text { and Maintained } \\
\text { in Million } £ \text {. }\end{array}$ & $\begin{array}{c}\text { Capital } \\
\text { Demanded } \\
\text { in Million } £ .\end{array}$ & $\begin{array}{l}\text { Demand per } \\
\text { Aunum for } \\
\text { New Capital } \\
\text { in Million } £ .\end{array}$ \\
\hline-1 & 10 & 100 & 1200 & 120 \\
\hline 0 & 15 & 150 & 1000 & 100 \\
\hline 1 & 20 & 200 & 700 & 70 \\
\hline 2 & 40 & 400 & 600 & 60 \\
\hline 3 & 50 & 500 & 500 & 50 \\
\hline 4 & 55 & 550 & 450 & 45 \\
\hline 5 & 60 & 600 & 400 & 40 \\
\hline
\end{tabular}

The second column contains the amounts that would be saved ultimately at the rates of interest given in the first column when the income of the community became what it would be with the capital in use stated in the third column. Suppose annual savings are $£ 40,000,000$ and that $£ 400,000,000$ is in use. Now suppose the rate of interest rises to 3 per cent. Immediately more than $£ 40,000,000$ would be saved, but not yet $£ 50,000,000$ - say $£ 48,000,000$. Then the extra $£ 8,000,000$ of industrial investment would raise income so that, when the elevation of income was felt, more than $£ 48,000,000$ a year would be laid by. Again income would be raised, and so things would go on until annual savings were $£ 50,000,000$ and the capital in use reached $£ 500,000,000$. Afterwards, other things being equal, annual savings would be constant.

Now we may read off the results of the table. At 3 per cent equal quantities of capital are demanded and supplied. 
Therefore, 3 per cent will become the market rate of interest in the long run. The amount of capital used will be $£ 500,000,000$ and $£ 50,000,000$ a year will be saved. The net annual marginal value of $£ 100$ of capital is $£ 3$. The annual marginal disutility of saving at this position of equilibrium may be expressed as $£ 3$ per $£ 100$.

Obviously there would be some saving even if saving were discouraged by a tax which exceeded its interest earningsthat is if the net result of saving were in effect negative interest. And obviously more capital would be employed if people were paid to use it. Notice in this connexion, however, that the rate of pure interest, even in the richest and most penurious community, could not possibly become a negative quantity which was greater than the cost of looking after stored valuables. If it did, people would hoard money or goods instead of lending. Actually the rate of pure interest, we may be sure, will never drop even to zero in our time, if it ever does. So, from a practical point of view, we are trifling in admitting the hypothesis of a negative rate.

Possibility of a zero rate of interest. - But why should not the rate of interest drop to zero? a critical reader may inquire. After all, is it so unreasonable to suppose that it should? From the point of view of the eommunity, zero interest simply means that the community is employing the most productive methods-the methods which yield the highest net incomo. Think of the use of capital as implying a roundabout method of production (pp. 78-80). If interest is zero the population is so distributed, winning eoal and ore, smelting metal, making machines, using machines and tilling the ground, and so forth, that the real income of the community is maximized. You will see at once that this must be so if you think of what is meant by the marginal utility of capital. When we say that the marginal utility of eapital is a certain amount-which means that interest must be that amount-we mean that the employment of another increment of capital (i.e. the employment of a little more labour in making machines and so forth) would raise the net income 
of the community by that amount. That is to say, there will be a net gain from employing more capital so long as the marginal utility of capital is above zero. Why then, is not capital applied to production until interest drops to zero?

The answer is as follows. Saerifice must be made in the form of deferment of consumption, or saving, some time before the reward is reaped. If the community were a single individual who could depend upon having a very long life, like a nation, and if this modern Methulselah were perfectly rational and far-seeing, capital would ultimately be employed until its" marginal net returns were zero, providing the individual could make the requisite initial sacrifices, and providing that he did not discount his future because it was future, as he hardly would I should imagine-though this is a controversial point-if he could depend on his future and was perfectly rational. Obviously he could not make the requisite initial sacrifices, if an amount of work, which left him no time to fashion instruments of production, was needed to provide him with sufficient sustenance, shelter and clothing, to keep him strong enough to work. However, this provision need not trouble us, because all communities have been able to save some capital; but it leads us to the conclusion that the amount of capital which our hypothetical individual would create each year would have to be limited. Ultimately, I have said, he would reach the position described. The first year he could only create a little. This little would raise his income. Then he could add to his previous creation of capital a larger amount, and so on. While he was working towards the ultimate goal, capital would have a marginal utility above zero.

When we substitute a community for our supposititious individual the problem is altered in some important respects. A community consists of many people and each person settles the disposal of his own incone. All are not perfectly rational ; all are not perfectly far-seeing; all are not likely to be in a position to make substantial temporary sacrifices, even if the community is very wealthy ; and many discount the future at a high rate. The community must save annually as a whole a certain proportion of its income if the marginal utility of capital is to drop to zero. If any individual saves less than this proportion of his income, some other person must save a larger proportion of his income to make up for tho 
deficit. As things are, the deficit to be made up is so great that an appreciable rate of interest results.

\section{Effect of progress on the rate of interest and value of} capital.-For our present purpose it will be sufficient to look at progress merely from the economic point of view. First we shall think of it as marked only by improvement in productive methods, and trace long-period effects.

An improvement in productive methods may directly raise or depress the marginal demand for the old quantity of capital. It may add to the processes performed by machinery. In so far as it does, it magnifies the marginal demand for the old quantity of capital. But it may shorten a process already performed by machinery - that is, cut out a link, or links, from the roundabout productive process involved in the use of capital-for instance, render some machine simpler, cheaper and more productive. In so far as it does this, it reduces the marginal demand for the old quantity of capital, though it augments at the same time the aggregate value of the old quantity of capital, as every invention obviously must. Whether interest will be raised or not by mechanical discoveries, depends upon the balancing of these two effects, after allowing for the fact that more capital would probably be saved when incomes were enlarged by the improvements in production. A fall in interest would seem, from a study of existing tendencies, to be far more likely than a rise.

Of course there can be no question that a new invention would at first elevate the rate of interest, whether it caused a rise or fall of interest ultimately. At first there would be the heavy cost of introducing the new productive idea. Finally the cost would be merely that of upkeep and replacement.

Next consider the effect of social progress, which means generally that the individual's "telescopic faculty" is sharpened and that he is rendered, not merely more far-secing, but 
also more far-acting. The effect would certainly be the saving of a larger proportion of income on the whole. For the few who erred previously on the side of parsimony, the many would have erred on the side of improvidence.

The chances are overwhelming that the two sorts of progress taken together would reduce interest; and I may add here, though I cannot argue the point, that if we unite to these sorts of progress the progress expressed in increased personal efficiency, which enables each man to manage more machinery, or make use of more auxiliary capital of any kind, the rate of interest would probably tend to be depressed still more, despite the enhanced value in the aggregate which the more efficient labour would confer upon machinery.

The theory of interest expounded above, you must be careful to understand, explains only the rate of interest on new investments of capital, that is the market rate of interest. It does not explain the rate of interest on those investments which have become fixed capital. The rate of interest on such an investment, in so far as the money was not lent at a fixed rate of interest, is settled by the marginal worth of the new capital devoted to the purpose for which the old investment was designed. In so far as the money was lent at a fixed rate of interest for a term of years, its interest earnings could not be affected by an alteration of the market rate of interest, but its capital value would be affected.

The earnings and value of fixed capital.- Suppose $£ 100$ is spent by the owner of a hosiery factory on a knitting machine. Let it yield 10 per cent a year gross, that is without deduction for risk and depreciation. We suppose that the market rate of interest gross for this industry is and continues to be 10 per cent. Now let an improvement be introduced into stocking-machinery and let time be given for as much capital as is demanded to be invested in the new machinery. The new investments would yield 10 per cent gross, Then the old investment could no longer coptinue to do so 
even if its efficiency were unimpaired. The $\$ 100$ of our imaginary case would yield an amount determined by the ratio between the efticiency of the machinery in which it was fixed and the efficiency of the new machinery, when both are expressed per unit of cost. The use of the new machinery would leave a surplus of $£ 10$ gross per $£ 100$. If the old machinery left a surplus of $£ 5$ gross only per $£ 100$ this sum would be its gross earnings. You may note incidentally that in this event the value of the original $£ 100$ of eapital in its fixed form would have depreciated 50 per cent.

Suppose now that productive methods have not changed but that the gross rate of interest for money offered to this industry falls for some reason to 8 per cent. Then more money would be put into hosiery factories until the marginal worth of their plant fell to 8 per cent gross. Imagine here and hereafter, for the sake of simplicity, that machinery remains wholly unimpaired until it breaks down completely. Then the original $£ 100$ would yield only 8 per cent ; but its worth would still be $£ 100$. Had the rate of interest risen to 12 , instead of falling to 8 , the gross yield of our original $£ 100$ would gradually have erept up to $£ 12$; and ultimately its market worth would be as before. But its yield would rise only very gradually, because it could only be affected by the wearing out of capital in the hosiery industry. In this ease actually, the efticiency of the old plant would become greatly impaired before the new position of equilibrium was reached, but allowing for this would not alter the character of our generalizations.

If the original $£ 100$ of our illustration had been lent at a fixed rate of interest, its capital value as well as its interest would, of course, be unaffected by productive improvements, on the assumption that the market rate of interest remained unaltered. But though its interest earnings could not be affected by an alteration of the rate of interest, its capital value could and would. The $£ 100$ was invested in 1900 , say, at 4 per cent. Let tho market rate for such an investment drop to 2 per cent. 'Then, if the investment were permanent, the documentary claim to the $£ 100$ invested in 1900 would become worth $£ 200$, because at the new rate of interest it would take $£ 200$ to realize an annuity of $£ 4$ a year. Were the investment irremovable for a term of years only, allowance would be made for the fact in re-valuation and the price of the investment of 1900 would not rise as high as $£ 200$. Similarly an advance of in- 
terest depreciates the value of earlier investments at a fixed rate of interest.

Effect of the appreciation and depreciation of money on the rate of interest. - When a steady appreciation or depreciation of money is foreseen the rate of interest must be affected. I will work out the case of the depreciation of money, that is a fall in its purchasing power (see p. 209). Let the market rate of interest, with the purchasing power of money constant, be 4 per cent. Let a steady depreciation of money at the rate of 1 per cent a year be anticipated. Then a man who had been willing to lend $£ 100$ at 4 per cent would want 5 per cent because goods bought with the money (apart from their wearing out) would rise 1 per cent a year in value. He would want 4 per cent over and above this. And the borrower could afford to pay 5 per cent instead of 4 , because what he acquired with the loan would rise in value at the rate of 1 per cent a year.

The effect of the appreciation of money would be the exact opposite. The proof is the same, mutatis mutandis. When the depreciation of money stopped, though its purchasing power would be lower than it had been, the rate of interest would be 4 per cent again, other things being equal, as it would be also in the case of the appreciation of money when it ceased.

Diagrammatic treatment. - A diagram will aid our understanding of the settlement of the rate of interest. In fig. 15 measure capital along $O X$, the positive rate of interest along $O Y$ and negative rate of interest (admitted for the sake of argument) along OY'. Ignore the dotted lines. Let $D$ be the demand for the whole volume of capital in use. Let $G$ be the supply curve and indicate, not saving per year, but the amount of capital which would be saved and maintained eventually at different rates of interest, positive or negative, in view of what the income of the community would be for the various amounts saved. Tet me illustrate. If the rate of interest were zero then eventually when the income of the community rose to what it would be with $\mathrm{O} c$ of capital in constant use, an amount would be saved each year which would keep $\mathrm{O} c$ of capital in constant use. If capital disappeared at the rate of 10 per cent a year on its not being recruited, the annual supply curve of capital would be a curve similar to the curve $S$, but with one-tenth of its abscissæ. According to our curves the rate of 
interest will tend to. settle at $a b$. The capital in use in the community will be $\mathrm{Oa}$.

The amount saved per annum can be obtained from the average rate of destruction of the capital in use.

If $D$ rose, the level of $S$ would drop (because the power to save would be greater) and the volume of capital used in the community would gradually expand till a new position of equilibrium was reached. An independent subsidence of $S$ would also lead to the employment of a greater amount of capital. The effect of a drop

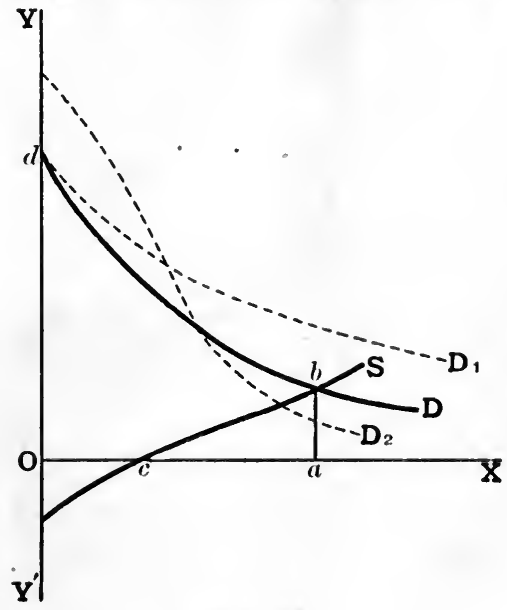

Fis. 15.

of $\mathrm{D}$, or an elevation of $\mathrm{S}$, would be gradually to contract the capital in use.

The effects of new inventions on demand may be shown by curves of which $D_{1}$ and $D_{2}$ are samples. A curve of the type $D_{2}$ takes the place of $D$ if inventions intensify the demand for capital ; but the new eurve will be of the type $D_{1}$ if demand is ex: tensified (see p. 276). You must not, of course, notice the intersection of $\mathrm{D}_{2}$ with $\mathrm{S}$ because when the demand curve alterk, inasmuch as it alters income, the supply curve is altered. To find the effect of inventions which transformed $D$ into $D_{2}$ we should have to construct a new.S which would be below the old $S$. 


\section{CHAPTER XXVI.}

\section{RENT AND QUASI-REN'T.}

Meaning of rent.-The term "rent" is made to serve many uses among which we may distinguish the following:-

1. A periodic payment made for the hiring of anything. This is best called "hiring charge."

2. A periodic payment for the use of land, together with any capital invested in it or on it, whether in the form of manure, drains, roads, hedges, gates and so forth, as in the case of farms, or whether in the form of houses, factories, or other premises, with the conveniences belonging to them, such as gas, water, and drainage connexions. "Rent" has this sense in common usage.

3. That part of the payment for farms, estates, and premises, which may be regarded as a payment for the land alone, apart from the investment of any capital in it or on it at any time.

4. A payment for any natural differential advantage in production enjoyed by any agent in production whether animate or inanimate.

A "differential advantage" means technically a property or quality, possessed by any agent in production, which causes it to have a greater economic value than the least valuable agent or factor in the same class which is nevertheless just valuable enough to be employed. Thus the bulk of the earnings of a clever doctor may be properly designated a "rent of his ability". The payment for the differential advantage is 
only called a "true rent" when the property or quality which is the source of the differential advantage is original and cannot be acquired by anybody or anything, as the case may be, so that, as I have put it, the differential advantage may be called "natural " in contrast with "acquired". This point may be ignored for the present. It will be elaborated later.

In order to render the fourth conception of rent precise, we must distinguish, you observe, between factors, or agents, of marginal capacity and factors of super-marginal capacity. This distinction has already been noticed (p. 38) but an illustration may be given here to refresh the reader's memory. Take the class of stone-masons. Pick out the least able men of the class, who are nevertheless just able enough to be engaged as stone-masons. They are the stone-masons who, in view of the demand for stone-masons, have marginal capacity. All the others who are abler possess super-marginal capacity in varying degrees. A stone-mason's original endowment of supernarginal capacity for stone-mason work yields him onduring differential advantages as a stone-mason if he develops his original powers.

Incidentally I must again draw your attention to the difference between the marginal thing of a class and the marginal use of a thing. The marginal thing of a class has just been defined. It is the thing with marginal capacity or quality. The marginal use of a thing means the additional value secured by increasing our use of a class of things by just one unit. The distinction is illustrated on pages 37-8.

Rent in the fourth sense given above might be entitled "economic rent"; and for rent in the third sense "ront of land" would be a suitable designation : but in what follows I shall assign to "rent" no fixed meaning. Its implication in each case must be wrested from the context.

Rent of differential fertility. - I shall expound the theory of rent in its broad outlines from simple imaginary cases. I 
take the case of farming in a particular country and suppose provisionally that the location of a farm does not matter and that only wheat is grown. The value of land per acre in this country, nevertheless, will not be the same for all plots, because of the diversities between plots in respect of fertility. All land is not equally fertile. It may be granted that a limited quantity of the land will have a very high degree of fertility, that a certain amount will be somewhat less richly endowed with fertility, and so on until we reach the land which is hardly cultivable, if cultivable at all. Ranging the land of the country in thought according to its fertility, let us call the best land quality $\mathrm{A}$, and the next best land quality $\mathrm{B}$, and the other land qualities $\mathrm{C}, \mathrm{D}, \mathrm{E}$ and so on, according to degrees of inferiority. When the land is ranged in this way, suppose that its fertility reveals a continuous gradation from the good to the less good, so that there is no great difference between the values of contiguous qualities of land. Now assume that all the land is owned by a small class, some of whom may engage in farming parts of their own land, but most of whom let such land as they can for what they can get, on the English system. We need not investigate in this chapter how the size of a holding is governed, apart from the operation of custom, as that detail has been fully examined on pages 90-5.

Having thus prepared our data, we shall begin our exposition by imagining population to be so thin that all the land of the highest quality, namely quality $\mathrm{A}$, is not demanded. In these circumstances, farmers would pay little or nothing for their farm land, because if the owners of the farms tried to exact any substantial land rent their efforts would be frustrated by the owners of other land of quality $\mathrm{A}$ which was not being farmed. Farmers would have the option of moving to the virgin soil. They would lose little in doing so because $e x$ hypothesi the land to which they would move would be as fertile as the land which they left. The owners of the un. 
occupied land of quality A would welcome the farmers and accept them as tenants for an insignificant land rent, because the alternative would be to do nothing with the land and get nothing for it. Remember the assumption made is that there is more than sufficient of the best land to satisfy all the needs of the community.

Now suppose such a growth of population that the whole of the best land is tilled and recourse must be had to the second best land, that is land of quality B. Instantly when land B comes into cultivation, the best land will begin to bear a rent. The amount of this rent will be such as to equalize the net earnings of two farmers of equal efficiency and industry, having normal access to capital, the one of whom farms land of quality $\mathrm{A}$ and the other land of quality B. That is to say, the rent of the best land will be the whole of the value of the differential advantages which it possesses in its superior fertility. We should say that in this state of affairs the land of secondary quality is the land of marginal fertility and the superior land is the land of super-marginal fertility. It is also usual to say technically that the margin of cultivation has fallen.

The best land will be more intensively cultivated when the land of secondary quality comes into cultivation. This is a significant point which must not be lost sight of. It should be apparent that a farmer who can get only a limited quantity of the richest land, and must have recourse to inferior soil, will apply more labour and capital than it received before to the superior soil, at the same time that he applies labour and capital to the fresh land which is inferior. If this is not so apparent as I suppose, it will at once become evident from the numerical example which I shall give finally on page 290. It follows at once from the fact that, according to the law of substitution or equi-marginal returns (pp. 95-6), farmers will work different kinds of land to such degrees of intensity respectively that their marginal returns will be 
equal. Observe that the law of rent affirms that the positions of farmers of equal intelligence and industry, working good and bad land respectively, will be made equal by the payment of rent for the good land, after the good land has been worked more intensively. Observe further that it is not the remuneration of farmers per acre worked which will be made equal by the payment of rent, but their remuneration per unit of work done. As superior land is tilled more intensively it needs more care per acre than inferior land. Hence a farm of inferior land would have to be larger than a farm of superior land if the tenant of the former was to make as large a net income for himself as the tenant of the latter.

If population advanced so that the margin of cultivation dropped again and farming covered land of third-rate quality, the land of secondary quality would begin to bear a rent. This rent would be determined exactly in the same way as the rent of the best land was determined in the case already discussed. The land of secondary quality would, in its turn, be worked more intensively than it had been before. And the best land would be cultivated yet more intensively, and its rent would rise. The rent of the very best land would now be settled by reference to earnings on third-rate land, just as it had been previously settled by reference to earnings on second-rate land.

I must here just hint a warning. My reader knows as well as I, no doubt, that as time flows on and population increases, if it does, the price of food does not rise as a rule. The retarding influence is economic progress. Inventions and productive improvements punctuate the passage of time. The control exercised by Nature over man, through decreasing returns is eternally evaded, and instead, through progress, man's control over Nature is made more complete. Progress may teach how some intractable and comparatively sterile soils can be persuaded to yield abundant harvests. 
Again there is the development of means of transport, which bears on situational advantages with which we shall deal later. The relations between the universal tendency to decreasing returns and the decline in the real cost of food from generation to generation are fully discussed and illustrated on pages 107-8. Notice, too, that the best land is not necessarily worked first, even apart from considerations of locality. The best land known, in view of existing knowledge, when other things are equal, is the first to be worked.

Another objection to the doctrine of rent just expounded may occur to the student. Is it not a fact, he may want to ask, that this doctrine implies a particular system of land tenure? Must there not be a separate doctrine of rent for every system under which land is held for payment? Certainly there must, if we take rent to mean the payment made for land, but not if we take rent to mean a payment for any differential advantages. If under any particular system of land tenure the tenant enjoys without payment certain differential advantages of his holding, we may say that they are his by customary right. The payment for them is made when he sells his produce, and the gain is revealed in his income. In this case we should say that he retained a share of the true economic rent of the land.

Finally observe, by way of bringing our theory into closer correspondence with facts, that a piece of land may be devoted to one or the other of many different purposes and that it is likely to have more valuable differential advantages for one purpose than another; and that the disposal of land to different uses is made accordingly.

Marginal value of land.-Let us now premise that all the land has come into cultivation and that there is still demand for more land, so that recourse would be had to yet worse land than the worst in the country if such land were to be found. But ex hypothesi such land is not to be found. It 
does not follow, however, that no more food can be obtained. Although the importation of food may be impossible, it is possible to raise additional supplies of food in the country by more intensive cultivation. All the land will, therefore, be more intensively cultivated, that is to say more labour and capital will be applied to the land per acre. The result of this more intensive cultivation will be that the worst land will bear a rent while the rents of the superior lands will rise.

Why will the worst land pay a rent? As population became denser, the demand for food would rise. And as, in the circumstances supposed, Nature could only be enticed by increasingly lavish outlays to yield additional food, the price of food would rise. This rise in the price of food would place farmers in a relatively better position than before, even in respect of the work done by them on the worst land. Their better relative position would be due to the fact that, when they raised from this land more food until their marginal costs equalled its price, their aggregate costs, including their own normal remuneration, would be less than the sum received for their output, that is price multiplied by output. The competition of the non-farming class for land in these circumstances would obviously bring it about that the value of the improved relative position of the farmer would have to be paid over to the landlord in the shape of rent.

Let me illustrate by means of a numerical example. A farmer of marginal land, say, when all the marginal land was not cultivated, used to produce 100 bushels of wheat a year at an average cost of $20 \mathrm{~s}$. a bushel, including the value of his own work. At the position of equilibrium 20 s. would also be the marginal cost of production in such circumstances. Let him now raise another bushel because the demand for wheat has mounted up. Let the extra cost involved be $21 \mathrm{~s}$. If it is worth his while to do this, the extra or marginal bushel must sell for its cost, that is $21 \mathrm{~s}$. That is to say, the price of wheat must 
be $21 \mathrm{~s}$. a bushel. The farmer then would make a gain of $1 \mathrm{~s}$. per bushel on his other 100 bushels if he sold them all, that is a gain of $\$ 5 . \mathrm{He}$ is to that extent better off than the nonfarmers, for the non-farmers have to pay more for their food as well as he. He can, therefore, be forced by competition to hand over the $£ 5$ as rent.

Now the rent paid for the worst land in these circumstances is a payment for land qua land. It is not, in the ordinary sense, a payment for differential advantages, seeing that the inferior fields possess no differential advantages over other fields. To call this "economic rent" would involve calling the charges for hiring all rare things which are limited in amount "economic rents," which I think is hardly advisable.

The payment of rent, which might be a high rent, for the marginal land in our fictitious case, is made because the demand for land is intense and there is not sufficient land to meet the demand fully. Before the complete absorption by cultivators of all the land of the community, there was as much land as was wanted of a kind and land to spare. Consequently the marginal worth of land qua land was zero. Land was in the same position as air on the surface of the earth. Air has great value, but where there is as much as we want of it and to spare, its marginal worth is zero. The marginal worth of air at the bottom of a coal-pit is not zero, because there a dearth of air is experienced. There, in consequence, air acquires a marginal value above zero. So when all the land of a country is in use and yet more is wanted, land acquires a marginal worth which is above zero.

We may say that in the circumstances supposed, in which all the land is used and more is wanted, the land rent paid for any piece of land which is not marginal is compounded of two distinct payments. These payments are, (1) an amount determined by the marginal worth of land qua land, and (2) an amount which measures the differential advantages pos- 
sessed by that particular piece of land. It is only the second payment which is a true economic rent.

Fortunately the world is not in such a position as yet (and probably never will be) that land qua land has any marginal value. There is plenty of land to be had in the thinly peopled parts of the world. The fact that this unworked land is far removed from the centres with the greatest density of population brings it about that land in proximity to those centres bears a high situational rent, the determination of which we shall consider soon.

The student will realize that if the gradations of quality in land are not continuous, as we have supposed on page 283 , so that there is a distinct gap between the land of quality $A$ and land of quality $B$, when cultivation of land A has passed a certain point farmers will have to pay something for it before land $\mathrm{B}$ comes into cultivation. This payment is not true economic rent, but is analogous to the charges for the hire of rare things.

Numerical Examples.-Let me now illustrate the gist of this demonstration with the aid of figures which are quite impossible but serve to represent the simplest imaginable case. In the first column of the subjoined table let the numbers stand for successive doses of labour and capital. By "a dose of labour and capital " is meant a sum of money, say $£ 10$, spent by the farmer as he thinks best in cultivating the land. In the other columns the marginal returns (in bushels of wheat per acre) to different doses are shown-I suppose, for the sake of simplicity, that on every piece of land diminishing returns begin at once. Thus, if three doses were spent annually per acre on land, whatever its quality, the marginal returns would be 18 on land $A, 17$ on land $B$, and 16 on land $\mathrm{C}$, while the total returns (the sum of the first three figures in the columns of returns) would be 57 on land A, 54 on land $\mathrm{B}$, and 51 on land $\mathrm{C}$. The meaning of the table needs no further elucidation. 


\begin{tabular}{|c|c|c|c|}
\hline $\begin{array}{c}\text { Doses of Labour } \\
\text { and Capital. }\end{array}$ & \multicolumn{2}{|c|}{$\begin{array}{c}\text { Marginal Returns per Acre in Bushels } \\
\text { of Wheat. }\end{array}$} \\
\cline { 2 - 4 } & On Land A. & On Land B. & On Land C. \\
\hline 1 & -19 & 19 & 18 \\
2 & 19 & 18 & 17 \\
3 & 18 & 17 & 16 \\
4 & 17 & 16 & 15 \\
5 & 16 & 15 & 14 \\
\hline
\end{tabular}

Now, if sufficient wheat is obtained when one dose of labour and capital is applied to A, none of land $B$ will be cultivated, as the marginal return on $A$, that is 20 , is higher than the highest return per dose which can be got from land $B$.

When population grows and $B$ land just comes into use, one dose being applied to $\mathrm{B}$, two doses will be applied to $\mathrm{A}$ to make the marginal returns from $A$ and $B$ the same. This will be done because it is the most economical thing to do. If one more dose were applied to $B$ and one less to A, 18 bushels would be gained, while 19 bushels would be lost, which is bad business. Similarly, when $\mathrm{C}$ comes under tillage and one dose is spent on it, three doses will be spent on $A$ and two on $\mathrm{B}$. At this position $\mathrm{C}$ will bear no rent, and the rent of A per acre, in bushels of wheat, will be $20+19+18$ $-18 \times 3$, that is 3 , while the rent of $B$ will be $19+18-$ $18 \times 2$, that is 1 .

Now let the margin of cultivation drop another point, so to speak, to 17, and suppose there is no land inferior to C. At once farmers must pay a rarity price of one bushel an acre per year for $\mathrm{C}$, while payments for $\mathrm{A}$ and $\mathrm{B}$, where equally the marginal returns will be 17 , will be respectively 6 and 3. Of these latter payments, 1 in each case will be the rarity price, and 5 and 2 the true economic rents. 
Diagrammatic representation.-Consider fig. 16. Doses of labour and capital are measured along OX. In each dose we include normal profits. The return in wheat is measured along OY. We suppose that the land grows only wheat. $P_{1}$ and $P_{2}$ are the curves of marginal returns of two fields. If a return $\mathrm{O} g$ of wheat is just sufficient to remunerate a dose of labour and capital, $\mathrm{O} a$ doses will be applied to the one field and $\mathrm{O} b$ to the other, because the marginal returns from each field, $a c$ and $b d$, must be equal. Of the best field Obde is the total return, and Obdg is needed as recompense for the doses of labour and capital. Then there is a surplus gdje. The whole of this surplus is corn rent, or rent in kind, if no part of it stands for the marginal worth of land qua land. The rent of the other field is obviously $k h c-g f k$. If $k h c$ equals $g f k$, this field must be a marginal field. If this field

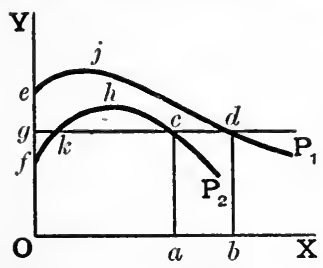

FIg. 16.

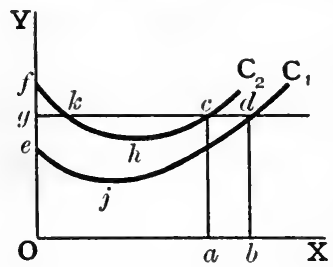

FIG. 17.

is the worst field cultivated and khe is greater than $g f k$, then $k h c-g f k$ is the marginal worth of land qua land. In this case the true rent of the other field would be gdje - $(k h c-g f k)$.

The same demonstration is given in another way in fig. 17. In this case the return of the fields is measured along $\mathrm{OX}$ and units of money along $O Y$. The curves $C_{1}$ and $C_{2}$ represent the marginal costs (including the farmer's remuneration) of different returns. The money rent of the one field will be gejd and of the other $k h c-f g k$. The latter field must be the marginal field if $k h c=f g k$.

Situational rent of agricultural land.-If we mean by rent a payment for differential advantages, the whole theory of rent is contained in the foregoing account of the way in which payment for the differential fertility of agricultural land 
is determined. But there are situational and other differential advantages, in addition to those based upon fertility. "Situational advantages" is a vague expression. It may be used very widely to cover all the advantages connected with a particular piece of land, apart from the properties of the soil,- - such as accessibility, climate and beauty of surroundings. Or it may be used very narrowly to denote merely the relations of the piece of land to other places in respect of communication and transport. Used in the former sense, it includes some of the determinants of fertility. It is sufficient to draw attention to the ambiguity, and to agree, when speaking of agricultural land, to exclude from situational advantages all that affect fertility, on the ground that they are already counted in fertility.

Even were all farming subsistence farming, the locality of some farms would be preferable to that of others. And locality becomes of immense importance when people farm not merely, or exclusively, for subsistence, but in order to sell their produce. For when they have to sell their produce, they must take into account, in selecting a farm, not only the expense of carrying what is needed to the farm, but also the expense of carrying their produce to market.

When land enjoys differential advantages both in respect of its fertility and of its location, it is impossible to say how much of its rent is due to each, because both enter into the settlement of the intensity of its cultivation. We may, however, show the influence of geographical position easily enough by taking two parcels of land of the same size which are equally fertile, and premising that one parcel is the most inconveniently placed of all the land of that quality in the country, which we suppose to be self-supporting. The excess of rent paid for the parcel of land in the more favourable locality we may reasonably attribute to its situational advantages. It might contain some small payment for the personal 
conveniences enjoyed by the farmer and his family in consequence of the location of the farm.

This example is sufficient to show how situational advantages enter into the settlement of agricultural rents. I had better, however, specifically draw the reader's attention to the following points :-

(1) Both situation and fertility are taken into account when farms are being selected, and farms are preferred according to their aggregate differential advantages.

(2) Consequently the least preferable land is not necessarily the least fertile, because some of the least fertile land might offer great situational conveniences.

(3) The cultivation of inconveniently situated land causes the more intensive cultivation of conveniently situated land. This needs no proof here. The proof is the same as that already advanced on pages 284-5 to show that the cultivation of inferior land causes the more intensive cultivation of superior land.

Phrasing this third point otherwise, we may say that, other things being equal, the most favourably situated land will be most intensively cultivated, just as, other things being equal, the most fertile land will be the most intensively cultivated.

Rent of building sites.-The rent of building sites depends almost exclusively upon the relative situational advantages of different sites. I say "almost exclusively" because foundations are more easily laid in some land than in others, and the value of a building site is affected by the cost of utilizing it. But this qualification may be forgotten in theorizing because nothing turns on it.

For illustration let us consider the value of sites for offices in some nightmare town in which only offices exist. The convenience of office accommodation, we may take it, diminishes with the height of the floor on which it is provided. We may also take for granted that the cost of buildings, 
above a certain height at any rate, is more than proportional to their height, despite the fact that one roof serves however many stories there are, because the higher buildings are the deeper must the foundations be and the firmer the sides. Now assume that a central situation in the town is the most valuable. Then, if the town were built up all at once for a known demand, edifices in the centre would be the tallest and those at the outskirts the shortest. Of course, if the town gradually grew in size, many low buildings might remain for years in the centre, because the value of their cleared sites would have to advance to a considerable figure before it would pay to destroy the capital fixed in them. The distance of the outskirts, and the means of getting to them, would help to determine the value of central sites, and the height of the buildings erected upon them, so far as height was elastic in view of building regulations and architectural possibilities.

Suppose a new central building has five stories of the same size let out in offices. Let the costs of production, the same expressed as annual payments, plus costs of management and of upkeep, and letting values be as follows :-

\begin{tabular}{|c|c|c|c|}
\hline $\begin{array}{l}\text { I. } \\
\text { Storey. }\end{array}$ & $\begin{array}{l}\text { II. } \\
\text { Cost. }\end{array}$ & $\begin{array}{l}\text { III. } \\
\text { Cost, expressed as } \\
\text { an annual payment, } \\
\text { plus management } \\
\text { expenses and } \\
\text { upkeep. }\end{array}$ & $\begin{array}{l}\text { IV. } \\
\text { Letting value. }\end{array}$ \\
\hline $\begin{array}{l}1 \\
2 \\
3 \\
4 \\
5\end{array}$ & $\begin{array}{c}£ \\
2000 \\
2200 \\
2600 \\
3200 \\
4000\end{array}$ & $\begin{array}{l}£ \\
200 \\
210 \\
230 \\
260 \\
300\end{array}$ & $\begin{array}{c}£ \\
500 \\
430 \\
370 \\
330 \\
300\end{array}$ \\
\hline 'Total & 14,000 & 1200 & 1930 \\
\hline
\end{tabular}


For upkeep and management we have allowed $£ 100$ a year per story, and for calculation of cost as annual payments we have taken the building at twenty years' purchase. So the figures in column III are obtained by dividing those in column II by 20 and adding to each quotient 100 . The second column means that a building of one storey would cost $£ 2000$, a building of two storeys $£ 2000$ plus $£ 2200$, that is $£ 4200$, and so on up to a building of five storeys which costs $£ 14,000$. The figures are not intended to be typical with reference to some particular style of building, but are simply illustrative. If the building were raised to five storeys, the top storey must be expected to let at $£ 300$, since cost will tend to equal price at the marginal position. In the fourth column we have the values of the office space provided, plus the value of its situational conveniences, over and above those of similar office space in the outskirts of the town.

One conclusion to be deduced from this supposed case is that the annual value of the site is $£ 730$, that is $£ 1930$ less $£ 1200$.

You should make a point of remarking that the marginal return of office convenience, so to speak, is the same on this site as at the outskirts and on any other site. For $£ 200$ at the outskirts $£ 200$ worth of office space plus zero situational conveniences, that is $£ 200$ worth of office conveniences, are obtainable. On the central site at the margin, that is on the top floor, for $£ 300$ the same office space is got, which we have valued at $£ 200$, and in addition $£ 100$ worth of situational conveniences, so that in all $£ 300$ worth of office conveniences are obtained. The situational conveniences of this top floor must be worth $£ 100$ as that is what the occupier finds it worth while to pay over and above the $£ 200$ for which he could get the same office space on the outskirts of the town. Hence the cost of office conveniences is the same at the margin on either site, on the assumptions made. 
You will now realize that the theory of situational rent is identical with that of fertility rent, and that there is in fact only one theory of rent when "rent" is understood to mean payment for differential advantages.

Finally I repeat that land will tend to be put to its most profitable use. If a piece of land will yield a rent of $£ 10$ an acre for agriculture and $£ 20$ a year for building it will be used for the latter purpose, unless it be withheld from the market in the expectation of a rise in its value for tuilding which will recoup its owner for waiting.

Personal rents.-Personal rents are strictly analogous to fertility rents. One employer can get more value out of his factors in production than another and can manage a larger business. $\mathrm{He}$, therefore, makes more than the other, and, if the other employer is marginal, the excess of the former's earnings is a personal rent. Similarly a very clever doctor will make more than a doctor of ordinary capacity.

Let us consider particularly the personal rents of employers. Suppose in a certain industry 100 employers survive. We may arrange the 100 surviving employers according to their value in employing. The one of least value, who is nevertheless just valuable enough to keep his position in view of his supply price, we call the employer of marginal value. The remaining 99 employers enjoy super-marginal value in different degrees. Now these super-marginal values constitute differential advantages in production. The employers who possess them will earn more than the employer of marginal value, according to the degrees of their differential advantages, because they can get more value out of a business of a given size, or can manage larger businesses, than the employer of marginal value. These super-marginal earnings are true rents, so far as they are dependent upon natural gifts. These rents may be classified according to the characters of the differential advantages upon which they are paid. There 
are (1) personal rents paid for super-marginal personal qualities, and (2) rents of circumstances, due, for instance, to the fortunate circumstances of birth or position which give men connexions or command over capital.

As there are great differences between employers in respect of their capacity, and between different parcels of land in respect of their fertility or situational conveniences, so there are great differences in efficiency and application between employees of the same grade. These differences between employees are differential advantages in production, and as differential productive advantages they have value. A specially rapid and skilful worker will tend to get an extra wage over and above that earned by the worker of marginal capacity in his trade, provided that the payment of this extra wage is not prevented by regulation or custom. This extra remuneration measures the value of his differential advantages in production. Hence there is a rent element in wages, as well as in profits, which is a true rent so far as it depends on natural gifts. Any given wage which is not marginal may be regarded as the marginal wage of a class plus a rent for the differential advantages enjoyed by the worker to whom it is paid.

Rent does not determine price.-The general correctness of the statement that rent which is a payment for differential advantages does not enter as a determining factor into price may be made apparent with the aid of examples. Farmers' costs of production on land which yields no economic rent settle the price of wheat, so far as it is settled from the side of supply. Had not farmers to pay any economic rent for land, they would charge for wheat as much as before, and produce as much as before. Were they to charge a little less they would cease to work the marginal land and would work the rest less intensively. But if supplies were reduced in this way the demand of consumers would send up price 
again to the old level, so that the old amount of wheat would be raised.

Consider again the rent of shops. If a shopkeeper in a shop on a well-chosen site charges more for his goods than a shopkeeper in an unfavourable position, who nevertheless gets as many customers, he is not enabled to do so because he pays a higher rent. He pays the higher rent because he can get the higher price. A sufficient number of customers to keep him fully employed are willing to pay somewhat higher prices for the convenience of stopping where his shop is, and the high rent of his shop is the result.

Of course rent enters into price in the sense that rents are paid out of the sums received in the form of the prices paid for things. But it does not enter into price in the sense that it governs price-that it has to be reckoned as one of the costs Jhich make up the supply price of a thing. This generalization holds of all rents, fertility, situational and personal, when they are taken as payments for differential advantages.

To the doctrine, understood as it has been enunciated above, there is no real exception in theory. There is an apparent exception when the marginal factory in some industry is found to pay a ground rent in order to get its site withdrawn from agriculture. This ground rent would be one of the costs determining price in the industry in question; but from the point of view of that industry it would not be a payment for a differential situational advantage but a payment for land qua land. The doctrine must not be taken to deny that a payment for marginal land for any purpose, if it bears a rent, is an element of the cost which helps to settle price.

Nor must the doctrine be read as asserting that the indirect consequences of rent payments have no influence upon the price of anything. Numerous examples might be brought forward to show, not merely that such an influence is common, but even that in some instances it is obvious and sensible. 
Suppose arable land is converted into pastures because of a rise in the value of grazing land. Then the price of wheat will rise-assuming that wheat is not imported-because of the relative dearth of suitable arable land.

Quasi-rent.-By quasi-rent I understand a differential advantage in production which can be increased deliberately, though not to a substantial extent for a long time.

People who are the first to get a new machine which proves successful earn for a time a quasi-rent by means of it. As more and more get the new machine the quasi-rent drops, till finally it disappears when enough new machines are produced for all who want them to get them. Then the machine has reached the margin and marginal cost of production will be cost of production with this machine (in view of its price, which may, of course, be above its cost of production because of patent rights).

We have an example of personal quasi-rents when the demand for, say, trained mechanics rises suddenly and considerably. Trained mechanics would for a time get an exceptionally high wage, but their wage would drop to the normal level after sufficient time had elapsed for as many mechanics as were wanted to be trained up. The old mechanics for the time would enjoy a differential advantage.

This last example will at once suggest difficulties to you. Suppose, you may say, that the demand for mechanies fell instead of rising, and that trained mechanics could not easily turn to anything else. For a time, then, they would receive less than normal earnings. Are we to say in this case that they are getting negative quasi-rents? We may say this, if we like, though it is awkward. If we admit negative quasi-rents, we must affirm, as regards all factors in production, that when conditions arise which make earnings more than normal, there are positive quasi-rents ; and that when conditions arise which make earnings less than normal, there are negative quasi-rents. 
Or, if we like, we may take as our standard earnings those which are lowest for the time being. In this case all quasi-rents would be positive. The latter course is probably the more scientific, and it brings the conception of quasi-rent, which is a short-period conception, into relation with short-period supply prices.

Some writers argue that the earnings of all machines (and of all factors in production once they are specialized), whether they are normal or not, are to be regarded as quasi-rents because their earnings do not govern the prices of the things that they make. The prices of things freely produced, so far as they are settled from the side of supply, are settled by the costs of bringing in fresh factors. The chief objection to this view is that it breaks the connexion between quasi-rents and differential advantages. If the whole of the payment for everything, as soon as it is active in production, is to be called "quasi-rent," a quasi-rent can hardly be described as a payment for (short-period) differential advantages. 


\section{CHAPTER XXVII. \\ - WAGES AND PROFITS.}

THE subject of wages and the earnings of employers for the work that they do are best taken together. Both are payments for living agents in production, and the supplies of labour and of organizing power are interlinked. Yet, from the formal point of view, there is more identity of theory between the doctrine of wages and the doctrine of interest than between the former and the explanation of how the payment for organizing is governed.

I shall frequently speak of the earnings of employers for the work that they do as "profits". I shall express myself so merely that I may have a convenient term. There is no word which unequivocally signifies the earnings of the employer for his productive activities as entrepreneur and industrial organizer, apart from the earnings of his capital. Ultimately I shall notice the various uses of the term "profits".

The value of services supplied by labour alone.-The economic value of agents in production is, as I have repeatedly insisted, the value of the things which consumers demand attributed, or referred back, to the agents engaged in making them. If the things demanded by consumers are supplied by people working without land or capital, there is no difficulty in finding the value of these people. Take the case of domestic servants of a certain kind, and suppose provisionally that they are equal in respect of efficiency and application. Their economic value is just the economic value of the services 
which they supply. Their earnings are just the marginal worth of their services, multiplied by the amount of those services. The marginal worth of their services is fixed by what the community will pay for different quantities of domestic service, and the quantities which will be forthcoming at different rates of pay. So the marginal worth of tea is fixed by what the community will pay for different quantities of tea, and the quantities that will be forthcoming at different prices. But when we go a stage further back in our analysis, we find a difference. For while the supply prices of domestic service are determined solely by the conditions of the labour market, broadly regarded the supply prices of tea are fixed by these in relation to the natural productivity of tea plantations and the effectiveness of capital and organization in raising, preparing, and distributing tea.

The reader must be careful not to misunderstand what is affirmed. I do not say that the wage of a domestic servant must equal her marginal worth to her employer when the latter employs only one servant, or two or three servants. Suppose the value of full-time domestic servants in a particular household would be apart from their keep

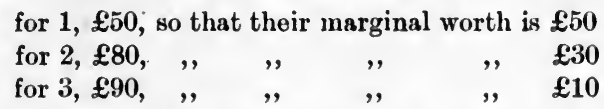

If the market rate of wages were $£ 20$ a year, in this household two servants would be employed, and paid $£ 20$ a year each, though their marginal value would be $£ 30$ each. In this particular household the wage cannot equal the marginal worth, because it is transparently impossible to engage less than a whole servant, and the number employed in the household is so small that marginal worth and the wage cannot be brought approximately to equivalence. Nevertheless, it is broadly true that the wage of domestic servants tends to equal their marginal worth as a body. It equals the value which 
would be lost were one servant withdrawn. The household which would sustain the loss, would be the household to which the marginal worth of domestic service was $£ 20$ a year. Housekeepers to whom the marginal worth of domestic service was more than $£ 20$ a year, would pay a little more rather than reduce their staffs. In no scientifically managed households would the marginal worth be less then $£ 20$ a year, exceptional circumstances apart. It must be added, in qualification of this doctrine, that custom is strong in the settlement of the wage for domestic service.

I have taken this example from domestic service because it will be familiar to everybody, but a better example would have been the labour employed in the loading and unloading of vessels. Because numbers of dock labourers are employed on each large ship, their marginal worth on each ship closely approximates'to their wage.

We may select another example from traders working on their own account. On the demand side, governing their earnings, is the utility of the work that they do when different quantities of it are done. Consider the exportation of crates of enamelled kitchen utensils to some market, let us say Liberia: If only 1000 crates annually were received in Liberia they would sell, say, for $£ 40$ each, but if 2000 crates were received, as the demand would be more fully satisfied, they would not fetch more than $£ 30$ each. Suppose 4000 crates get exported to Liberia and realize $£ 15$ each. Suppose they can be bought from the manufacturers at $£ 10$ each and that the cost of carriage comes to $£ 3$ per crate. Then $£ 2$ a crate will be the marginal piece-rate worth of the trading work done and traders will earn at the rate of $£ 2$ per crate exported. This case is identical with that of domestic service, except that in this case payment is reckoned per piece instead of per unit of time, and that the merchant is not a wage-earner but employs himself. 
Wages and profits under group production.-We pass next to the producers of tangible things. Let us consider the construction of furniture. In a simple state of society in which workmen employ themselves, the earnings of cabinetmakers equal the marginal value of what they produce, less the expenses incurred in their work, such as outlay on wood, rent of premises, and interest on such capital as they possess or can borrow.

Now imagine that somebody thinks of employing a number of cabinet-makers, providing them with tools, paying them wages and selling their product. If he did so, and left them to work just as they had done before, it would not prove worth his while. They would turn out about as much per head as they had turned out previously, and the employer could not pay them any less than they had earned previously, because, if he did, they would prefer to work on their own account. The employer could, however, make it worth his while to employ them, and worth their while to be employed, provided he could raise their net value per head. And he could do so in various ways, as we have perceived in reflecting upon the economies of group production. He might, for instance, so arrange the work of his hands as to secure a high degree of division of labour in his factory ; and, if he were wealthy and enjoyed good credit, he could certainly augment the productivity of his employees by furnishing them with more capital per head than they had normally worked with when independent. It would, therefore, be possible for our employer to offer weekly wages which would improve the monetary position of those who accepted them, and yet be left with substantial profits after deducting interest on his capital. We may note in passing that some part of the group organization of labour might be carried out co-operatively (see pp. 134-8).

Our imaginary first employer will pay just as much as is 
needed to induce as many cabinet-makers as he wants to join him. Suppose that he must pay 25s. a week and at that wage can get all the labour that he wants. We have then to consider how many people he will want. He would not want an indefinite number of cabinet-makers at $25 \mathrm{~s}$. a week each, for reasons stated in Chapter X. After he had engaged a certain number, he would find that any addition would bring him in less than their wages, because as his business grew the degree of detailed management possible would diminish. After a certain point has been reached the marginal value of labour to an employer must fall.

Now it should be immediately apparent (see pages 93-5) that the employer will want just so many men that the addition of another man would increase his net returns by no more than the wage paid, namely $25 \mathrm{~s}$. a week. In the technical language to which the reader has become accustomed, it is commonly said that the employer will enlist labour until its marginal worth to him drops to 25s. a week. Strictly speaking, we ought to say that wages are determined at any one time by the discounted employer's expectation of the marginal effects of labour upon the product, because wages are as a rule paid before the product of the labour for which they are paid has been sold. In a competitive system this expectation should closely correspond with fact, because persons without judgment are eliminated from the industrial field. We assume, of course, that for any quantity of labour the quantity and arrangement of the other factors in production will be the most appropriate possible in view of their cost. The remuneration of the employer for the work that he does will be the aggregate value of the output, less interest on capital, wages and other expenses.

I now advance a step nearer to actual affairs by allowing for competition among employers. Before there was competition our original employer decided to engage, it may be, 150 
men at a wage of $25 \mathrm{~s}$. a week each. After the appearance of competition he might have to revise his decision. There might be so many men anxious to make a profit by employing labour that there would not be enough labour for them to get 150 men apiece. In fighting with one another with the weapons of business, and out-bidding one another to entice labour, they would force wages up and the average size of the business (reckoned in numbers employed), and profits, down. The progressive shrinkage of expected profits, as competition ground out its results, would discourage some of the possible employers, and fewer and fewer would be left who found it worth while to continue struggling for a place.

Finally, suppose a state of equilibrium is reached at which there are 100 employers who absorb all who are willing to be cabinet-makers at the wage paid and make for themselves, apart from interest on capital, $£ 10$ a week each. Let each employer have 110 hands whose marginal worth to each employer is $30 \mathrm{~s}$. a week, which will be the wage. We are assuming provisionally that the employers are equal in ability and have equal control over capital. It must be then, in the case imagined, that there are just 100 men fit to be employers who will do the work of employing for $£ 10$ a week. If profits were higher more people would be attracted to the business of employing in this trade; if profits were lower fewer people would be attracted to the business. Thus the earnings of employers are settled by employers' supply prices of themselves (or what they will work for) and the profits to be made when different numbers of employers are in the field.

Notice the remarkable similarities between the determination of the earnings of the trader and the determination of the earnings of the employer as industrial organizer. The trader makes his earnings out of distributing commodities appropriately, that is, so to speak, out of arranging them in such a fashion in relation to customers that their value is enhanced. 
The industrial organizer makes his earnings out of arranging his factors in production in such a fashion in relation to one another that their value is enhanced.

\section{Allowance for differences in efficiency between em-} ployers. - The demonstration above is highly abstract. We shall correct it to make it an exact analytic presentment of actual affairs as we go on, beginning at once. We have supposed that those aspiring to be employers are all equally well equipped with ability of the right sort, control over capital, and perseverance. This, of course, cannot be, as the most limited acquaintance with human nature will persuade us. So we must say that the would-be employers who survive in the competitive struggle are those who are the best equipped generally, other things being equal. They are also the persons who are ready to do the work of organizing for the lowest pay, other things being equal. Hence it might come about that of two employers at the margin the one would be more efficient than the other. The other would manage to keep his position because he put a lower reserve value on his labour. In the world of our previous abstraction more than 100 men would be willing to do the work of employing, but only 100 we suppose have such efficiency that they could make enough to induce them to do it. Aspirants other than the successful 100 are squeezed out by competition. By "efficient" in this statement we mean valuable for employing purposes generally. As we have perceived, of two men equally valuable for employing purposes, the one may be cleverer at industrial work, but the other may make up for his deficiency in this sort of cleverness by astuteness as a commercial man, or by his greater command over capital.

Between established employers there will be great differences in respect of efficiency. In consequence of these differences, in the same industry all businesses, even if fully 
grown, will not be of the same size, however we measure size. This is a point which has been explained already on pages 90-5. Turning to these pages we see that in any industry businesses will be found of various magnitudes and of various types of organization. The admission of this fact, and of the fact that some businesses are small because they are only growing up, does not invalidate the demonstration given of the settlement of wages and profits. That demonstration remains sound in principle. In order to make it applicable to the more complicated circumstances now recognized, we have merely to make it more complicated. We are not required to alter its character.

Of the rent elements in wages and profits, both true rents and quasi-rents, which are payments for differential advantages, I have spoken in the chapter just preceding this.

Definition of profits.-I now offer my belated definition of profits. "Profits" is used indifferently to cover all or some of the following payments:-

1. Industrial interest (gross interest).

2. Industrial interest less certain charges such as insurance and payments against depreciation of plant.

3. Payment to the employer for his exercise of the undertaking function, which has an industrial and a commercial side.

4. Payment for industrial organizing.

5. Payment for commercial organizing.

6. Payment for detailed managing.

The functions distinguished in this tabulation are explained in Chapters VII and X. As to the sense in which "profits" should be used, it is impossible to dogmatize, since the current usage of the word is so elastic. But it would certainly be a great convenience if the term "interest," qualified according to its application, were always used to indicate payments 1 and 2 ; if 3 were called "undertaker's profits"; 4 , "industrial 
profits"; 5, "commercial profits"; and 6, "payments for business management".

Supplies of labour.-We have learnt what constitutes the demand for labour and how it settles the wages of labour, but we have yet to learn how the supplies of labour of different kinds offered in different industries are determined. The supply of a particular sort of labour cannot be regarded as fixed, because population may expand or contract and also because a man can choose between different occupations.

That the level of wages has a bearing on the rate of increase of the population, nobody would venture to deny in face of the facts. But population is governed by other things besides wages, and the influence of wages themselves appears to vary from period to period and from class to class. The problem of population as a whole is so perplexing, and our notions about it are in many respects so vague at present, that nothing would be gained from attempting any detailed analysis of it in this treatise.

I must, however, speak at some length of the way in which a given population gets distributed amongst the industries of the country, because this has a most weighty influence both upon the general level of earnings and upon the ratio between earnings in the several occupations of the country.

The labour of a country is not all of one sort. We may think of it as divided up into a number of grades or classes. Thus, there are (1) unskilled labourers, (2) skilled artisans, (3) the lower middle classes, (4) the upper middle classes, (5) the wealthier, or predominantly capitalistic, classes. This classification is sufficient for our present purposes, but in a more advanced treatment of the problem of the supply of labour, it would be necessary to make a more elaborate classification. Observe that this division refers to economic characteristics only and not at all to social characteristics. It is economic characteristics that we have primarily in view in Political Economy. 
The position of any individual in the labour grades of the community is settled in part by the position of his parents, in part by his capacity, and in part by his enterprise. The extent to which it is settled by his capacity depends upon the extent to which parents are ambitious for their children; the extent to which the former have the means, and the requisite knowledge, to prepare their children for better positions than those occupied by themselves; and the extent to which educational facilities are offered to the rising generation.

To each of the grades of labour to which I have referred a number of occupations are open. The occupations open to each grade are those which require about equal amounts of ability and endurance. Once a man has started in a trade, naturally it is not easy for him to change, though it is not impossible. But between the occupations offered to any one grade, the free disposal of the labour of the rising generation is but slightly restricted. A child still inclines to follow his father's calling, but under modern conditions it is almost as easy for him to enter any of the callings which effectively appeal to the class to which the father belongs. Hence, in so far as the trades filled from one grade of labour are equally pleasant, the wages paid will tend to be the same cateris paribus. If in one of such equally pleasant, or unpleasant, trades lower wages were paid than in the others, the flow of labour into it would be checked. The check would continue until the numbers in the trade had so dwindled that the wages paid in it rose again to the normal level.

But in so far as the different kinds of work offered to labour of one grade differed in agreeableness there would be a difference in wages, because, other things being equal, people choose the most comfortable situations. To get adequate supplies of labour, employers in the industries in which work was disagreeable would have to offer wages somewhat above the normal level for the kind of labour that they wanted. So 
we may conclude that differences in wages within each grade will roughly measure the amenities or discomforts of different avocations. Of course, whether a calling is found to be pleasant or not is largely a matter of individual taste, and this fact must be allowed for when we frame our final conclusions. The wages in different occupations in the same grade will also tend to vary with the cost and length of training required and the probability of success and of regular work-though it may be that uncertainties are apt to be under-estimated.

I may remind the reader that the degree of the flow of labour between trade and trade in the same grade is known as the degree of horizontal trade mobility. It must be distinguished from geographical mobility, which refers to the degree in which labour is attracted from place to place by the prospects of better wages. The degree of horizontal trade mobility of the rising generation is high, because, in the plastic age, a person can easily take up any one of the occupations for which he is suited.

Competition between grades-vertical mobility. The various grades of labour have been termed non-competing groups. But they are not entirely non-competing, though it is true that labour moves less easily, whether in youth or later life, from one grade to another grade than from one trade to another trade within the same grade. We may, therefore, affirm that the level of earnings within a grade, in relation to the levels of earnings in the grades above it and below it, do govern to some extent the proportion of the population within that grade. But it cannot be declared off-hand whether a grade will increase in numbers or not when the incomes made by those who belong to it rise relatively to the incomes earned in other grades.

Thus, let us take the grade which we have termed the lower middle-class. Let us suppose that earnings in this grade increase and that earnings in other grades remain un- 
changed. Now, whether the lower middle-class grade will contract or expand relatively, depends upon the degrees of the inflows and outflows set up by this increase of earnings. Its ampler earnings make the lower middle-class grade more attractive than it was in relation to the artisan grade. Hence we may expect more people to climb into it from the artisan grade. Similarly the higher middle-class grade is made relatively less attractive to the lower middle-class than it was when the lower middle-class were not so well off. Hence we should expect fewer of the lower middle-class to pass upwards into the grade of the higher middle-class.

There are two reasons, then, for supposing that the lower middle-class will grow in numbers in the circumstances imagined. Forces are generated which tend to check the depletion of this class, while other forces are generated which tend to insure its more rapid recruiting. But we must not go too fast. Yet a third set of forces begin to stir. The degree in which a lower class contributes to a higher class depends not merely upon the will of its members to do so, but also upon their power to do so. Now the elevation of earnings of the lower middle-class enhances their power of placing themselves or their children in the higher middleclass, because money in this matter is power. Consequently, after the incomes of the lower middle-class had increased, some of that class, who would not have risen otherwise, would be enabled to push into the higher class. The upward flow brought about in this way might conceivably counteract the other tendencies already described, so that actually the lower middle-class would lose in numbers.

As regards the lowest class of all, that of the unskilled labourers, it is more likely than not that its prosperity will relatively deplete it, because there is no lower class for it to draw upon, in order to make up for the loss of those who are aided in their advancement to a higher grade by the 
augmentation of their wages, or the wages of their parents or relatives.

The lowest economic grade of labour does not, of course, compete directly with the highest, at any rate to a noticeable extent. But it is brought appreciably into competition with the grade just above it, in the manner portrayed. And the grade just above it is in turn brought appreciably into competition with the grade just abovo itself. Competition in this way links up grade and grade from the top to the bottom. So the lowest grade of all does compete indirectly with the highest grade of all.

The movement of labour from grade to grade is known as the vertical mobility of labour. It is probably slight among older people. And it is not so great among younger people as it is possible to make it. However, progress in this matter has been marked. It should need no demonstration to convince the reader that the more easily people move vertically to the kind of work suited to their capacities, the better is it for society as a whole. The man who gets on, and by getting on adds to the supply of organizing power, or displaces somebody else who otherwise would have filled his position less satisfactorily, benefits not only himself, but also the community at whose disposal his superior selvices are placed.

Conclusions as regards the determination of wages.We have now completed our analysis of the conditions governing the supplies of labour offered to the different industries of the country. These conditions of supply, taken in conjunction with the conditions of the demand for labour, analysed at the beginning of this chapter, account for the wages paid in the several industries of the country. Our final conclusion, which should hold approximately, is that in any industry the quantity of labour employed will be that quantity for which the supply price and the marginal worth of labour 
to employers are the same amount, and that this amount will be the wage.

As regards the contention that the standard of living plays a dominant part in the settlement of wages, we may at once concede that it plays a very large part. But the forces operating on the side of demand must not be left out of account. Wages cannot depart far from the marginal worth of labour. The standard of living is, however, effective in driving a man to reach a marginal worth the money expression of which is sufficient to maintain his standard of living. A man may reach the desired marginal worth by making special efforts to find the work which just suits him and by putting the best of himself into his work. People will make speeial efforts to keep their income sufficient to maintain their standards of living, which have reference not only to themselves but also to the bringing up of children. In order not to slip down in the social grade and be forced to contract his standard of life, a man would usually work very hard and put himself to no end of trouble and worry, and even change his home and trade if need be, which otherwise he might never have dreamt of doing, and even defer marriage if he is unmarried. To an extent, therefore, the theory of wages which I have expounded may be called a " subsistence theory". That it is also a "productivity theory" will be immediately patent.

Let me finally present a summary of the influences affecting wages. When the efficiency of labour rises, since its marginal utility is raised, wages rise. When labour is more appropriately placed and trained, since its marginal efficiency is raised, wages rise. When the marginal ability of employers is raised, since they make better use of labour, and its marginal utility is thereby raised, wages rise. When more people are enabled to force their way into the ranks of the organizers, since more organizing is then done and organizers are stimu- 
lated to their best endeavours, the marginal utility of labour is raised and wages rise. The more employers, or would-be employers, there are to compete with one another, the better is it for labour. As inventions are made, and enterprise is intensified and more capital is saved, the marginal utility of labour is raised and wages rise.

The doctrine of the wages fund and the iron law of wages. -Wages, it has been said, depend upon capital. It is just as true to say that profits and interest depend upon labour. Wages do depend upon capital in the sense that the more capital there is the higher wages are. The more aids to production men have to work with the more wealth can they make.

It was not, however, in this general sense that the statement with which the previous paragraph began used to be made. By it was meant that wages were governed entirely by the amount of wealth which was predestined, so to speak, for the payment of wages. Such wealth was known as the wages fund and the statement was known as the "wages fund doctrine". It was to this doctrine that expression was circuitously given when it was laid down that "demand for commodities is not demand for labour ". The amount of the wages fund at any time was supposed to have been definitely fixed by antecedent eonditions. Let labour suddenly double in efficiency, and wages would for a time remain as before, it was dogmatically declared. Let it rain good fortune in the shape of discoveries which eould be at once turned to productive uses, and wages would be as before for a time.

All this is radically wrong (as the reader who has mastered the present and the previous chapter could decide for himself), if " for a time" is to be understood as meaning "for a lengthy period". If those who adhered to the wages fund doctrine had allowed that the time might be only a few days, or weeks, their position could have been so defined as to be theoretically unassailable.

Of what, we must inquire, was the wages fund supposed to consist? It was sometimes conceived as money, sometimes as goods. But if conceived as money, it is evident that the fund is highly elastic. Expectations of the profits to be derived from different courses of action determine employers in deciding how much to 
spend upon industrial wages, how much upon plant and how much upon themselves. Expectations of the profits to be made out of employing labour determine, too, all other people with money in deciding how much to invest in industry. And the amount of available money is in itself elastic within limits. Let expectations of profit rise, and more bank money may be created. It, therefore, dawns upon us, when we think of the wages fund as money, that it is a highly elastic fund which instantaneously, by swelling or contracting, accommodates itself to any alterations in the value of labour. A rise in the value of labour means magnified expectation of profit, and it means, therefore, on the instant almost, a corresponding rise in the wages fund.

If the wages fund is conceived as goods, the doctrine of the wages fund equally melts away. When the wages fund is conceived as goods, the doctrine asserts that the stock of goods which can be consumed by workmen is for an appreciable time fixed in amount. But the goods of the world cannot be divided into workmen's goods and other goods. No doubt yò could pick out goods which would only be consumed by workmen, like corduroy trousers, and goods which could only be consumed by wealthy people, like diamond tiaras. But when you had selected all the goods which could be earmarked on inspection as of such a character that they could be consumed only by the working classes, a large mass of goods would remain over which could be consumed by these classes or other classes. Workmen, as well as people with higher incomes, can ride in motors, wear smart clothes on holidays and go to the theatre. When the employers' demand for labour rises because high profits are anticipated, money wages rise, and more of the class of goods not earmarked by their character for use by a particular class find their way into workmen's homes, or are otherwise appropriated by the working classes.

Again, the quantities of most commodities of any kind in existence can be very rapidly increased. There exists in a country at any one time a certain quantity of finished articles ready to put into the hands of consumers, a certain quantity of articles which need another process to be performed upon them before they are ready for consumers, a certain quantity which requires two more operations to be performed upon them, and so on almost indefinitely. Mapy of the articles nearly finished may be finished so as to be 
suitable for consumption by workpeople or by others, and a much larger proportion of the goods which are not nearly finished can be worked up into such a form that they meet the demands of workpeople. Almost on the instant the proportions of goods of different kinds in the world can be altered.

So the supposed fixed wages fund of workmen's goods has vanished. It is seen to be a well-nigh indefinitely expansible fund. It expands as expectations of the profit to be made out of employing labour expand.

The wages fund doctrine was publicly interred many years ago. I refer to it now because one path to a firm grasp of the truth may be hacked through error, and because examiners cherish the memory of the doctrine.

For the same reasons I may also refer here to a kindred theory of wages, known as the iron or brazen law of wages, which used to he held many years ago. It proclaimed that wages could never for long be sufficient to provide more than bare necessaries for the labourer and his family. If wages rose above the bare subsistence limit, it was thought that population would increase until, through the excess of labour, they ultimately fell again. The theory may have been approximately true of the peculiarities of the time when it was put forward, but that it is not applicable to Western communities to-day, the facts relating to population, which have been commented upon (page 309), will make abundantly plain. 


\section{CHAPTER XXVIII.}

\section{PRODUCERS' SURPLUS AND LABOUR PROBLEMS.}

Summary of the theory of distribution.-The gist of the theory of normal distribution under conditions of group production is as follows. Under group production value is created by organized collections of capital, land, and workers of various kinds, which function in unison under the direction of an employer or employers. We cannot say that so much of the output is produced by the capital, so much by one class of operatives, so much by the land or the material derived from it, and so forth, any more than I can say that so much of the manuscript of this book was produced by my thought, so much by my hand and so much by my will. In somewhat the same sense in which the manuscript of this book must be attributed to my faculties and bodily parts regarded as making up an organic whole, must the output of a business be attributed to the several agents or factors in the business regarded as making up an organic whole. How, then, is distribution among the factors or agents of the business fundamentally governed?

With respect to employed agents, the units of which in each class may be provisionally taken as equal in efficiency, distribution is settled by demand and supply. Demand in this connexion means the marginal worth to employers of different quantities of each factor, in view of the supplies and costs of other factors, both employing and employed. Supply means (a) the quantity of any factor in production, if 
its quantity offered for employment is temporarily or permanently fixed, or $(b)$ the quantities which will be forthcoming at different prices or earnings. The remuneration of an employed factor will tend to equal its marginal worth on the one side and its supply price, when it has one, on the other side. The marginal worth of employed factors depends inter alia upon the supply of organizers, and the supply of organizers depends upon what they can earn, that is upon what is left over in a business when all the employed factors are paid for.

Another way of putting the theory when all employed factors have supply prices, is to affirm that employers try to adopt the most economical of the innumerable combinations of factors in production which are theoretically possible. The most economical combination is that which, in view of the cost of factors, yields the greatest profit. It has been demonstrated in earlier chapters that the most economical combination of factors in production must be that in which the marginal worth of each factor equals its cost. The position of equilibrium is obviously reached when the organized businesses are such in character and number $(a)$ that the earnings of employers equal their supply prices (assuming employers to be similar in efficiency), and (b) that the quantity of each class of factor employed (assuming that its units are similar in efficiency) equals the quantity which will be supplied at the price paid, .when it has a supply price, or equals its supply, if this is limited, or is such that its marginal worth is zero (for instance in the case of land where any amount is to be had).

To complete the theory of normal distribution, we have simply to add that factors in production which possess differential advantages in production tend to be paid, in addition to the normal remuneration of factors of marginal efficiency, the full value of their differential advantages. These extra payments are called rents. 
You will realize that, if we like, we can so shape our abstractions that rent payments are merged in payments to cover marginal worth. Take all the labour in an industry which enjoys differential advantages of a given amount, and treat it as an independent class of factors in production. This class would get its marginal worth ; and its marginal worth would equal the value of its differential advantages plus the marginal wages of the group of labour from which the special class was abstracted.

I need not impress upon you again that this beautiful theory of distribution is not literally true. I mean that the precision of our theory is not attained in the working of the socia! system. Our generalizations hold only of tendencies. With the understanding of these tendencies, you are making only a beginning of an understanding of the social system. Of large sections of the business world the theory hardly holds at all. It is as if you were studying some machine, and I had explained to you the principles embodied in it, assuming a perfect fit of parts such as Vulcan alone could forge. You would have to observe next how imperfectly the machine was constructed, and discover and allow for the actual quality of its metallic limbs. Do not suffer this analogy to lead you astray. You must not take for granted that the ideal or perfect society is that which our theory would exactly fit.

Producers' surplus.-I may now. point out that corresponding to a consumers' surplus there exists a producers' surplus. Like consumers' surplus, producers' surplus may be expressed in money, or in terms of utility, and with respect to groups or individuals. I shall first express its group reference in terms of money.

After your study of production and distribution up to this point, it will not be necessary to prove again that the aggregate paid for the output of an industry is less than the aggregate of the supply prices of all the factors involved. The difference is called "producers' surplus". Some of it accrues to labour, 
some to employers, some to capital and some to natural agents. "Producers' surplus" is not invariably used in this sense, but in this sense the conception appears to be most serviceable. I must not pause to argue controversial points.

In order to make the notion of producers' surplus precise, you must distinguish between the general supply price of a factor in production and its special supply price, if it has one. By its "special supply price" I mean its supply price for a particular industry. This is naturally regulated by what the factor could earn in another industry. The general supply price of a given acre of ground would be nothing where land qua land had no marginal worth, but its special supply price as a building site would be the rent which it could earn when applied to any other purpose. Supply price with reference to producers' surplus had better be understood as general supply price, unless you want to distinguish between two kinds of producers' surplus.

Just as every person enjoys a consumer's surplus of utility as a consumer, so every worker enjoys a producer's surplus of utility as a producer. An operative works, let us imagine, fifty-four hours a week, and gets a wage of $£ 2$. In spending this wage he realizes a consumer's surplus of utility, as we have seen. But in earning it he may have obtained some utility directly also. Some of the hours of work were tiresome, to say the least, but some were less tiresome than others, and some may actually have been enjoyable. Generally speaking from most kinds of work we derive some direct satisfaction. We may start the day's task with groaning of spirit, because of the inertia which we have to overcome, but, as we get into the swing of the work, exhilaration usually supervenes. After a time, however, monotony begins to tell, or exhaustion is felt. If we continued our toil long enough, disutility or dissatisfaction would certainly take the place of utility or satisfaction, and steadily increase. So you may think of the week's work 
as producing so much disutility and so much utility directly, in addition to the wages.

Producer's surplus of utility is sometimes defined as the utility enjoyed in working less the disutility. This might not be a positive quantity on balance, in which case there would be no producer's surplus. But it is more usual to say that the producer's surplus is the utility got directly from working, less the disutility got from working, plus the marginal utility of the wage multiplied by its amount, because this is what the producer gains over and above consumer's rent.

Diagrammatic exposition of producer's surplus of utility.In fig. 18 measure the daily hours of labour along $\mathrm{OX}$, utility aloug $O Y$, and disutility along $O Y^{\prime}$. Let the curve ke represent the

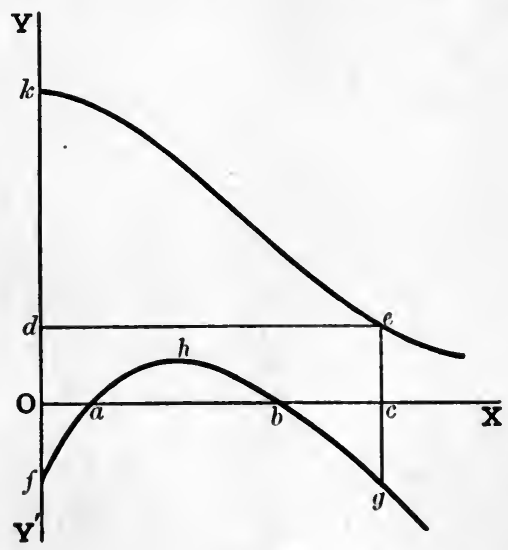

Fig. 18.

additions made to the utility derived from consumption as the wage rises when the hours of labour increase. Let the curve fhg represent the way in which the utility (positive or negative) of working varies with the working day. Let the working day be $\mathrm{Oc}$. 
When the worker can effectively control the length of the working day, it would tend to be such that ec equals $c g$. 'To work longer would be to suffer a disutility greater than the utility got from the wages for working longer. Remember in interpreting this figure what I mean by utility (see pp. 22-3). When the working day is Oc, the worker's consumer's surplus will be kde. And his producer's surplus will be, according to the view you take of producer's surplus, either $a h b-\mathrm{O} f a-b c g$, or this amount plus Oced. The quantity $\mathrm{cg}$ is not, observe, the disutility actually experienced in the last moment of work. It represents the long-period effect of the last moment of work: Utility might conceivably accompany the last minutes of work each day.

The hours of labour.-The question of the hours of labour may fitly engage our attention at this juncture.

As the employer need not himself work all the time his factory is running, to take the case of a manufacturer, he will be 'governed in his attitude to the question of the normal working day, other things being equal, by the productivity of labour in the long run when toiling different hours per day. Now the value of labour, in relation to the hours of work, in every industry must be subject to variations similar to those shown in the table beneath for imaginary circumstances:-

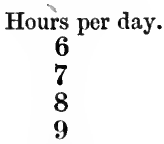

10

11

12
Value of Labour per week in shillings.

34
38
40
41
40
39
37

The fall in the value of labour after the working day exceeds nine hours, in these imaginary circumstances, is due to the fact that impaired vitality-physical, mental, or moralor irregularity (where that is possible as in the case of colliers) after a time reduces the productivity of labour directly or indirectly. 
Evidently in this case, it would be to employers' interests to run their businesses nine hours a day. But far-sighted operatives would almost certainly prefer a shorter day because the ninth hour only makes a difference of $1 \mathrm{~s}$. a week to their value-and so to their wage-and, even if working the ninth hour is no strain, an extra hour's leisure a day is likely to be worth more than a shilling a week. You must remember that we are treating now of long-period results, which may not be fully realized. The ultimate effects of the reduction of working hours on efficiency are apt to be overlooked by everybody.

Actually any difference between employers and employees, as regards the duration of the normal working day, is settled by bargaining. There is no appreciable difference to settle when there are shift arrangements in use which are such that shorter hours for the workmen do not entail short hours for the machinery. Shift arrangements which lengthen the working day of machinery are economical because they enable more value to be squeezed out of each unit of capital, upon which interest must be paid even for the hours when it is at rest. Doubling the working time of capital would have roughly the same effect upon the national production in the long run as doubling the quantity of capital. But to shift systems objections may be urged from the social point of view, and from the point of view of health, as well as certain economic objections. Whether in any industry their adoption should be approved, or recommended, can be settled only by a balancing of advantages against disadvantages. In some industries, where processes must be continuous, they are unavoidable.

The more severe the strain of work and the more monotonous the work, other things being equal in each case, the shorter will be the working day demanded by labour. And the higher the wage per hour, the briefer will the operative desire 
the hours of toil to be, other things being equal. With the higher wage a little more leisure is likely to be bought as well as a little more of all other goods, especially in view of the fact that the value of leisure is enhanced by an advance of earnings. But we must not omit the qualifying "other things being equal," because the higher wage, which enabled the operative to get more nourishing food and more comforts, might raise the level of his vitality and lead to his wanting to work longer and earn more.

Another determining condition of the normal working day is the amount of over-time to be expected in a trade over a given period. Over-time permits of elasticity of output, which is of more importance in some industries than in others, but it may be grossly abused. The higher rate commonly paid for over-time checks its abuse. Why this higher rate has become so common, is explained by the fact that the average disutility of exerting oneself for pecuniary gain is much greater during the period of over-time than during normal working hours.

Progress is affecting the duration of the time devoted to earning an income in a variety of more or less obvious ways. Machinery is assuming the heaviest tasks in the world, but the nervous strain of work is probably being intensified under modern conditions. Rising wages are removing the necessities which forced many people to labour almost unceasingly, and are causing leisure to be more highly appreciated. Education also is making leisure more valuable, and at the same time, both directly and through its reaction on productive methods, tending to render much work more absorbing. Generally speaking, an outstanding effect of progress under the most advanced conditions has been that many operatives while working for wages have had to draw increasingly on their nervous strength and mental energy though called upon to toil for fewer hours in the day and fewer days in the year. You would do well to 
refer back at this stage to the observations on pages $85-8$ about the effect of machinery.

Collective bargaining.-In advanced communities the system of settling wages and the hours and conditions of labour through the medium of organizations of masters and men is spreading. This system is known as collective bargaining. It means that the professional expert displaces the individual in voicing the forces of demand and supply. It must result in greater uniformity of conditions. We cannot discuss here the merits and demerits of the system. Nor can we discuss the policies which have been pursued by employers' associations and trade unions in giving effect to their views. Strategy and tactics, no less in business than in other spheres, must raise highly controversial issues. We may, however, notice the broad effects of trade unions on distribution.

Trade unions can do a great deal to better the general conditions of labour - to secure that factories shall be healthier and brighter and the operatives more comfortable at their work-both directly and by pressing for legislation. Workmen, when they act individually, are much less likely to bring about improvements of this kind. And the march of reform is made easier for employers when at each step all competitors are kept in line. The individual employer, as well as the individual workman, frequently finds the dead-weight of inertia in the surrounding system too much for him, however anxious he may be to ameliorate the conditions of labour.

Upon wages, as well as upon the general conditions of labour, trade unions can exert direct influence. If in any trade wages tend to settle at a level beneath the marginal worth of labour in that trade for the time being, the trade union can at least lever wages up to its marginal worth without causing any displacement of labour. It is alleged that the recompense of workpeople does tend to be kept on an average by a sort of 
social friction at a level beneath their marginal worth when earnings are settled competitively without any concerted action on their part.

The birth of trade unions may also be followed by reactions which elevate people's efficiency. A calling may get "professionalized," so to speak, when it is organized in a trade union. Standards of diligence, regularity and good workmanship, may be created and become despotically powerful. And as the marginal worth of labour is augmented, the wage can advance. The' opposite of this effect of trade unions, that is any tendency set on foot by trade unions to level down efficiency and reduce the individual's output, would be almost certain to exert in the long run a depressing influence upon wages, other things being equal. I say " other things being equal," because when the operative is driven or induced to work at high speeds, or for long hours which are detrimental to his health, a curtailment of his work, though it would at first reduce the output, would bring a balance of gain in the long run both to the operative and the community.

Let us now consider what can be effected by a strong trade union in any particular trade or section of a trade. If the union is strong enough to stop influxes of labour into the occupation, it can magnify the marginal worth of labour by restricting entries, and so add to the pecuniary rewards of its members. But in many cases it is difficult for operatives to carry out this policy, because there happens to be an easy alternative method of obtaining the commodity which they help to produce, or because the demand for the commodity is not very elastic, or because their wages are a large part of the total expenses of production of the commodity (so that a rise in their wages will greatly raise its price and diminish the demand for it), or because the other classes of workers and the employers with whom they are associated in production can also restrict their numbers artificially. 
It is evident that the position of a trade union which is favourably placed is a delicate one. It might inflict injury on other groups of labour, although it had no intention of doing so. On the other hand, it might not; though a check on influxes into the trade might have to be imposed to prevent its gains from being dissipated. It could secure its members in their gains, we may remark, not only by directly restricting entries to the trade, but also by compelling employers to reserve certain work for its members, and laying down rules as to the quantity of machinery allowed per head and the number of assistants permitted. But in doing this merely with the object of keeping its members' wages high, it would inflict loss on society as a whole, in so far as the substitution of economical for uneconomical methods of production was hampered. At the same time it must be conceded that trade unions have the right to resist reactions of demand or supply on their wages which are consequent upon the prevalence of unreasonably low wages among certain sections of the labour world.

The problem presented by trade-union action with reference to the level of wages is extremely complicated. When reflecting upon it, you must bear in mind similar problems, for instance, those relating to doctors and solicitors whose rates of remuneration are settled by regulations. No doubt the services supplied by doctors and solicitors are of a distinctive character, but the differences between various kinds of work are largely matters of degree.

The gist of the above argument, you will understand, holds not merely of labour but of capital and land as well. And, manifestly, there are economic objections to keeping wages artificially below the marginal, or differential, worth of labour analogous to those which relate to keeping them artificially above it, in addition to the obvious disadvantages of low wages. 
Piece-rates, time-rates, premium systems, sliding scales, and profit-sharing.- The defect of the time-rate is that the workman is not induced to do his best. The defect of the simple piece-rate is that he is induced to rush, perhaps to the detriment of his health, perhaps to the deterioration of his work. Premium systems have been tried to cure the defects of piece-rates without sacrificing their advantages. The idea of the premium system, of which there are many varieties, is that a standard output should be assented to, and that for outputs in excess of this lower piece-rates, perhaps progressively lower piece-rates, should be paid. When the rates progressively diminish as the operative increases his output, the incentive to increase it still more is diminished. There is, therefore, less chance of his scamping his work or overworking. Of course, if in other ways the operative is pressed to strain every nerve to turn out all that he can, more or less regardless of quality, the premium system simply insures that the rapid worker shall not be paid all that he is justly entitled to receive.

Which system of wages is best, depends upon the character of the industry. In all industries piece-rates cannot be designed. Work in some industries is not reducible to a limited number of uniform units. In other industries, where machinery is responsible for the bulk of the process of production, the quantity of the output cannot be controlled by the workman in any appreciable degree. In some industries the quality of the output is a matter of fundamental importance; in others it is not; and in yet others the workman cannot affect the quality.

The system of assigning a task to a group of men and paying so much for the whole job may be called "the system of group piece-rates". It has met with marked success in many undertakings. An important condition of its success is that each group should be limited in size, so that the individual 
incentive may be strong and the influence exerted by each person on the collection of persons may be penetrating.

Sliding-scales are attempts to arrange for the variation of wages with the profitableness of an industry. They have many blemishes both in theory and practice. It is not always feasible to get an index of the profitableness of an industry. The prices of the product serve in an industry like coal-mining, but they do not in industries in which many factors, subject to variations in price, contribute to the product. In the latter industries it is necessary to calculate indices of the differences between the prices of the product and the costs of material and other elements which enter into it. When in addition the product is of several kinds, the difficulty of getting a satisfactory index may be well-nigh insuperable.

There are other flaws in the sliding-scale system. It provides for a slide of wages with the prosperity of the period just before the wages settlement, whereas, naturally, wages are determined by anticipated prosperity. Again, conditions affecting the supply of labour are left out of account by slidingscales. Owing to a difference in the circumstances governing the supply of labour or other factors, it might be that a given degree of profitableness in an industry would tend to bring about naturally one wage at one time and another wage at another time. But the sliding-scale might provide for the same wage on both occasions.

Further, it has to be settled whether a moderately steady wage or a fluctuating wage is most desirable in any given case. I cannot argue the matter now, but I may point out that the question of the economical expenditure of income (see pp. 26-7), and the question of the reaction of each kind of wages on trade oscillations (see p. 335), enter into its determination.

The sliding-scale system used to be extremely popular in England, but to-day it is seldom resorted to. It is hardly discredited, and it might at any time be brought again into 
prominence. It has certainly played a valuable part in the evolution of the settlement of wages. With all their theoretical and practical imperfections, sliding-scales have worked and made for peace. The strength of their advocates has been their emphasis of reasonableness and regard for the interests of all parties. By necessitating the existence of joint committees, sliding scales have brought representatives of employers and employees periodically together, and assisted them to understand one another. If too much is not expected of the slidingscale, if its defects are recognized and it is readily revised as need arises, there is no reason why in certain circumstances it should not prove a happy device. Its use for a time-even its use under inauspicious conditions-may firmly establish a joint committee which will learn to manage satisfactorily without the sliding-scale the matters previously settled in large part by means of it.

Sliding-scales might be described broadly as profit-sharing, because they arrange for a slide of wages with the profitableness of an industry, but the term "profit-sharing" is commonly reserved for the sharing of the wage-earners in the profits of particular firms. Profit-sharing proper tends to win for a business the devotion of its employees to its interests. It is of especial value in those businesses in which such devotion has a high value-where carefulness on the part of the employees of a firm saves waste or consolidates and adds to the firm's connection. It is naturally denounced by organized labour when it undermines the worker's independence, or is so arranged as to enable an incompetent firm to survive at the expense of wages. Reference should be made to what I have said of labour co-partnership on pages 137-8.

Methods of industrial peace.-It has become increasingly the custom for trades to have joint wages boards, representative of employers and employees (and perhaps with an impartial chairman), which meet periodically, or when need 
arises, for the purpose of discussing proposals for altering wages or the conditions of labour. These boards educate both employers and employees, so that failures to agree become less common. Members of the boards learn to keep their tempers and concentrate their attention dispassionately on the points at issue. Where there is a joint board it is understood that there shall be no strike or lock-out before the matter in dispute has been laid before the board.

But all trades have not got joint boards; and few joint boards are constituted under an agreement which provides for a compulsory resort to arbitration. And disagreements about wages and the conditions of labour rapidly generate heat, which frequently causes strikes or lock-outs before negotiation has had time to reach a settlement. Hence general conciliation boards and mediation by persons of influence have been tried with success. The good mediator does his work by inducing the interested parties to debate points again in a spirit of patience, and keeping them negotiating until they hit upon a working agreement. He may offer fruitful suggestions, propose compromises and plead his views without seeming to push himself into the position of an arbitrator. Within recent years every leading country has taken steps by. legislation or otherwise to promote methods of industrial peace.

Turning to arbitration proper, we must draw a dividing line between the interpretation of existing contracts and the arrangement of new labour contracts. In the case of the former no fundamental objections can be raised against a general resort to arbitration. If the contract is held to have implied what one party never really intended, at the proper time the contract can be set aside. In Germany and France there have existed for many years industrial courts for the settlement of most disputes of this kind, and other disagreements of a trivial character. 
Arbitration when new contracts are being proposed is more awkward. The questions in dispute are indeterminate from the legal point of view. Yet it is frequently better, if conciliation fails, to refer the matter for decision to some person with wide experience, sound common-sense and an impartial mind, rather than to incur the loss and suffering which a strike or lock-out would inevitably entail.

The prohibition of strikes and lock-outs and compulsory resort to the decision of a majority of a wages board, or to the pronouncement of a judge or arbitrator, is being tried in New Zealand and Australia. It remains to be seen how it will work in the long run. One difficulty is naturally the enforcement of awards if they are resisted. Another, which would be more serious in a large industrial country such as England, is that wages might be thrown for long periods out of relation to the relative demands for different kinds of labour, so that the responsiveness of the productive system to changes in consumers' demands would be debilitated, and enterprise and the investing of capital would be discouraged. In fundamental industries, upon the steady activity of which the whole community is dependent-for instance transportation-there is most to be said for the system of compulsory arbitration.

Drastic action is another matter where the conditions of labour are wretched, and where the forces which ordinarily ensure that the conditions of labour shall be at least tolerable are operating only very feebly. Anti-sweating wages boards with unusual powers may effect more, directly and indirectly, than some critics have foretold. 


\section{CHAPTER XXIX.}

\section{UNEMPLOYMENT.}

Causes of unemployment.-Our argument hitherto has gone to show that it is the impulse of human wants which is directly and indirectly responsible for the employment of labour. And since human wants as a whole may be regarded as insatiable, there is no end to the demand for labour. How comes it, then, according to this theory, that anybody is ever unemployed against his will? The answer is, because the social system works against friction, because the co-ordination of its parts is imperfect even under the most advanced conditions, because the trade cycle is a fact to be reckoned with, because some trades are seasonal, because wages in some callings may be inappropriate, and because some labour is inefficient.

The causes of unemployment, including under-employment, may be divided into the subjective and objective. The chief of the subjective causes are physical, mental or moral defects. These may be inborn or acquired, and curable or incurable. One of the conditions most unfailingly creative of the sort of character which makes for unemployment is the undirected drift of the rising generation into wage-earning. When the start in life is ruled in the main by chance, many young people are drawn into paths in which they neither undergo training nor learn discipline.

Among the possible subjective, or semi-subjective causes of temporary unemployment in a trade, we must reckon the 
successful insistence of the work-people on a wage at which, as it eventually transpires, all in the trade cannot find work. The work-people may over-estimate the demand for labour. Mistakes of this kind are inevitable from time to time, but when discovered they can be rectified.

The chief objective causes of unemployment, or under-employment, are as follows: (1) trade cycles, (2) seasonal demand, (3) seasonal supply, (4) industrial changes which are neither cyclical nor seasonal, (5) the system of casual labour, (6) the social time-lag.

Trade cycles have already been described and explained. Periods of business depression recur after more or less regular intervals. When business is depressed employment is not offered for all the labour of the community, and at such times some industries tend to suffer more than others. We have already discovered grounds for trusting that in the future the range of trade oscillations will be restricted.

As regards the present effects of the trade cycle, there are other points to notice. Trade unions may aggravate its bearing upon unemployment by trying to keep wages up when demand is dropping down. They may choose more unemployment in preference to lower wages. And it may be that, so acting, they further the interests of their members and administer a check on the trade cycle. When difficulties are put in the way of reducing wages at times of trade depression, some employers may be persuaded to make greater efforts to keep business steady. On the other hand, if wages rose as trade expanded, over-trading would be directly retarded. These difficult matters of policy I cannot adequately discuss here.

Many trades are seasonal, but the slackness does not always come in the winter. Colliers are least in demand in the summer, and the printing trades meet with seasonal depressions just before and after the publishing seasons. As other 
examples of economic irregularity which is seasonal, we may take the periodic demands for labour for gathering in and shifting harvests; the climatic impediments in the way of the building trades in severe winters; seasonal demands for muslins, furs, and other articles of clothing (partly determined by weather); and other demands which are socially seasonal.

The causes of trade seasonality are natural or social, and the natural may operate on the supply of things or on the demand for them. The seasonal limitation of the work to be done in certain industries, which is met with when natural causes affect the conditions of supply, is ultimately irremovable. When the cause is seasonal demand, which is traceable to variations in weather, it is possible to meet it by continuous production. Seasonal demands for clothes only necessitate seasonal production because of the caprice and domination of fashion (which may become less), and the impossibility of completely anticipating fashion. If the cost of irregular work gets relatively higher, far-reaching anticipation of demand will become increasingly the rule; and we have learnt that the cost of irregular work is rising.

No appreciable distress should be periodically suffered by the wage-earners in the seasonal or vacational trades. The nature of these trades is known, and they should naturally be shunned by the rising generation unless the wages paid in them are relatively high. It must be recognized, however, that, in consequence of the vagaries of weather, exceptional degrees of seasonal unemployment occasionally catch us unawares; and also that much seasonal unemployment means at least a wastage of producing power.

Industrial rearrangements are constantly being made as a result of changes in methods of production on the one hand and in demand on the other hand. When a change takes place in the demand for things it is reflected in the relative demands of different industries for labour. Ordinarily, when 
the relative numbers in an industry must be reduced, wages suffer a decline, the industry becomes less attractive, entries fall off, and the industry dwindles automatically without the dismissal of many operatives. More often than not changes are brought about tardily as a rule on the side of supply, because plant does not wear out rapidly, and new ideas are not readily taken up and are not as a rule economical just at first; while in demand revolutions are practically unknown. Moreover, though an operative dismissed from one industry cannot turn to any calling, he is employable at once as a rule within a limited range of occupations. If the demand for cotton goods shrank suddenly to such an extent that some operatives had to be discarded, they could turn to the linen or woollen trades, were there room for them, as there might be seeing that a decline in one textile trade would in all probability be accompanied by an expansion of some other. It is sometimes overlooked that the contraction of some industries, which is not attributable to a diminishing population, must inevitably involve the growth of others; and that if the former must discharge adults, the latter must obtain additional adults who cannot be already specialized at the new work which they take up. In view of industrial changes, the importance of encouraging a high degree of adaptability in labour will be realized.

The casual labour system means engaging people for particular jobs which do not last long instead of providing them with regular work. The jobs are scrambled for and more people are drawn into the scramble than can be employed. Many persons who are prone to slackness like, or drift into, work of the casual kind; and many who take to it succumb to slackness, and irregularity in the provision of work is consequently encouraged. At each place where the jobs are apportioned out, casual labour tends to congregate at least in sufficient numbers to meet the maximum demand 
of that place, which actually may be seldom reached. A large proportion of the problem of unemployment is the problem of casual labour.

When abstraction is made of cyclical and seasonal unemployment, of casual labour and unusual industrial readjustments, also of the unemployable and the lazy, there still remains a percentage of unemployment which is never wholly absent. The cause of this residual unemployment is the social time-lag, which operates also in keeping high the percentage of unemployment ascribable to trade cycles and other causes already analysed.

The social time-lag is measured by the period which intervenes on an average before a workman who has left one post gets appointed to another. Ordinarily this period is more than appreciable. The new opening has to be found, or made, and some employers may be tardy in taking steps to meet an increased demand. The period of the time-lag is lengthy when bad trade prevails. It varies; too, with the character of the labour and with the economic features of the country. Possibly it is shorter in the United States than in England, despite the lower density of population in the former country. It is obviously reducible, but it is not wholly removable. If it were zero the percentage of unemployment of the employable, apart from casual labour, in times of normal trade, should be zero. Observe that owing to the existence of the social time-lag over and under demand for labour may be experienced at the same time, the former by employers and the latter by employees. When there is such divergence of experience, it is due to the fact that demand and supply are not brought rapidly into contact.

Remedies.-We shall now discuss some suggested means of reducing unemployment.

There seems to be a possibility of curtailing the social timelag through the agency of labour exchanges. As it has been 
already remarked above, we often find at the same time unoccupied labour and an unsatisfied demand for just the kind of labour unoccupied. Yet the two do not readily get into touch. A man who loses his work, if he is not a trade unionist, must, in the absence of labour exchanges, enter upon an undirected search for a place; and not infrequently he must spend time and effort lavishly in discovering one, and suffer a heavy tax in anxiety. The trade unionist is not so badly off, since the trade union is a self-contained trade registry office for its members. But the non-unionists have no organization at all, and I confess to amazement, not at the time that it normally takes a non-unionist to find a new post -which I imagine to be fairly long-but at the fact that he ever does find the post which exactly suits him. His position to-day may be likened to that of a person in a concert hall who has a numbered ticket for a seat which he is trying to find, in the midst of a crowd similarly engaged, when the seats are not arranged in any order. And when a trade unionist wants, or is compelled, to change his trade, he is in as awkward a plight as the non-unionist. Moreover, people in work who could better themselves are frequently unable to do so, because they are ignorant of its being possible, and are occupied at the only times when effective inquiries can best be made.

The economic gain which is caused by reducing the social time-lag, and making effective the latent trade and geographical mobility of labour, should repay liberal expenditure upon labour exchanges. I shall notice later the argument for State action in relation to them.

The system of the Labour Exchange can be applied to children on their leaving school. Its application to them directly, or through their parents or guardians, is at least as important as its application to adults. When applied to children it is desirable that advice should be tendered with information. And it is desirable, too, that this advice should 
relate also to the continued education of children after they have left school, in view of the careers which they have chosen, so that more of them may benefit from continuation training, where it is not compulsory. How much economic waste, I wonder, is attributable to the misplacement of people in the social system, or their lack of proper preparation for their positions, and to what extent could it be avoided, were information and expert direction readily available at the critical time in people's lives!

The labour exchange system can be applied to minimize the evils of casual labour. The prime need is that the casual labourer should get more regular work. Special exchanges have been set up at some docks, so that labour can be directed at once to the places where it is most in demand. Also systems of insuring priority of employment to regular dock hands have been tried. The regular dock hands are thus provided with more continuous work and the casual hand is discouraged.

As regards the treatment of the unemployment caused by trade fluctuations, particularly those which make up trade cycles, there are two outstanding proposals. The one is to encourage the system of spreading the reduced demand for labour over all in the affected trades; the other is to make the public demand for labour compensatory as far as possible.

The spreading of temporary unemployment by the running of an industry short time, or by working with short-time shifts of labour, is eminently commendable from the point of view of the work-people. It is obviously better that all the operatives in an industry should earn less money a week than that some should earn nothing at all, if aggregate wages in the industry are no less or barely less in the former case. It is possible that such spreading of unemployment will become more common.

Probably much of the demand of public authorities for 
labour could be made to vary inversely as the trade cycle without great trouble or loss. Whether in addition it is desirable that work which would not otherwise be undertaken should be started by public authorities, is a question about which there is much difference of opinion. If such work is provided, when it is selected its usefulness. should be taken into account, so that the waste involved may be as small as possible; and the work should be properly organized and carefully supervised. But here we are encroaching upon a matter of public economics.

Among the proposed remedies of unemployment we must notice those which bear on the subjective side of the problem. Home labour colonies, widely interpreted, are of use in the solution of the problem of unemployment, if properly specialized to different purposes, $(a)$ for the reformation, or at least retention, of drunkards, vagrants, and other idlers and loafers, and (b) for the restoration of those who have become unemployable through physical unfitness, but are curable. These colonies need not be wholly, or even mainly, agricultural in character. Apart from such institutions, and in connexion with them also, training establishments for those who need training, either to become efficient in their trades, or for the purpose of changing their trades, if the change is needful, cannot fail to be of service.

Means of mitigating the distress caused by unemployment.-The provision of some useful work by public authorities when trade is bad is in part a means of reducing unemployment and in part a means of mitigating the distress caused by it. Saving is another, and the most obvious, means of mitigating the distress caused by it. Unemployment is not so grave a mishap to those who have saved. To those who have not saved it means privation, the breaking of old habits, perhaps reduced efficiency, and possibly a permanent fall in the social scale. Saving, with a view to the chances of 
unemployment, through the agency of associations if possible, is, therefore, to be encouraged.

But we must not suppose that it is a simple matter to organize insurance against unemployment, except through such institutions as trade unions. Risks of unemployment do not happen to be evenly spread over all trades, or all persons in the same trade. And it is awkward to determine in each case the point at which slackness in seeking work becomes negligence which should be penalized. Moreover, disagreements can easily arise over the wage at which work must be accepted or unemployment benefits be sacrificed, and over the nature of the work which must be accepted by those drawing benefits. Obviously a fair and effective insurance scheme is bound to be complicated and must be administered with acute discrimination. Trade unions are peculiarly well equipped to undertake insurance against unemployment, because they determine the wage which may be accepted; because they wield a certain authority over their members and find them places which they are expected to show reasonable ability to keep; and because they are organized by trades. When any public authority subsidizes insurance against unemployment, the objection, which is apt to be felt by the more employable workmen, that they are paying in their premiums for their own risks of unemployment, and in addition for a part of those of the less employable workmen, can be mitigated or removed. 


\section{BOOK VII.}

\section{PUBLIC ECONOMICS AND PUBLIC FINANCE.}

\section{CHAPTER XXX.}

THE STATE IN RELATION TO BUSINESS.

Classification of State action which is economic.Public economics, apart from public finance, is concerned with the function of the State in relation to economic activities. It is not a part of economic science. It is the section of normative economics which overlaps normative politics, combined with so much of the art of political economy as falls within the bounds of politics. On pages 2-8 explanations are given of the distinctions just laid down. Inasmuch as modern communities are broken up into many political parties, the subject of public economics is highly controversial, particularly on the fringe. Where it is, my aim will not be to recommend the designs, or defend the achievements, of any particular school, but to make as definite as I can the points at issue.

I may start by classifying the State activities which I have in mind into (1) those which have more or less reference to business (producing and exchanging), though they may have an important social bearing; and (2) those of which the primary justification is widely social, though they may have an important economic bearing. The division is not strictly 
logical, but it will serve a useful purpose. In this chapter the former will claim our attention.

The State may function with reference to economic activities $(a)$ by controlling them; (b) by encouraging them; (c) by undertaking them itself. Control may be called for when private enterprise is not lacking in vigour, but is apt to do damage incidentally. Encouragement may be needed when private enterprise falls short of furnishing what the community wants. Finally, there is prima facie a case for the undertaking of certain enterprises by the State when control or encouragement is needed, but is costly or fails, and when the State happens to be an effective producing instrument. There are also certain other reasons for State initiative. By the State is meant here the central government or local governments.

The need for supplementing private enterprise.I may now proceed in a very general way to particularize the more obvious faults of omission and commission, on the business side, of a system wholly competitive.

(a) There are certain businesses which are bound, or almost bound, to get organized as monopolies. When so organized, I have dubbed them "social monopolies" (page 139). In the provision of gas, water, and urban transportation we have examples. In these and like matters, the choice of the community lies between conferring a monopoly upon a company and public management. And in other allied cases, though monopoly is not so inevitable, centralized management of the service may be the most economical. If private monopolies are suffered, there remains the baffling task of so controlling them that the work will be done well and not charged for exorbitantly. Nevertheless, it is not hard to imagine circumstances in which the best results are achieved by delegation of some of these functions to a company. Much depends on the efficiency of the governmental agencies. 
Of the social monopolies, or semi-social monopolies, generally, or largely, assumed by central governments, postal services may be singled out for special mention. Railway transportation may be placed apart, as the question of the State in relation to it is still contentious. But where the State does not manage the railways it regulates them on the ground that they are semi-monopolies, and that they provide what are necessities to an advanced community. Into the railway problem military and social considerations may also enter as important elements and prove the determining factors. To railways I shall have to refer again.

(b) Certain productive functions have been subsidized or assumed by the State because of the suspicion, or conviction, that the incentive of private gain fails to insure provision of what is wanted even when its provision would pay.

It may plausibly be maintained that individuals in their business transactions will not be swayed by the supposed effect of their actions upon the unborn successors of a generation yet unborn, but that when these same individuals deliberate together as representatives of their nation they will naturally take the national point of view and think of distant goods. In order to meet these remote claims, it is argued, therefore, that the nation must act through its Government. Examples of State undertakings which have arisen from doubts of the adequacy of private forethought are to be found in afforestation and the checking of coast erosion. Other partial illustrations are furnished by certain railways which were originally started by Governments, or subsidized by them, in order to hasten economic development, and were defended on the ground of the effects which they would bring about after many years. The same lack of confidence in the attractive force which a distant future exerts upon the individual will, also accounts to some extent, as we shall see later, for the protective foreign trade policies of certain countries. 
Another group of cases is found where extensive organization, and much concerted action, is needed to achieve the desired end, and where private inducement is not strong enough to make it probable that the requisite measures will be taken. The undertaking may be very costly and troublesome, like the inter-linking of internal waterways, or its benefits may not be commonly realized and may be widely - diffused, such as those conferred by experimental agricultural stations.

(c) We may suitably place next in our catalogue certain purely economic services which in private hands would never yield a revenue, but which, nevertheless, it would pay a community to furnish itself with. There are services from which a very large consumers' rent (to put it technically) could be reaped if they were obtainable at reasonable prices, but services, the demands for which, and conditions of supply of which, are such that no possible charges could cover the cost of the outlay entailed in their provision. These services the State may secure for the public by producing them itself or subsidizing private endeavour. No doubt portions of many railway systems, and many bridges, exemplify the case in point.

My mention of bridges may lead you to inquire why no charge is made for the use of most public bridges, and public roads which are in the same category. No fees are exacted because of the great inconvenience caused to the public by the collection of tolls, and because the gratuitous use of roads and bridges does not result in wasteful reactions of an appreciable amount. The gratuitous offer of motor-cars on demand would be of quite another order. If motor-cars could be hired for nothing, and their supply was such that anybody could get one when he wanted it, we should have to be taxed very heavily to cover the cost. So we should be prevented from buying what we would rather have than unlimited rides in motor-cars. 
Under this heading we notice the increase of consumers' rent which can theoretically be brought about by encouraging in some degree industries subject to increasing returns to the discouragement of those subject to decreasing returns. The gain emerges from the circumstance that the larger output of the former industries reduces their costs of production and that the smaller output of the latter industries reduces their costs of production. You must not run away with the idea, however, that it is bound to be beneficial to tax the latter industries in order to pay bounties to the former. To do so might be to place a burden on the poor, in order to make living cheaper for the rich. It is highly questionable whether the State can ever produce benefit in this way to any substantial extent; but it might be possible to find partial examples in certain unremunerative municipal undertakings.

The theoretical point raised in the above paragraph may be illustrated geometrically with the aid of diagrams, like those on page 395, to which, however, you had better not refer till you have read Chapter XXXIII. In fig. 20, if $S^{\prime}$ is the original supply curve, the output can be raised to $\mathrm{O} a$ by a bounty of $d h$ which means an outlay of $d h \times \mathrm{O} a$. The gain in consumers' rent would be $e d c f$. By taxing the thing to which fig. 19 relates, which is produced according to decreasing return, a sum $d h \times \mathrm{O} b$ could be obtained at a loss of consumers' rent of $e f c d$, if $\mathrm{S}$ is the original supply curve in fig. 19. If figs. 19 and 20 are drawn to the same scale and $d h \times O b$ (in fig. 19) equals $d h \times O a$ (in fig. 20), it is at once apparent, subject to the qualifications stated above, that in this case taxing the thing subject to decreasing returns, and paying the proceeds as a bounty on the production of the thing subject to increasing returns, would result in a gain of $e d e f$ (in fig. 20) less e d c $f$ (in fig. 19).

It is not essential that the bounty-fed industries should be subject to increasing returns and the taxed industries to decreasing returns, though in such a case the gain tends to reach its maximum. There may be a theoretical gain when both sets of industries are subject to increasing returns, provided that increas- 
ing returns are more strongly marked in the bounty-fed industries ; and also when both sets of industries are subject to decreasing returns, provided that decreasing returns are more strongly marked in the taxed industries. A final refinement of theory can be introduced when we allow for increasing and decreasing returns with reference to aggregate costs in whole industries (pp. 104-5).

(d) There are cases in which a private gain is made at the expense of a heavy economic loss to society. A trust, or other voluntary combination, may exploit the public; and the perpetrators of certain acts on stock and produce exchanges in enriching themselves may cause widespread damage. In these cases it is transparently the State's duty to consider whether it cannot protect the community by exercising some control.

(e) There are cases in which private initiative is not effectually induced by competition to produce satisfactory qualities of what is wanted, either because of the ignorance of consumers, or because of the difficulty which consumers experience in trying to determine the quality of what is supplied, or for other reasons. Hence, when the purity of the supply is a matter of importance, it is usual for the State to take special cognizance of it; but it may be able to attain its ends merely by inspecting, and penalizing the practice of adulteration and the selling of inferior goods under false or misleading designations.

In this connexion we may notice the currency. Uniformity in a country's currency is essential, and the prosperity of a country is so directly dependent upon its possessing a sound system of currency, and good coins which will always be above suspicion, that fow would venture to deny that it is best for the Government to issue all coins itself.

The matter of the provision of media of exchange brings in its train a complex of momentous problems. As you know, credit media of exchange and the activities of banks have become an integral part of the machinery whereby exchanges 
are facilitated. Some States, therefore, have issued notes themselves as well as coin (partly for the sake of profit), and some States have undertaken the office of banking. Other States, however, have been content to regulate the note issue and otherwise control banks.

$(f)$ There remain cases in which States have controlled, subsidized, or undertaken some form of production, broadly regarded, for reasons which are not in any substantial degree economic. The maintenance of armaments will at once occur to you.

State industries.-There are some to-day who would like to witness a vast extension of the State's purely economic exertions. They have been encouraged in this view, or it may be persuaded to it, by the triumphs of democracy of late years. The reflection, however, that a system which works well enough in politics might not work well as a rule in business should impose a check on hasty decisions. Perhaps the most important function in both politics and industry is performed in the selection of directing heads. In politics this selection must be conscious and deliberate. There is no alternative; and it may be that choice so exercised turns out to be ordinarily appropriate in view of the services required of representatives in Parliament. But there are grounds for apprehending that the general substitution of some like system for the existing natural selection of leaders in the economic field might prove calamitous (see pp. 132-4). Moreover we must not be forgetful of small economies, which in the aggregate may reach stupendous sums, and which are apt to melt away when private inducements are eliminated from a business. Again, there is the matter of driving force. Can we be sure that this is not weakened when State action is substituted for free enterprise? Thorough-going State management-especially when carried far into the lives of the people-might turn out a neat business economy and a well- 
behaved community; but it is not the docile who seek adventures at home and abroad, push on to new things and create lusty colonies. Further, in invoking the machinery of the State for economic objects, we must bear in mind that, owing to difficulties in selecting leaders and in other ways, the State might be less responsive than the competitive system to individual needs. Inappropriateness of production is bound to have a depressing effect upon the community, and is consequently apt to produce stagnation.

We should do well to bear in mind that the inventions which created many of the undertakings now assumed by not a few public authorities arose under competition. If the assumption of a business by local or central governments should remove a field of invention from competitive influences, the State would act prudently in proceeding very tentatively. This difficulty, however, is less than would at first appear. If all electric trams were run by local authorities, competition would still rule in the electrical industry which provided them with their plant and accessories.

The considerations advanced above are not equally weighty with reference to all economic activities. In the case of some they may be negligible. And, on the other hand, we must not overlook the elimination of waste which frequently accompanies the unification and systematization of some industry when the State undertakes it. We must ask, with reference to each proposal, whether the gains are greater or less than the losses which may be incurred. Nobody can affirm dogmatically of the present, and still less of the future, where exactly the advantageous limits of the extension of the State activities of any community lie.

The distribution of productive functions between the central government and local governments scarcely calls for remark here. It must obviously depend upon the efficiency of each and the localization of the service in question. 
State control.-Whether the State should assume responsibility for running any particular business or not, must depend upon the other courses open to it and the prospects of their success. Of these State control is one. And the difficulties of State control are frequently great. Imagine a country nervously anxious about its banking reserves and attempting to frame rules for their prudent management. It would most likely find-as States which have dealt with this matter have found again and again-that the rule which yielded an advantage of one kind stood in the way of advantages of another kind. If it wanted to sacrifice nothing, it might soon have such an unworkably complex system of fundamental regulations, and regulations providing for exceptions, that it might reasonably decide to take over the work itself.

The difficulties of State control have been felt in particular in relation to monopolies. Whether their formation can be stopped or not, when they are voluntary, remains to be seen, and also, it may be added, whether it is desirable always that their formation should be stopped. And, as we have seen, some monopolies, which we have called "social monopolies," are inevitable. Given the monopoly, how can the community be protected against exorbitant charges, and a minimum of efficiency in the conduct of the business be enforced? Confiscation of profits above a certain maximum prevents profits above that maximum from being earned. Yet consumers may be no better off, since carelessness of management, instead of low prices, may explain why net earnings are no greater than they are. One ingenious device is to link prices to profits and insist that as profits rise prices shall fall according to some fixed rule. But even this device labours under the defect of permitting excessive profits or diminishing the inducements to economy and a progressive policy. Rules, too, have a way of becoming obsolete. The only control which is 
thoroughly scientific is that which is the outcome of continuous experience of the business to be controlled; but unfortunately it involves duplication of management. Duplication of management is wasteful, and it divides responsibility and so runs the risk of leaving nobody responsible. The difficulties which are frequently found to lie in the way of the inspection involved when State regulations are imposed, are too obvious to need dwelling upon.

I am not desirous of leaving the impression that control is impossible. Where control has limited objects in view, it may achieve what is wanted with a minimum of disadvantage. But we must realize that, as State management has its défects, so has the alternative of State control.

Bounties or subsidies. - At the one extreme the State is frequently called upon to bridle private initiative. But, as we have observed, at the other extreme private initiative fails to respond, or to respond adequately, to the wants of the community. The need at the latter extreme is State encouragement, if the State decides to enlist the forces of private initiative instead of undertaking the work itself.

The State may encourage businesses positively or negatively. It encourages them positively when it subsidizes them. It encourages them negatively when it protects them against competition, and so ensures them a market. But in some cases protection against competition is futile, either because there is no competition, or because the protected business is still left unremunerative. With protection I shall deal in the next section. Our present subject is to be bounties or subsidies.

The bounty has assumed many forms. A guaranteed minimum of profit is one form. This has been criticized as economically unsound, because no inducement is left to the enterprise to make as much as it can. But in some circumstances it may be advisable. Capital may be most easily obtained when interest is guaranteed, and much capital may 
be wanted, and the enterprise may be one from which great public utility will be derived. Again it may be desirable, for social or political reasons, to attract the capital of small investors and so secure their interest or good-will. Guaranteed profits may be the most enticing offer that can be made to such people. This is one ground upon which the guaranteeing of the dividends of railways in France has been defended. We may, however, conclude that a subsidy which varies directly in some way with the quantity and quality of the work done is best, other things being equal.

Bounties on export, if the industry to be encouraged can export, have the recommendation of being cheaper than bounties on output. ' But they have the obvious disadvantage of persuading producers to attend more to their foreign markets than to their home markets.

The worst of all State encouragement of business, both positive and negative, when the State encouragement must be continued for an indefinite time, is that vested interests are created by it. But sometimes temporary assistance is all that is needed. An industrial system, driven by the spring of self-interest so-called, is in parts like a cheap watch. The spring of the cheap watch may be strong enough to keep the works going, but, after winding, the watch may want shaking to make it start. So temporary stimuli may be requisite to get parts of the industrial system to work. Ordinarily there is no difficulty in administering the fillip which is wanted. For suitable purposes the State can furnish loans at a low rate of interest, or even make a contribution to capital expenditure without asking for repayment.

Protection, fair trade, retaliation, and reciprocity.We have examples of protection in patents of inventions and copyright. This protection, which lasts only for a limited period, pays the community on the whole, because in its absence the monetary proceeds of inventing or writing would 
be paltry and the best way of insuring that people shall produce what is wanted most is to allow them to get an adequate share of the value of what they produce. The same kind of protection has been tried outside the fields of invention and authorship. Trading or industrial privileges have been conferred on certain persons with the object of promoting particular businesses, or for other reasons. Protection of this type frequently leaves the State with an awkward problem of control to solve.

The most famous, and the most hotly debated, form of protection is that which encourages home industries by placing restraints on foreign trade. The question is an immense one. We must, therefore, content ourselves with a hasty glance at some only of its most conspicuous features.

The arguments urged in favour of protective import duties relate to political as well as purely economic ends. Some of their advocates think almost exclusively of political ends. Nationalism on a broad foundation, with all that it implies, is what they hope to foster. An examination of this notion would carry us too far afield, and raise issues remote from the confined objects of the present treatise. Suffice it to say that a careful investigation of the plea for protecting infant industries and declining industries reveals arguments for and against. There are cases in which infant industries would flourish without protection, and cases in which they would not. But protection of industries should ordinarily hasten their development. And it would not be desirable for a country that international division of labour should be carried to such an extreme that it, the country in question, would be restricted to the narrow economic life of providing little else than food and raw materials on the one hand, or certain manufactures on the other hand, for itself and the rest of the world. But it must not be assumed that, in the absence of protection, international division of labour would be carried 
to this extreme. Of course immediate economic loss almost inevitably results from imposing import duties (see pp. 396-9), but there may be an ultimate gain.

It must be recognized, however, that whenever and wherever a country encourages the home production of things which can be imported, it runs the risk of getting industries unsuited to its conditions established, or getting certain industries established on an unsuitable scale. Moreover, it may learn to its cost that it is as difficult to effect the removal of the protection, intended only for infant industries, from those which have reached a lusty maturity, as to effect its removal from those which remain weaklings and are parasitical on the community. Further the contention of persons who plead that foreign competition has a bracing effect on economic life, of which few countries can afford to discard any portion, is not to be lightly dismissed. And, finally, the fear lest the public be sacrificed through the operation of sinister interests and the agency of corruption is not baseless, much human nature still being what it is.

Just as protection can be applied to a country, so it can be applied to the larger unit consisting of the country and its colonies, when it possesses colonies. And for this kind of protection political considerations may be the dominant ones. The idea is to introduce greater unity into the colonial empire by giving it an economic as well as a political foundation. It is argued that the bonds uniting the mother country and her colonies are tightened when trade within the Colonial Empire is accorded privileges not enjoyed by other commerce touching any of its shores. Opposition has run along two lines. Some. persons admit a certain or probable gain, but contend that the loss involved in surrendering a substantial part of the economic advantages derived from trade with foreign countries far transcends it. Others refuse to recognize any element of gain. They dwell upon the possibilities of quarrels within the 
Empire over business matters, and argue that the industrial development of the colonies must be retarded under the scheme unless the preference is to be practically valueless to the mother country from an economic point of view.

Of late years protection against a special kind of foreign competition has been demanded, namely, against dumped goods. Dumping has been fully explained on pages 179-81. Dumped goods are said to disturb home industries. The reply of those who object to anti-dumping tariffs takes more than one line. It is maintained that dumping is insignificant in comparison with trade of an ordinary kind, and that its effect is trivial. It is argued also that the importing country gains the cheap dumped goods; but it should be noticed, as regards this reply, that they are not very cheap since they need not be sold for appreciably less than home products. It is contended further that the dumped goods cannot easily be distinguished from others of the same kind, and that duties on all goods, whether dumped or not, might entail enormous loss, and would largely fail in their object, because, ex hypothesi, the dumped goods would still be sent even if they were to realize much less.

Upon the question of the right commercial policies for different conditions, the views held are numerous. At the one extreme are Free Traders who admit of no exceptions. At the other extreme are thorough-going Protectionists who believe in placing a barrier against all foreign competition. Midway are those who believe in what they call "fair trade". They grant that universal free trade would be best for all, at any rate after industrial development, had reached a certain level, but they argue that a free trade country in the midst of Protectionist rivals must lose. Their position is by no means unassailable, but into the technical minutia of the points debated we cannot now enter. Some persons hold that a flank attack on protection with the weapon of protection, that is 
retaliation, is calculated to improve a country's trading prospects. Such open tariff wars as have broken out have damaged heavily all parties engaged in them; but the fear of retaliation may, of course, keep restrictions on commerce within bounds.

Reciprocity is different from retaliation in that it proceeds by mutual concessions. But in the tariff bargaining which has been conducted of late, reciprocity has been hardly distinguishable in essentials from methods more overtly bellicose. The first drafts of tariff measures may be intended to threaten. In so far as they are, retaliation usurps the place of reciprocity. Each nation in effect declares in this event what damage it is prepared to inflict if its wishes are not met.

In tariff laws the interests of free-trade nations are safeguarded by the most-favoured-nation clause. This clause, as commonly interpreted hitherto, declares that no country's goods shall be treated more favourably than those of the free trade country. It has been argued that a free trade country might in effect, nevertheless, be discriminated against if tariffs were made so detailed that the peculiar qualities of goods which it and it alone exported in bulk were taxed at a rate exceptionally high in comparison with the duties on other qualities which competed with the former to some extent, but in which the free trade country did not specialize. Were the mostfavoured-nation clause commonly interpreted so as to exclude free trade nations from sharing in the concessions secured by tariff bargaining, its value, in view of the modern practice of tariff-making, would be but meagre.

Laws to facilitate business. - The question of the general law relating to business belongs rather to the legal branch of social science than to public economics, but a few words may be said of it. Without protection against dishonesty no community could advance far in economic development. Wise laws relating to the limitation of the liability of partners and 
shareholders, whereby enterprise is encouraged ; to bankruptcy, whereby, while the fraudulent are punished and the reckless are kept from inflicting further damage, the unfortunate are replaced in a position in which their efforts are not handicapped ; to company promotion and the publication of certified balance sheets in certain cases; to associations such as trade unions and professional societies-to mention a few instances - such laws promote to an incalculable extent the evolution and efficient functioning of society on its business side. 


\section{CHAPTER XXXI.}

\section{THE STATE IN RELATION TO SOCIAL CONDITIONS.}

In this chapter I have to treat of State activities which are of economic importance but have in the main a social reference, if a somewhat vague expression be permitted.

Factory acts and public health acts.-Regulations of the type of the factory acts are not identical in their bearing on adult males, women, young persons and children; nor is their justification the same with reference to all these classes of workpeople.

(a) I take first the case of adult males. Broadly speaking the ground for State interference is that the knowledge of individuals, or their self-interest or philanthropy, cannot be relied upon to bring about such conditions as an enlightened community feels compelled to insist upon as a minimum. The workpeople in combination may not be strong enough to enforce their will, and all workpeople are not combined. The most high-minded employers are limited in their freedom by the competition of less high-minded rivals. And finally the knowledge and ideals of the bulk of the interested parties, even of those who are anxious to secure the best conditions of labour, may not be such as to insure that they will choose aright.

In the dangerous trades the strongest case for regulation can be made out. In some of these trades certain acts may be a source of physical harm not only to the person who is 
responsible for them but also to his companions-for instance striking lights in coal-mines. There can be no doubt but that people should be protected against the possibility of an individual's acting out of foolhardiness or ignorance in a manner menacing to their lives or health. In other trades the commission or omission of certain acts are likely to prove hurtful only to the parties who perform them or neglect to perform them. Why should the State enforce what is prudent as regards acts of this kind? The State does not punish an inexpert climber for attempting a dangerous ascent which is beyond his powers. The answer can only be hinted at. It rests upon the distinction between the day's work and recreation, and involves the question of how far the individual can be suffered to regard his health and his life as just his own property. Moreover the danger which has to be guarded against is frequently hidden from the less intelligent and least instructed, and even when it is explained to them they may not realize its seriousness. Convincing reasons can be advanced for protecting people against themselves; and they are extensively protected against themselves in many countries.

The rules which I have chiefly had in mind so far are those binding upon workpeople. But in the dangerous trades, technically understood, and in other trades where work of some sorts may involve danger, safety cannot be even approximately secured unless precautionary measures are taken by the employer. Where this is so, and the danger is substantial and not remote, they are commonly insisted upon. When left free, the employer may be constrained by competition to let his workpeople take their chance, or he may not be fully alive to the risks.

We may observe at once that all injunctions relating to public health, whether they bear on workpeople at their work, or occupiers of houses, or landlords, employers, or 
doctors, are covered by portions of the above discussion. Separate examination of hygienic enactments is not therefore necessary.

Excessive hours of labour may undermine health and strength, and in any event they banish comfort. In the light of the foregoing analysis, the reader will understand how in some cases State interference with the hours of labour, in the interests even of adult males, can be justified. But Government in coming to a decision when health is not seriously threatened must have due respect for the liberty of the subject and try to realize all that the exercise of liberty may mean to society in the future.

Prudent regulations in the interest of safety, health, and comfort, may actually increase the product per head in the longirun. And even if they do not, they may be commendable because safety, health, and comfort are things of value. Sometimes, as we have observed, the hours of labour are long simply through defective organization. Time may be wasted, and if it is not, the same work might be done in shorter hours without undue effort (see p. 323).

(b) The argument for such protection of labour as we have been considering is even more unassailable when the labour consists in women and children. Ordinarily women cannot be so strongly organized in trade unions as men. The former are less capable, therefore, than the latter of looking after their own interests. The former also in competing with men, who are naturally endowed with greater physical endurance and muscular power, are terribly apt to commit themselves to excessive exertions. Moreover the vigour, physique, and general health of women, who are or may become mothers, should engage the solicitous care of the community. Upon them the future of the race is peculiarly dependent. It is, therefore, comprehensible why women are so generally excluded in modern communities from certain 
kinds of employment and why their work is more stringently regulated as a rule than that of men.

Some of the special considerations which apply to women workers apply to children and young persons also. And there is this further thought to be weighed, that over-exertion is far more likely to damage the human organism in the early than in the middle period of life.

The cost of inspection, its imperfections and the degree of friction which an excess of it is bound to occasion, must limit to some extent the scope of the State regulation of industry. There is also the matter of the elasticity of rules and their rapid modification, when they are detailed, to suit changing conditions. This matter broaches the question which is now beyond us, of the place respectively of statutory direction and direction by administrative order in a scheme of industrial control.

The State in relation to wages and employment.Wages constitute one of the chief elements determining the conditions of labour, and in most countries the State has taken cognizance of the wages contract.

By Truck Acts employers are prevented from paying wages in forms which may lead to the workman's being defrauded of some part of the income to which he is entitled. No special justification is needed. These acts simply prohibit contracts which were found to work in many instances to the detriment of employees. Other contracts which bind labour for immoderate periods have likewise been set aside by law.

1 We have already observed (pp.331-3) that many advanced States have legislated with a view to preventing the disastrous strikes and lock-outs which periodically remind us how incomplete our civilization still is. The ground for State action is the failure of competition to insure industrial peace. Some 
reformers despair of competition in this matter and contend that wages ought to be determined authoritatively by legally constituted Boards or Courts, as they are in New Zealand and Australia. The objections which have been urged against compulsory arbitration and similar plans have been noticed on page 332. When the State is the proposed arbiter, it has been maintained, in addition, that political dangers might succeed and social reactions of an undesirable kind. Self-government, self-direction of one's life, self-settlement of one's wages, are said to be beneficial, not necessarily because they are likely to produce the best immediate results, but because they develop self-reliance, watchfulness and foresight, and strengthen the springs of action in individual wills, which are the ultimate guarantees of social vigour.

To conditions which are abnormal, for instance to "sweating," "these reflections cannot be said to apply.

There is a difference, which by many is held to be of great significance sociologically, between doing something for a person and removing obstacles which prevent his doing it. In the one case there is complete transference of responsibility. In the other case the final responsibility is left with the individual, but impediments which confine his real liberty of action are removed. Impediments serve their purpose, but, when every conceivable reform has been carried out, quite a sufficiency of impediments for our proper discipline will still remain in all probability. We have seen (p. 339) that obstructions innumerable have to be painfully surmounted by many persons when they are seeking work. Forcible arguments have been adduced in support of the view that nothing short of a national system of recording the demand for and the supply of labour, and of disseminating information about them, will fully meet modern industrial requirements. Inasmuch as the development of such a national system out of individual initiative within a reasonable time is much to hope 
for, the State can hardly be recommended to stay its hand. The bearing of labour exchanges on unemployment has been noted (pp. 338-40). Action has already been taken by Government in England and Germany. Its outcome will be watched with the keenest interest.

The provision of work by the State-apart from the provision of work entailed when the State naturally assumes responsibility for the conduct of certain industries-raises fresh issues. What the State should do, if it should do anything, must obviously depend upon the degree of success achieved by the competitive system in keeping a community fully active productively. In inquiring in Chapter XXIV what this degree of success has been, we were confronted with the phenomenon of the trade cycle. There is no doubt but that in the recurrent periods of bad trade, such dislocation of the connexions between the consumption and the production of wealth is suffered, and such paralysis of enterprise, that much employable labour is left in a state of enforced idleness. In view of this unassailable fact, and of the present state of providence and the present level of wages, it has been contended that the State should not only positively encourage, and even subsidize, insurance against the unemployment which is unavoidable from the point of view of labour (with which we shall deal soon), but also find some work for those most in need of it. In so many cases, work is even more necessary than wages because demoralization is caused by long periods of idleness and hopeless searching for jobs. It is maintained

- by some that for very many years to come it will be necessary for public authorities to start undertakings in times of bad trade which need not have been entered upon but for the existence of an army of unattached labour-that it will be necessary to do this in addition to so arranging the direct or indirect demand of public authorities for labour that it shall be most intense when business is most depressed, and in 
addition to offering suitable training for any who may be deprived of their trade by industrial changes.

The State in relation to social insurance.-In some countries steps have been taken to secure maintenance for work-people when their earnings cease or are diminished through accident or sickness, and to a less extent when need arises through a temporary dearth of employment. The schemes are so various that it will not be easy to generalize.

The new policy as regards accident exacts contributions from the employer. So some portion at least of the expenses entailed by industrial accidents is compulsorily added to the money cost of production; which seems not unreasonable when we remind ourselves that they form a part of the real cost of production. It is maintained that the gain will be, not only the preservation of many families from want when the wage-earner is badly hurt or killed, but also the eradication of avoidable dangers from productive processes. Businesses which seem to be unfortunate, as regards the number of accidents that take place in them, will probably learn how not to be unfortunate. With reference to sickness, the common principle of the latest reforms is to share its cost between the work-people, employers, and the State. In some countries the financial sources of old-age pensions are similar, but elsewhere, including England, they are paid entirely out of the proceeds of taxation. Insurance against unemployment has so far been handled only tentatively. The general principle is for the State or some local authority to subsidize trade union benefits, or raise a special fund out of public money, premiums from work-people and perhaps enforced contributions from employers. Membership of the fund may bo optional or compulsory.

Some authorities have argued that in consequence of the State's having assumed a large share of responsibility in these matters, work-people will tend to become less provident on 
their own behalf. It is apprehended that they will form the habit of supinely looking to the State at every crisis in their lives, and of assuming that no thrift beyond what is compulsory need be practised. However, there are authorities who, while assenting to the statement that such reactions may be looked for, express the opinion that they will probably be negligible in comparison with the advantages directly conferred. And there are yet other authorities who think that desirable, instead of undesirable, social reactions are not unlikely. They consider that when people are bound to act as they would were they provident, the gain will be nut only the social insurance but also the general acquisition of habits of providence in other matters. The suggestion is thrown out that in social affairs, if effects are insisted upon, the causes that would naturally have produced those effects may emerge of themselves. Let me illustrate with an analogous piece of unsettled practical psychology. Because we tend to smile when we are feeling amiable, we have been advised to cultivate smiling in order to become amiable. This social theory is of profound significance. If it should be substantiated by experience, it will wonderfully simplify the problem of social reform.

As I have already mentioned incidentally, the English old age pensions, unlike the German ones, are not contributory. They have been justified on the ground that luck as well as law governs success in life, and that as, in a sense, all have helped to make the incomes of the well-to-do (since the community works as one productive whole) no serious infringement of property rights is involved in offering small pensions to the aged who have been the least fortunate. But this is not to be represented as the sole raison d'étre for the type of pension which England has adopted. In fact fundamental reasons have been only perfunctorily searched out, generally speaking. English un-introspective opportunism, which shies at abstract principles 
and compromises between practical proposals, is answerable for them to no slight extent. There has been no doubt a widely disseminated feeling of the justice of the point of view which I have already expounded, however vaguely it may have been conceived. But at the same time expectation of saving in the cost of public aid to set against the expense has played its part, and also the hope that the pensions will stimulate providence by rendering the task of providing for old age less hopeless of fulfilment. Our pensions might have been of such a form as directly to encourage thrift by endowing it, or directly to encourage desert by endowing it. But schemes of this kind were assailed with criticisms the nature of which I cannot now analyse; and they suffered in particular from the defect that they made but a faint appeal to the mass of the population.

The State in relation to the proxision of opportunities.-Opportunities are subjective or objective. Subjective opportunities are furnished by the discovery and training of our latent capacities. Objective opportunities consist in the means of exercising our powers.

A community may be regarded as constituted of an inchoate mass of capacity. Experience and theory teach with equal force that the bulk of this capacity will remain undeveloped if individuals are left to fight their own way unassisted, except for the aid lent by relatives or friends, who may be neglectful of their obligations or ignorant of the value of training. It is no longer disputed that the State should provide educational facilities, and further that it should apply the authority which it derives from the community to compel people to be educated to some extent at least. Now subjective opportunities may be intellectual or physical. Of late some public authorities have been drawn into schemes for assuring to more of the rising generation the physical power which is their rightful inheritance. And voluntary associations with this end in view must 
not be overlooked. So far as these schemes mean interference with family life, unwary procedure may be fatal, for the family is the microcosm of the community. In touching the family we are intruding into vital social functioning of so subtle and intangible a character that its very existence is apt to be overlooked. But it is to the interest of the State that the most valuable actualities, mental and physical, should be made of each generation's potentialities-that persons should be turned out into the world physically strong, imbued with the right social motives and with their latent selves developed. In this matter our position bears a traceable resemblance to that of the surgeon who is trying to repair defects in a human organism, and who is occasionally in danger-unless he has a marvellously intimate knowledge of the human organism and the imagination to foresee all possible consequences-of performing operations the direct benefit of which will be more than lost in indirect reactions. Despite, however, full recognition that in the normal home is hidden the essence of what makes the good or the bad in society, we need not share the views of those whose attitude is one of timid acquiescence in the ills that be.

Nobody knows with any degree of exactitude the extent to which in the modern world persons without wealth or influence are enabled to give expression to their powers. Whether there is need for public interest in this matter generally, and whether the State can improve objective opportunities, and should do so if it can, are difficult questions for the satisfactory answering of which much thought and much investigation would be requisite. We may notice, however, that experiments have been made in England with legislation aimed at the adequate provision of small holdings, partly with the object of making opportunities for the more capable and aspiring of the agricultural population. It was maintained that in view of custom, social and legal impediments, cost, and lack of initia- 
tive, small holdings would not necessarily be established even were they economical.

Public provision of the higher social goods and housing.-With the higher social goods, such as parks, libraries and picture galleries, a community can only supply itself adequately when it acts as an organized whole.

The demand for the beautiful city is a part of the demand for the higher social goods. The demand cannot be met without some corporate action. Town-planning has already advanced beyond the stage of discussion. It has a nongovernmental side in garden city and garden suburb associations.

Connected with town-planning on the one side and public health on the other, is the question of housing. Without believing that the State should be universally, or to any appreciable extent, house-landlord for the community, many social thinkers welcome municipal enterprise in housing because a way is thereby indicated, from the national point of view, which can be followed by competition, and must be so followed if municipal enterprise creates a taste which shapes future demand.

Public aid.-The problem of public aid, or poor relief as it has been commonly called, is multiform, and the opinions about it are many. Three leading schools may be distinguished.

1. There are those who think that the aid given should be in the main voluntary; that the State should do as little as possible. They believe in personal charity. The thoroughgoing organization of public aid fosters dependence, in their opinion, and involves an attitude to the indigent which bruises their spirit and demoralizes the charitable. They are distrustful of scientific methods. This school has little influence in America, Germany, and the United-Kingdom, of the leading countries of the Western world. 
2. There are those who believe in the thorough-going organization of public aid, but think there is a danger of undermining the self-reliance of the population. They there-. fore propose that certain principles, which we shall examine, should be acted upon, and that the work of furnishing aid should be divided between the State and voluntary organizations.

3. There are those who, like the second school, believe in thorough-going organization, but do not believe in the gravity of the subtle reactions on character about which the second school is apprehensive. On the contrary they contend that the adoption of certain of the principles recommended by the second school does more harm than good. They want to see the bulk, if not the whole, of public aid in the hands of the State.

Distress is due to many causes, subjective and objective. And all the subjective causes are not attributable to the faults of those reduced to distress. It is urgent, if the right sort and amount of help is to be given, that the causes of the distress should be known. It is also urgent that the capacity of the person in need should be known, if he or she can be restored to partial or complete independence. The special cases of children, the non-able bodied and the aged, we momentarily set aside.

The careful study and separate treatment of each particular case of need is known as individualizing. To carry it out completely an army of workers must be recruited. For this reason, and also to supplement and leaven the official attitude, recourse is had to voluntary workers. Where needful the voluntary workers are intended to influence those in distress for their good. At Elberfeld in Germany this individualizing plan was started many decades ago and has since been perfected. Hence it has come to be known as the Elberfeld system. 
Equally desirable with particularizing, is the adequate provision of institutions of various kinds for training and remedial treatment and for the retention of incurable beggars. Some of these institutions have come to be known as labour colonies.

Thus far, both the second and third schools go together. And both schools believe in what may be called the principle of less eligibility, which lays it down that those in distress should certainly not be maintained in a position of comfort superior to what is normal in the case of any of the self-supporting. We need not argue here whether it should be markedly inferior. But the second school thinks that many claimants for public aid suffer from weakness of characterparticularly from improvidence and a lack of self-reliance. This weakness, according to their reading of human nature, is fostered when aid is given, especially when the donor is the State. And if aid is easily obtainable, they think the weakness may be encouraged in others. The spread of this weakness throughout a large class would, they hold, be fatal to economic efficiency and progress. They, therefore, advise that in the first instance, in cases which are not hopeless, assistance should be tendered by voluntary organizations, and that it should be withheld until it is really indispensable. In their opinion, the person who has applied prematurely for aid, or has not really come to the end of his resources, should be encouraged to see if he could not manage without the public aid. If he takes public aid, it is thought that at the next crisis he will be even less able to do without it. Help from relatives is not expected to create in the individual a disposition to dependence like help from strangers or the State.

The third school, on the contrary, regards much indigence as analogous to physical disease. The longer a person with a physical disease puts off seeing a doctor the harder is it to 
cure him. And the longer a person in distress puts off applying for public aid the harder his cure becomes, it is pleaded, when restorative treatment is needed. Restorative treatment means training, or physical or moral bracing. The second school would reply that the peculiarity of this social disease is that in so many instances self-cure is the only cure. The third school further insists that those who do not require remedial treatment are apt to become demoralized if their applications are not met promptly.

Here I may point out that public money could not be spent to provide the kind of assistance which would be most helpful in certain exceptional cases. I may give as an instance expensive special training, or a loan to start a shop or some small business. For such cases voluntary funds must be resorted to. The alternative might be for the person who had met with excessive misfortune to sink in the social scale, though he would have been efficient in the higher position.

With the aged, the non-able-bodied, and children, fewer difficulties arise, because there is no question of restoration to independence. But there is the matter of the example to others. The principle of less eligibility has been widely recommended in these cases also. Where desirable it could be generously interpreted. And many would like to see voluntary funds used to provide special comforts in exceptional cases.

The doctrine of maximum satisfaction.-In concluding my cursory examination of the question of the State in relation both to business and social conditions, I may bring to your notice the doctrine sometimes known as the doctrine of maximum satisfaction from which the famous maxim of laissez faire was a practical deduction.

The doctrine of maximum satisfaction has been interpreted in more than one way. In one sense, it recognizes the faults in the competitive system, but declares that the State nevertheless does more harm than good when it takes upon itself 
responsibility for the performance of services beyond the maintenance of order, the penalizing of dishonesty, the relief of destitution, and so forth. Taken in this sense, the doctrine has been widely repudiated, but there is still general dispute as to where the line limiting the functions of government should be drawn. In a more moderate form, the doctrine of maximum satisfaction lays it down that the view just enunciated is correct ordinarily but that there exist numerous exceptions.

No reasonable person has ever accepted the doctrine in its extremest possible form and asserted that private enterprise, restricted only by laws maintaining order and preventing dishonesty, brings about perfect results. Granting that the competitive system tends to sift out the capable, enforce efficiency and economy, and render the productive system responsive to demand, it may still be insisted, as we have seen, that its performances are marred by faults both of omission and commission, particularly when a broad social view is taken. This conclusion holds, though in a less degree, even if we suppose that all individuals are endowed with perfect prevision and that they never make mistakes about what they want and how to get it. We should do well, however, to remind ourselves that the correction can be applied to the competitive system in some respects by voluntary organization as well as by the State.

Of the reactions of the competitive system on human nature I have spoken little, and must not now speak at length. These are matters for the sociologist. But I may recall to your minds the statements made on pages 17-18, and suggest that if it be true that in imperfect humanity competition has fostered self-seeking, a sordid spirit and low ideals, it is as likely to be true that it has brought out some of the best qualities in human nature, industry and endurance, self-reliance, courage and enterprise, through which the external world has been progressively subdued to the service of man. 


\section{CHAPTER XXXII.}

\section{PUBI. FINANCE.}

Public finance may be defined as that part of political economy which discusses the way in which Governments obtain their revenues and manage them. It includes the principles according to which contributions should be made by the members of a community to the expons9s of their government. For a proper grasp of public finance a knowledge of the theories of the shifting and incidence of taxes is requisite. To these theories our next chapter will be devoted. It goes without saying that we can glance only cursorily now at the immense subject of public finance, and that whole sections of importance must be ignored.

Public revenues. - Governments get their revenues, exclusive of gifts, from (1) their property, (2) fines and penalties, (3) fees, (4) their business undertakings, and (5) taxes.

The revenue obtained from fines and penalties arises incidentally. Fines and penalties are not imposed primarily in order to produce revenue. Some portion of the revenue in the form of fees must also be regarded as arising incidentally. A fee we may define as a charge imposed on a person for a non-eccnomic service. It is not necessarily equal to the cost of the service for reasons which will transpire ; and one ground for demanding it may be to prevent people from giving unnecessary trouble. The charge for a specific economic 
service which can be refused I shall call a "price". A tax will be defined later.

The principles according to which the members of a community should contribute to the expenses incurred by Government, central or local, depend upon the nature of the work done by Government. The work done by Government may be classified for our present purpose as follows :-

1. Services, little or none of $($ (a) Ordinary political serthe benefit of which can be traced to particular individuals. vices.

(b) Economic services, such as the maintenance and lighting of highways.

2. Services, much of the benefit of which can be traced to particular individuals. These may be regarded as consisting mainly in economic services, such as the carriage of letters, and the provision of gas by local governments.

The division between political and economic services implied in this classification is shadowy, and there is no time now to force upon it an artificial distinctness.

It seems evident that the cost of any benefits which are traceable to particular individuals should normally be claimed from the beneficiaries. Usually, in so far as these benefits are traceable to individuals, prices are charged if they are economic, or fees if they are not primarily economic. These prices and fees are not classed customarily as taxes. But there are cases in which people cannot reject a State benefit as they can refuse to buy any article (see the section on "betterment," pp. 383-4); and there are, moreover, exceptional services of class 2 for which it is not desirable to charge fees or prices. The latter are the services from the extensive private use of which the community gains largely, and of which the individual can, if he pleases, considerably contract his use. It may be desirable to raise the 
whole sum to cover the cost of such services by taxation, in order to avoid discouraging the individual from stinting himself in his use of them. The provision of household supplies of water may be a case in point. The cleanliness of a population is a public amenity. If people had to pay directly for every gallon of water they consumed, some of them would economize their use of water too muoh, and these would probably be the people who ought least to do so. Hence, for the bulk of the household consumption of water, it is common to make a fixed periodic charge varying with the rent of the house, and not to charge per quantity consumed.

For services of class 1 payments proportional to benefit conferred cannot be exacted from individuals. The expenses of these services, and the residue of the expenses of services the cost of which is not wholly covered by fees or prices, must be disbursed out of the proceeds of taxation.

We may define a tax as a compulsory contribution made to Government, under stated conditions, when the contribution is not a quid pro quo for a specific service rendered. Thus the money paid by me for a dog licence is a compulsory contribution made to Government, but its payment is conditional upon my having a dog, and is not made on account of any service rendered by the government in connection with the dog. Again when a Government carries letters and demands more for the service than is requisite to reimburse it, the excess charge is to be considered a tax.

The principle of equity in taxation.-Now, as regards taxation, the first thing to settle is the principle according to which its burden should be distributed. It is commonly agreed at the present time that taxation should be designed so as to cause equal proportional sacrifice among the taxpayers. When there is equality of proportional sacrifice, people are left in the same relative positions after being taxed as before, This principle we must accept here as 
axiomatic. To justify it we should have to make a long flight through the rare atmosphere of social philosophy. Broadly speaking, by way of suggesting its justification, I may say, with reference to taxation to cover the expenses of the activities of the Government which have a public and not a private purpose, that the community must be conceived not merely as an aggregate of individuals but also as a social whole.

This principle has been called the "principle of equality of sacrifice". It is better, however, to call it the "principle of proportional sacrifice," because equality of sacrifice might be interpreted to mean equality of absolute sacrifice and not of proportional sacrifice. If the utility of income were constant and the same for all-as it is not-and a man with $£ 1000$ a year and a man with $£ 500$ a year contributed $£ 10$ a year each in taxes, equal amounts of sacrifice would be entailed, but the man with $£ 500$ would be involved in a greater proportional sacrifice. The proportional sacrifice of the man with $£ 500$ a year would be the same as that made by a man with $£ 1000$ a year who paid $£ 10$ in taxes, if the former paid not $£ 10$ but $£ 5$, on the assumptions made as regards the utility of income.

It is repeatedly affirmed that the right theory of taxation is the faculty theory. Generally speaking, the faculty theory lays it down that a person should pay taxes in proportion to his power to do so. Whether the faculty theory is the correct theory or not, according to the concensus of expert opinion, depends upon the exact meaning that we read into it. Let us take an example from a primitive community. The State needs a particular piece of work to be done. Then, some say, for the whole community to turn out to do the work, and for each person to work according to his strength would be for each to contribute to the service of the State according to faculty. But would this be the equitable thing? If all worked 
ten days, the man of great capacity would be doing absolutely more for the State than the man of little capacity. But the latter would be making a greater proportional sacrifice than the former. He would be doing so because the man of great capacity, who could make much in a year, in yielding up ten days of his time would be surrendering comparative superfluities, whereas the man of little capacity in yielding up ten days of his time would be surrendering comparative necessities. The force of this argument will be more fully appreciated when it is put in terms of money. Equal sacrifices of time are equivalent to proportional sacrifices of money income, but, as we shall observe soon, proportional sacrifices of money income are not equivalent to proportional sacrifices of real income, that is of the utility of income, which is the thing that ultimately counts. However, the faculty theory may be interpreted in such a way as to be made identical with the theory of proportional sacrifice.

The so-called ability theory is either the faculty theory in the form first analysed above, or the theory of proportional sacrifice. If we mean by any theory that proportional sacrifice alone is equitable, it is best to call it the "theory of proportional sacrifice" so as to prevent any misunderstanding.

When we are seeking the fundamental principle according to which people should share the burden of taxation we are trying to discover what has been called the "principle of equity in taxation". The right principle of equity is commonly held to be the principle of proportional sacrifice, as regards taxes to cover the cost of governmental work which has a public object.

Progressive taxation. - Taxation which embodies the principle of proportional sacrifice must be progressive. By the principle of progression is meant in general that the higher the clear net income of a person the greater must be the rate at which he is taxed. "Clear net income" I must 
define later. The need of progression is derived from the known facts as regards the variation of the utility of income with its amount. In view of the rate at which the marginal utility of income falls, it is practically certain that taxation proportional to income exacts a greater proportional sacrifice from the poorer of any two persons, other things being equal.

Let there be two persons, $\mathrm{X}$ and $\mathrm{Y}$, of whom the former has $£ 200$ a year and the latter $£ 400$ a year. Let the variation of utility with income be the same for both. For both let the utility of $£ 100$ a year be " $a$," and for both let the addition of a second $£ 100$ a year to income add utility " $b$," the addition of a third $\$ 100$ utility " $c$," and the addition of a fourth $£ 100$ utility " $d "$. Suppose a tax of 50 per cent is imposed on the income of each. Then ratios of sacrifice to the utility of the income left will be

$$
\frac{b}{a} \text { for } \mathrm{X} \text { and } \frac{c+d}{a+b} \text { for } \mathrm{Y}
$$

It will be evident that for all likely quantitative relations between $a, b, c$, and $d$ (which, according to the law of the diminishing utility of income, must be related so that $a$ is greater than $b$, and $b$ than $c$, and $c$ than $d), \frac{b}{a}$ will be greater than $\frac{c+d}{a+b}$. At the same time you must observe that

$$
\frac{b}{a}>\frac{c+d}{a+b}
$$

does not necessarily follow from

$$
a>b>c>d \text {. }
$$

The great obstructions in the way of applying the principle of progression with scientific accuracy are (1) that utility varies with income differently for different persons, and even for the same person at different times, and (2) that the variations of utility with income cannot be accurately measured.

The words "degressive" and "regressive" have been applied to taxation. When they are used, "progressive" is given a special denotation. Progressive.taxation then denotes taxation involving proportional sacrifice. Degressive taxation 
means that large incomes are taxed at a higher rate than smaller incomes, but not in a degree which involves as great a proportional sacrifice for the former as for the latter. Regressive taxation means taxing the smaller incomes at a higher rate than the larger incomes.

The important thing, observe, is that a taxing system as a whole should be properly progressive, and not that every tax in the system should be progressive.

There cannot be said to be complete agreement as to what should be understood by a person's clear net income. It is evident, however, that it is exclusive of expenditure incurred in earning the income which otherwise would not have been incurred. We have one example in the extra rent paid by a doctor for his house because he needs space for his surgery and consulting-rooms, and another in the cost of a doctor's carriage, in so far as it is used by him in his professional work. It is evident also that clear net income is exclusive of what a person who earns his living has to save in view of certain contingencies which may be disregarded by the person whose income is derived from investments.

Other principles of taxation.-Besides the prineiple of equity, other principles of taxation may be laid down. On these some comments are made below.

The principle of economy, as it might be called, is a two-sided principle which declares that, other things being equal, taxes should be chosen (1) the cost of collection of which is small in proportion to the proceeds, and (2) the loss occasioned by which to the country is small in proportion to the proeeeds. Taxes which are not very productive but which are such that a large army of inspectors must be kept actively at work to see that they are not evaded, offend against the first clause of this principle. From the second clause of the prineiple and the theory of the incidence of taxes on commodities, we may deduce that it is bad finance to impose a tax on the 
products of an industry which is strongly subject to increasing returns. For proof of this, see pages 394-6.

It has been pointed out that taxes on luxuries may achieve miracles in the way of economy when costliness enhances the degree in which they are prized. Diamonds would go out of fashion if their price dropped to twopence apiece, but an enormous tax on wearing them might conceivably bring them into fashion again. Analogously the taxation of things the consumption of which beyond a certain point is detrimental is peculiarly economical, for example the taxation of alcoholic beverages. It discourages what is undesirable and at the same time raises revenue.

The principle of convenience advises that, other things being equal, taxes should be so selected and so arranged that the taxpayers are put to the minimum of inconvenience. Indirect taxes put the ultimate payers to no inconvenience, because the ultimate payers do not make a separate payment of the tax but pay it as a part of the price of the things taxed. It is an inconvenience to be constantly interviewed by an official, or to have to make complicated returns repeatedly; and the annoyance is the more objectionable the smaller the sums which are at stake. Since trouble is a cost, the principle of convenience, as so far expounded, may be regarded broadly as included in the principle of economy. But there are inconveniences of another order to avoid, if "inconvenience" be widely understood. In every country, according to the dispositions and prejudices of its inhabitants, certain acts on the part of tax-collectors would be resented as an infringement of the tax-payers' rights and privileges. For instance, people are apt to be offended by the prying of officials, even when they, the tax-payers, are perfectly honest. With feelings which are deeply and widely rooted, Governments would be unwise to collide. Nothing damages a Government more than an unpopular tax, when its unpopularity is im- 
bedded in political instincts, whether the latter be reasonable or not. But this matter is one of politics rather than of economics.

To these principles is sometimes added what has been called the " principle of clearness". The principle of clearness affirms that people who have to make independent payment of taxes must be able to discover, and without difficulty, what they have to pay, when they have to pay, and why they have to pay. The time of payment must not be left for the collector to settle each year despotically. Moreover no person must be assessed arbitrarily. Each person must be charged on principles, and be informed of the principles applied in determining what his particular contribution is. Also the calculations involved in settling his obligations should be of a simple kind, so that he can verify them for himself.

In addition, under the principle of clearness, it is sometimes laid down that every person should know, or be easily able to ascertain, exactly how much he is paying directly and indirectly in taxes. This requirement, however, would seem to be impracticable, and it is by no means evident that it is desirable as things are. Always to know what you pay is always to feel what you pay. A perpetual chafing at fancied exactions of Government, and short-sighted penuriousness in matters of State expenditure, might result from giving prominence to the full burden of taxation in its incidence on individuals. The best of men are very human when they are paying taxes. On the other hand, a knowledge on the part of each tax-payer of exactly how much he was contributing, directly and indirectly, would be a check on any disposition of Government to tax disproportionately a section of the community, and would insure effective criticism of Government extravagance. And certainly it is advisable that as a rule exceptional expenditure, for instance on war, should be accompanied by an addition to the burden of taxation which is unmistakably felt. When a community demands what is costly, it should be made 
to realize that it is costly for the sake of tempering its judgment. These points, again, are largely political.

The principles which we have been cross-examining are not always known by the titles conferred upon them above, and they cannot be said to form a part of the invariably recognized currency of Economics or Politics.

In the foregoing exposition we have not exhausted by any means the outstanding maxims of taxation. The rest must be omitted, however, except for a hasty glance at a few points. Vacillation in taxing is to be deprecated. As it has been put paradoxically, an old tax is a good tax and a new tax is a bad tax. Time is needed for the community to adapt itself to a new tax, and in the process of accommodation much loss and inequity in incidence may be involved. Of other maxims not the least important are those which have reference to the financial relations between local governments and the authority standing over them.

I must also draw attention to the need of variety in a taxing system and a selection of taxes which, so to speak, supplement one another. Every tax tends to bear inequitably on some people, but when a taxing system is well designed it ought not as a whole to bear inequitably, to any sensible extent, on anybody. Finally there is the matter of elasticity. A taxing system as a whole should be elastic in the sense that its yield can be increased, within moderate limits, by raising in appropriate degrees the rates of all or some of its constituent taxes, without altering substantially the incidence of the system or the proportionate real burden imposed on the country.

Betterment and the unearned increment.-What is technically known as betterment comes upon the scenes when any public authority, in carrying out a work of public utility, incidentally confers value in a peculiar degree upon certain pieces of property. Thus, when a public bridge is thrown across a river, demand for the land about the two ends of the bridge is intensified. The claim has been advanced, and 
admitted in law in many countries, that a special public charge should be imposed upon the value thus incidentally created, which, since it is produced by the public authority, has been adjudged as belonging in a sense to the community.

Unearned increment, like betterment, relates to an accession to the worth of property which has been brought about without labour or sacrifice on the part of the owner of the property ; but, while betterment implies that the cause of the value is traceable to specific undertakings of governmental authorities, unearned increment, as commonly viewed, does not. Unearned increment, thus regarded, is the accession to the value of things which is the product of social growth or social progress. The augmentation of the value of the ground covered by a town, which is a never failing concomitant of the enlargement of a town, is unearned increment. When it is possible to locate it and measure it, many people hold that it is a singularly suitable object of taxation, since the community made it-involuntarily it is true-and its taxation cannot operate as a discouragement of production or saving. However, when the taxation of unearned increment is first adopted, allowance should be made for the fact that the price at which property is changing hands may embrace some discounted anticipation of future values. Nobody should be charged, in addition to his fair share of the burden of general taxation, an unearned increment tax on an unearned increment which he has paid for.

Public debts. - The individual should manage his expenditure so that he is not lavish one year at the cost of having to pinch another year, and the State likewise should control its finances so that the burden of taxation does not vary substantially and irregularly. The State may consequently have to borrow to meet unusual expenditure; and it is justified in borrowing provided that it makes arrangements for the repayment of the loan before the unusual burden is likely to recur. 


\section{CHAPTER XXXIII.}

\section{THE INCIDENCE OF TAXES.}

Nature of the problem of incidence.-We must begin our study of the incidence of taxes, as the subject to which we shall now give attention is commonly called, by drawing a distinction between the impact and the incidence of a tax. The impact is upon the person from whom the tax is collected, but the incidence is upon those who pay eventually. The process by which ultimate incidence is brought about is known as the process of the shifting, or rolling, or repercussion of taxes.

If the incidence of a tax is upon the same person as its impact, the tax is sometimes said to be direct. If incidence and impact are upon different persons, it is said to be indirect. But "direct" and "indirect" are sometimes applied to taxes to mark another contrast. By a direct tax is not infrequently meant a tax on persons apart from the nature of their callings, while by an indirect tax is meant a tax on trades, or on commodities or services, or things or events incidental to their provision. This is probably the commoner use of the terms, and it is the use to which they will be put here.

Some people speak of the shifting of taxes as if in each case a particular payment, or some part of it, were passed on from person to person until some individual was reached who could not pass it on to anybody else. Thus a tax of a penny a pound, say, is placed on soap in some country and the question is asked, Who pay the pennies on the pounds of soap consumed 
in that country? This is far too simple a way of stating the problem of incidence. Take the example given and suppose that soap is not imported. The Government will raise a penny from each pound of soap consumed in the country, but the loss inflicted upon the taxpayers may be greater or less than the sum received by the Government. If the incidence of this tax is on the ultimate purchasers of soap, they pay what the Government gets, but they may be involved in contingent gains or losses which must be deducted from or added to this payment. If, in consequence of the diminished consumption of soap brought about by the tax, the price of soap, apart from the tax, falls, the tax-payers make a contingent gain, but if the effect of diminished consumption is the opposite they suffer a contingent loss. Again, among the losses inflicted by the soap tax, we must certainly reckon the damage done to those who, as it is said, "escape" the tax, or some part of it, by giving up consuming the taxed article wholly or partially. To give up consuming what we like, and substitute for it what we desire less, is not a matter of indifference. Whenever the demand for a thing taxed is not absolutely inelastic there is a sacrifice of this kind. It is not always practicable, and it is seldom of much value, to separate the deprivations entailed by payment of the tax from contingent losses or gains.

From the foregoing we may infer that it is not exactly correct to speak of the incidence of a tax. What we should say is "the incidence of the effects of a tax". However, the shorter phrase is in common use and serves to save words. The best way to deal with the problem of the incidence of taxes, so called, is to ask, first, What is the loss entailed? and, secondly, How is the loss distributed?

A few preliminary remarks on the conditions under which taxes may be shifted will not be out of place. If a tax is placed on all men over six feet in height, obviously no ways of escaping the tax are open to them except to emigrate or cease 
to exist. They cannot give up being six feet high. Therefore, providing they elect not to emigrate, they must pay the tax. Similarly, if people are taxed in proportion to their wealth, and the tax amounts to only a small fraction of their possessions, those who earn an income are not likely to be induced by the tax to earn less. Consequently they cannot shift the tax. But if carpenters are taxed, while bricklayers, plumbers, and gardeners are not, the trade of carpentering will at once be made relatively less attractive than bricklaying, plumbing, and gardening. Perhaps only a few carpenters will forsake their calling in consequence, but certainly the proportion of the next generation brought up as carpenters will be reduced. Hence ultimately the supply of carpenters will shrink relatively, and the price paid for their work will be bound to rise. So the effects of the tax will be shifted from the carpenters on to the public who employ carpenters.

We shall trace in detail in succeeding paragraphs the incidence of certain taxes which have been selected to illustrate the theory of incidence. We shall be concerned only, remember, with what tends to happen in the long run, though ultimate effects may be long delayed and obscured by intermediate effects, and be commonly overlooked in consequence, as the rise of the tide may be when we watch the waves. Further we shall assume provisionally that the repercussion of taxes cannot be in any degree negatived, though it may be delayed, by social friction. We suppose that people will break their habits to escape a tax, and that, when a trade is taxed, people in the trade will not be depressed into a lethargy which will rivet the burden upon them and their children. Of the latter point I shall have to speak again later.

Taxes on income, property, and saxings. - By a "property tax " is meant here a tax on the possession of all forms of property from estates to household furniture and clothing. The incidence of income and property taxes is upon the 
persons upon whom they are imposed, in so far as they do not penalize those who work in particular trades, or discourage the acquisition of particular kinds of property ; and on these provisos incidental gains and losses are negligible.

The incidence of duties on the transference of a person's property at his death is similar to that of general ad valorem property taxes, as above described. One merit of the former is that their weight falls, so to speak, between two stools. The deceased does not pay them, and any person who benefits has never had what the State gets out of the estate.

Savings may be taxed by the imposition of a special charge upon investments or upon income from investments. Such a charge may be regarded as negative interest. It will probably cause the annual supply of capital to shrivel up somewhat and costs of production to swell. Hence some of the incidence of a tax on savings will be upon the community as a whole.

Taxes connected with land.-The problem of the incidence of taxes on land, or land and any capital fixed in it, disconcertingly complicated though it appears when unsystematically presented, readily lends itself to a p:ecemeal solution. I shall try, therefore, to bring out the principles involved by exainining a fow leading cases in the abstract.

(a) Taxes on pure economic rent fall upon the persons who receive the rent. This proposition holds of all true rents, whatever their nature, including personal rents. It is assumed, of course, that the taxes are made to apply to all rents of a given class. The conclusion follows from the fact that the taxes, being on rent, do not affect cost directly or indirectly. Were a tax imposed on the rent of land only when the land was used for growing turnips, say, then a part of the incidence would be upon the consumers of turnips, because some land would be withdrawn from turnip-growing and devoted to other purposes. 
(b) The incidence of a tax on land proportional to the quantity of its tangible produce next claims our attention. Such a tax makes an addition to the cost of obtaining the produce which is the same for every unit of the produce. Suppose the demand for the produce is absolutely inelastic. Then price will rise by the amount of the tax, and consumers will lose what the Government gets. And rent will be as before. Rent is the difference between the aggregate costs of the produce and the total receipts for it. The costs are increased by the tax multiplied by the amount of the produce; and the receipts are increased by the same amount. Hence the difference between them is what it was before.

But the demand for the produce cannot be absolutely inelastic. When the price of the produce rises, less will be consumed. When less is consumed, the marginal cost will fall (see pp. 289-91). Hence price will rise by less than the amount of the tax and rent will fall. Consequently in the loss occasioned by the tax landlords will share.

This demonstration holds whether the produce of the land is the fruit of the earth, or milk (on dairy farms), or cattle and sheep, or office-room (on building sites), or house-room, or what not.

(c) In setting out to trace the effects of a tax on the annual value of what is produced from the land (including accommodation in buildings), we had better be content, on a first perusal of this book, to consider the simple circumstances explored in the next two paragraphs, and pass over the intricacies concentrated in the small print which follows.

Take the case of house property. Each house is taxed according to the annual value of site and house. Consider houses of exactly the same kind. A house at the situational margin pays a rent of $£ 40$. This is a charge for the house alone; the marginal site may be asssumed provisionally to have no value. Another house pays $£ 60$ a year. This is 
$£ 40$ for the house and $£ 20$ for the site. Let each be taxed (or rated for local purposes) 25 per cent. Suppose, first, that the demand for houses is quite inelastic. Then for the house at the margin $£ 50$ must be paid, $£ 40$ rent and $£ 10$ rates. For the house $£ 40$ must be paid as before (as we shall understand better after studying on pages 394-6 the incidence of taxes on commodities, which include buildings), because this is its cost of production and management expressed as an annual payment. Then for the other house the occupier would pay at most $£ 50$, plus its situational value of $£ 20$, that is $£ 70$ in all, including rates. He would not pay more because the situational value is as before, and we suppose that he occupies the house because he was the highest bidder for it. Consequently the rent of this house would have to drop from $£ 60$ to $£ 56$, because $£ 56$ plus 25 per cent (the rates) equals $£ 70$, the most that would be paid for it and any charges upon it. The site value will, therefore, fall from $£ 20$ to $£ 16$, since $£ 40$ must still be paid for the house. That is to say, in this case and like cases, if the demand for houses is quite inelastic, the tax paid will fall on the house and the site in proportion to the amount of each in the total rent ultimately paid. But actually the demand for houses is not quite inelastic, so the situational margin would rise. Hence situational rent would fall still more.

If, instead of a residential house, business premises are on the site, the tax which does not fall on the ground rent falls on those who ultimately consume the utilities furnished in the business premises. This conclusion follows from the fact that otherwise the profits of businesses using much land would be reduced and people would be less eager to enter them.

This demonstration holds only of cases in which the quantity of accommodation which can be provided on a given site is fixed, and no doubt there are many such cases. There are also many cases in which the quantity of accommodation which can be provided on a 
given site is not fixed. Blocks of flats are erected in the centres of some big cities which would never be erected in the suburbs, and these blocks may be of various heights. In these cases rates would cause less use to be made of central sites (lower buildings would be placed upon them), as I shall prove in the next paragraph, and the boundaries of the town would be thrust outwards. Now ordinarily the area for building in the immediate outskirts of a town is extensive and the inconvenience of living a moderate distance from the centre is not appreciably less than the inconvenience of living a substantially greater distance from the eentre. Consequently the chances are that the value of a given amount of accommodation in the centre would not be appreciably affected by the spreading of the town's suburbs. We may conclude, therefore, that it is so highly probable as to be certain for practical purposes that the annual value of central sites, and the aggregate site value of the town, would both fall in the long run in a greater degree than they would if a fixed quantity of accommodation were always provided when a site was used.

That rates would cause less use to be made of central sites is easily demonstrable. Take a block of flats with eight stories. Suppose that on the eighth story a rent of $£ 90$ a year will be paid for accommodation which could be obtained in a house of two stories on the outskirts of the distant suburbs for $£ 30$ a year. Then for the situational conveniences of the flat $£ 60$ is being paid. Now we may assume that the provision of our flat on the eighth story costs in all with profits a sum of which a rent of $£ 90$ a year is an equivalent.

We suppose, to begin with, that there are no rates. Now, let rates of 50 per cent on rent be imposed, and take it provisionally that the demand for house-room is quite inelastic. Then the man in the marginal suburban house pays rates of $£ 15$ a year on his $£ 30$ house, that is, $£ 45$ in all. Then the man in the top flat would pay $£ 45$, plus the value of his situation, which was $£ 60$ and, on the suppositions made, remains pretty much the same. So he would pay $£ 105$ in all, supposing, for the sake of argument, that the value of his situation is still $£ 60$. And as rates are 50 per eent of rent, this means that he would pay a rent of $£ 70$ and rates amounting to $£ 35$. Rather than pay more he would get himself a $£ 30$ house built on the country side of our marginal $£ 30$ house in the suburbs. But a 
rent of $£ 90$ only just covers the cost of providing his flat. Consequently, after the rates were imposed, no more flats with eight stories would be built. Finally observe that this result, whatever the rates, could not possibly be prevented by a rise in the value of central accommodation because such a rise could only be brought about by a spreading out of the town for which ex hypothesi a curtailment of the height of central buildings is essential.

You will realize after a few moments' thought that the theory of the incidence of taxes on the annual value on the spot of the produce of farms, is similar in form to the theory of the incidence of taxes on building sites used for business purposes when the amount of accommodation obtainable from a site is not to be taken as rigidly fixed.

(d) The theory of the incidence of a tax on all land per acre, which you would think should be easy, is in parts difficult. The theory is easy enough, if the tax is imposed on all land, whether used or not, and cannot be evaded by giving up ownership of land. In this event it must fall entirely on landlords, because the use made of any piece of land, and marginal cost, would not be affected. But when the tax is imposed only on land which is devoted to some service or other, the theory may become involved.

Let us begin our examination of the incidence of the latter tax, by taking first a very simple case where the theory is simple. Consider building plots, on each of which the same, and an invariable, amount of accommodation is provided. If the demand for such plots is quite inelastic, rent after the imposition of the tax would be as before. The reason is that the owners of marginal sites can escape the tax by withholding land from use. The reader can prove the conclusion by constructing a numerical example. The whole incidence of the tax would be on the occupiers of the residences, or on the consumers of the commodities or services proceeding from the premises, as the case might be, if demand were quite inelastic, but if it were not rent would suffer some reduction. 
Complexities are introduced into the problem when we suppose that the quantity of accommodation which can be furnished on a site is variable. We have, on such a supposition, circumstances similar to those of land in agricultural use. You may read what follows as relating either to farming land or to building land in the long run-only the long run would be much longer in the latter case.

A tax proportional to acreage on land in use would throw out of use all land of which the economic rent per acre, under the conditions created by the tax, was less than the amount of the tax. And as other land would be worked more intensively, the marginal cost of its produce (whether it were corn, or cattle, or buildings, or what not), would rise, and consequently the price of its produce would rise. Hence consumers could not possibly escape being hit; and in fact they would almost certainly have to pay substantially more than the proceeds of the tax. The proof of this proposition is too elaborate for insertion here, as is also the proof of a correlative proposition which holds of this case, namely, that the aggregate paid in rent would, with the same degree of likelihood, be increased despite the loss of rent on the land thrown out of use.

In connexion with land taxation there are three other points which I ought to mention.

The first is that the incidence of land taxes on persons is naturally affected by leases, because leaseholders are tied to their land for specified periods. The leaseholder is to be viewed-as landowner in this matter, except with respect to taxes on the rent received by landlords and apart from any provisions which modify the leaseholder's liabilities according to changes in circumstances.

The second point is that a tax upon unoccupied land which could be used, brings a portion of it at least into the market and so tends to lower the value of sites. When such a tax is resolved upon, it is not desirable that it should be so heavy as 
to discourage all withholding of land from present use in view of future needs.

Thirdly and finally I must notice the principle of amortization. When a recurrent impost is placed on the possession of a thing, allowance is made for the charge when the thing is purchased. Hence a land tax which reduces rent lowers the capital value of land. Similarly a tax on the transfer of nonreproducible property lowers its exchange value by the amount of the tax. It is noteworthy, though apparent, that the value of land is sensitive to expectations of change in the rate and nature of taxes affecting its net earnings.

Taxes on commodities and services. - This section will have no reference to import and export duties, which will be specifically treated later, nor to conditions under which supply is monopolized.

Taxes on commodities may be treated as additions to their costs of production. If the demand for a taxed commodity, in the supply of which competition rules, is wholly inelastic, its price must rise by the amount of the tax, and the incidence of the tax must be entirely on the consumers. But demand is never wholly inelastic. Consequently after a tax has been imposed on a commodity, less of the commodity will be bought and less produced. Now the cessation of consumption will itself cause loss in the manner described above. Moreover, when a smaller quantity is produced than before, the marginal cost of production may rise or fall. If it rises, price will rise by more than the amount of the tax and the loss of consumers will be increased accordingly. If it falls the loss of consumers will be correspondingly reduced.

From these conclusions two maxims may be deduced. The one is not to tax things the demand for which is elastic, other things being equal, when the prime object of the tax is revenue; because when demand is elastic a small tax will cause a large contraction of consumption. The other is not to tax things 
the production of which is subject to marked increasing returns, other things being equal, because to do so is to throw away the advantages of increasing returns.

The theory of the incidence of taxes on services is identical with that of the incidence of taxes on commodities. A commodity is merely a service indirectly rendered. Taxes on transfers of reproducible things, or on contracts relating to their provision (like stamp duties on bills of exchange), when they are indispensable, are evidently additions to the cost of producing or delivering things and are therefore to be classed with taxes on commodities.

Diagrammatic treatment of taxes on commodities. - In order to grasp completely the principles underlying the theory of the incidence of taxes you are recommended to read again the section on

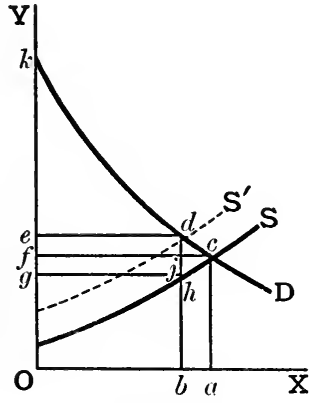

Fig. 19.

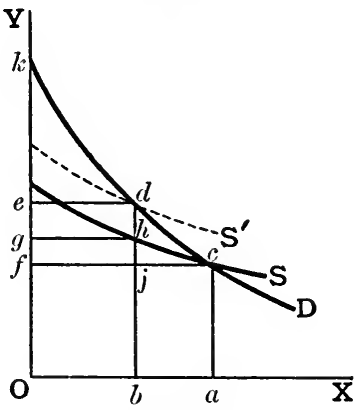

Fig. 20.

consumers' rent (pp. 49-53). After refreshing your memory of that section you might consider with advantage the following diagrammatic form of the exposition already given of the incidence of taxes on commodities, but only if you find diagrams an aid to your under. standing of economic theory, as all students do not.

The conditions of demand and supply of a commodity subject to decreasing returns, and of another subjêct to increasing returns, are represented in figs. 19 and 20 respectively. A tax of $d h$ per unit 
is imposed on each commodity. Consequently the supply curve in each case is raised from $S$ to $S^{\prime}$. The output in each case is reduced from $\mathrm{Oa}$ to $\mathrm{O} b$. The loss of consumers' rent is efcd, that is to say, consumers suffer a loss equivalent to a loss to them of efcd in money. The gain of the Government in money is eghd. In fig. 19, relating to diminishing returns, eghd is greater than efcd, but it would cease to be if the inclination of $S$ were so slight that $f g h j$ were no greater than $c d j$. In fig. 20 , relating to increasing returns, eghd is less than $e f c d$, and is bound to be. The reader can construct a figure for himself to show that, in the case of constant returns, the excess of loss of consumers' rent over the gain of the Government would be approximately half of the tax per unit multiplied by the reduction of output.

Taxes on monopolies. - If the reader suspects that his recollection of chapter XVIII on monopolies is hazy, he would be well advised to study that chapter again before grappling with the problem of the incidence of taxes on monopolies.

A tax of a lump sum on a monopoly, if it falls short of reducing profits below normal profits, must rest exclusively on the monopolist, provided that his output is so arranged that his net takings are maximized, as it would tend to be in the absence of any of the limitations on his liberty of action discussed on page 183 . If in this event he is taxed $£ 1000$ a year whatever his output, on reducing his output he would meet only with additional loss. A percentage tax on monopoly revenue would have a similar incidence, if we suppose that the trouble saved when output is reduced is practically negligible. A tax on the output would probably induce the monopolist to restrict his output and thus some of the incidence would be on the consumers. Of course were the tax in any of these cases so large as to swallow up the monopoly revenue and something more, the output would ultimately come to an end.

Import and export duties.-We must confine ourselves here to the broadest issues only. In what follows, I shall deal mainly with import duties. From the principles brought out 
in their examination, the effects of export duties can be readily deduced. The reader may find it helpful to conceive of import and export duties as additions made to the cost of transport between countries exacted by the parties imposing the duties.

I take first protective import duties; but we are concerned here, observe carefully, with the burden of such duties and its incidence, and not with arguments for protection and free trade. These arguments we have briefly reviewed in Chapter $\mathrm{XXX}$. Here we are leaving out of account certain advantages, apart from the cost of things, which are claimed for protection on the one hand, and on the other hand certain advantages of a similar order, connected with foreign intercourse and emulation in the arts of peace, which are claimed for free trade.

I begin my inquiry by asking the question whether taxing the foreign sources of supply of an article is likely to cause any peculiar losses. Now the affirmative answer seems necessary. Over and above the loss which would be occasioned by simply reducing the consumption (analysed on p. 386), there may be loss due to the fact that consumers are prohibited from getting what they do consume from what are to them the most economical sources of supply. Consequently, when revenue is raised by taxation of commodities, the burden on the consumers is likely to be increased if any source of supply is treated preferentially. Conceivably, though improbably, the sources of supply favoured under a system of import duties might bə the most economical. This you may infer from the cases put on pages 347-8.

I shall now broaden the argument, mainly with the object of showing what is the right answer to the question commonly asked in the form, Does the consumer or the foreigner pay import duties? We may assume ordinarily that before the import duties were imposed the countries affected naturally engaged most in those industries which they could prosecute to the greatest advantage. By the duties some of their 
activities would be shifted into less profitable channels. Hence there would be loss. However, as we have discerned, this doctrine does not hold quite universally. It has been pointed out that conceivably some of the new channels might be more profitable than the old ones. If they were, there would be gain instead of loss. Nevertheless, in a broad determination of effects, the chance that any such gain would be relatively large muy be ignored.

How is the aggregate or net loss distributed between the trading countries? The gist of the theory which must be expounded in answer to this question may be conveyed in a few words. Let the country which imposes the import duties be France. Dismiss from your mind at first all cases in which France, or any one of the countries exporting to it, exclusively consumes or produces an article of international trade. Such cases of what might be loosely termed national monopoly (though strictly there is no monopoly, as neither consumers nor producers, as the case may be, are under agreement to act unitedly) present certain peculiarities, but they have little or no application to the generality of trade. In the remaining case we have France exporting what other countries produce also, and importing what other countries are also consuming. Now the imposition of import duties on certain goods by France, if they are not prohibitive, means that in the new state of trade, when a position of equilibrium is again reached, the prices of these goods in relation to the prices of other things must exceed their cost of production abroad, expressed in the same way, by the amount of the import duties, as otherwise these goods could not continue to be imported. This new position of trade can be brought about by a re-adjustment of the magnitudes of different industries, $(a)$ abroad, or $(b)$ in France. If the totality of the industries affected abroad is large in relation to the size of the corresponding industries in France, the result will be attained 
mainly by method $(b)$; but in the opposite case mainly by method $(a)$. It is evident, therefore, that the foreigners will not ordinarily bear any important part of the loss occasioned by a particular import duty (because they will not be involved in any substantial industrial re-adjustments) when the sum of all the industries producing the taxed commodity abroad is very large in proportion to the size of the industry producing it in France.

It is almost superfluous to add that, if any import duty is prohibitive, the treasury of the taxing country gains nothing, though there is likely to be a loss, as previously demonstrated, and this loss is likely to fall most heavily on the taxing country.

From the above you will immediately apprehend that an import duty on a commodity which is not produced at home is simply a tax on consumption and does not present the peculiarities of the protective import duty, unless it is designed to protect the production of a substitute.

Let us now try to trace the incidence which may be expected when the consumption or production of a commodity affected by a duty is confined to one country. Above we assumed provisionally that no such national monopoly, if we may properly call it monopoly, was involved in the trade.

Suppose that some country has such a monopoly of consumption of some article. Say, for instance, that China alone consumes opium. Then if China put an import duty on opium, and her demand for opium was very elastic, and opium was produced according to diminishing returns, much of the incidence would be abroad; but much of the incidence would still be on the Chinese consumer in all probability.

Suppose, next, that some country has such a monopoly of production of some article. Suppose, for instance, that Borneo alone can produce nutmegs with facility. Then were Borneo to place an export duty on nutmegs, and were the demand for 
them inelastic, the bulk of the incidence would be on foreign consumers of nutmegs. In this case the whole tax might be paid for Borneo by the foreigner.

Incidence of a taxation system as a whole.-To conclude this chapter a few words must be said of the reactions which may succeed the incidence of all the taxes in a taxing system. These might be called the secondary reactions. They are slower in their operation and tend to be more extensively counteracted by social frietion than the primary reactions, but they may alter both the burden of taxation and its distribution.

Secondary reactions are brought about by the effect of taxes upon the power and willingness of people to raise themselves or their children in the social soale, and upon saving. For instance, were the taxes of a country to press with exceptional severity upon the class of people with incomes of less than $£ 100$, the flow of people from this class to the next higher class would almost certainly be retarded (though a position in the latter class would be made relatively more attractive) because their power to raise themselves or their children would be reduced. Power to mount up in the social scale seems at present to be a much more effective determinant of the degree of vertical movement, among the masses of the population, than the relative attractiveness of incomes in different grades. If the relative numbers of the people in the lowest classes were ultimately increased by the tax, the burden of the tax upon the community would be made heavier because the national income would shrink when more people than previously were doing work of small value. And of the burden, thus increased, the share of the poorer people would be magnified, for they would suffer a reduction in wages, owing to the relative increase of their numbers, in addition to having to pay the heavy taxes. The earnings of the classes above them would rise relatively to theirs, because the numbers 
in these higher classes taken as a whole would relatively diminish.

Finally one has to take into account the depressing effect which the reduction of small incomes has on those who earn them. The ambitions of parents for their children might be damped so effectually by heavy taxes that the children's opportunities would be curtailed out of all proportion to the limitation of the parents' power to provide them. In order to understand these reactions fully the reader is advised to study again pages $309-13$. As regards the example of repercussion just treated above, it must be remembered that vertical mobility suffers many retardations.

In order to illustrate the secondary reactions on taxes as a whole, I have taken a case in which the means possessed by people play a large part in determining their choice of avocations for themselves and their children. In other cases means have no influence, but a substantial alteration of the relative attractiveness of different positions in the social system might have an appreciable influence. As regards the secondary reactions which affect saving, the dependence of saving on the means to save needs no words of comment. 



\section{APPENDIX.}

\section{SELECT LIST OF BOOKS.}

AFTer mastering these outlines, those who desire to make a more complete study of Political Economy should at once read :-

Marshall's Principles of Economics, Vol. I.

Nicholson, Principlès of Political Economy, three vols.

Of recent, or comparatively recent, outlines in English or treatises on a smaller scale than the two referred to above, mention may be made of those by Bullock, Ely, Fetter, Flux, Gide (translated from French), Hadley, Nicholson, Seager, Seligman and Walker. The student who aims at getting an all-round knowledge of Political Economy would benefit from examining a few of these works, each of which naturally differs from the present volume in some respects-either in point of view, manner of treatment, or matters of detail.

Another general treatise in two volumes by 'laussig will appear almost simultaneously with this work.

The most important general treatises in foreign languages are :in German, those by Conrad, Cohn (Vol. II on Finance, translated), Philippovich, Roscher (Vol. I, translated), Schmoller (translated into French), and Wagner (translated into French); in French, those by Cauwès, Colson, Gide, Landry, Leroy-Beaulieu and Pareto ; in Dutch, Pierson's two volumes (Vol. I, translated) ; and, in Italian, Graziani's work.

The literature of Political Economy is so voluminous that it is impossible to do more now than indicate some few of the most modern books in English which might be perused by those who are specially interested in particular sections of the subject, and it is not likely that I have been so fortunate as to have omitted no work which ought to be mentioned. In putting forward the list that 
follows I may offer a word of caution. It must be remembered that. many parts of Political Economy, particularly parts which touch conflicting interests, or opinions as regards State action, are controversial. Consequently many economic works, which are not intended for beginners and deliberately made impartial, must be read in an especially questioning frame of mind. In the appended collection, books have been placed in the class which seems to have the first claim upon them though they may rightfully belong to more than one class.

Scope, Method, Fundamental Ideas and Consumption: Keynes, Scope and Method of Political Economy; Patten, Consumption of Wealth; and Smart, Introduction to the Theory of Value.

Capital AND Interest : Böhm-Bawerk, Theories of Interest and Positive Theory of Capital (both translated with introductions by Smart); Gonner, Interest and Saving; Irving Fisher, Nature of Capital and The Rate of Interest.

Mankets: Emery, Stock and Produce Exchanges; Jones, Economic Crises; Withers, Stocks and Shares. (For book on the Money Market see under the heading "Money and Banking".)

INDUSTRIES: It must suffice here merely to mention that numerous studies of particular industries and businesses have been made.

Trusts and Combinations : Ely, Monopolies and Trusts ; Jenks, The Trust Problem; Macgregor, Industrial Combination. The facts as regards Great Britain are reviewed in Macrosty's Trust Movement in British Industry.

Co-operation: Fay, Co-operation at Home and Abroad; Industrial Co-operation, edited by Catherine Webb; Wolft's People's Banks.

International Trade: Bastable, International Trade; Fisk, International Commercial Policies; Goschen, Foreign Exchanges.

Money and Banking: Clare, Money Market Primer; Conant, Principles of Money and Banking; Darwin, Bimetallism; Irving Fisher, The Purchasing Pover of Money; Withers, The Meaning of Money. Jevons, Laughlin, Nicholson and Walker have also produced works on Money. Small books on banking havo been writton by Attfield, Dunbar, and Sykes.

Wages and Labour Questions: Beveridge, Unemployment; Bowley, Wages in the United Kingdom in the XIX Century (statistical); Brassey and Chapman, Wages and Employment; Gilman, 
Profit-sharing; Knoop, Industrial Arbitration ; Pigou, Methods of Industrial Peace; Schloss, Methods of Industrial Remuneration; 'Taussig, Wages and Capital ; Webb, Industrial Democracy; Ashley, Adjustment of Wages.

Mathematical Economics: All who are sufficiently equipped with a knowledge of mathematics should read at least the Appendix to Marshall's Principles of Economics. Other mathematical expositions in English are: Cunynghame, Geometry of Political Economy; Edgeworth, Mathematical Psychics; The Appendix to Flux's Economic Principles; Jevons, Theory of Political Economy; Wicksteed, Alphabet of Economic Science.

General : Carver, Distribution of Wealth; Clark, Distribution of Wealth and Essentials of Economic Theory; Hobson, The Industrial System and Evolution of Modern Capitalism; Pantaleoni, Pure Economics (trans.); Sidgwick, Political Economy; Smart, Distribution of Income; Wells, Recent Economic Changes; Wicksteed, Commonsense of Political Economy; Wieser, Natural Value (trans.).

Public Finance and Taxation: Bastable, Public Finance; Pigou, Protective and Preferential Import Duties ; Seligman, Shifting and Incidence of Taxation, and other works on taxation. Introductory Manuals on Public Finance have been prepared by Armitage-Smith, Daniels and Plehn.

Public Economics: The field of Public Economics, including Socialism and Economic and Social Legislation, is too extensive for any satisfactory recommendations as to reading to be made in this brief bibliography. Portions of many of the works mentioned above cover some of the ground.

Statistics: Bowley, Elements of Statistics and Elementary Manual of Statistics ; Giffen's Essays ; Jevons' Essays ; MayoSmith, Science of Statistics ; Udny Yule, Introduction to the Theory of Statistics (highly mathematical).

History of Political Economy : Bonar, Philosophy and Political Economy and Malthus and his Work; Cannan, Production and Distribution in English Political Economy; Cossa, Guide to the Study of Political Economy; Higgs, The Physiocrats; Ingram, History of Political Economy; Price, Political Economy in England.

Portionsiat least of the works of some of the following writers in 
English should be read by those who are making themselves acquainted with the history of Political Economy: Adam Smith, Ricardo, Malthus, James Mill, Senior, J. S. Mill, Cairnes, Cliffe Leslie, Bagehot and Jevons.

Economi History : Introductory sketches of English Economic History have been written by Cheyney, Cunningham and McArthur, Meredith, Price and Townsend Warner. The most comprehensive works are Cunningham's and Ashley's. The latter is not yet completed. Treatises on special topics and periods cannot be mentioned here.

Journals : The official journal of the Royal Economic Society is the Economic Journal. Notices of the contents of current issues of the chief journals abroad will be found at the end of each number. The American Economic Review is the organ of the American Economic Association. Of American economic journals there are many. The Journal of the Royal Statistical Society and the Quarterly Publications of the American Statistical Association should be added to the list of journals in English.

Dictionaries : Palgrave's Dictionary of Political Economy will be found useful as a work of reference. The nost exhaustive dictionary is the Handwörterbuch der Staatswissenschaften, edited by Conrad, Elster; Lexis and Loening (8 vols.). Schönberg's Handbuch der Politischen Oekonomie contains many valuable monographs.

Official Publications: The statistical and other publications of Public Offices contain much useful information. Some of the reports of Commissions and Select Committees are of particular value. 


\section{INDEX.}

Abstract method, 15-18. Accident, insurance against, 365. Agents in production, 67. - - supply prices of, 321. Agricultural systems, 128-31. Aid, public, 369-72.

Alternative demand (see substitutes).

- supply, 67, 168.

Amortisation, principle of, 394 . Anticipating, risks of, 120-4. Appreciation of money, 209-10. Arbitration, 332-3, 363. Arts of economics, 5, 6 . Assimilation, social, 12-14.

BANK Act, English, 233-4.

- amalgamation, 223-4.

Banking in relation to trade cycles, 261-2.

- loans, 213-9.

- reserve, 216.

- theory, 213-24.

Banks, function' of, 222-3.

- interdependence of, 223-4.

Bargaining, collective, 326-8.

Barter, 149-52, 197-200.

Bearing, 119.

Betterment, 383-4.

Bimetallism, 238-42.

Bounties, 352-3.

Brassage, 229.

Bulling, 119.

Businesses, elasticity of, 97.

- growth of, 90.7.

- marginal, 38.

- private, 131-4

- specialization of, 97-100.
Calls, 113.

Capital, 71.80.

- auxiliary, 76.

- circulating, 77-8.

- consumers', 76 .

- demand for, 267-8.

- effect of progress on demand for, 276-7.

- fixed, 76, 277-9.

- industrial, 75-6.

- international immobility of, 185-6.

- markets for, 115.6.

- natural, 75.

- personal, 75.

- production with, a round-about process, $78-80$.

- saving of, 268-70.

- social, 71-4.

- specialized, 77.

- supply and demand, interaction of, $272-4$.

Casual labour, 337-8.

Cheques, 222, 231-2.

Circulating capital, 77-8.

Circulation of money, 204.

Coinage, debased, 229, 234.

- free, 228-30.

- gratuitous, 229.

Coining credit, 219.

Collective bargaining, 326-8.

Colonial preference, 355 .

Comforts, 58-61.

Commerce, distinguished from industry, 64.

Commercial organization, reactions of on industrial organization, 126-7. 
Companies, 131-4.

Demand, composite, 168.

Comparative values, doctrine of, - elasticity of, 40 . $186-8,191$.

Competition, 147-8, 344-9, 362, 372-3.

- joint, 28, 167-9.

- marginal, 39.

- market, 39, 40.

Competition between labour grades, 311-3.

Complements, 28, 36-7.

Composite demand and supply, 168.

Conciliation, 392.

Constant returns, 103-5.

Consumers' capital, 76.

- surplus, 49-53.

Contract curve, 152.

Control of economic enterprise by state, 351-2.

Co-operation, 134.9.

Co-operative credit, 138.

Co-partnership, 137-8.

- tenants, 138-9.

Copyright, 353.

Cost, 161-2.

- marginal, 161.

- prime, 172.

- supplementary, 172 (see also supply prices).

Credit, co-operative, 138.

- money, 219-22, 231-2.

- trade in, 216-7.

Currency, 225-43.

- and arts, distribution of gold between, 203-5.

- debased, 229, 234.

- paper, 234-8.

Cycles, trade (see fluctuations).

Déts, public, 384.

Decreasing returns, 102-8.

- - abstract law of, 106.

- - realistic law of, 107.

Deductive method, 15-18.

Degressive taxation, 379-80.

Demand, 23-8, 39-42, 154-6, 171.

- alternative (see also substitutes), 168.

- and supply in relation to agents of production (see interest, ront, wages).

- - equilibrium of, 163-7, 173-4.

- systems of, 26-8.

Depreciation of money, 209-10.

Differences, dealing in, 114.

Differential advantages, 281-300.

Differentiation of markets, 112.

- of productive systems, 124-6.

Diminishing returns (see decreasing returns).

- utility, 29-34.

Discriminations, price, 177-9.

Distribution, analysis and summary of, 263-4, 318-20.

Divisions of political economy, 20.

Dumping, 179.81, 356.

Dynamics, economic, 7.

Economic man, 15.

- studies, classification of, 8-9.

Efficiency, necessaries of, 59.

- of labour, 69-70.

Elasticity of businesses, 97.

- of demand, 40.

- - for money, 209.

- of taxes, 383.

Entrepreneurs, function of, 68.

Equilibrium, normal and sub-normal, 163-7, 173-4.

Equi-marginal returns in businesses, 95-6.

- - in consumption, 43-8.

- - in exchange, 149.

- - in production, 95-6.

Ethics, economic, 5-6.

Evolutionary economics, 7-8.

- law of increasing returns, 107-8.

Exchanges, foreign, 244-7.

- labour, 338-40, 364.

- produce, 112-5.

- stock, 115.

Exports, bountios on, 353.

- duties on, 397, 399, 400 .

- effects of foreign loans on, 195-6. 
Exports, invisible, 195.

External economies, 101.

Factors in production (see agents in production).

Factory Acts, 359-62.

Fair trade, 356.

Firm, marginal, 38, 159.60.

- normal, 157-60.

- representative, 159.

Fluctuations in trade, explanations of, 255-60.

- - banking in relation to, 261-2.

- - periodicity of, 254-5.

- - synchronism of, 254-5.

Foreign exchanges, 244-7. - trade (see international trade). Free Will, 10-12.

Futures, 112-15.

Geographical factors, influence of, on production, 70 .

Gold, distribution of, between arts and currency, 203-5.

- exchange system, 243.

- methods of stopping foreign drains of, 247-50.

Goods, nature and classification of, 55-8.

Government (see State).

Grade, selling by, 111.

Gresham's law, 230-1.

Group production, 91, 318.

Growth of businesses, 90-5.

HABITS, 27.

Health Acts, 359-62.

Historical methods, 16, 18, 19.

History, economic, 8.

Hours of labour, 323-6.

Housing, 138-9, 369.

IMPACT of tax, 385-7.

Imports, duties on, 354, 397-400.

- effects of foreign loans on, 195-6.

- English balance of, 194-5.

- invisible, 195.

- pay for exports, 193-5.

Incidence of taxes, 385-401.
Inconvertible money, 234-8.

Increasing returns, 103-8.

- - abstract law of, 106.

- - evolutionary law of, 107.8.

- - realistic law of, 107.

Index numbers, 210-12.

Indifference curve, 151-2.

- law of (see equi-marginal returns).

Inductive method, 18.

Industrial peace, methods of, 331-3.

- organization, reactions of commercial organization on, 126-7.

Industries, localization of, 101-2.

- walled and unwalled, 97.

Industry, distinguished from commerce, 64 .

Instrumental goods, 71-2.

Insurance against accident, sickness, and unemployment, 341-2, 365.

- state in relation to, 365-7.

- and saving, 271-2.

Interest, 264-80.

- effect of, on saving, 269-70.

- - of progress on rate of, 276-7.

- gross and net, 264-6.

- possibility of zero rate, 274-6.

Internal economies, 101.

International immobility of labour and capital, 184-6.

- trade, 184-96.

- - most favoured nation clause, 357.

- values, 188-93.

JorNt demand, 28, 167-9.

- supply, 67, 168-9.

- utility of complements and of substitutes, 36-7.

KARTELS, 140-5.

Labour, casual, 337-8.

displacement of, by machinery, 82-4.

- effect of specialization and maohinery on, 85-8.

- efficiency of, 69-70. 
Labour, Exohanges, 338-40, 364 .

- grades of, 309-13.

- hours of, 323-6.

- international immobility of, 184-5.

- marginal, 38.

- mobility, geographical, 311.

- - horizontal, 311.

- - vertical, 311-3.

- productive, 65.

- specialized, productive advantages of, 84-5.

- supplies of, 309-11.

Laissez faire, 372-3.

Land, marginal, 38.

- - value of, 286-91.

- taxes on, 388-94 (see also agricultural systems, decreasing returns, and rent).

Leaseholders, 130-1.

Legal tender, 226-7.

Life, standard of, 14.

Limping standard, 243.

Loans, bank, 215-9.

- foreign, 195-6.

Localization of industries, 101-2.

- of markets, 110.

Long-period effects, 154-7.

Luxuries, 58-61.

Machinery, displacement of labour by, 82-4.

- economy of, 81.2, 85-8.

Marginal cost, 93-5, 161.

- demand, 39.

- firm, 38, 15960.

- land (see land and rent).

- returns of business, 94.

- thing and marginal use of thing, 37.8.

- utility, 29-32, 54-5.

- - of money, 46-7.

- value of agents in production (see interest, rent, wages).

- workman (see labour).

Marketing function, 119-20.

Markets, 109-27.

- evolution of, 110-12.

- for capital, 115-16.
Markets, private, 126.

Measurable data, 19.

Mediation, 332.

Métayage, 129-30.

Methods, abstract, historical, inductive and realistio, 15-19.

Minimum sensibles, 47-8.

Mintage, 229.

Money, appreciation of, 209-10.

- artificial, 228.

- classification of, 225-31.

- commodity, choice of, 200-2.

- credit, 219-22, 231-8.

- depreciation of, 209-10.

- determination of the purchasing power of, 202-8.

- elasticity of demand for, 209.

- functions of, summarized, 208-9.

- inconvertible, 234-8.

- marginal utility of, 46-7.

- natural, 228.

- standard, 227-8.

- token, 231.

Monopoly, classes of, 139-40.

- limitations of, 183.

- prices, theory of, 175-83.

- social, 139-40.

- taxes on, 396 (see also kartels and trusts).

Necessaries, 58-61.

- conventions], 61.

- of efficiency, 59.

- of life, 59.

Normal effects, 154-7.

- firms, 157-60.

- man, the, 17.

- price, 163-9.

Normative science of economics,2-6. Note issue, natural limits of, 220-1. - - government limitation of, 232-4.

Oppontunities, State in relation to provision of, 367-9.

Options, 113.

Patents, 353.

Pessant proprietorship, 128-9. 
Pensious, old age, 366 .

Periodic settlements, 114.

Perpetualism, fallacy of, 8.

Politics, relation of economics to, 2-3.

Positive science of economics, $2-6$.

Preference, colonial, 355.

Price discriminations, 177-9.

- marginal demand, 39.

- market demand, 39-40.

- monopoly, 175-83.

- of fixed stocks, 152-3.

- normal (long period), 163-9.

- sub-normal (short period), 172-3.

- steadiness and its effects, 116-7, 242-3.

Prices, index numbers of, 210-12.

Prime cost, 172.

Private enterprise, advantages and defects of, 132-4, 344-9.

Producers' surplus, 320-3.

Production, agents in, 67.

- definition and classification of, 62-5.

- group, 91.

- influence of geographical factors on, 70 .

- law of substitution in, 95-6.

- responsiveness of, 66-7, 70 .

- with capital a round-about process, 78-80 (see also cost).

Productive labour, 65.

- organization, types of, 128-45.

- systems, differentiation of, 124-6.

Profits, 304-9.

- definition of, 308-9 (see also interest).

Profit-sharing, 331.

Progressive taxation, 378-80.

Protective import duties, 354, 397400.

Psychological basis of demand, 24-6.

Public aid, 369-72.

- debts, 384 .

- Health Acts, 359-62.

- revenues, 374-6.
Purchasing power of money, 202-6.

Puts, 113.

QUASI-RENT, 299-300.

RATES, 388-92.

Reciprocity, 357.

Regressive taxation, 380.

Rent, meaning of, 281-2.

- of building sites, 293-6.

- of differential fertility, 282-6.

- personal, 296-7.

- quasi, 299-300.

- relation to price, 297-9.

- situational 291-6.

Repercussion of taxes, 385-7.

Reserves, 216, 247-53.

Responsiveness of production, 66-7, 70.

Retaliation, 357.

Revenues, public, 374-6.

Rolling of taxes, 385-7.

SAMPLE, selling by, 111.

Satiability of wants, 35-8.

Satisfaction (see utility).

- doctrine of maximum, 372-3.

Saving, dependent on power to save, 270-1.

- - will, 268-9.

- effect of insurance on, 271-2.

- - rise in rate of interest on, 269-70.

- taxes on, 387-8.

Seasonal unemployment, 335-6.

Seigniorage, 229.

Selfishness, 17, 18, 147.

Settlements, periodic, 114.

Shifting of taxes, 385-7.

Short period, 170-2.

- - equilibrium, 173-4.

- - prices, 172-3.

Sickness, insurance against, 365 .

Sliding scales, 330-1.

Social assimilation, 12-14.

Specialization, 92-3.

- by process and product, 100-1.

- effect on labour, 85-8.

- of agents, economies of, 84-5. 
Specialization of businesses, 97-100. Specialized capital, 77.

Specie points, 245.6.

Speculation, effect on prices, 117-9.

Standard, limping, 243.

- money, 227-8.

- of life, 14, 26.

Standardization, 88.

State control, 351-2.

- economic action, classification of, 343-4.

- in relation to housing, 369.

- - social insurance, 365-7.

- - the provision of opportunities, 367-9.

- industries, 349-50.

- laws of, to facilitate business, 357-8.

- limitation of note issues, 232-4.

- provision of higher social goods, 369.

- - of work, 364.

Statics, economic, 7.

Stock Exchange, 115.

Stocks, fixed, price of, 152-3.

Sub-normal prices, 172-4.

Subsidies, 352-3.

Substitutes, 28, 168.

- joint utility of, 36-7.

Substitution, law of (see equi-marginal returns).

Sun spot theory, 255-6.

Supplementary costs, 172.

Supply, alternative, 67, 168.

- composite, 168.

- joint, 67, 168-9.

- prices, normal, 157-61.

- - of factors in production, 321 (see also interest,profits, wages).

- and demand (see demand and supply).

Surplus, consumers', 49-53.

- producers', 320-3.

Sworting, wages boards to prevent, 333.

Symmetallism, 243.

Taxation, degressive, 379.80.

- faculty theory, 377-8.
Taxation, principle of clearness in, 382.

- - of convenience in, 381-2.

- - of economy in, 380-1.

- - of equity in, 376.8.

- progressive, 378-80.

- regressive, 380.

Taxes, connected with land, 388-94.

- definition of, 376.

- direct, 385.

- elasticity of, 383.

- impact of, 385.

- incidence of, 385-401.

- indirect, 385.

- on commodities, 394.6.

- on income, 387.8 .

- on monopolies, 396.

- on property, 387.8.

- on savings, 388.

- on transfers, $388,395$.

- on services, 394-6.

- repercussion, rolling or shifting of, $\mathbf{3 8 5} \cdot 7$.

Token money, 231.

Trade, balance of, 193-5, 247.

- fluctuations (see fluctuations).

- international, 184-96.

- unions, 326-8.

Transfers, taxes on, 395.

Trimetallism, 243.

Truck Acts, 362.

Trusts, 140-5.

UNDERTAKEns, functions of, 68 .

Unearned increment, 383-4.

Unemployment, causes of, 334-8.

- means of mitigating the distress caused by, $341-2$

- romedies for, 333-41.

Unions, trade, 326-8.

Universalism, fallacy of, 8.

Utility, 22-6.

- basis of laws of, 37.

- consumer's surplus of, 49-51.

- dimiuishing, 29-34.

- elemental, 55.

- form, 55.

- joint, of substitutes, 36-7

- marginal, 29-32. 
Utility, marginal, of money, 46-7. Wages, determination of, 301-8, - place, 55.

- producer's surplus of, 321-3. 313-5.

- time, 55.

- total, 30-32 (see also equi-marginal returns).

Valoe in use, 54-5.

- fund doctrine, 315-7.

- group piece rates, 329.

- iron or brazen law of, 317.

- piece-rates, 329.

- premium systems, 329.

Values, comparative, doctrine of, 186-8, 191.

- international, 188-93.

WAGES boards, anti-sweating, 333.

- sliding scales, 330-1.

- subsistence theory, 314.

- time rates, 329.

Wants, 22-24.

- satiability of, 35-8.

- - joint, 331-2.

Wealth, 55-8. 




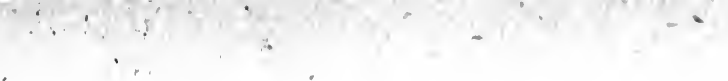

1 



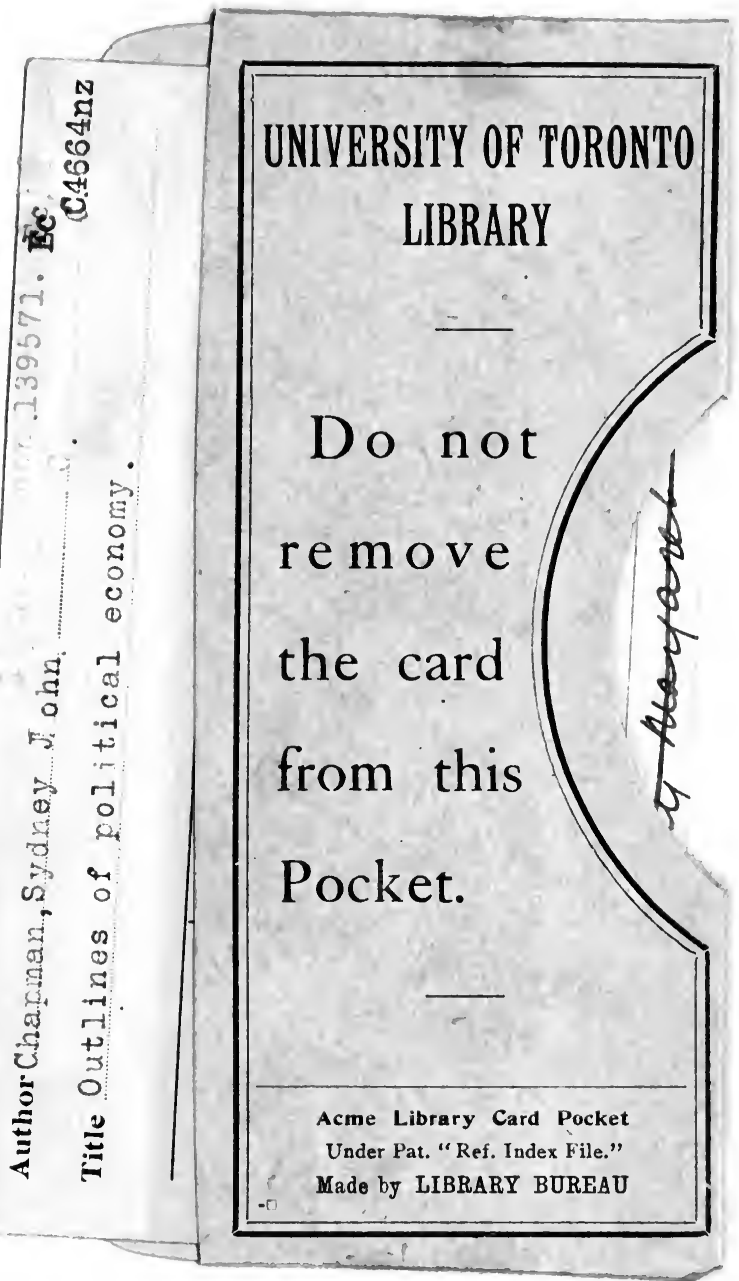


